\title{
KINETIC STUDIES ON THE NUCLEATION AND GROWTH OF SILICON VIA CHEMICAL VAPOUR DEPOSITION
}

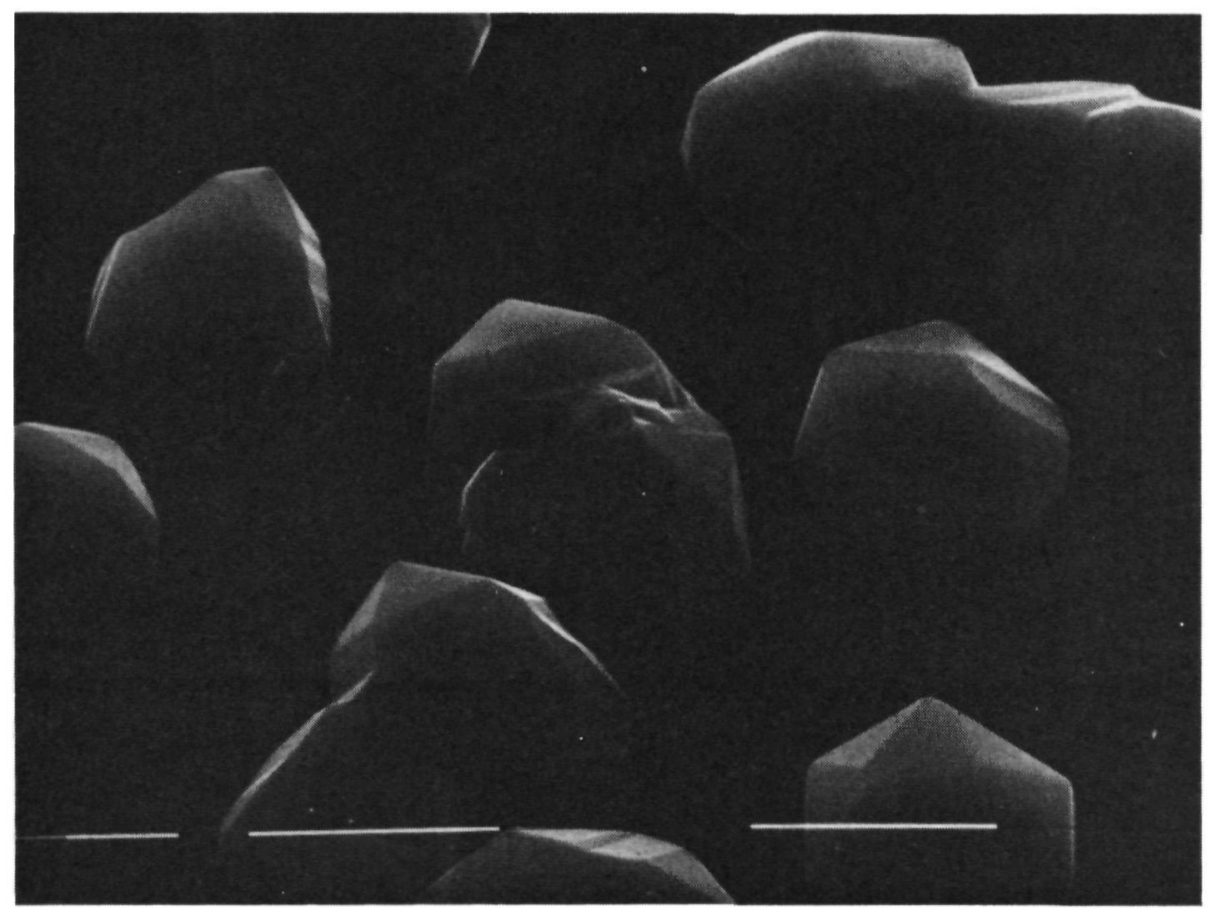

W.A.P. CLAASSEN 

PROMOTOR: PROF.DR. J. BLOEM 



\title{
KINETIC STUDIES ON THE \\ NUCLEATION AND GROWTH OF \\ SILICON VIA CHEMICAL VAPOUR DEPOSITION
}

\author{
PROEFSCHRIFT \\ TER VERKRIJGING VAN DE GRAAD VAN DOCTOR \\ IN DE WISKUNDE EN NATUURWETENSCHAPPEN \\ AAN DE KATHOLIEKE UNIVERSITEIT TE NIJMEGEN, \\ OP GEZAG VAN DE RECTOR MAGNIFICUS \\ PROF.DR. P.G.A.B. WIJDEVELD, \\ VOLGENS BESLUIT VAN HET COLLEGE VAN DECANEN \\ IN HET OPENBAAR TE VERDEDIGEN OP \\ VRIJDAG 27 FEBRUARI 198I DES NAMIDDAGS TE 4.00 UUR \\ DOOR
}

WILHELMUS ANTONIUS PETRUS CLAASSEN GEBOREN TE UDEN

Drukkerij Gema B.V. - Eindhoven 

Aan Gerry

Lina

Dirk

Willem

Madrten 


\section{ACKNOWLEDGEMENTS}

All the experiments described in this thesis were carried out at Philips Research Laboratories, Eindhoven, The Netherlands. I would like to express my gratitude to the management of these laboratories for consenting the puplication of these results in the present form.

Further I would like to thank all those who have contributed to this work in any way, in particular Mrs. C.W.T. Bulle and Mrs. G. v. Leeuwen for making the SEM and TEM photomicrographs. Mr. J. Goorissen and members of his group are thanked for valuable discussions and critical reading of the manuscript. 
II THF NUCLEATION OF CVD SILICON ON $\mathrm{S}_{1} \mathrm{O}_{2} \quad$ IND $\mathrm{S}_{3} \mathrm{~N}_{4}$ SUB STRATES

I THL $\mathrm{SIH}_{4} \mathrm{HCI}_{2}$ SYSTEM AT HIGH TEMPLRATURLS 3

1 Introduction 3

2 Experumental 4

3 Expcrunental results 5

31 Introduction 5

32 Nucledtion on a $\mathrm{S}_{1} \mathrm{O}_{2}$ substrate 8

33 Nucleation on $\mathrm{S}_{13} \mathrm{~N}_{4}$ substrate differences compdred with a $\mathrm{S}_{1} \mathrm{O}_{2}$ substrate 10

4 Discussion 14

41 Nucleation theory 14

42 Addtom concentration and surfacc coverages 16

43 Interpretation of the results 17

5 Conclusions 21

Appendix Calculation of adatom concentrations $\quad 22$

References 25

III THE NUCLEATION OF CVD SILICON ON $\mathrm{S}_{1} \mathrm{O}_{2}$ AND $\mathrm{S}_{3} \mathrm{~N}_{4}$ SUB STRATES,

III TIIE $\mathrm{S}_{1} \mathrm{H}_{4}-\mathrm{HCl}-\mathrm{H}_{2}$ SYSTEM AT LOW TEMPCRATURLS 27

1 Introduction 27

2 Experımental and experimental results $\quad 27$

3 Discussion 31

3 I Introduction 31

32 Interpretation of the results 33

33 Adsorption on $\mathrm{S}_{1} \mathrm{O}_{2}$ and $\mathrm{S}_{13} \mathrm{~N}_{4}$ substrales 40

4 Conclusion 42

Refirences $\quad 43$

IV THE NUCLEATION OF CVD SILICON ON $\mathrm{S}_{1} \mathrm{O}_{2}$ AND $\mathrm{S}_{3} \mathrm{~N}_{4}$ SUB STRATES,

II THE $\mathrm{SiH}_{2} \mathrm{Cl}_{2} \mathrm{H}_{2} \mathrm{~N}_{2}$ SYSTEM 44

1 Introduction 44

2 Expermental 44

3 Experımental results 45

31 Introduction 45

32 Nucledtion on a $\mathrm{S}_{1} \mathrm{O}_{2}$ substrate 45

33 Nucleation on a $\mathrm{S}_{3} \mathrm{~N}_{4}$ substrate differences compared with a $\mathrm{S}_{1} \mathrm{O}_{2}$ substrate 
3.4 Nucleation of $\mathrm{S}_{1}$ on $\mathrm{SiO}_{2}$ and $\mathrm{Si}_{3} \mathrm{~N}_{4}$ substrates : comparison of the $\mathrm{SiH}_{2} \mathrm{Cl}_{2} \cdot \mathrm{H}_{2}$ system with other silicon-containing compounds in hydrogen

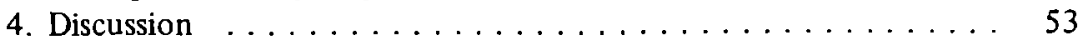

4.1 Adatom concentration and surface coverage ....... 53

4.2 Interpretation of results $\ldots \ldots \ldots \ldots \ldots \ldots \ldots \ldots$

4.2.1 The $\mathrm{SiH}_{2} \mathrm{Cl}_{2}-\mathrm{H}_{2}-\mathrm{N}_{2}$ system $\ldots \ldots \ldots \ldots \ldots 57$

4.2.2 Comparison between different silicon-containing compounds in a $\mathbf{H}_{2}$ medium $\ldots \ldots \ldots \ldots \ldots \ldots$

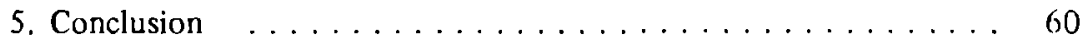

Appendix : Reaction scheme for the $\mathrm{SiH}_{2} \mathrm{Cl}_{2} \cdot \mathrm{H}_{2}-\mathrm{N}_{2}$ system $\ldots \ldots .61$

References ...................... 64

$\checkmark$ RATE-DETERMINING REACTIONS AND SURFACE SPECIES IN CVD OF SILICON, I THE $\mathrm{SiH}_{4} \cdot \mathrm{HCl}-\mathrm{H}_{2}$ SYSTEM 65

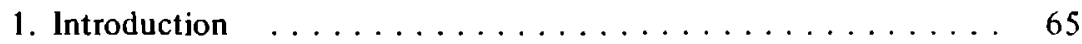

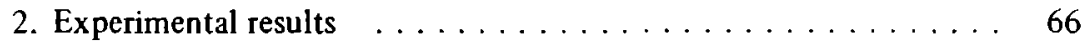

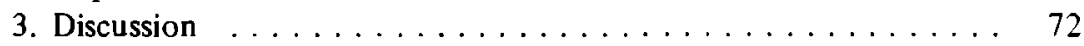

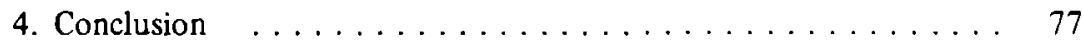

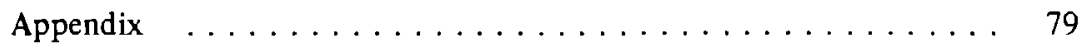

References ............................ 84

VI RATE-DETERMINING REACTIONS AND SURFACE SPECIES IN CVD OF SILICON, II THE $\mathrm{SiH}_{2} \mathrm{Cl}_{2}-\mathrm{H}_{2}-\mathrm{N}_{2}$-HCl SYSTEM $\ldots \ldots .85$

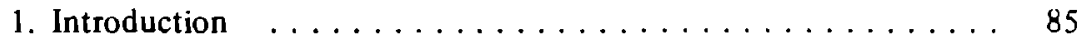

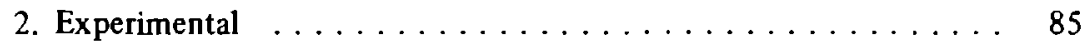

3. Discussion . . . . . . . . . . . . . . . 89

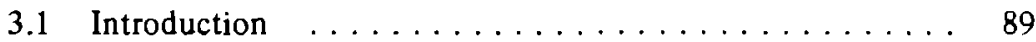

3.2 Interpretation of results $\ldots \ldots \ldots \ldots \ldots \ldots \ldots \ldots \ldots$

3.2.1 The $\mathrm{SiH}_{2} \mathrm{Cl}_{2} \cdot \mathrm{H}_{2} \cdot \mathrm{N}_{2}$ system $\ldots \ldots \ldots \ldots \ldots \ldots 91$

3.2.2 The $\mathrm{SiH}_{2} \mathrm{Cl}_{2}-\mathrm{H}_{2} \cdot \mathrm{HCl}$ system $\ldots \ldots \ldots \ldots \ldots \ldots . . \ldots 2$

3.2.3 The $\mathrm{SiH}_{2} \mathrm{Cl}_{2}-\mathrm{N}_{2}-\mathrm{HCl}$ system $\ldots \ldots \ldots \ldots \ldots .97$

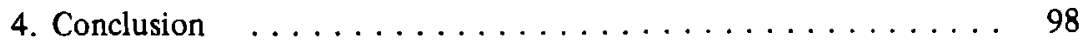

References ........................... 99

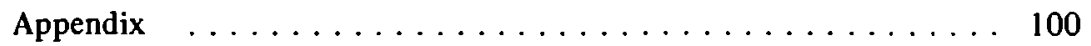

VII RATE-DETERMINING REACTIONS AND SURFACE SPECIES IN CVD OF SILICON, III THE $\mathrm{SiH}_{4}-\mathrm{H}_{2}-\mathrm{N}_{2}$ SYSTEM $\ldots \ldots \ldots \ldots .104$

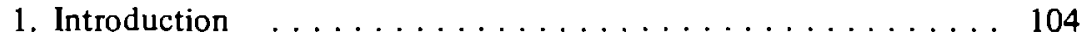

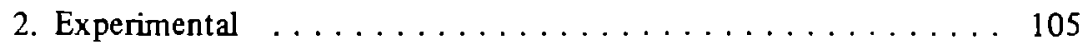

3. Discussion ....................... 109

3.1 Reaction scheme for the $\mathrm{SiH}_{4}-\mathrm{H}_{2}-\mathrm{N}_{2}$ system $\ldots \ldots \ldots .109$

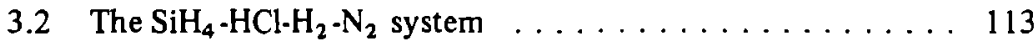

3.3 Adsorption on the silicon surface $\ldots \ldots \ldots \ldots \ldots \ldots \ldots 116$

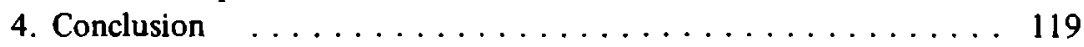

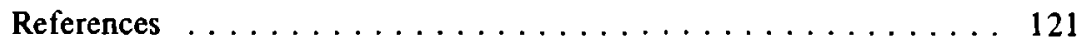


VIII KINETIC STUDIES ON THE NUCLEATION AND GROWTH OF SILICON VIA CHEMICAL VAPOUR DEPOSITION $\ldots \ldots \ldots \ldots \ldots 122$

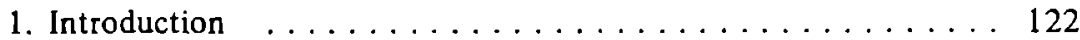

2. Nucleation of silicon on $\mathrm{SiO}_{2}$ and $\mathrm{Si}_{3} \mathrm{~N}_{4}$ substrates $\ldots \ldots \ldots \ldots 127$

3. Growth of silicon on silicon $\ldots \ldots \ldots \ldots \ldots \ldots \ldots \ldots \ldots$

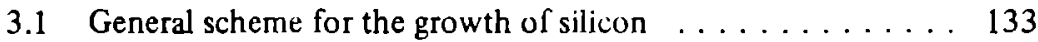

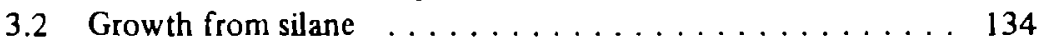

3.3 Growth from $\mathrm{SiH}_{4}$ plus $\mathrm{HCl} \ldots \ldots \ldots \ldots \ldots \ldots$

3.4 Growth via $\mathrm{SiH}_{2} \mathrm{Cl}_{2} \ldots \ldots \ldots \ldots \ldots \ldots \ldots \ldots$

3.5 Growth from $\mathrm{SiHCl}_{3} \ldots \ldots \ldots \ldots \ldots \ldots \ldots \ldots$

4. Adsorption on the silicon surface $\ldots \ldots \ldots \ldots \ldots \ldots \ldots \ldots 144$

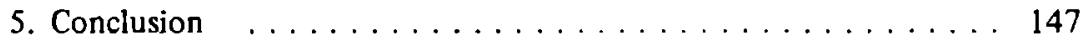

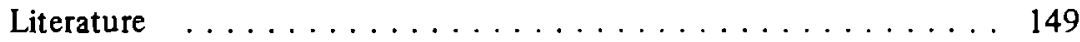

IX THE GROWTH OF SILICON FROM SILANE IN COLD WALL CVD

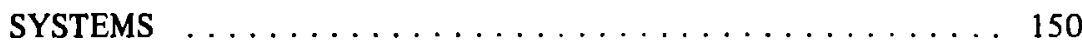

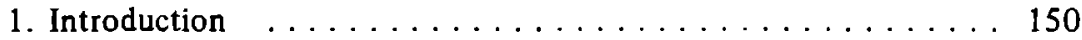

2. Growth from silane $\ldots \ldots \ldots \ldots \ldots \ldots \ldots \ldots \ldots \ldots \ldots$

2.1 Comparison of the silicon growth rate as a function of hydrogen content of the carrier gas at atmospheric pressure . . . . 152

2.2 Reduced pressures . . . . . . . . . . . . . . . . 156

2.3 Comparison between the growth rate of silicon at atmospheric pressures and at reduced pressures . . . . . . . . . 159

3. Temperature dependence of the growth rate $\ldots \ldots \ldots \ldots \ldots 2$

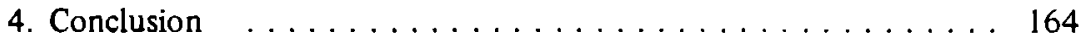

References ..................... 165

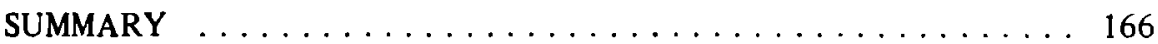

$\begin{array}{ll}\text { SAMENVATTING } & 168\end{array}$

$\begin{array}{ll}\text { CURRICULUM VITAE } & 170\end{array}$ 
The chapters II to IX have been published or are submilled to J Electrochem Soc.. J. Crystal Growth. Rccl. Trav. Clum Pays-Bas and Pholips Journal of Research.

Chapter II

The nucleation of CVD silicon on $\mathrm{S}_{1} \mathrm{O}_{2}$ and $\mathrm{St}_{3} \mathrm{~N}_{4}$ substrates. I the $\mathrm{SiH}_{4}-\mathrm{HCl}-\mathrm{H}_{2}$ system at high temperatures

W.A.P. Claasscn and J. Blocm, J Electrochem. Soc. 127. 194 (1980).

\section{Chapter III}

The nucleation of ( VD silicon on $\mathrm{S}_{1} \mathrm{O}_{2}$ and $\mathrm{SI}_{3} \mathrm{~N}_{4}$ substratcs.

III the $\mathrm{S}_{1} \mathrm{H}_{4}-\mathrm{HCl}-\mathrm{H}_{2}$ system at low temperatures

W.A P. Claassen and J Bloem, submitted to J Electrochem. Soc.

\section{Chapter IV}

The nucleation of CVD silicon on $\mathrm{SiO}_{2}$ and $\mathrm{Si}_{3} \mathrm{~N}_{4}$ substrates, II the $\mathrm{SiH}_{2} \mathrm{Cl}_{2}-\mathrm{H}_{2}-\mathrm{N}_{2}$ system

W.A.P. Claassen and J. Bloem, J. Flectrochem. Soc. 127. 1836 (1980).

\section{Chapter V}

Rate-determining reactions and surface species in CVD of silicon.

I the $\mathrm{SiH}_{4} \cdot \mathrm{HCl}-\mathrm{H}_{2}$ system.

J. Bloem and W.A.P. Claassen, J. Crystal Growth 49, 435. (1980).

\section{Chapter VI}

Rate-determining reactions and surface species in CVD of silicon, II the $\mathrm{SiH}_{2} \mathrm{Cl}_{2}-\mathrm{H}_{2}-\mathrm{N}_{2}-\mathrm{HCl}$ system.

W.A.P. Claassen and J Bloem, J. Crystal Growth 50, 807 (1980).

\section{Chapter VII}

Rate-determining reactions and surface species in CVD of silicon, III the $\mathrm{SiH}_{4} \cdot \mathrm{H}_{2} \cdot \mathrm{N}_{2}$ system.

W.A.P. Claassen and J. Bloem, submitted to J. Crystal Growth.

\section{Chapter VIII}

Kinetic studies on the nucleation and growth of silicon via chemical vapour deposition.

J. Bloem and W.A.P. Claassen, Recl. Trav. Chim. Pays-Bas 99, 217 (1980).

\section{Chapter IX}

The growth of silicon from slane in cold wall CVD systems.

W.A.P. Claassen and J. Bloem, submitted to Philips Journal of Research. 


\section{CHAPTER I - INTRODUCTION}

Monocrystalline sucon is of great importance in semiconductor technology in the manufacturing of bipolar and MOS (metal-oxide-semiconductor) devices and integrated circuits (IC) Thin polycrystalline slicon layers are also used extensively, for example as a gate matenal in MOS field effect transistors These thin slicon layers are grown on various substrates under atmospheric or reduced total pressures by means of chemical vapour deposition (CVD technique) For this purpose a slicon-containing compound is added to a carrier gas, mostly hydrogen, and fed into the reactor, in which substrates are heated to the desired deposition temperature The slicon-containing gases mostly used are slane $\left(\mathrm{Sitl}_{4}\right)$ and the chloroslanes $\left(\mathrm{S}_{1} \mathrm{H}_{2} \mathrm{Cl}_{2}, \mathrm{~S}_{1} \mathrm{HCl}_{3}, \mathrm{SlCl}_{4}\right)$

In the growth of slicon two temperature regumes can be distınguished At low temperatures $\left(\mathrm{T}<1000^{\circ} \mathrm{C}\right)$ the growth of slicon is limited by a chemical or surface-controlled process Chemical reactions such as adsorption, desorption, surface diffusion and incorporation of slicon atoms into the ldttice involve an activation energy The reaction rates $\left(r_{\mathbf{s}}\right)$ of these activated processes increase exponentially with increasing temperature and can be described by the expression

$\mathrm{r}_{\mathrm{S}} \propto \exp (-\Delta \mathrm{E} / \mathrm{RT})$

where $\Delta E$ is the activation energy for the process, $R$ the gds constant and $T$ the absolute temperature For the growth of silicon from slane and the chlorosilanis $\Delta \mathrm{E}$ is about $40 \mathrm{kcal} / \mathrm{mole}$ [1] Goung to higher temperature $\left(\mathrm{T}>1000^{\circ} \mathrm{C}\right)$ the surface reactions become so fast that the real rate-limiting step has to be found in the duffusion of the reactant cowards the surface If the growt'l rate is completely determıned by gas phase diffusion only a weak temiperature dependence of the growth rate of slicon can be expected as the diffusion coefficient of the reactant in the gas phase is approxumately proportional to $\mathrm{T}^{3 / 2}$

$I_{d} \propto T^{3 / 2}$

In the simplest model of the growth of sulicon the slicon-containing molecules are adsorbed on the surface, followed by a chemical reaction leading to slicon adatoms According to Burton, Cabrera and Frank [2] these adatoms diffuse to steps and find a stable kink site position (terrace-ledge-kink model) In this model diffusion of adatoms is easily possible and the kink site is energetically the most attractive one because of the formation of two new slicon-slicon bonds The growth of sulicon is two-dimensional provided that repeatable atomic steps are present on the sulicon surface, that the substrate temperature is high enough and that surface contaminants such as oxygen and carbon are absent [3] On such a surface slicon growth proceeds by the lateral movement of the atomic steps At lower temperatures the surface diffusion of slicon adatoms becomes more and more difficult and 
slicon adatoms interact with each other before a stable kink site position has been reached This results in the formation of three-dimensional nuclei between the steps, leading to polycrystallıne silıcon layers On a perfect crystal face without steps, and for the growth of silicon on a foreın substrate, three-dimensional clusters can also be formed if the cohesive forces between the adatoms are stronger than the adhesive forces between adatoms and substrate atoms. If the temperature is still further decreased adatoms become almost ummobule, resulting in the growth of amorphous layers. The transition between monocrystalline and polycrystalline growth and between polycrystalline and amorphous growth depends on the combination of growth temperature and growth rate, but also on the gas phase composition, as adsorption of different species on the surface could hamper surface diffusion of slicon adatoms. The purpose of the present study is to verify the general statements made above and to ascertain the rate-limiting steps between the various surface reactions.

The outline of thus thesis is as follows. In chapter II and III the nucleation of slicon on slicon-oxide $\left(\mathrm{SiO}_{2}\right)$ and slicon-nitride $\left(\mathrm{Sl}_{3} \mathrm{~N}_{4}\right)$ substrates is discussed for the $\mathrm{SiH}_{4}-\mathrm{H}_{2}-\mathrm{HCl}$ system at high and low temperatures, respectively. The expenmental data are compared with existing nucleation theories and the size of the critical nucleus is calculated. In chapter IV the nucleation of silicon on $\mathrm{SiO}_{2}$ and $\mathrm{Sl}_{3} \mathrm{~N}_{4}$ substrates is described for the $\mathrm{SiH}_{2} \mathrm{Cl}_{2}-\mathrm{H}_{2}-\mathrm{N}_{2}$ system and the data are compared with those described in chapters II and III

The growth of silicon on silicon is discussed in chapter $\mathrm{V}\left(\mathrm{SiH}_{4}-\mathrm{HCl}-\mathrm{H}_{2}\right.$ system), VI $\left(\mathrm{SiH}_{2} \mathrm{Cl}_{2}-\mathrm{H}_{2}-\mathrm{N}_{2}-\mathrm{HCl}\right.$ system $)$ and VII $\left(\mathrm{SiH}_{4}-\mathrm{H}_{2}-\mathrm{N}_{2}\right.$ system $)$. The expenmental data of these systems are mutually compared, and the outcome is a model in which the rate-determining reactions are selected between the dufferent gas phase and surface reactions.

Chapter VIII gives a review of the expermental data described in chapters II to VII and also treats the role of surface adsorption on the growth rate. Chapter IX discusses the growth of silicon from slane in a cold wall apparatus, comparing the influence of total pressure with the influence of the addition of an inert gas. Thermodynamically this should give comparable results and differences are traced back to kinetic barriers present in the vanous reactions.

\section{References}

1. W.A.P. Claassen and J. Bloem, this thesis, chapter IX.

2. W.K. Burton, N. Cabrera and F C Frank, Phul. Trans. Roy. Soc. 243, 299 (1951).

3. B.A. Joyce, Rep. Prog. Phys. 37, 363 (1974). 


\title{
CHAPTER II
}

\section{THE NUCLEATION OF CVD SILICON ON $\mathrm{SiO}_{2}$ AND $\mathrm{Si}_{3} \mathrm{~N}_{4}$ SUBSTRATES}

\author{
I. The $\mathrm{SiH}_{4}-\mathrm{HCl}-\mathrm{H}_{2}$ system at high temperatures
}

\begin{abstract}
Abstrace
The grain size in polycrystalline sulicon layers is subject to various external conditions among which the initial nucleation of silicon on the substrate may play a decisive role. This article describes experiments with silicon on $\mathrm{SiO}_{2}$ and $\mathrm{Si}_{3} \mathrm{~N}_{4}$ substrates in the $\mathrm{S}_{1} \mathrm{H}_{4}-\mathrm{HCl}-\mathrm{H}_{2}$ system lor temperatures between $925^{\circ}$ and $1200^{\circ} \mathrm{C}$. The saturation cluster densities are determined as a funcition of gas phase composition and teinperature and could be varied between $10^{4}-10^{11}$ $\mathrm{cm}^{-2}$ The esperimental results are compared $w_{1}$ th predictions of existing nucleation theories using analysis of the monomer silicon adatom concentration In this way the nucleation can be described satislactorily and approsimate values tor the size of the critical cluster can be derived
\end{abstract}

\section{Introduction}

Polycrystalline silıcon layers, whuch are grown by pyrolysis of silane, are widely used in the electronıc industry, e.g. in the fabrication of MOS (Metal-Oxıde-Silicon) field effect transistors and integrated circuits. The electrical properties of these layers closely depend on the size of the polysulicon grains in the layers [1]. It is not very well known how the grain size depends on the total number of nuclei and whether nucleation of new grains continues in the course of further growth.

Nucleation experiments with silicon on amorphous, polycrystalline and monocrystalline substrates have been reported [2-15], but attempts to make a more systematic study and quantitative evaluation of the results are relatively scarce. Joyce and Bradley [3] (pyrolysis of sllane in vacuum) and Brooker and Unvala [4] (vacuum-evaporation) observed three-dimensional nucles in the deposition of silicon on a monocrystallıne sulicon substrate. However, in a more recent article Joyce et al. [5] in collaboration with Charig and Skinner [6] showed that the initial growth becomes two-dimensional if surface contaminants such as $\mathrm{C}$ and $\mathrm{O}$ are removed by heat treatment up to $1300{ }^{\circ} \mathrm{C}$ in UHV. Nishizawa and co-workers [7] formed perfect $\{111\}$ facets on nearly $\{111\}$ oriented silicon substrates. By hydrogen reduction of $\mathrm{SiCl}_{4}$ at $1200{ }^{\circ} \mathrm{C}$ nuclei in the form of pyramids are formed on the perfect $\{111\}$ facet, with a density depending on growth temperature and $\mathrm{SiCl}_{4}$ concentration. Since these pyramids are distributed homogeneously on the facet and have a uniform size, the conclusion was drawn that they correspond to growth nuclei without lattice defects. Abrahams [8], Blank and Russell [9], Mercier [10], Bicknell et al. [11] and Cullen et al. [12] investigated nucleation processes of silicon on monocrystalline $\mathrm{Al}_{2} \mathrm{O}_{3}$ substrates. They observed three-dimensional islands. However, at temperatures higher than $800{ }^{\circ} \mathrm{C}$, the $\mathrm{Al}_{2} \mathrm{O}_{3}$ surface reacts with the deposited silicon. High temperatures and relatively low silane pressures, or a silicon compound containing chlorine, favour this etching reaction. 
Brown et al. [13] have reported a similar etching reaction for low silane input concentration on a monocrystalline quartz substrate. On amorphous and polycrystalline substrates, such as given by $\mathrm{Si}_{3} \mathrm{~N}_{4}$ and $\mathrm{SiO}_{2}$, three-dimensional nuclei are observed as shown by Alexandrov et al. [14] (pyrolysis of silane on $\mathrm{Si}_{3} \mathrm{~N}_{4}$ and $\mathrm{SiO}_{2}$ substrates in vacuum) and Kamins and Cass [15] (pyrolysis of silane in an $\mathrm{H}_{2}$ atmosphere on $\mathrm{SiO}_{2}$ substrates). It has been shown that nucleation of silicon on a foreign substrate like $\mathrm{SiO}_{2}$ or $\mathrm{Si}_{3} \mathrm{~N}_{4}$ needs a higher supersaturation than nucleation on a clean silicon surface. This prompted studies on selective epitaxial growth of silicon on silicon slices partly coated with an oxide or nitride layer. Selective epitaxial growth of $\mathrm{Si}$ has been studied by Ogawa [16] on windows in $\mathrm{Si}_{3} \mathrm{~N}_{4}$ layers ( $\mathrm{SiCl}_{4}-\mathrm{H}_{2}$ system), by Ray-Choudhury [17] on windows in $\mathrm{SiO}_{2}$ layers ( $\mathrm{SiCl}_{4}-\mathrm{H}_{2}$ and $\mathrm{SiH}_{4}-\mathrm{H}_{2}$ systems), by Druminski [18] on windows in $\mathrm{SiO}_{2}$ and $\mathrm{Si}_{3} \mathrm{~N}_{4}$ layers $\left(\mathrm{SiH}_{4} \cdot \mathrm{HCl} \cdot \mathrm{H}_{2}\right.$ system) and by Sirtl and Seiter [19] on windows in $\mathrm{SiO}_{2}$ layers ( $\mathrm{SiCl}_{4} \cdot \mathrm{Br}_{2}-\mathrm{H}_{2}$ system). Ogawa et al. determined a critical $\mathrm{SiCl}_{4}$ pressure for the nucleation on $\mathrm{Si}_{3} \mathrm{~N}_{4}$ substrates as a function of growth temperature. In the $\mathrm{SiH}_{4} \cdot \mathrm{H}_{2}$ system it was necessary to use a relatively high deposition temperature $\left(>1200^{\circ} \mathrm{C}\right.$ ) in order to prevent growth on the $\mathrm{SiO}_{2}$ mask. In the $\mathrm{SiCl}_{4}-\mathrm{H}_{2}$ system the $\mathrm{SiO}_{2}$ was entirely removed for high $\mathrm{SiCl}_{4}$ concentrations $\left(>1200^{\circ} \mathrm{C}\right)$, while the $\mathrm{Si}_{3} \mathrm{~N}_{4}$ film was not deteriorated at all for any growth condition. Sirtl and Seiter used $\mathrm{Br}_{2}$ instead of $\mathrm{HCl}$ because the purity of $\mathrm{Br}_{2}$ is much higher than that of $\mathrm{HCl}$. The bromine added to the $\mathrm{SiH}_{4}-\mathrm{H}_{2}$ mixture is converted to $\mathrm{HBr}$ by the hydrogen, while thermodynamically $\mathrm{HBr}$ acts as $\mathrm{HCl}$.

In order to obtain a more coherent picture of the nucleation of silicon as a function of gas phase composition and temperature a systematic experimental study was started to study nucleation and growth of silicon on $\mathrm{SiO}_{2}$ and $\mathrm{Si}_{3} \mathrm{~N}_{4}$ substrates. It was found that the total number of nuclei could be varied between $10^{4}-10^{11} \mathrm{~cm}^{-2}$ by variation of temperature, input concentration of silane and by addition of small quantities of $\mathrm{HCl}$ to the carrier gas.

\section{Experimental}

Most of the nucleation experiments were performed in a horizontal epitaxial R.F. heated reactor, consisting of a rectangular water-cooled fused silica tube, provided with a pyrographite coated carbon susceptor covered with a thin layer of silicon. Nucleation of silicon was performed on silicon slices (2-inch wafers) covered with amorphous, $1500 \AA$ thick LP-CVD $\mathrm{SiO}_{2}$ and $\mathrm{Si}_{3} \mathrm{~N}_{4}$ layers. The effective crosssection of the reactor was about $13 \mathrm{~cm}^{2}$. The gas system was provided with AFC 550 automatic flow controllers for the $\mathrm{H}_{2}$ carrier gas and the $\mathrm{SiH}_{4}$ source $\left(5 \% \mathrm{SiH}_{4}\right.$ in $\mathrm{H}_{2}$ ). The flow rate of pure undiluted $\mathrm{HCl}$ was determined by a conventional Brooks flowmeter. Some experiments were performed in a horizontal air-cooled R.F. heated reactor. The system was also equipped with a mass flow-controller for $\mathrm{HCl}$. The equipment is shown schematically in Figure 1. 


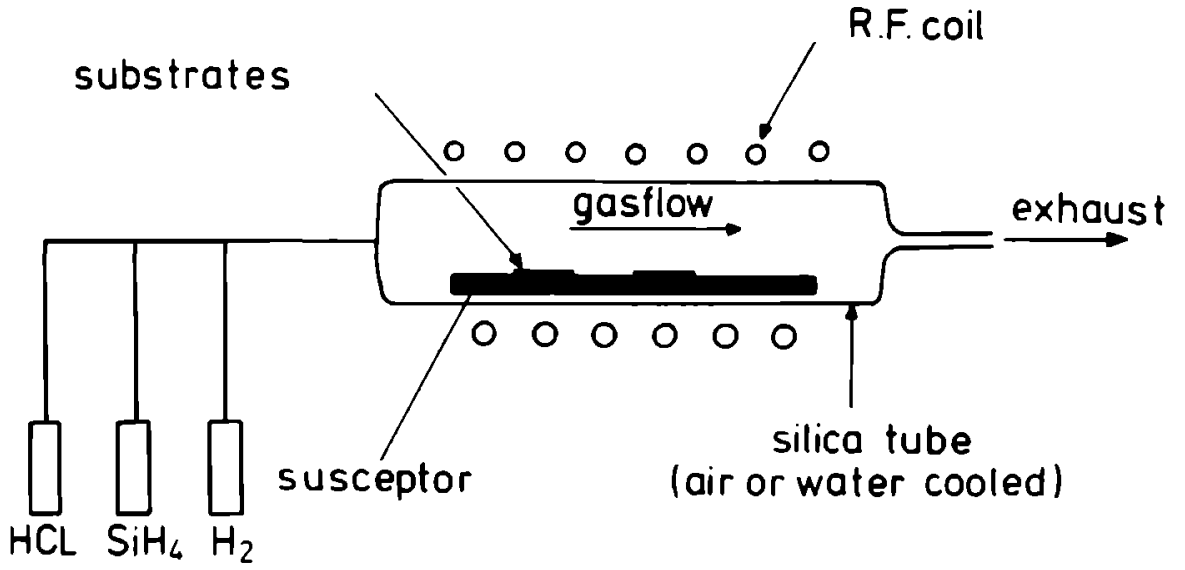

Figure 1.

Schematic view of the equipment.

The carrier gas was purified of $\mathrm{H}_{2} \mathrm{O}\left(<1\right.$ p.p.m.) and $\mathrm{O}_{2}(<1$ p.p.m.) with a A.S.M. gas purifier. Before each experiment the slices were cleaned by etching with 0.2 vol. $\% \mathrm{HCl}$ in $\mathrm{H}_{2}$ at about $1000^{\circ} \mathrm{C}$ for five minutes. After this the reactor was flushed with a stream of $\mathrm{H}_{2}$, while the substrate was brought to the desired nucleation temperature. During the nucleation experiment hydrogen loaded with $\mathrm{SiH}_{4}$ and $\mathrm{HCl}$ was passed over the slices. To ensure stable gas flow conditions a room temperature gas velocity of about $50 \mathrm{~cm} / \mathrm{sec}$ was chosen. Because of the rapid nucleation only short pulses of specific $\mathrm{SiH}_{4}-\mathrm{HCl}$ mixtures were often sufficient. It was found that reproducible results could be obtained with a constant $\mathrm{HCl}$ flow and a short additional pulse of $\mathrm{SiH}_{4}$ gas. This procedure was followed throughout, including the experiments in which longer deposition times were used. The temperature of the slices was measured with an optical pyrometer focussed on the surface of an uncoated silicon slice; the readings were corrected for the emissivity of silicon and the absorption and reflection of the system. SEM and TEM photomicrographs were made from each slice in order to determine the morphology of the layer during the initial stage of deposition. These photomicrographs provided an easy means of measuring of the density of observed silicon islands.

\section{Experimental results}

\subsection{Introduction}

To study the initial stages of deposition of polycrystalline silicon on $\mathrm{SiO}_{2}$ and $\mathrm{Si}_{3} \mathrm{~N}_{4}$ substrates, we carried out a series of short depositions at different temperatures and different combinations of $\mathrm{SiH}_{4}$ and $\mathrm{HCl}$ concentrations. For a constant substrate temperature and fixed $\mathrm{SiH}_{4}$ and $\mathrm{HCl}$ concentrations the density of nuclei 
was measured as a function of the time of growth After an incubation period the density of Si clusters very quickly reached a saturation value with respect to exposure tume where the exposure time is defined as the duration of the $\mathrm{SiH}_{4}$ pulse in the mass flowcontroller After thus hardly any new clusters were formed The existing clusters showed a very narrow size distribution The initial nucleation took place in a short time, after which the clusters merely increased in size until coalescence occurred Figure 2 gives a typical example for a constant ratio of $\mathrm{SiH}_{4}$ and $\mathrm{HCl}$ at $1000^{\circ} \mathrm{C}$ and a $\mathrm{SiO}_{2}$ substrate, where the nucleus density is plotted as a

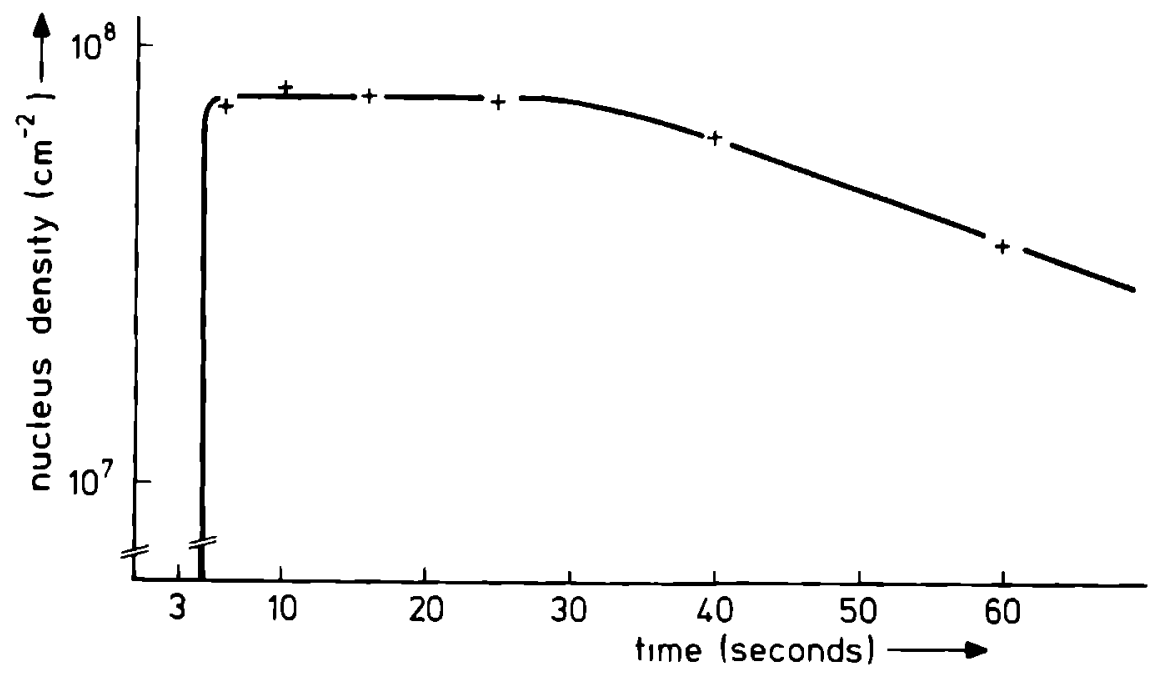

Figure 2

The nucleus density as a function of the exposure time for $P_{S_{l} H_{4}}=88 \times 10^{-4}$ bar and $\mathrm{P}_{\mathrm{HCl}}=44 \times 10^{-3}$ bar at $1000^{\circ} \mathrm{C}$ on a $\mathrm{SlO}_{2}$ substrate

function of growth time The corresponding SEM photomicropgraphs are shown in Figure 3 Up to 3 seconds no clusters were observed on SEM (Figure 3a) or TEM photomicrographs In the case of TEM the detection limit is $150 \AA$ A constant nucleus density is present between 6 and 25 seconds in which tume the mean radius of the nuclei increases from 01 to $025 \mu \mathrm{m}$ (Figure $3 \mathrm{~b}-\mathrm{e}$ ), after which coalescence occurs It could be observed that the exusting clusters show a narrow size distrbution which supports the argument that the initial nucleation takes place in a very short period of time

It was also observed that the tume needed to reach the saturation density is shorter for a $\mathrm{Sl}_{3} \mathrm{~N}_{4}$ substrate than for a $\mathrm{S}_{1} \mathrm{O}_{2}$ substrate, also these periods are longer for hugh $\mathrm{HCl}$ concentrations and low $\mathrm{S}_{1} \mathrm{H}_{4}$ concentrations Further these periods decrease with increasing temperature It is found that, for the $\mathrm{S}_{1} \mathrm{H}_{4}-\mathrm{HCl} \mathrm{H}$ system in the temperature range of $925^{\circ}-1200^{\circ} \mathrm{C}$, this incubation time is of the order of $1-60$ seconds 


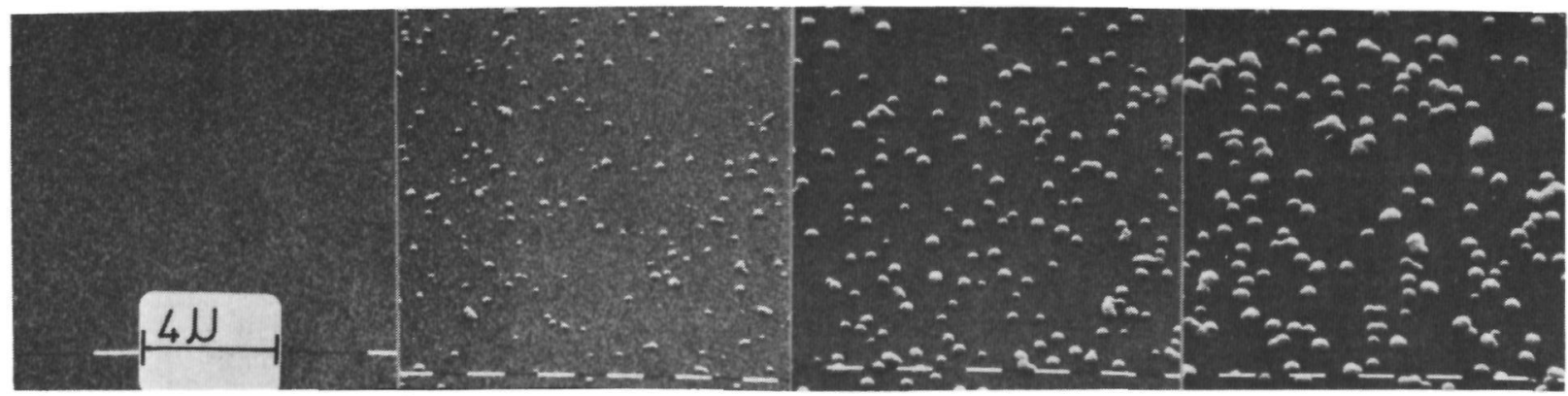
a) $t=3 \mathrm{sec}$.
b) $t=6 \mathrm{sec}$.
c) $t=10 \mathrm{sec}$.
d) $t=16 \mathrm{sec}$.

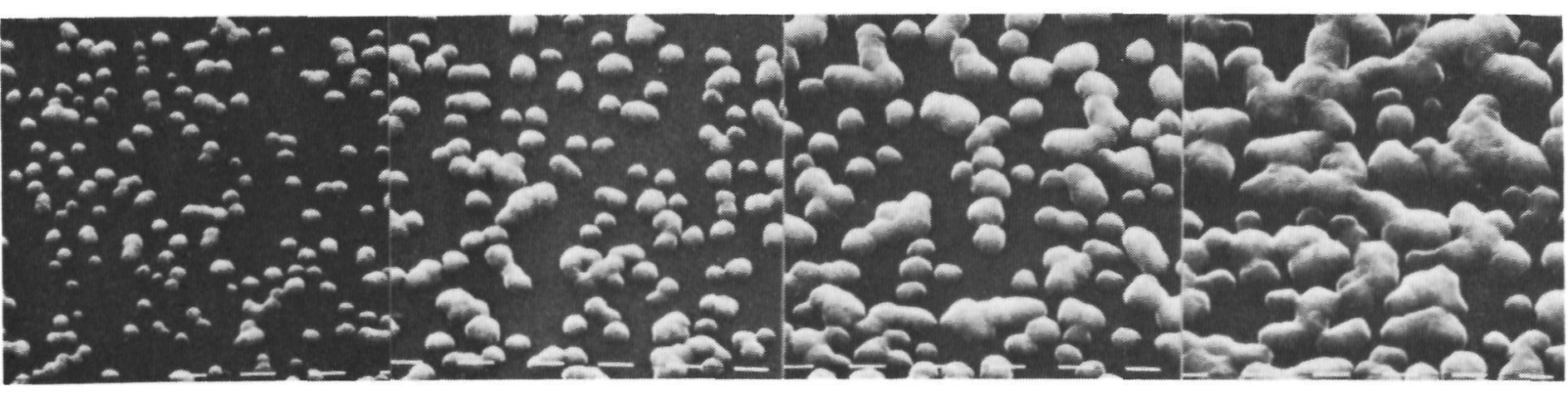
e) $\mathrm{t}=\mathbf{2 5 \mathrm { sec }}$.
f) $t=40 \mathrm{sec}$.
g) $t=70 \mathrm{sec}$.
h) $t=120 \mathrm{sec}$. 
If we assume that the clusters are hemispherical, we can calculate the number of deposited atoms. With reference to Figure 3 it can be observed that the total deposited volume is small until coalescence is reached. After this the deposited volume increases linearly with time with the same slope as obtained on silicon substrates. In the latter case no incubation time is observed. This behaviour is an additional indication of the incomplete condensation in the early stages of nucleation and growth on the foreign substrates.

\subsection{Nucleation on a $\mathrm{SiO}_{2}$ substrate}

The experimentally observed saturation densities of Si clusters are collected in Tables I and Il. Figure 4 presents SEM photomicrographs for different input concentrations of $\mathrm{SiH}_{4}$ and a $\mathrm{SiO}_{2}$ substrate at $1000^{\circ} \mathrm{C}$.

In Figure 5 the saturation density of $\mathrm{Si}$ clusters is plotted as a function of temperature for different input concentrations of $\mathrm{SiH}_{4}$ and $\mathrm{HCl}$ on a $\mathrm{SiO}_{2}$ substrate. It is apparent that the introduction of $\mathrm{HCl}$ reduces the number of nuclei and increases the temperature dependence of the formation process. It is also observed, but not shown here, that the nucleus density decreases at temperatures below $925^{\circ} \mathrm{C}$. In a later publication this feature will be discussed. Further it was measured that at $1200^{\circ} \mathrm{C}$ the $\mathrm{SiO}_{2}$ surface partly deteriorates when relatively low input concentrations of $\mathrm{SiH}_{4}$ and long exposure times are used. It will be shown in the discussion that between $925^{\circ}$ and $1200^{\circ} \mathrm{C}$ the experimental data on the saturation density of nuclei $\left(\mathrm{N}_{\mathrm{S}}\right)$ as a function of temperature and gas phase compositions can be described by:

$N_{S}=A\left\{\frac{B^{\circ} P_{S_{i H}}}{C^{\circ} \mathrm{P}_{\mathrm{HCl}}^{2}}\right\}^{a} \quad \exp \frac{E}{\mathrm{kT}}$,

where $\mathrm{C}^{\circ}=6 \times 10^{6}$ when $\mathrm{PSiH}_{4}$ and $\mathrm{PHCl}_{\mathrm{H}}$ are expressed in bars. The exponent a and the activation energy $E$ still depend on gas phase composition. In Figure 6 the saturation density of clusters at $100{ }^{\circ} \mathrm{C}$ is plotted as a function of $\mathrm{PSiH}_{4} /\left(6 \times 10^{6}\right.$ $\mathrm{P}_{\mathrm{HCl}}^{2}+1$ ). For $\mathrm{SiH}_{4}$ the equilibrium vapour pressure (above which decomposition of $\mathrm{SiH}_{4}$ can be expected) is $\sim 10^{-6}$ bar [20]. This value is nearly independent of temperature in the range of interest and in good agreement with the results given in Figure 6. From experiments as given in Figure $5\left(\log N_{S}\right.$ vs $\left.1 / T\right)$ for temperatures above $925^{\circ} \mathrm{C}$ an apparent activation energy can be obtained from the Arrhenius plot. The experimental values of $\mathrm{E}$ are given in Figure 7 as a function of the gas phase composition, the latter expressed as $\mathrm{PSiH}_{4} /\left(6 \times 10^{6} \mathrm{P}_{\mathrm{HCl}}^{2}{ }^{+1}\right)$.

It is observed that at high supersaturations the activation energy comes to a limiting value of $1.9 \mathrm{eV}$. At lower supersaturations the activation energy increases, this behaviour is accompanied by a strong decrease in the number of nuclei. 


\begin{tabular}{|c|c|c|c|c|c|c|c|c|c|c|c|c|c|}
\hline \multirow[t]{2}{*}{$\begin{array}{l}P_{\mathrm{HCl}} \\
\text { (bar) }\end{array}$} & \multirow[t]{2}{*}{$\underset{\text { (bar) }}{\mathrm{PSiH}_{4}}$} & \multicolumn{3}{|c|}{$1200^{\circ} \mathrm{C}$} & \multicolumn{3}{|c|}{$1100^{\circ} \mathrm{C}$} & \multicolumn{3}{|c|}{$1000^{\circ} \mathrm{C}$} & \multicolumn{3}{|c|}{$925^{\circ} \mathrm{C}$} \\
\hline & & $\begin{array}{c}t \\
(\mathrm{sec})\end{array}$ & $\mathrm{SiO}_{2}$ & $\mathrm{Si}_{3} \mathrm{~N}_{4}$ & $\begin{array}{c}t \\
(\mathrm{sec})\end{array}$ & $\mathrm{SiO}_{2}$ & $\mathrm{Si}_{3} \mathrm{~N}_{4}$ & $\begin{array}{c}t \\
(\mathrm{sec})\end{array}$ & $\mathrm{SiO}_{2}$ & $\mathrm{Si}_{3} \mathrm{~N}_{4}$ & $\begin{array}{c}t \\
(\sec )\end{array}$ & $\mathrm{SiO}_{2}$ & $\mathrm{Si}_{3} \mathrm{~N}_{6}$ \\
\hline - & $2.8 \times 10^{-4}$ & 5 & - & $1.7 \times 10^{9}$ & 8 & - & $2.7 \times 10^{9}$ & 15 & $3 \times 10^{9}$ & $7 \times 10^{9}$ & 20 & $1.1 \times 10^{9}$ & $1.6 \times 10^{10}$ \\
\hline - & $7.3 \times 10^{-4}$ & 5 & $4.7 \times 10^{8}$ & $2.2 \times 10^{9}$ & 5 & $1.4 \times 10^{9}$ & $3.9 \times 10^{9}$ & 5 & $6 \times 10^{9}$ & $1 \times 10^{10}$ & 5 & $8 \times 10^{9}$ & $2 \times 10^{10}$ \\
\hline $1.8 \times 10^{-3}$ & $3.7 \times 10^{-4}$ & 5 & $3.3 \times 10^{6}$ & - & 10 & $1.3 \times 10^{7}$ & $6.8 \times 10^{8}$ & 15 & $1.2 \times 10^{8}$ & $1 \times 10^{9}$ & 30 & $3.2 \times 10^{8}$ & $1.0 \times 10^{8}$ \\
\hline $1.8 \times 10^{-3}$ & $7.3 \times 10^{-4}$ & 5 & $2.2 \times 10^{7}$ & $2.5 \times 10^{8}$ & 5 & $6.1 \times 10^{7}$ & $1.4 \times 10^{9}$ & 5 & $3.9 \times 10^{8}$ & $2.2 \times 10^{9}$ & 5 & $1.5 \times 10^{9}$ & $3.5 \times 10^{9}$ \\
\hline $1.8 \times 10^{-3}$ & $2.6 \times 10^{-3}$ & 3 & $6.7 \times 10^{7}$ & $3.1 \times 10^{8}$ & 3 & $2.8 \times 10^{8}$ & $7 \times 10^{8}$ & 5 & $8.5 \times 10^{8}$ & $*$ & 10 & $*$ & $*$ \\
\hline $3.6 \times 10^{-3}$ & $2.8 \times 10^{-4}$ & 20 & $6 \times 10^{3}$ & $1.0 \times 10^{8}$ & 30 & $1.6 \times 10^{4}$ & $1.0 \times 10^{7}$ & 60 & 0 & o & 120 & $3 \times 10^{3}$ & 0 \\
\hline $3.6 \times 10^{-3}$ & $7.3 \times 10^{-4}$ & 5 & $3 \times 10^{5}$ & $5.4 \times 10^{7}$ & 5 & $9 \times 10^{5}$ & $5.3 \times 10^{8}$ & 5 & $7 \times 10^{7}$ & $1.3 \times 10^{9}$ & 15 & $7.2 \times 10^{8}$ & $1.8 \times 10^{9}$ \\
\hline $3.6 \times 10^{-3}$ & $1.4 \times 10^{-3}$ & 5 & $1.4 \times 10^{6}$ & $2.1 \times 10^{8}$ & 10 & $7.9 \times 10^{6}$ & $*$ & 15 & $2.9 \times 10^{8}$ & $*$ & 25 & $9.5 \times 10^{B}$ & $*$ \\
\hline $3.6 \times 10^{-3}$ & $2.6 \times 10^{-3}$ & 3 & $3.1 \times 10^{7}$ & $1.1 \times 10^{B}$ & 5 & $6.5 \times 10^{7}$ & $*$ & 8 & $6.1 \times 10^{8}$ & - & 13 & $1.9 \times 10^{9}$ & * \\
\hline $5.5 \times 10^{-3}$ & $7.3 \times 10^{-4}$ & 5 & $8 \times 10^{4}$ & $2.3 \times 10^{7}$ & 30 & $2 \times 10^{4}$ & $1 \times 10^{8}$ & 30 & $3.0 \times 10^{7}$ & $6.0 \times 10^{8}$ & 30 & $2.5 \times 10^{8}$ & $5 \times 10^{8}$ \\
\hline $7.2 \times 10^{-3}$ & $7.3 \times 10^{-4}$ & 5 & $3 \times 10^{3}$ & $5.4 \times 10^{7}$ & 60 & $8 \times 10^{3}$ & $1.5 \times 10^{7}$ & 30 & $9 \times 10^{4}$ & $3 \times 10^{6}$ & 240 & $2.4 \times 10^{6}$ & \\
\hline $7.2 \times 10^{-3}$ & $1.4 \times 10^{-3}$ & 5 & $6 \times 10^{3}$ & - & 10 & $1.1 \times 10^{5}$ & $1.4 \times 10^{B}$ & 15 & $1.4 \times 10^{7}$ & $5 \times 10^{8}$ & 30 & $3.9 \times 10^{8}$ & $1.9 \times 10^{9}$ \\
\hline
\end{tabular}

\section{TABLE I}

Saturation nucleus density $\left(\mathrm{cm}^{-2}\right)$ for the $\mathrm{SiH}_{4}-\mathrm{HCl}-\mathrm{H}_{2}$ system on $\mathrm{SiO}_{2}$ and $\mathrm{Si}_{3} \mathrm{~N}_{4}$ substrates between 1200 and $925{ }^{\circ} \mathrm{C}$ (water-cooled R.F. Reactor): * means coalescence takes place and o means no nucleation is observed. $t$ is the exposure time. 


\begin{tabular}{|c|c|c|c|c|}
\hline \multirow{2}{*}{$\begin{array}{c}\mathrm{P}_{\mathrm{HCl}} \\
\text { (bar) }\end{array}$} & \multirow{2}{*}{$\begin{array}{c}\mathrm{P}_{\mathrm{S}_{1} \mathrm{H}_{4}} \\
\text { (bar) }\end{array}$} & \multirow{2}{*}{$\begin{array}{c}\mathrm{t} \\
(\mathrm{sec})\end{array}$} & \multicolumn{2}{|c|}{ substrate } \\
\hline & & & $\mathrm{S}_{1} \mathrm{O}_{2}$ & $\mathrm{SlH}_{4}$ \\
\hline - & $1 \times 10^{-5}$ & 370 & & $27 \times 10^{9}$ \\
\hline- & $9 \times 10^{-5}$ & 35 & $66 \times 10^{8}$ & $17 \times 10^{10}$ \\
\hline - & $22 \times 10^{-4}$ & 15 & $14 \times 10^{9}$ & $1.4 \times 10^{10}(*)$ \\
\hline - & $4.4 \times 10^{-4}$ & 5 & $5.0 \times 10^{9}$ & $28 \times 10^{10}$ \\
\hline - & $88 \times 10^{-4}$ & 3 & $6.5 \times 10^{9}$ & $4.0 \times 10^{10}$ \\
\hline - & $1.7 \times 10^{-3}$ & 3 & $8 \times 10^{9}$ & * \\
\hline $4.4 \times 10^{-4}$ & $88 \times 10^{-4}$ & 5 & $2.5 \times 10^{9}$ & $1.1 \times 10^{10}(*)$ \\
\hline $8.8 \times 10^{-4}$ & $8.8 \times 10^{-4}$ & 5 & $16 \times 10^{9}$ & $9.1 \times 10^{9}\left({ }^{*}\right)$ \\
\hline $1.3 \times 10^{-3}$ & $8.8 \times 10^{-4}$ & 5 & $8.0 \times 10^{8}$ & $7.1 \times 10^{9}$ \\
\hline $22 \times 10^{-3}$ & $8.8 \times 10^{-4}$ & 5 & $3.8 \times 10^{8}$ & $50 \times 10^{9}$ \\
\hline $4.4 \times 10^{-3}$ & $8.8 \times 10^{-4}$ & 10 & $80 \times 10^{7}$ & $1.1 \times 10^{9}$ \\
\hline $6.6 \times 10^{-3}$ & $88 \times 10^{-4}$ & 30 & $9 \times 10^{5}$ & $40 \times 10^{7}$ \\
\hline
\end{tabular}

\section{TABLE II}

Saturation nucleus densities $\left(\mathrm{cm}^{-2}\right)$ for the $\mathrm{S}_{1} \mathrm{H}_{4} \cdot \mathrm{HCl}-\mathrm{H}_{2}$ system (air-cooled R F reactor) on $\mathrm{S}_{1} \mathrm{O}_{2}$ and $\mathrm{Sl}_{3} \mathrm{~N}_{4}$ substrates at $100{ }^{\circ} \mathrm{C} t$ is the exposure tıme and * means that coalescence occurs

\section{Nucleation on a $\mathrm{Sl}_{3} \mathrm{~N}_{4}$ substrate, differences compared with a $\mathrm{SlO}_{2}$ substrate}

Tables I and II also present experımental data for the saturation densities of stable clusters in the $\mathrm{SiH}_{4} \cdot \mathrm{HCl}-\mathrm{H}_{2}$ system for $\mathrm{S}_{3} \mathrm{~N}_{4}$ substrates From the Tables it can be observed that the saturation density of $\mathrm{S}$ clusters is always larger for a $\mathrm{Sl}_{3} \mathrm{~N}_{4}$ substrate than for a $\mathrm{SiO}_{2}$ substrate (other things being equal) This means that coalescence takes place much earler on a $\mathrm{Si}_{3} \mathrm{~N}_{4}$ substrate than on a $\mathrm{SiO}_{2}$ substrate. In spite of the rapid nucleation and coalescence we were able to observe the saturation cluster density by choosing an appropriate exposure time. Figure 8 gives a plot of the saturation nucleus density for two different mixtures of $\mathrm{S}_{1} \mathrm{H}_{4}$ and $\mathrm{HCl}$ as a function of temperature for both substrates. In the case of the $\mathrm{Sl}_{\mathbf{3}} \mathrm{N}_{4}$ substrate, too, the addition of $\mathrm{HCl}$ reduces the number of clusters and increases the temperature dependence of the saturation density, though to a smaller degree than for the $\mathrm{SiO}_{2}$ substrate. The expenmentally found expression for the saturation nucleus density (eq. 1) as a function of gas phase composition for the $\mathrm{SiO}_{2}$ substrate can also be used for a $\mathrm{Si}_{3} \mathrm{~N}_{4}$ substrate between $1200-925^{\circ} \mathrm{C}$, as will be shown in the discussion

The nucleus density as a function of $\mathrm{PS}_{\mathrm{S}_{4}} /\left(6 \times 10^{6} \mathrm{P}_{\mathrm{HCl}}^{2}+1\right)$ for a $\mathrm{Sl}_{3} \mathrm{~N}_{4}$ substrate at $1000{ }^{\circ} \mathrm{C}$ is plotted in Figure 6 For temperatures above $925^{\circ} \mathrm{C}$ an apparent 

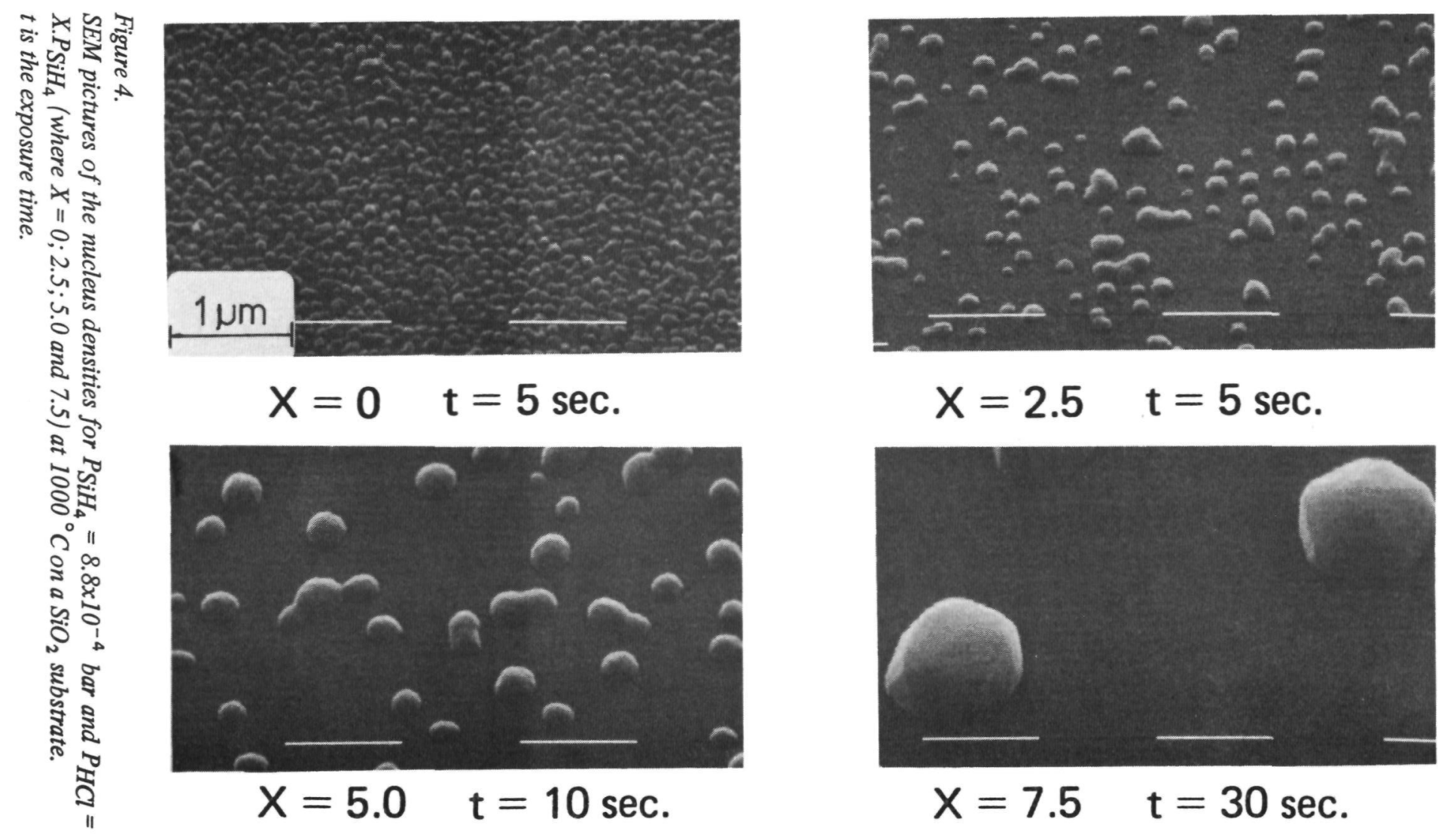

$$
X=0 \quad t=5 \mathrm{sec} .
$$

$$
X=2.5 \quad t=5 \mathrm{sec} .
$$
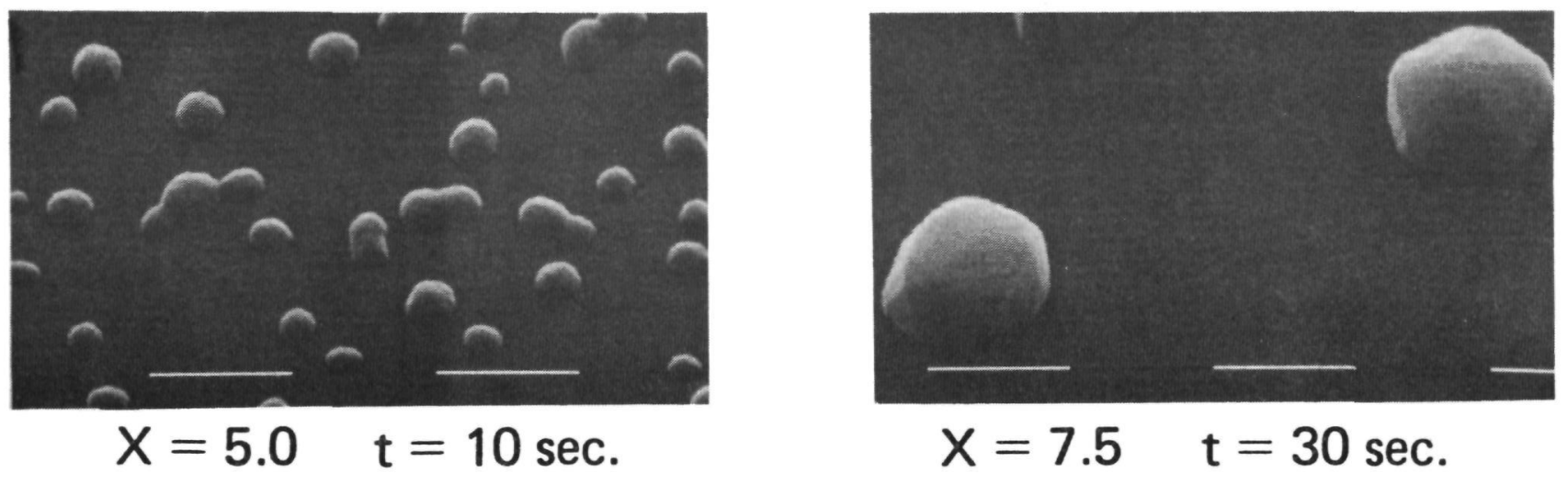
$1200^{\circ} \mathrm{C} \quad 1100^{\circ} \mathrm{C} \quad 1000^{\circ} \mathrm{C} \quad 925^{\circ} \mathrm{C}$

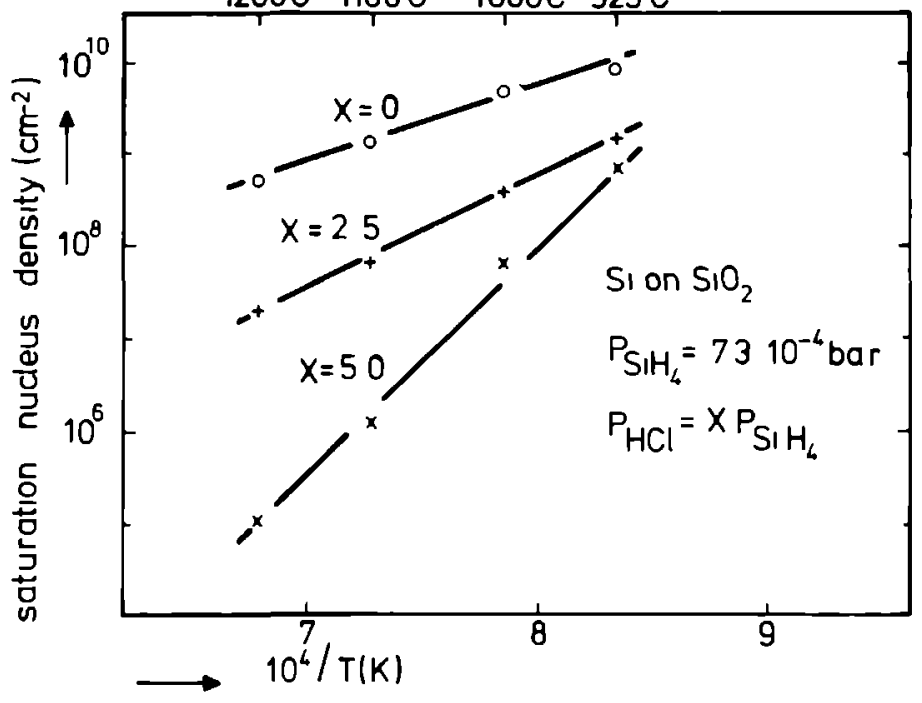

Figure 5.

The saturation nucleus density as a function of the reciprocal temperature for different mixtures of $\mathrm{SiH}_{4}$ and $\mathrm{HCl}$ on $\mathrm{SiO}_{2}$ substrates.

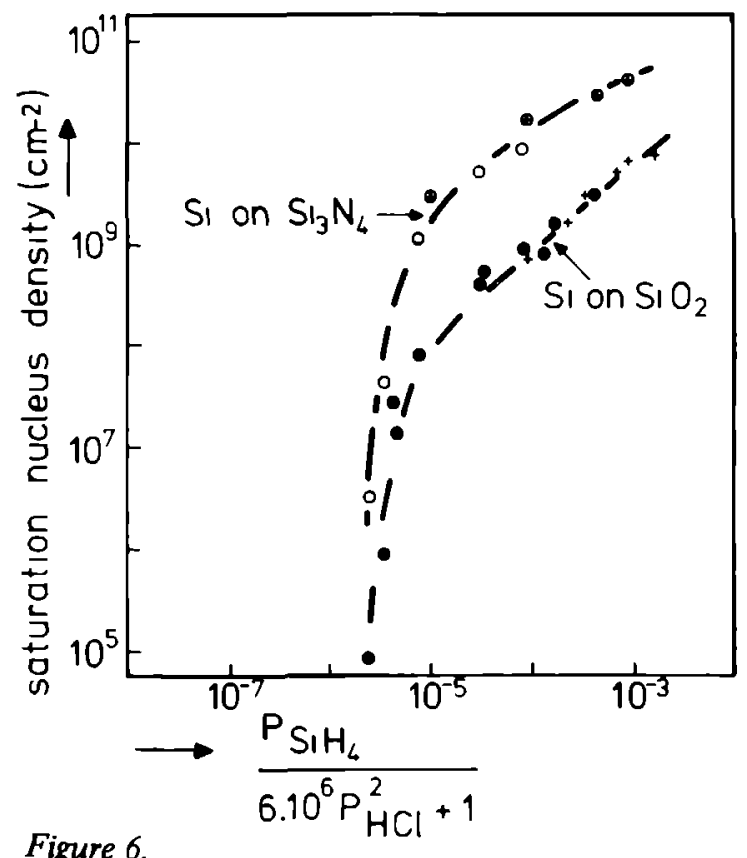

The saturation nucleus density of Si clusters on a $\mathrm{SiO}_{2}$ and $\mathrm{Si}_{3} \mathrm{~N}_{4}$ substrate at $1000^{\circ} \mathrm{C}$ for different input concentrations of $\mathrm{SiH}_{4}$ and $\mathrm{HCl}++, \oplus$ only $\mathrm{SiH}_{4} ; \mathrm{O}_{\text {, }}$ mixture of $\mathrm{SiH}_{4}$ and $\mathrm{HCl}$ ). 


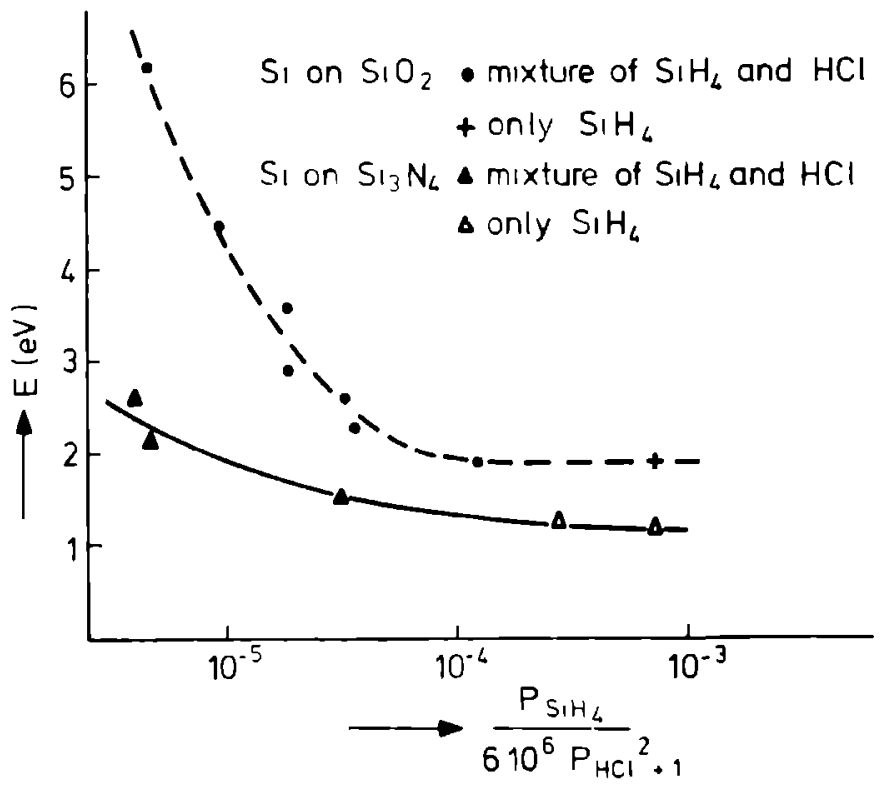

Figure 7.

The relation between the activation energy for cluster formation and the input concentrations of $\mathrm{SlH}_{4}$ and $\mathrm{HCl}$ for $\mathrm{SiO}_{2}$ and $\mathrm{Si}_{3} \mathrm{~N}_{4}$ substrates.

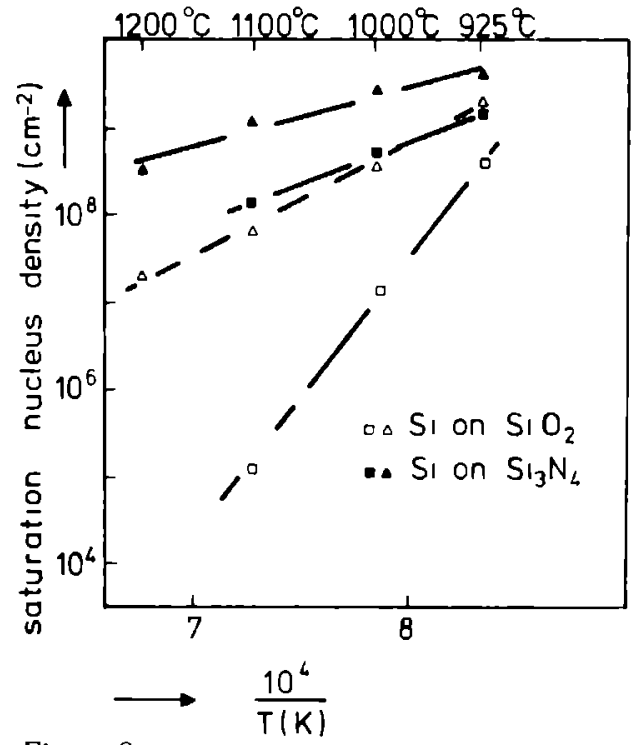

Figure 8.

The saturation cluster density of $S_{l}$ clusters as a function of temperature for two $\mathrm{SiH}_{4}-\mathrm{HCl}$ mixtures on $\mathrm{SlO}_{2}$ and $\mathrm{Sl}_{3} \mathrm{~N}_{4}$ substrates $\left(\triangle, \triangle \mathrm{PSiH}_{4}=7.3 \times 10^{-4}\right.$ bar and $\mathrm{P}_{\mathrm{HCl}}=1.8 \times 10^{-3}$ bar $\sqcup, \mathrm{PSiH}_{4}=14 \times 10^{-3}$ bar and $\mathrm{PHCl}_{\mathrm{HCl}}=7.2 \times 10^{-3}$ bar 
activation energy can be obtaned from the Arrhenius plot $\left(\log \mathrm{N}_{\mathrm{S}}\right.$ vs $\left.1 / \mathrm{T}\right)$ The experimental values of $\mathrm{E}$ for $\mathrm{S}_{3} \mathrm{~N}_{4}$ substrates are included in Figure 7 which also gives $\mathrm{E}$ values for $\mathrm{S}_{1} \mathrm{O}_{2}$ substrates It is observed that with increasing supersatur ation the activation energy decreases and this decrease is stronger for the $\mathrm{SiO}_{2}$ substrate than for the $\mathrm{S}_{3} \mathrm{~N}_{4}$ substrate

\section{Discussion}

\section{Nucleation theory}

The growth of thin films on a substrate starts with the formation of small cap shaped clusters if the cohesive forces between the atoms in the cluster are greater than the adhesive forces between adsorbed atoms (adatoms) and the substrate The formation of the small clusters begins with the arrival of atoms or molecules from the vapour After adsorption, and perhaps chemical reaction, adatoms are formed on the surface These adatoms diffuse across the surface where, through statistical fluctuations in local concentration, they form small clusters of atoms which grow and decay by addition or loss of single atoms If the cluster exceeds a critical size (supercritical cluster) further growth becomes energetically favourable Clusters that are smaller than the critical size (subcritical) can decay

In the chemical thermodynamic approach we can write for the radius $r^{*}$ of the critical cluster

$$
\mathrm{r}^{*}=\frac{2 \delta \mathrm{v}}{\mathrm{kT} \ln \mathrm{p} / \mathrm{pe}_{\mathrm{e}}}
$$

where $\delta$ is the surface free energy which is taken isotropic, $v$ is the atomic volume and $\mathrm{kTlnp} / \mathrm{p}_{\mathrm{e}}$ is the supersaturation function giving the gain in free energy on crystallisation Using the experimental results we can give an estımation of $r^{*}$ In Figure 6 the saturation density of Si clusters is plotted as a function of the gas phase composition This gives us the opportunity to calculate the supersaturation $\mathrm{p} / \mathrm{Pe}$, where $\mathrm{Pe} \sim 10^{-6}$ bar is the equilibrium vapour pressure of $\mathrm{SiH}_{4}$ Using equation (2) with $v=2 \times 10^{-21} \mathrm{~cm}^{3}$ and $\delta=10^{-4} \mathrm{~J} / \mathrm{cm}^{2}$ [21] gives $\mathrm{I}=15 \mathrm{~nm}$ for $\mathrm{p} / \mathrm{p}_{\mathrm{e}}=5$ and $\mathrm{r}=04 \mathrm{~nm}$ for $\mathrm{p} / \mathrm{pe}_{\mathrm{e}}=10^{3}$ This means that for high supersaturation the radius of the critıcal cluster approaches molecular dimensions, but in that case the thermodynamic interpretation of surface energies is no longer justified These difficulties are avoided when the nucleation process is treated by writing the partition function and potential energies for the adatoms and cluster as is done in the atomistic nucleation theory Walton [22], in an approxumate treatment, considered the potential energy difference $E_{1}$ between 1 adatoms and a cluster of 1 atoms For the reaction on the surface

$1 \mathrm{n}_{1} \rightleftharpoons \mathrm{n}_{1}$ 
he found for the density of critical clusters $n_{1}$ if no stable clusters are present and $\mathrm{n}_{1} \gg \mathrm{n}_{1}$,

$$
\frac{n_{1}}{n_{0}}=C_{1}\left(\frac{n_{1}}{n_{0}}\right) \exp \frac{E_{1}}{k T}
$$

where $n_{1}$ is the concentration of adatoms, $n_{O}$ is the number of surface sites, $C_{1}$ is a statistical weighting factor and $E_{1}$ is the heat of formation of the cluster consisting of 1 atoms Equation (3) is generally used in the atomistic nucleation theories to find a general expression for the saturation density of stable clusters

The rate of formation of adatoms as a function of exposure time $t$ and the incoming flux $\mathrm{J}_{1}$ can be given by

$$
\frac{\mathrm{dn}}{\mathrm{dt}}=J_{1}-\frac{\mathrm{n}_{1}}{\tau_{\mathrm{eV}}}-\frac{\mathrm{n}_{1}}{\tau_{\mathrm{I}}}-\frac{\mathrm{n}_{1}}{\tau_{\mathrm{g}}}-
$$

where $\tau_{\mathrm{ev}}$ is the mean residence time before evaporation, $\tau_{\mathrm{r}}$ is the $\tau$ value if adatoms are removed by chemical reaction and $\tau_{\mathrm{g}}$ is the $\tau$ value for the capture of adatoms by stable clusters In the case of complete condensation the $\tau_{\mathrm{ev}}$ and $\tau_{\mathrm{I}}$ values are supposed to be so great that no desorption or etching of adatoms occurs The adatom concentration increases with time until the diffusional flux has grown sufficiently to substantially reduce the value of $n_{1}$ Evaporation or reaction come into play for incomplete condensation and the smallest $\tau$ values in the series determines the value of $\tau_{S}$ and therefore the value of $n_{1}$ giving

$$
n_{1}=J_{1} \tau_{S} \text { for } t \gg \tau_{S}
$$

The surface concentration $n_{1}$ is attained before nucleation starts As nucleation proceeds $\tau_{\mathrm{S}}$ will decrease because adatoms also disappear by incorporation in stable clusters Between the clusters the value of $n_{1}$ eventually drops below the initial steady state concentration, whereupon the production of new nucles ceases. The maximum cluster density is one of the easily measurable quantities when the nucleation rate is too high to be measured Following Venables [23] we can write for the formation rate of stable clusters

$$
\frac{\mathrm{dn}_{\mathrm{X}}}{\mathrm{dt}}=\mathrm{U}_{1}-\mathrm{U}_{\mathrm{c}}-\mathrm{U}_{\mathrm{m}}
$$

where $n_{X}$ is the density of stable clusters at the time $t U_{1}$ is the nucleation rate and $\mathrm{U}_{\mathrm{c}}$ and $\mathrm{U}_{\mathrm{m}}$ are the rates at which stable clusters are lost due to coalescence and cluster moblity, respectively In the $\mathrm{SiH}_{4}-\mathrm{HCl} \cdot \mathrm{H}_{2}$ system at temperatures between $925^{\circ} \mathrm{C}$ and $1200{ }^{\circ} \mathrm{C}, n_{\mathbf{X}}$ reaches a saturation value $N_{s}$ long before coalescence 
occurs (see Figure 2), hence $\mathrm{U}_{\mathrm{c}} \ll \mathrm{U}_{\mathrm{m}}$ Stowell s analysis of data on the nucleation of $\mathrm{Au}$ and $\mathrm{Ag}$ on alkalı halide substrates shows that cluster mobility becomes umportant at temperatures above $400{ }^{\circ} \mathrm{C}$ [24] Lewis [25] assumes that the detach ment of peripheral atoms of hemispherical clusters determines the activation energy of the mobility process In that case the activation energy for cluster diffusion is independent of cluster size, while the actual cluster mobility strongly depends on the size, viL, via a pre exponential entropy term Masson et al [26] measured relatively large diffusion coefficients, which are probably caused by non-epitaxial orientation of the clusters According to Behmdt [27] liquid nucleı, with con sequently a relatively high surface mobility, are also possible at temperatures which are much lower than the melting pount of the condensate For the case where all stable clusters are mobile, at least initially untill $n_{X}$ saturates, Venables gives an expression describing the maximum cluster density $\mathrm{N}_{\mathbf{S}}$ for incomplete condensation

$\frac{N_{s}}{n_{0}} \cong\left(\frac{J}{n_{0} \nu}\right)^{\frac{1+1}{2}} \exp \frac{(1+1) E_{a}+E_{1}+E_{m}-E_{d}}{2 k T}$

where $E_{a}$ is the activation energy of desorption, $E_{x}$ the activation energy for surface diffusion of moble clusters, $E_{d}$ the activation energy for surface diffusion of adatoms, $\mathrm{n}_{\mathbf{O}}$ the number of surface sites and $\nu$ the adatom vibration frequency, the other parameters have already been defined (eqs 3 and 5)

In the $\mathrm{S}_{1} \mathrm{H}_{4} \cdot \mathrm{HCl} \cdot \mathrm{H}_{2}$ system there is an incubation period for the formation of a significant number of stable clusters and a non-linear increase of the deposited volume in the early state of growth (see section 31 ) which supports the arguments for incomplete condensation The relation deduced by Venables (eq 7) can be compared with the experimentally found supersaturation with the help of eq 5 and the calculated adatom concentration $\left(n_{1}\right)$ as given in eq A-16 of the appendix

\section{Adatom concentration and surface coverages}

To arrive at an expression determining the adatom concentrations of $S_{1}$ on the substrates the man processes responsible for formation and removal are summarzed in appendix A It is concluded that the following steps may be important

a diffusion of slane towards the surface,

b adsorption of slane, dffusion across the surface and chemical reaction (formation of adatoms),

c etching reactions of $\mathrm{HCl}, \mathrm{H}_{2}$ and $\mathrm{SiO}_{2}$ with silicon adatoms,

d desorption of reaction products,

e diffusion of reaction products away from the surface

Since the value of the diffusion coefficient in the gas phase is rather insensitive to temperature (ideal gas $\mathrm{D} \propto \mathrm{T}^{3 / 2}$ ) the processes a and $\mathrm{e}$ wll have a low activation energy 
In order to obtain realistic information about the concentration of adatoms and free surface sites some additional information may be helpful

1. From nucleation experuments in the $\mathrm{S}_{1} \mathrm{H}_{2} \mathrm{Cl}_{2}-\mathrm{H}_{2}-\mathrm{N}_{2}$ system at temperatures between $900^{\circ}$ and $1100{ }^{\circ} \mathrm{C}$ on $\mathrm{S}_{1} \mathrm{O}_{2}$ and $\mathrm{S}_{3} \mathrm{~N}_{4}$ substrates [28] it is found that hydrogen strongly influences nucleation on $\mathrm{SiO}_{2}$ substrates In the case of $\mathrm{Sl}_{3} \mathrm{~N}_{4}$ substrates there is hardly any difference in saturation density between the results in $\mathrm{H}_{2}$ or $\mathrm{N}_{2}$ ambient

11 The saturation cluster density in the $\mathrm{S}_{1} \mathrm{H}_{2} \mathrm{Cl}_{2}-\mathrm{N}_{2}$ system is equal for both substrates at temperatures between $925^{\circ} \mathrm{C}$ and $1100^{\circ} \mathrm{C}$

w. From nucleation experiments in the $\mathrm{SiH}_{4}-\mathrm{H}_{2}$ system at temperatures between 900 and $600{ }^{\circ} \mathrm{C}$ [28] we know that for $\mathrm{S}_{1} \mathrm{O}_{2}$ substrates the saturation density decreases with decreasing temperature, whereas $\mathrm{Sl}_{3} \mathrm{~N}_{4}$ substrates show the opposite behaviour The observations mentioned above suggest that the adsorption of hydrogen has a great unfluence on the nucleation kunetics, especially for the $\mathrm{S}_{2} \mathrm{O}_{2}$ substrates Under normal operating conditions $\left(925^{\circ}-1200^{\circ} \mathrm{C}\right.$, $\mathrm{P}_{\mathrm{H}_{2}} \cong 1$ bar) it is thus likely that hydrogen adsorption will occur, but it is only below $900{ }^{\circ} \mathrm{C}$ that hydrogen adsorption will influence nucleation on $\mathrm{SiO}_{2}$ substrates by limiting the number of surface sites where $\mathrm{SiH}_{4}$ adsorption may occur.

For the silicon adatom concentration on a $\mathrm{StO}_{2}$ substrate equation $\mathrm{A}-16$ can be used. If hydrogen adsorption does not limit the number of surface sites and with $\mathrm{n}_{\mathrm{O}} \gg\left[\mathrm{SiH}_{4}^{*}\right],\left[\mathrm{Cl}^{*}\right]$ one obtains

$\frac{\mathrm{n}_{1}}{\mathrm{n}_{\mathrm{O}}}=\frac{\mathrm{K}_{1} \mathrm{k}_{2} \mathrm{P}_{\mathrm{S}_{1} \mathrm{H}_{4}}}{\left(\mathrm{k}_{-2} \mathrm{P}_{\mathrm{H}_{2}}^{2}+\mathrm{k}_{6} \mathrm{P}_{\mathrm{HCl}}^{2}+\mathrm{k}_{9}\right)}$

For nucleation on $\mathrm{Sl}_{3} \mathrm{~N}_{4}$ substrates also eq A-16 can be used In that case $\mathrm{k}_{9}$ can be disregarded on thermodynamic grounds as reaction of $\mathrm{S}_{1}$ with $\mathrm{Sl}_{3} \mathrm{~N}_{4}$ will be slow, also hydrogen adsorption is not rate-limiting It is observed, moreover, that the number of stable clusters saturates at high concentrations and $\left[\mathrm{SiH}_{4}{ }^{*}\right]$ cannot be neglected Therefore $n_{1}$ can be given as

$\frac{n_{1}}{n_{0}}=\frac{K_{1} k_{2} P_{S_{1} H_{4}}}{\left(k_{-2} P_{H_{2}}^{2}+k_{6} P_{H C l}^{2}\right)\left(1+K_{1} P_{S_{1} H_{4}}\right)}$

For $\mathrm{P}_{\mathrm{HCl}}=0$ and $\mathrm{K}_{1} \mathrm{PS}_{\mathrm{S}_{1}}<1$ the temperature dependence of $\mathrm{n}_{1}$ is determined by $K_{1} K_{2}$ which, in the temperature region of interest, is nearly independent of temperature According to the JANAF Tables $[20], d\left(1 n K_{p}\right) / d(1 / T) \cong 0$ around $1000^{\circ} \mathrm{C}$.

\section{Interpretation of results}

In this section we compare the expression obtained by Venables (eq. 7) with the 
results of the nucleation experiments in the $\mathrm{SiH}_{4} \cdot \mathrm{HCl}-\mathrm{H}_{2}$ system on $\mathrm{SiO}_{2}$ and $\mathrm{Si}_{3} \mathrm{~N}_{4}$ substrates in the temperature region of $925^{\circ}-1200^{\circ} \mathrm{C}$. Equation 7 can be modified by introducing $n_{1}=J_{1} \tau_{S}$, where $n_{1}$ is given by eq. (8) or (9) and $\tau_{\mathrm{S}}$ is defined as $\tau_{\mathrm{s}}=\nu^{-1} \exp \mathrm{E}_{\mathrm{a}} / \mathrm{kT}, \mathrm{E}_{\mathrm{a}}$ being the enthalpy of desorption and $\nu$ the adatom vibration frequency. The modified expression (eq. 7) then reads for $\mathrm{SiO}_{2}$ substrates:

$\frac{N_{s}}{n_{0}} \cong\left\{\frac{K_{1} k_{2} P_{S i H_{4}}}{\left(k_{-2} P_{H_{2}}^{2}+k_{6} P_{H C l}^{2}+k_{9}\right)}\right\}^{\frac{i+1}{2}} \exp \frac{E_{i}+E_{m}-E_{d}}{2 k T}$

It should be realized that the expression between curly brackets already presents a simplified version of a more complex expression. A possible activation energy from this relation has to be added to the exponential term. This, however, depends on which of the terms in the denominator prevails and whether $\mathrm{HCl}$ is present or not. In order to put eq. (10) into a form that permits evaluation of the experimental data we can write

$N_{S}=A\left\{\frac{\mathrm{BPSiH}_{4}}{\mathrm{CP}_{\mathrm{HCl}}^{2}+1}\right\}^{\frac{i+1}{2}} \exp \frac{\mathrm{E}_{\mathrm{i}}+\mathrm{E}_{\mathrm{m}}-\mathrm{E}_{\mathrm{d}}}{2 \mathrm{kT}}$

in which $A$ is a constant (equal to $n_{0}$ )

$$
\begin{array}{ll}
B=\frac{K_{1} k_{2}}{\left(k_{-2} P_{H_{2}}^{2}+k_{9}\right)} & =B^{\circ} \exp \frac{-E_{r, 1}}{k T} \\
C=\frac{K_{6}}{\left(k_{-2} P_{H_{2}}^{2}+k_{9}\right)} & =C^{\circ} \exp \frac{-E_{r, 2}}{k T}
\end{array}
$$

The values of $\mathrm{i}, \mathrm{B}$ and $\mathrm{C}$ thus depend on temperature and gas phase composition and will be different for nucleation on different substrates. For the $\mathrm{SiO}_{2}$ substrate the constants $\mathrm{A}, \mathrm{B}^{\mathrm{O}}$ and $\mathrm{CO}^{\mathrm{O}}$ can be calculated as follows. From Figure 6 we know that, for pure $\mathrm{SiH}_{4}, \mathrm{~N}_{\mathrm{S}}$ is proportional to $\mathrm{PSiH}_{4}$. This means that (i+1)/2=1 for $\mathrm{PSiH}_{4}$ ranging from $9 \times 10^{-5}$ to $1.7 \times 10^{-3}$ bar. Making use of the corresponding values of $\mathrm{E}$ (Figure 7) we find $\mathrm{AB}^{\mathrm{O}}=2 \times 10^{5}$. The mixture $\mathrm{PSiH}_{4}=2.6 \times 10^{-3}$ bar and $\mathrm{PHCl}_{\mathrm{HCl}}=1.8 \times 10^{-3}$ bar gives a cluster density higher than the corresponding one for the lowest pure $\mathrm{SiH}_{4}$ concentration. This leads to the conclusion that $(i+1) / 2=1$ for this $\mathrm{SiH}_{4}-\mathrm{HCl}$ mixture as well. Inserting $\mathrm{ABO}^{\circ}=2 \times 10^{5},(\mathrm{i}+1) / 2=1$ and $\mathrm{E}=1.9$ $\mathrm{eV}$ (the activation energy for this special $\mathrm{SiH}_{4}-\mathrm{HCl}$ mixture) in eq. (11) we obtain $\mathrm{CO}^{\mathrm{O}}=6 \times 10^{6}$. The linear relationship $(\mathrm{i}+1) / 2=1$ between $\mathrm{N}_{\mathrm{S}}$ and $\mathrm{PSiH}_{4}$ for silane pressures between $9 \times 10^{-5}$ and $1.7 \times 10^{-3}$ bar leads to a critical cluster size of $i=1$. In 
that case $\left(\mathrm{PHCl}_{\mathrm{HC}}=0\right)$ the experimentally found activation energy for cluster formation (E) becomes

$$
E=\not z\left(E_{i}+E_{m}-E_{d}-2 E_{r, 1}\right)=1.9 e V
$$

As to the value of $E_{i}$, a cluster can be called stable when half of the possible bonds are formed between atoms in the cluster and between cluster and substrate [29]. For silicon, therefore two bonds have to be realized per sulicon atom. In order to arrive at a relation between the binding energy $E_{i}$ of a cluster of $i$ atoms on $\mathrm{SiO}_{2}$ and the $\mathrm{Si}-\mathrm{Si}$ bond energy $\left(\mathrm{E}_{\mathrm{b}}\right)$ a triangular lattice of oxygen atoms on the substrate is shown schematically in Figure 9. For amorphous $\mathrm{SiO}_{2}$ a triangular lattice is acceptable because short-range order (regions of crystallinity $10-100 \AA$ in size) may exist [30]. Amorphous $\mathrm{SiO}_{2}$ forms a random three-dimensional network where each silicon atom is tetrahedrally surrounded by four oxygen atoms and each oxygen atom is bonded to two silicon atoms with an average $\mathrm{Si}-\mathrm{O}$ distance of $1.62 \AA$, an average 0.0 distance of $2.65 \AA$ and an average Si-Si distance of $3.00 \AA$ [31]. At the surface, however, a silicon atom can be bonded in three different ways to the oxygen lattice. In the first place a Si atom can have a single bond to an oxygen atom (Si-adatom). Further a double and a triple bonding of a $\mathrm{Si}$ atom with the oxygen lattice is possible. The triple bonding, which is the most stable one, can
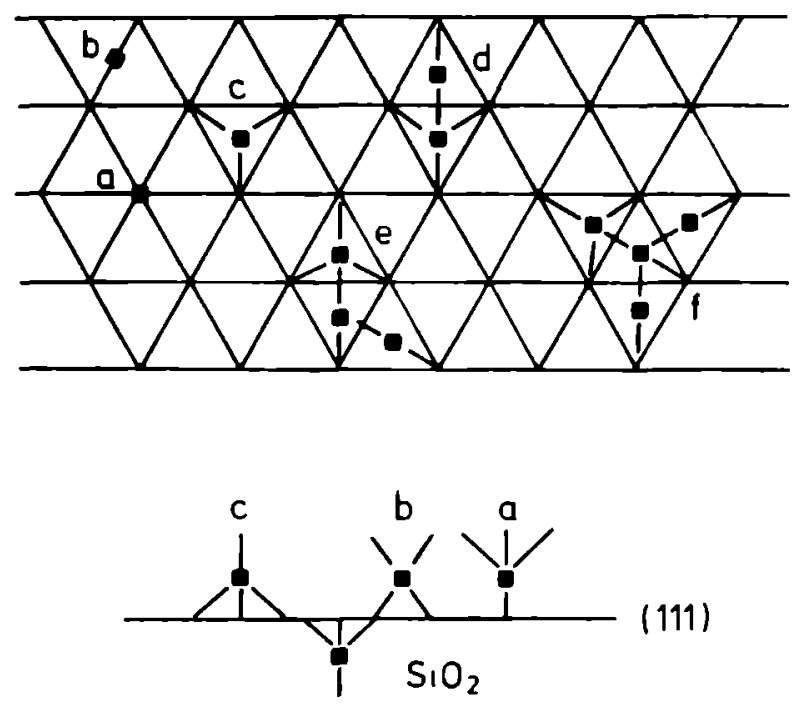

Figure 9.

Binding energies of atoms and clusters on a nearest-neighbour bond model of nucleation on a triangular oxygen lattice: a single bonded, $b$. double bonded, c. triple bonded, $d$. critical cluster size $i=1$, e. critical cluster size $i=2, f$. critical cluster size $i=3$. 
be seen in Figure 9 ('c'). In this simple model a Si-Si bond is formed only when a $\mathrm{Si}$ atom ('a' in Figure 9) on the surface forms a bond with the triple-bonded $\mathrm{Si}$ atom (giving ' $d$ ' in Figure 9). In this case the critical cluster consists of one atom only (the triple-bonded $\mathrm{Si}$ atom belongs to the $\mathrm{SiO}_{2}$ lattice). This model can be extended to clusters containing more than two Si atoms (' $e$ ' and ' $f$ ' in Figure 9 for $i=2$ and $i=3$ ), so that for the critical cluster it leads to an energy gain over the binding energy of one $\mathrm{Si}$-Si bond

$\mathrm{E}_{\mathrm{i}} \cong \mathrm{iESi-Si}$

For $\mathrm{i}=1$ and $\mathrm{ESi}_{\mathrm{S}-\mathrm{Si}}=2 \mathrm{eV}[32]$ eq. (14) leads to

$\mathrm{E}_{\mathrm{m}}-\mathrm{E}_{\mathrm{d}}-2 \mathrm{E}_{\mathrm{r}, 1}=1.8 \mathrm{eV}$

If we compare the results for the $\mathrm{Si}_{3} \mathrm{~N}_{4}$ substrate and the $\mathrm{SiO}_{2}$ substrate in the temperature region $925^{\circ}-1200^{\circ} \mathrm{C}$ we see that the composition of the gas phase where nucleation is no longer observed (Figure 6) is almost the same for both substrates. This justifies the use of equation (11) for the saturation density on $\mathrm{Si}_{3} \mathrm{~N}_{4}$ also. From Figure 7 we know that $\mathrm{E}$ is nearly constant at silane pressures between $5 \times 10^{-5}$ and $10^{-3}$ bar. This means that the cluster size is constant in this region. From Figure $6\left(\log \mathrm{N}_{\mathrm{S}}\right.$ vs $\mathrm{PSiH}_{4}$ eff $)$ it can be observed that in this particular region the tangent changes from 1 to $1 \frac{1}{2}$. At high supersaturation $\mathrm{N}_{\mathrm{S}}$ probably saturates because the concentration of free surface sites is a function of the $\mathrm{SiH}_{4}$ pressure (eq. 9). Thus, at silane pressures between $5 \times 10^{-5}$ and $10^{-3}$ bar we have $\mathrm{i}=1$ and in that case $\mathrm{E}$ becomes

$E=1 / 2\left(E_{1}+E_{m}-E_{d}-2 E_{r, 1}\right)=1.2 \mathrm{eV}$

With $\mathrm{ESi}_{\mathrm{Si}}=2 \mathrm{eV}[32]$ this gives

$E_{m}-E_{d}-2 E_{r, 1}=0.4 e V$

Introducing $\mathrm{E}_{\mathrm{r}, 1} \cong 0 \mathrm{eV}$ for $\mathrm{Si}_{3} \mathrm{~N}_{4}$ (as discussed in section 4.2) into eq. (18) gives $E_{m}-E_{d}=0.4 \mathrm{eV}$. Lewis expects $E_{m} \geqslant 2 E_{d}$ [25], which then should give $E_{m} \cong 0.8 \mathrm{eV}$ and $E_{d} \cong 0.4 \mathrm{eV}$ as maximum values.

Coming back to the nucleation on $\mathrm{SiO}_{2}$ substrates, we note that eq. (16) with $\mathrm{E}_{\mathrm{m}}-\mathrm{E}_{\mathrm{d}}=0.4 \mathrm{eV}$, as obtained above, leads to $\mathrm{E}_{\mathrm{r}, 1}=-0.7 \mathrm{eV}$. The difference between $E_{r, 1}$ for $\mathrm{SiO}_{2}(-0.7 \mathrm{eV})$ and $\mathrm{E}_{\mathrm{r}, 1}$ for $\mathrm{Si}_{3} \mathrm{~N}_{4}\left(\mathrm{E}_{\mathrm{r}, 1} \cong 0 \mathrm{eV}\right)$ can be explained as being due to reactions with the substrate and the formation of $\mathrm{SiO}\left(\mathrm{k}_{9}\right.$ in eq. 8), but for $\mathrm{Si}_{3} \mathrm{~N}_{4}$ substrates this reaction is absent. This means that $\mathrm{k}_{9}$ has an activation energy of $0.7 \mathrm{eV}$, and the formation of $\mathrm{SiO}$ is promoted by the presence of hydrogen. The reaction between a silicon adatom and the $\mathrm{SiO}_{2}$ substrate can be described as 
$\mathrm{Si}+\mathrm{O}_{\text {substrate }}+\mathrm{H}_{2} \stackrel{\mathrm{k}_{9}}{\rightarrow} \mathrm{SiO} \uparrow+2 \mathrm{Had}_{\mathrm{ad}}$

In this way the coverage of the substrate with the first silicon layer is impeded, the more so the higher the temperature, as found experimentally for $\mathrm{SiO}_{2}$ substrates in hydrogen, where at $120{ }^{\circ} \mathrm{C}$ the $\mathrm{SiO}_{2}$ surface partly deteriorates. If $6 \times 10^{6}$ $\mathrm{P}_{\mathrm{HCl}}^{2}>1$, the activation energy for cluster formation becomes

$E=1 / 2\left[E_{i}+E_{m}-E_{d}-(i+1)\left(E_{r, 1}-E_{r, 2}\right)\right]$.

In the experiment on $\mathrm{SiO}_{2}$ with $\mathrm{PSiH}_{4}=2.6 \times 10^{-3}$ bar and $\mathrm{PHCl}=1.8 \times 10^{-3}$ bar, where $\mathrm{i}=1$ as discussed before, the activation energy equals that of pure silane (Figure 7). From this it can be expected that $E_{\mathrm{r}, 2}$ is small and can be disregarded in the first approximation. For low supersaturations the activation energy increases because of the increasing value of $i$ and $E_{i}$. The highest value found for $E_{i}$ of $6.2 \mathrm{eV}$ with $E_{m}-E_{d} \cong 0.4 \mathrm{eV}, E_{r, 2} \cong 0$ and $E_{r, 1} \cong-0.7 \mathrm{eV}$ and using eq. (15), gives a critical cluster with $i=4$. For $\mathrm{Si}_{3} \mathrm{~N}_{4}$ the highest $E$ value is $E \cong 2 \mathrm{eV}$ and a similar approach then leads to a critical cluster of $i=2$.

\section{Conclusions}

In an attempt to understand and be able to monitor the crystallite size in polycrystalline silicon layers we have studied the nucleation of silicon on various substrates. Experiments on the nucleation of $\mathrm{Si}$ on $\mathrm{SiO}_{2}$ and $\mathrm{Si}_{3} \mathrm{~N}_{4}$ substrates are reported for the $\mathrm{SiH}_{4} \cdot \mathrm{HCl} \cdot \mathrm{H}_{2}$ system in the temperature range of $925^{\circ}-1200^{\circ} \mathrm{C}$. The differences and conformities between the two substrates are discussed. It is observed that the saturation nucleus density increases with decreasing temperature for both substrates. This effect, which is stronger for the $\mathrm{SiO}_{2}$ than for the $\mathrm{Si}_{3} \mathrm{~N}_{4}$ substrate, is attributed to the size and the formation energy of the initial critical cluster and to the reaction with the substrate, especially in the case of $\mathrm{SiO}_{2}$ in which the $\mathrm{H}_{2}$ ambient plays an important role. The introduction of $\mathrm{HCl}$ strongly reduces the nucleus density, resulting in an increased grain size in the polycrystalline material. The experimental results can be explained by the application of an expression as obtained by Venables, together with an analysis of the silicon adatom concentration on the substrate as a function of gas phase composition. It is found that the number of silicon atoms in the critical cluster varies between 1 and approximately 4 in the experimental range under discussion. It will be obvious that the values of the activation energies are open to criticism, because slightly different assumptions could change the picture. However, the impression remains that nucleation of silicon on $\mathrm{SiO}_{2}$ and $\mathrm{Si}_{3} \mathrm{~N}_{4}$ substrates at temperatures higher than $900{ }^{\circ} \mathrm{C}$ can be explained semi-quantitatively on the basis of existing statistical nucleation theory supplemented by arguments of a chemical and kinetic nature.

\section{Acknowledgements}

The authors wish to thank Mrs C.W.T. Bulle and Mrs G. v. Leeuwen for the SEM and TEM photomicrographes and Mr. C.F.W. Flinsenberg for making available his water-cooled R.F. reactor. 


\section{APPENDIX: CALCULATION OF ADATOM CONCENTRATIONS}

The main process responsible for nucleation and growth of silicon on a monocrystalline silicon substrate in the $\mathrm{SiH}_{4}-\mathrm{HCl}-\mathrm{H}_{2}$ system is described by Bloem and Giling [33]. Nucleation of silicon on a $\mathrm{SiO}_{2}$ substrate will differ from that on a monocrystalline silicon substrate, but the processes which take place are approximately of the same nature.

a. Supply of $\mathrm{SiH}_{4}$ by means of gas phase diffussion:

$\mathrm{SiH}_{4}(\mathrm{~b}) \stackrel{\mathrm{k}_{\mathrm{a}}}{\rightarrow} \mathrm{SiH}_{4}(\mathrm{~g})$.

$\mathrm{SiH}_{4}$ (b) is the concentration of $\mathrm{SiH}_{4}$ in the bulk of the gas phase and $\mathrm{SiH}_{4}(\mathrm{~g})$ the concentration of $\mathrm{SiH}_{4}$ near the surface.

b. Adsorption of $\mathrm{SiH}_{4}$ on a free site on the surface (denoted by *):

$$
*+\mathrm{SiH}_{4}(\mathrm{~g}) \underset{\mathrm{k}_{-1}}{\stackrel{\mathrm{k}_{1}}{\rightleftharpoons}} \mathrm{SiH}_{4}^{*}
$$

c. The reaction of $\mathrm{SiH}_{4}$ at the surface:

$$
\mathrm{SiH}_{4}^{*} \underset{\mathrm{k}_{-2}}{\stackrel{\mathrm{k}_{2}}{\rightleftharpoons}} \mathrm{Si}^{*}+2 \mathrm{H}_{2}
$$

d. Adsorption of hydrogen, chlorine and $\mathrm{SiCl}_{2}$ :

$$
\begin{aligned}
& { }_{2} \mathrm{H}_{2}+* \underset{\mathrm{k}_{-3}}{\stackrel{\mathrm{k}_{3}}{\rightleftharpoons}} \mathrm{H}^{*} \\
& \mathrm{HCl}+* \underset{\mathrm{k}_{-4}}{\mathrm{k}_{4}} \mathrm{Cl}^{*}+1 / 2 \mathrm{H}_{2} \\
& \mathrm{SiCl}_{2}(\mathrm{~g})+* \underset{\mathrm{k}_{-5}}{\stackrel{\mathrm{k}_{5}}{\rightleftharpoons}} \mathrm{SiCl}_{2}^{*} .
\end{aligned}
$$

e. Etching of adatoms by chlonine:

$$
\mathrm{Si}^{*}+2 \mathrm{HCl} \stackrel{\mathrm{k}_{6}}{\rightarrow} \mathrm{SiCl}_{2} \uparrow+\mathrm{H}_{2}+*
$$


f Growth of sulicon by diffusion of Si adatoms on the surface and incorporation into a stable cluster

$$
\mathrm{Sl}^{*} \stackrel{\mathrm{k}_{7}}{\rightarrow} \mathrm{Sr}(\mathrm{s})+*
$$

g Evaporation of silicon adatoms

$$
\mathrm{Si}^{*} \stackrel{\mathrm{k}_{\mathrm{g}}}{\rightarrow} \mathrm{S}_{1}(\mathrm{~g})+*
$$

h Reaction of $\mathrm{S}_{1}$ adatoms with the substrate

$$
\mathrm{Si}^{*}+\mathrm{SiO}_{2} \stackrel{\mathrm{k}_{9}}{\rightarrow} 2 \mathrm{~S} 1 \mathrm{O} \uparrow+*
$$

1 Reaction of $\mathrm{SiH}_{4}$ in the gas phase

$$
\mathrm{SiH}_{4}(\mathrm{~g}) \stackrel{\mathrm{k}_{10}}{\rightarrow} \mathrm{S} 1(\mathrm{~g})+2 \mathrm{H}_{2}
$$

Formation of sulicon-containing compounds other than $\mathrm{SiCl}_{2}$, such as $\mathrm{SiH}_{2} \mathrm{Cl}_{2}$ ' $\mathrm{SiHCl}_{3}$ and $\mathrm{SiCl}_{4}$, can be disregarded on the grounds of thermochemical data avaulable in literature $[34,35]$ In a steady-state situation the $\mathrm{SI}^{*}$ and $\mathrm{SiH}_{4}$ * concentrations are constant, given by

$\mathrm{n}_{1}=\left[\mathrm{SI}^{*}\right]=\frac{\mathrm{k}_{1}\left[\mathrm{~S}_{1} \mathrm{H}_{4}^{*}\right]}{\mathrm{k}-2_{2} \mathrm{P}_{\mathrm{H}_{2}}^{2}+\mathrm{k}_{6} \mathrm{P}_{\mathrm{HCl}}^{2}+\mathrm{k}_{7}+\mathrm{k}_{\mathrm{B}}+\mathrm{k}_{9}}$

$\left[\mathrm{S}_{1} \mathrm{H}_{4}^{*}\right]=\frac{\mathrm{k}_{1} \mathrm{PS}_{\mathrm{S}_{4}}(\mathrm{~g})[*]+\mathrm{k}_{-2} \mathrm{n}_{1} \mathrm{P}_{\mathrm{H}_{2}}^{2}}{\mathrm{k}_{2}+\mathrm{k}_{-1}}$

In A-13 the second term in the numerator can be expected to be small compared with the first term, in which case

$n_{1}=\frac{k_{1} k_{2}[*] P_{S_{1} H_{4}}(g)}{\left(k_{2}+k_{-1}\right)\left(k_{-2} P_{H_{2}}^{2}+k_{6} P_{H C l}^{2}+k_{7}+k_{8}+k_{9}\right)}$

For nucleation of $\mathrm{Si}_{1}$ on a $\mathrm{SiO}_{2}$ substrate in the $\mathrm{SiH}_{4}-\mathrm{HCl}-\mathrm{H}_{2}$ system, several approximations can be made We have seen that, after an incubation penod, the nucleus density very quickly reached a saturation value On the basis of these experiments it will be assumed that the tume taken to attain the population of ad. atoms is short, so that $n_{1}$ reaches a constant value before nucleation occurs Then 
$k_{7}$ can be omitted untul nucleation takes place The existence of an incubation period further means that the reaction is surface-controlled and the greater part of the slane will desorb before reacting $\left(k_{-1}>k_{2}\right)$. Because of the surface-controlled reaction, and provided gas phase nucleation can be left out of account, we can put $\mathrm{P}_{\mathrm{S}_{1} \mathrm{H}_{4}}(\mathrm{~g})=\mathrm{P}_{\mathrm{S}_{1} \mathrm{H}_{4}}$ (b) during the induction period $\left(\mathrm{k}_{1}<\mathrm{k}_{\mathrm{a}}\right)$ The presence of a carner gas prevents evaporation $\left(\mathrm{k}_{8}<\mathrm{k}_{-2} \mathrm{P}_{\mathrm{H}_{2}}^{2}\right)$ The desorption of $\mathrm{S}_{1} \mathrm{Cl}_{2}$ in the initial stage before nucleation is not expected to be rate limiting, and therefore the surface coverage of $\mathrm{SiCl}_{2}$ will be low and can be disregarded In that case we can write for the concentration of free surface sites

$$
[*]=\mathrm{n}_{\mathrm{O}}-\left[\mathrm{SiH}_{4}^{*}\right]-\left[\mathrm{H}^{*}\right]-\left[\mathrm{Cl}^{*}\right]-\mathrm{n}_{1}
$$

where $\mathrm{n}_{\mathrm{O}}$ is the total number of sites at the surface In adsorption equulbrium for every species an expression can be found as for $\left[\mathrm{H}^{*}\right]$, where eq. (A-4) leads to

$$
\left[\mathrm{H}^{*}\right]=\mathrm{K}_{3} \mathrm{P}_{\mathrm{H}_{2}}^{12}[*], \mathrm{K}_{3}=\mathrm{k}_{3} / \mathrm{k}_{-3}
$$

For $\mathrm{n}_{1} \ll \mathrm{n}_{\mathrm{O}}$ thus gives

$$
[*]=\frac{\mathrm{n}_{\mathrm{O}}}{1+\mathrm{K}_{1} \mathrm{P}_{\mathrm{S}_{1} \mathrm{H}_{4}}+\mathrm{K}_{3} \mathrm{P}_{\mathrm{H}_{2}^{1 / 2}}^{1 / 2}+\mathrm{K}_{4} \mathrm{P}_{\mathrm{HCl}} / \mathrm{P}_{\mathrm{H}_{2}^{1}}^{12}}
$$

With the above approximation the steady state $S_{1}$ adatom concentration becomes

$$
\frac{n_{1}}{n_{\mathrm{O}}}=\frac{\mathrm{K}_{1} \mathrm{k}_{2} \mathrm{P}_{\mathrm{S}_{1} \mathrm{H}_{4}}}{\left(\mathrm{k}_{-2} \mathrm{P}_{\mathrm{H}_{2}}^{2}+\mathrm{k}_{6} \mathrm{P}_{\mathrm{HCl}}^{2}+\mathrm{k}_{9}\right)} \cdot \frac{1}{\left(1+\mathrm{K}_{1} \mathrm{P}_{\mathrm{Sl}_{1} \mathrm{H}_{4}}+\mathrm{K}_{3} \mathrm{P}_{\mathrm{H}_{2}}^{1}+\frac{\mathrm{K}_{4} \mathrm{P}_{\mathrm{HCl}}}{\mathrm{P}_{\mathrm{H}_{2}^{\prime 2}}^{\prime 2}}\right)}
$$

In this equation the formation of silicon adatoms is governed by the equllbrium adsorption of $\mathrm{SiH}_{4}\left(\mathrm{~K}_{1}\right)$, the rate of reaction of $\mathrm{SiH}_{4}\left(\mathrm{k}_{2}\right)$ and the total amount of free surface sites (as given by eq. A-15), divided by the ways in which adatoms are removed from the surface in the initial stages before the actual nucleation starts, 1.e. etching by $\mathrm{HCl}$ and $\mathrm{H}_{2}$ and reaction with the $\mathrm{SiO}_{2}$ substrate $\left(\mathrm{k}_{9}\right)$ 


\section{References}

1 J.Y.W. Seto, J. App. Phys. 46, 5247 (1975).

2 See for example: B.A. Joyce, Rep. Prog. Phys. 37, 363 (1974).

3 B.A. Joyce and R.R. Bradley, J. Electrochem. Soc. 110, 1235 (1963).

4 G.R. Booker and B.A. Unvala, Phil. Mag. 11,11 (1965).

5 B.A. Joyce, J.H. Neave and B.E. Watts, Surface Science 15, 1 (1969).

6 J.M. Charig and D.J. Skinner, Surface Science 15, 277 (1969).

7 J. Nishizawa, T. Terasaki and M. Shimbo, J. Cryst. Growth 17, 241 (1972).

8 M.S. Abrahams, C.J. Buiocchi, R.T. Smith, J.F. Corboy Jr., J. Blanc and G.W. Cullen, J. App. Phys. 47, 5139 (1976).

9 J.M. Blank and V.A. Russell, Trans. of the Metall. Soc of AIME 236, 291 (1966).

10 J. Mercier, J. Electrochem. Soc. 118, 962 (1971).

11 R.W. Bicknell, B.A. Joyce, J.H. Neave and G.V. Smith, Phil. Mag. 14, 31 (1966).

12 G.W. Cullen, J.F. Corboy and J.T. McGinn, Semiconductor Silicon (1977) p. 235 (Editors H.R. Huff and E. Sirtl, The Electrochem. Soc. 1977).

13 A.S. Brown, B.A. Joyce, J.H. Neave and D.J. Stirland, J. Appl. Cryst. 1, 70 (1968).

14 L.N. Alexandrov, F.L. Edelmann and V.V. Voskoboinikov, Thin Solid Films 32, 241 (1976).

15 T.I. Kamins and T.R. Cass, Thin Solid Films 16, 147 (1973).

16 G. Ogawa, T. Nishinaga, M. Kasuga and T. Arizumi, Jap. J. App. Phys. 10, 1675 (1971).

17 P. Rai-Choudhury and B.K. Schroder, J. Electrochem. Soc. 118, 107 (1971, 120, 664 (1973).

18 M. Druminski and R. Gessner, J. Cryst. Growth 31, 312 (1975).

19 E. Sirtl and H. Seiter, Semiconductor Silicon (1969), p. 189 (R.R. Haberecht and E.L. Kern, Editors The Electrochem. Soc. 1977).

20 JANAF Thermochemical Tables 2 nd ed. June 1971, NSRDS-NBS-37.

21 R.J. Jaccodine, J. Electrochem. Soc. 110, 524 (1963).

22 D. Walton, J. Chem. Phys. 37, 2182 (1962).

23 J.A. Venables, Phil. Mag. 27, 697 (1973).

24 M.J. Stowell, Thin Solid Films 21, 91 (1974).

25 B. Lewis, Surface Science 21, 289 (1970).

26 A. Masson, J.J. Métois and R. Kern, Surface Science 27, 463 (1971).

27 K.H. Behrndt in "Techniques of Metals Research", Vol. I, part 3 (1968).

28 W.A.P. Claassen and J. Bloem, to be published.

29 D. Turnbull, Thermodynamics in Physical Metallurgy (Am. Soc. Met. Novelty, 1950) p. 282.

30 E.H. Fontana and W.A. Plummer, Phys. and Chem. of Glasses 7, 139 (1966).

31 R.L. Mozzi and B.E. Warren, J. Appl. Cryst. 2, 164 (1969).

32 S.R. Gunn and L.G. Green, J. Phys. Chem. 65, 779 (1961). 
33 J. Bloem and L.J. Giling in 'Current Topics in Materials Science', Ed. E. Kaldis, North-Holland Publishing Comp., Vol. I, Chapter 4 (1978).

34 P. van der Putte, L.J. Giling and J. Bloem, J. Cryst. Growth 41, 133 (1977).

35 V.S. Ban and S.L. Gilbert, J. Electrochem. Soc. 122, 1382 (1975). 


\title{
CHAPTER III
}

\section{THE NUCLEATION OF CVD SILICON ON $\mathrm{SIO}_{2}$ AND $\mathrm{Si}_{3} \mathrm{~N}_{4}$ SUBSTRATES}

\author{
III The $\mathrm{SiH}_{4} \cdot \mathrm{HCl}-\mathrm{H}_{2}$ system at low temperatures
}

\begin{abstract}
The growth of polycrystalline silicon layers on $\mathrm{S}_{1} \mathrm{O}_{2}$ and $\mathrm{St}_{3} \mathrm{~N}_{4}$ substrates can be hampered in the early stages of growth by the presence of different species adsorbed on the surface In this article nucleation experuments with sucon on $\mathrm{SiO}_{2}$ and $\mathrm{S}_{3} \mathrm{~N}_{4}$ are described in the $\mathrm{SLH}_{4}-\mathrm{H}_{2}$ $\mathrm{HCl}$ system at temperatures between $600^{\circ}$ and $900^{\circ} \mathrm{C}$ In this temperature regume (and without $\mathrm{HCl}$ addition) the saturation nucleus density of sulicon clusters on $\mathrm{S}_{1} \mathrm{O}_{2}$ substrates shows a decrease in density with decreasing temperature, whereas on $\mathrm{Si}_{3} \mathrm{~N}_{4}$ substrates the opposite occurs Experiments with nitrogen as a carrier gas, however, give almost the same saturation nucleus densities of silicon clusters on $\mathrm{S}_{1} \mathrm{O}_{2}$ and $\mathrm{S}_{3} \mathrm{~N}_{4}$ substrates Additions of $\mathrm{HCl}$ to the $\mathrm{S}_{1} \mathrm{H}_{4}-\mathrm{H}_{2}$ system produce a decrease in the nucleus saturation density on $\mathrm{S}_{1} \mathrm{O}_{2}$ and $\mathrm{S}_{3} \mathrm{~N}_{4}$ substrates, and the density also decreases with decreasing temperatures below $900^{\circ} \mathrm{C}$ It is further shown that selective growth of sulicon on partly coated sulicon substrates becomes more difficult at lower growth temperatures Adsorption of different surface species $(\mathrm{H}, \mathrm{Cl}$, $\mathrm{SiCl}_{2}$ and $\mathrm{SiH}_{2}$ ) on $\mathrm{SlO}_{2}$ and $\mathrm{Sl}_{3} \mathrm{~N}_{4}$ substrates is discussed and it is concluded that a strong adsorption of atomic hydrogen, notably on $\mathrm{S}_{1} \mathrm{O}_{2}$ surfaces, may explain the difference in nucleus densities on $\mathrm{SiO}_{2}$ and $\mathrm{S}_{3} \mathrm{~N}_{4}$ substrates at temperatures below $900^{\circ} \mathrm{C}$
\end{abstract}

\section{Introduction}

In two preceding papers [1,2] (referred to in the following as part I and part II) nucleation experments are described on $\mathrm{SiO}_{2}$ and $\mathrm{S}_{3} \mathrm{~N}_{4}$ substrates Part I contains expenmental data on the $\mathrm{S}_{1} \mathrm{H}_{4} \cdot \mathrm{HCl}-\mathrm{H}_{2}$ system at temperatures between $925^{\circ}$ and $1200^{\circ} \mathrm{C}$, whule part II describes the nucleation behaviour in the $\mathrm{SiH}_{2} \mathrm{Cl}_{2}-\mathrm{H}_{2}-\mathrm{N}_{2}$ system at temperatures between $800^{\circ}$ and $1100^{\circ} \mathrm{C}$ In parts I and II it was demonstrated that nucleation of sulicon on a foreign substrate involves the presence of free slicon adatoms, acting as nucleation centres, whereas on a silicon substrate growth proceeds va the incorporation of adsorbed species at surface steps $\left(\mathrm{SiH}_{2}, \mathrm{SiCl}_{2}\right)$. As long as this layer growth is possible there is no need for separate nucleation between the steps, and therefore growth can already proceed at low supersaturations This effect also explains the selective growth found under conditions of low supersaturations [3,4] It is not known in what way the nucleation of sulicon proceeds at lower temperatures, where an increased surface adsorption could change the nucelation behavour. For this reason nucleation and growth exper1ments were performed for the $\mathrm{S}_{1} \mathrm{H}_{4}-\mathrm{H}_{2}-\mathrm{HCl}$ system at temperatures between $600^{\circ}$ and $900{ }^{\circ} \mathrm{C}$, on $\mathrm{SiO}_{2}$ and $\mathrm{S}_{3} \mathrm{~N}_{4}$ substrates

\section{Experimental and experimental results}

The nucleation experiments were performed in a horizontal aur-cooled, R.F. heated reactor. The experimental conditions have been described in parts I and II, but 
some additional information is given below. The carrier gases hydrogen and nitrogen were purified to water and oxygen concentrations below $1 \mathrm{ppm}$. The flow rates of the carrier gases, silane (5\% in hydrogen) and hydrogen chloride, both electronic grade, were controlled by means of automatic mass-flow controllers. The temperature was measured with the aid of a calibrated radiation pyrometer on an uncoated silicon slice. Silicon slices covered with an amorphous $1500 \AA$ thick LPCVD layer of $\mathrm{SiO}_{2}$ or $\mathrm{Si}_{3} \mathrm{~N}_{4}$ were used as substrates. Because of the relatively high temperatures used and the small partial pressures of oxygen and water present it can be assumed that the $\mathrm{Si}_{3} \mathrm{~N}_{4}$ surface is free of oxygen in contrast with $\mathrm{Si}_{3} \mathrm{~N}_{4}$ which is exposed to air [5]. After the nucleation experiments SEM and TEM photomicrographs were used to count the density of the nuclei formed.

Just as in the $\mathrm{SiH}_{4}-\mathrm{HCl}-\mathrm{H}_{2}$ system at high temperatures (part I), it is found that after an incubation period the density of stable clusters very quickly reaches a saturation density with respect to exposure time. This incubation period becomes longer with decreasing temperature and high hydrogen chloride concentrations combined with low silane concentrations. Furthermore, these periods are longer for $\mathrm{SiO}_{2}$ substrates than for $\mathrm{Si}_{3} \mathrm{~N}_{4}$ substrates, notably when hydrogen is the carrier gas. Figure 1 shows TEM photomicrographs for an input of 0.1 vol. \% silane in hydrogen as a carrier gas at $800{ }^{\circ} \mathrm{C}_{\text {on }} \mathrm{SiO}_{2}$ substrates and different exposure times. As noted before, the nucleus density of silicon clusters, after the incubation period, remains almost constant until coalescence occurs. In the following, therefore only saturation nucleus densities of silicon clusters (referred to as $N_{S}$ ) will be used. Figure 2 gives $\mathrm{N}_{\mathrm{S}}$ values as a function of temperature on $\mathrm{SiO}_{2}$ and $\mathrm{Si}_{3} \mathrm{~N}_{4}$ substrates and an input of 0.1 vol. \% silane in a hydrogen ambient. The experimental data at temperatures above $925^{\circ} \mathrm{C}$ are discussed in part I and only given here for comparison. As will be noticed, $\mathrm{N}_{\mathbf{s}}$ decreases with decreasing temperature, on $\mathrm{SiO}_{2}$ substrates at temperatures below $900{ }^{\circ} \mathrm{C}$, while at temperatures above $900{ }^{\circ} \mathrm{C}$ the opposite occurs. On $\mathrm{Si}_{3} \mathrm{~N}_{4}$ substrates $\mathrm{N}_{S}$ varies only slightly with temperature; in the temperature region under discussion no maximum in $\mathrm{N}_{\mathrm{S}}$ is observed. It was expected that hydrogen adsorption would strongly reduce the saturation nucleus density of silicon clusters, notably for $\mathrm{SiO}_{2}$ substrates, in analogy with the $\mathrm{SiH}_{2} \mathrm{Cl}_{2}-\mathrm{H}_{2}-\mathrm{N}_{2}$ system (part II).

Such an affect is indeed observed: for 0.01 vol. \% $\mathrm{SiH}_{4}$ in hydrogen at $700{ }^{\circ} \mathrm{C}$ the nucleus density is extremely low and is estimated at $2 \times 10^{7}$ per $\mathrm{cm}^{2}$, whereas when nitrogen is the carrier gas $\left(0.2\right.$ vol. $\% \mathrm{H}_{2}$ is present from the silane source, being 5 vol. $\% \mathrm{SiH}_{4}$ in $\mathrm{H}_{2}$ ) the nucleus density rises to $1.2 \times 10^{11}$ per $\mathrm{cm}^{2}$. The corresponding TEM photomicrograph for the $\mathrm{SiO}_{2}$ substrate after an exposure time of $30 \mathrm{sec}$ is shown in Figure 3. From the $\mathrm{N}_{\mathrm{S}}$ values in hydrogen and nitrogen a variation of $\mathrm{N}_{\mathrm{s}}$ proportional to $\mathrm{P}_{\mathrm{H}_{2}}^{-3 / 2}$ can be deduced. Figure 4 shows the influence of hydrogen pressure on $\mathrm{N}_{\mathrm{S}}$ for $\mathrm{Si}_{3} \mathrm{~N}_{4}$ substrates and an input of 0.01 vol. \% $\mathrm{SiH}_{4}$. It can be observed that $\mathrm{N}_{\mathrm{S}}$ decreases with increasing hydrogen pressure: by plotting $\mathrm{N}_{\mathrm{S}}$ versus $\mathrm{P}_{\mathrm{H}_{2}}$ a linear relationship can be obtained. Figure 5 gives $\mathrm{N}_{\mathrm{S}}$ values on $\mathrm{SiO}_{2}$ and $\mathrm{Si}_{3} \mathrm{~N}_{4}$ substrates at $700^{\circ} \mathrm{C}$ as a function of input concentrations of silane. 

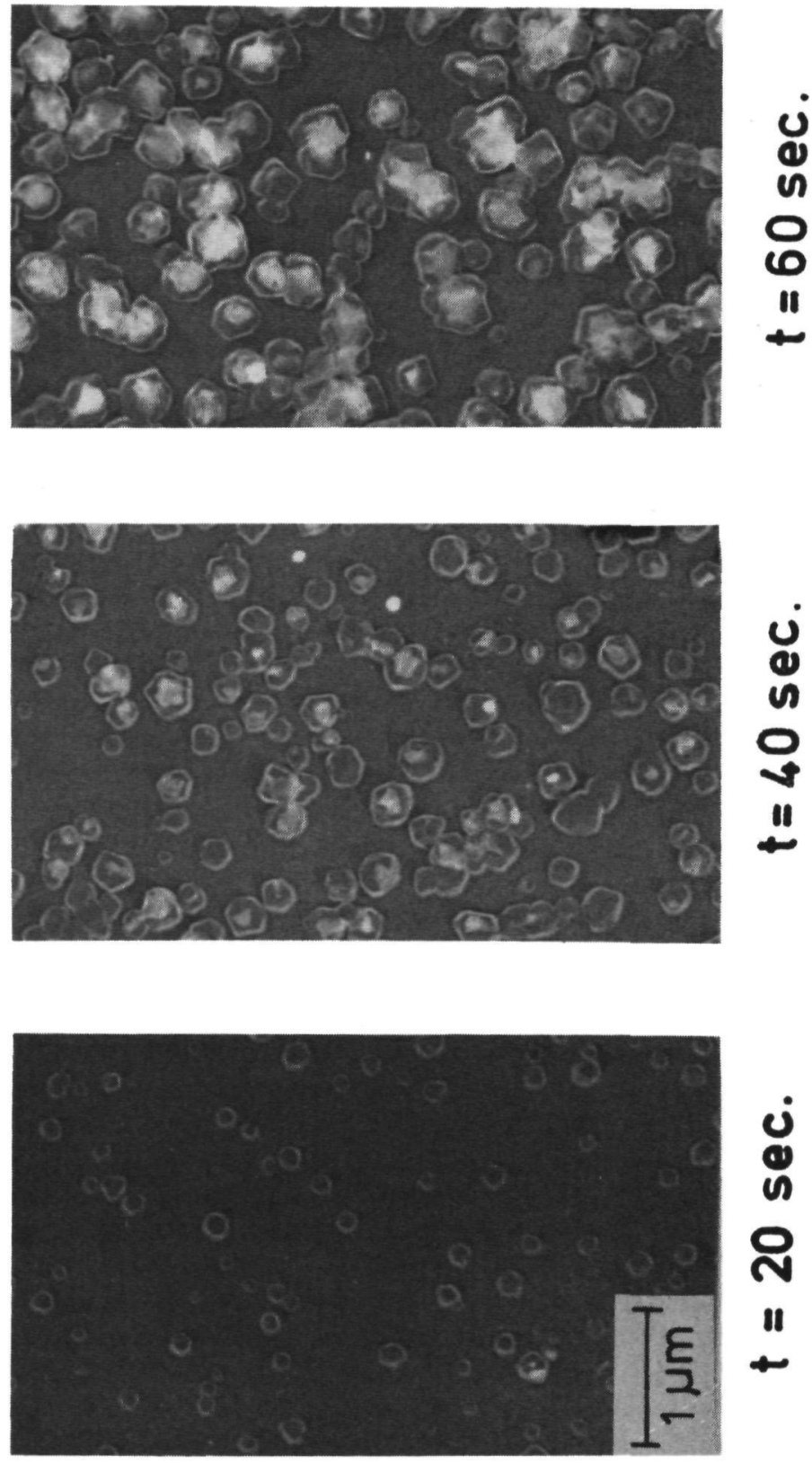

Figure 1.

TEM photomicrographs of the nucleus density on a $\mathrm{SiO}_{2}$ substrate for an input of $0.1 \mathrm{vol} . \%$ silane in hydrogen at $800^{\circ} \mathrm{C}$ as a function of the exposure time. 


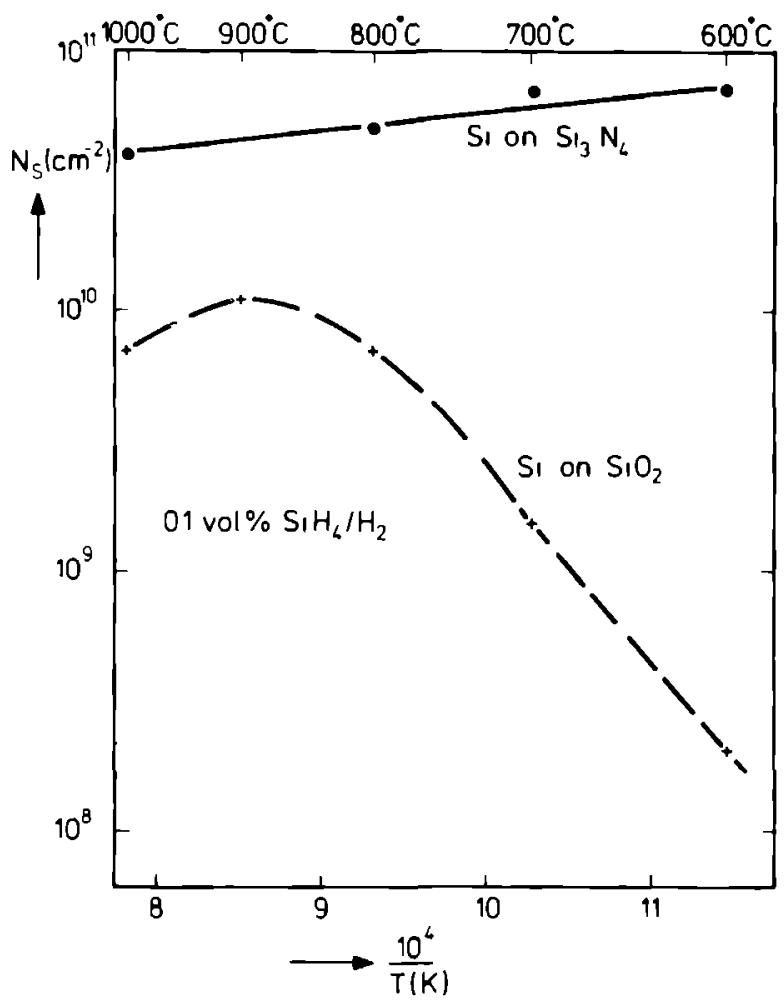

Figure 2.

The saturation density of silicon clusters $\left(N_{S}\right)$ as a function of temperature for an input of 0.1 vol. \% silane in hydrogen as a carrier gas on $\mathrm{SiO}_{2}$ and $\mathrm{Si}_{3} \mathrm{~N}_{4}$ substrates.

For the input concentrations used in these experiments, $\mathbf{N}_{\mathbf{S}}$ is linearly proportional to the silane input pressure in a first approximation. Addition of $\mathrm{HCl}$ to the $\mathrm{SiH}_{4}-\mathrm{H}_{2}$ mixtures greatly reduces the number of stable silicon clusters as can be seen from Figure 6. In this figure $\mathbf{N}_{\mathrm{S}}$ is plotted as a function of the input concentration of $\mathrm{HCl}$ at $800{ }^{\circ} \mathrm{C}$ on $\mathrm{SiO}_{2}$ substrates and for an input of 0.1 vol. \% $\mathrm{SiH}_{4}$. For higher input concentrations of hydrogen chloride than those given in Figure 6 no nucleation is observed. Figure 7 shows the influence of the addition of various amounts of $\mathrm{HCl}$ to the $\mathrm{SiH}_{4}-\mathrm{H}_{2}$ mixture on the density of nuclei as a function of temperature, both for $\mathrm{SiO}_{2}$ and for $\mathrm{Si}_{3} \mathrm{~N}_{4}$ substrates. At $900{ }^{\circ} \mathrm{C} \mathrm{N}$ shows a distinct maximum, for both $\mathrm{SiO}_{2}$ and $\mathrm{Si}_{3} \mathrm{~N}_{4}$ substrates.

Another point appears from the observation that silicon layers can be grown selectively on partly oxide-coated or nitride-coated silicon slices $[3,4]$. The selectivity is explained on the basis of a more difficult nucleation on foreign substrates. In figure 8 this selectivity is shown as a function of temperature for the 


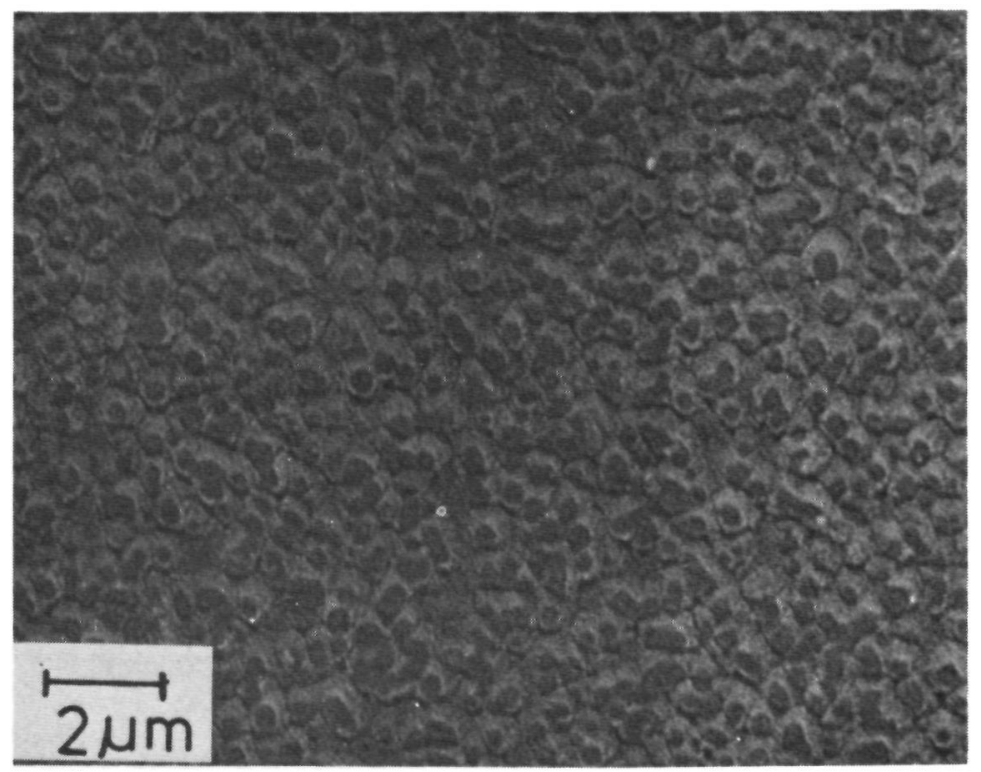

Figure 3.

TEM picture of the nucleus density for an input of $0.01 \mathrm{vol} . \%$ silane and $0.2 \mathrm{vol} . \%$ hydrogen in nitrogen as a carrier gas on a $\mathrm{SiO}_{2}$ substrate at $700{ }^{\circ} \mathrm{C}$.

$\mathrm{SiH}_{4}-\mathrm{HCl}-\mathrm{H}_{2}$ system in which the ratio $\mathrm{PSiH}_{4} / \mathrm{P}_{\mathrm{HCl}}^{2}$ is used as a measure of the supersaturation. Three regions can be distinguished: I no selective growth, II selective growth and III etching of the silicon slices. It will be seen that with decreasing temperatures the region where selective growth can take place becomes smaller, and at temperatures below $800^{\circ} \mathrm{C}$ the selectivity between silicon and $\mathrm{SiO}_{2}$ or $\mathrm{Si}_{3} \mathrm{~N}_{4}$ has disappeared.

\section{Discussion}

\subsection{Introduction}

In part I it was concluded that an expression given by Venables [6] could be used to characterize the saturation density of silicon clusters $\left(\mathrm{N}_{\mathrm{S}}\right)$ in the present case where incomplete condensation has to be assumed. Venable's expression for the case of mobile clusters can be rewritten as

$\frac{\mathrm{N}_{\mathrm{S}}}{\mathrm{n}_{\mathrm{O}}} \cong\left(\frac{\mathrm{n}_{1}}{\mathrm{n}_{\mathrm{o}}}\right)^{\frac{\mathrm{i}+1}{2}} \exp \left[\left(\mathrm{E}_{\mathrm{i}}+\mathrm{E}_{\mathrm{m}}-\mathrm{E}_{\mathrm{d}}\right) / 2 \mathrm{kT}\right]$ 


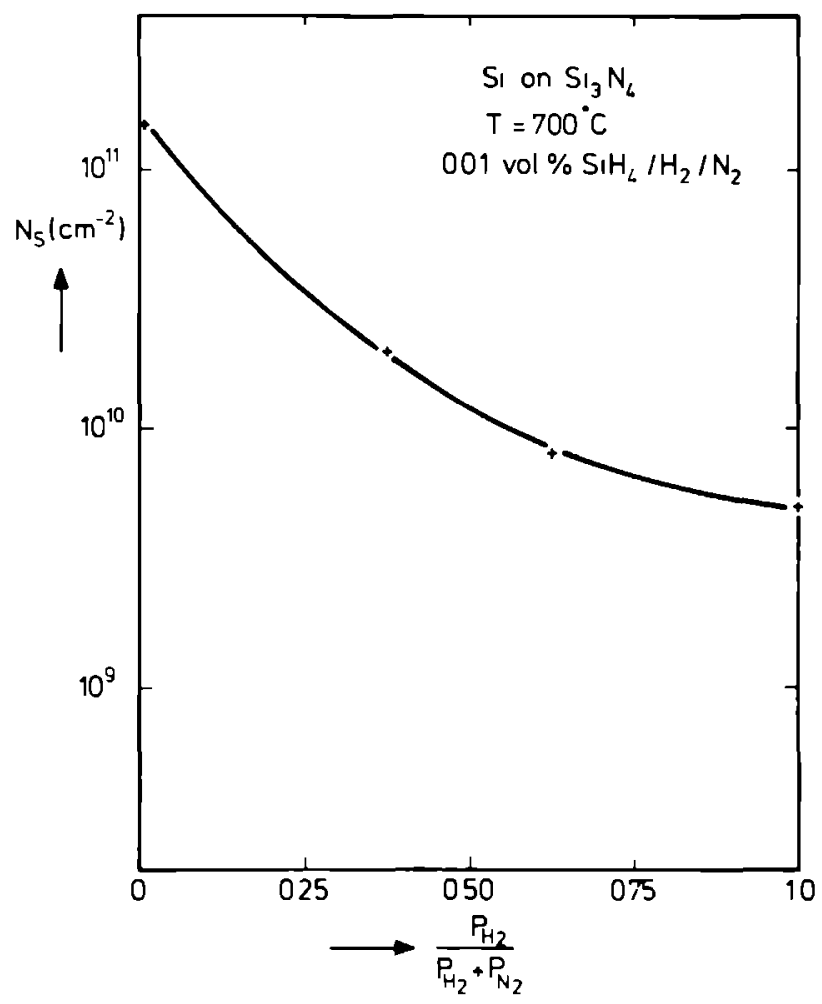

\section{Figure 4.}

The saturation density of silicon clusters $\left(N_{S}\right)$ for 0.01 vol. \% silane and some hydrogen-nitrogen mixtures on $\mathrm{Si}_{3} \mathrm{~N}_{4}$ substrates at $700^{\circ} \mathrm{C}$.

where $i$ is the number of atoms in the initial cluster, $E_{i}$ the heat of formation of a cluster consisting of $i$ atoms, $E_{m}$ is the activation energy for surface diffusion of mobile clusters, $E_{d}$ the activation energy for surface diffusion of adatoms, $n_{1}$ the concentration of adatoms per unit area and $n_{0}$ the total number of surface sites per unit area. If only small clusters are mobile at low temperatures equation (1) has to be replaced by

$\frac{N_{s}}{n_{0}} \cong\left(\frac{n_{1}}{n_{0}}\right) \exp \left[\left(E_{m}-E_{d}\right) / 2 k T\right]$

In the following section we give reaction schemes in order to arrive at expressions for $\mathrm{n}_{1} / \mathrm{n}_{0}$. 


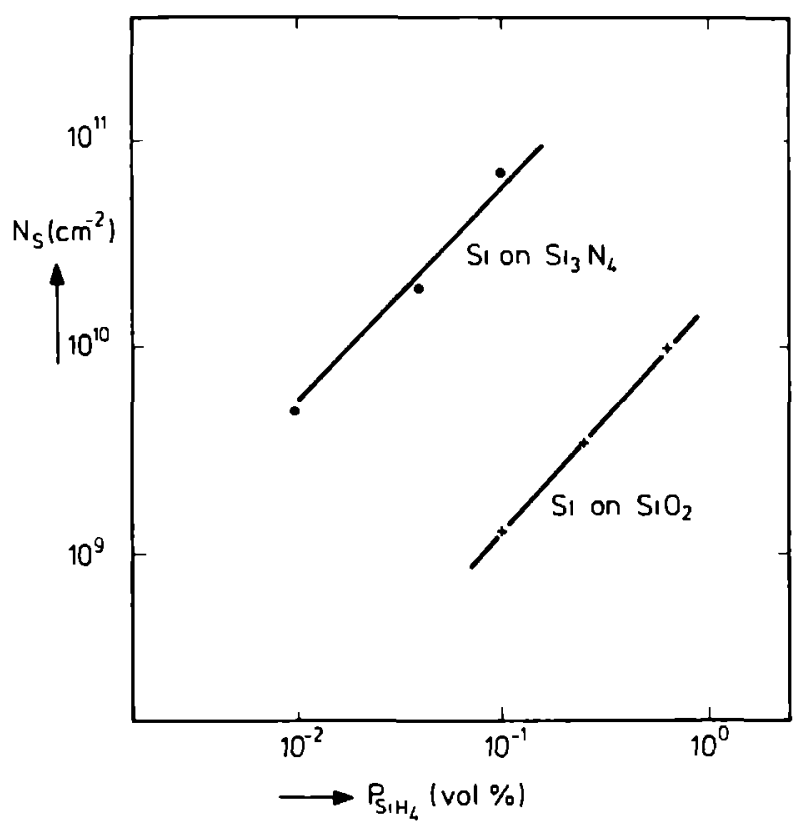

Figure 5 .

The saturation nucleus density on $\mathrm{SiO}_{2}$ and $\mathrm{Si}_{3} \mathrm{~N}_{4}$ substrates at $700{ }^{\circ} \mathrm{C}$ as a function of the input concentration of silane in a hydrogen ambient.

\subsection{Interpretation of the results}

In order to describe the nucleation experiments in the $\mathrm{SiH}_{4}-\mathrm{HCl}-\mathrm{H}_{2}$ system at temperatures below $900^{\circ} \mathrm{C}$ it is necessary to consider a number of possible reactions that can take place at or near the surface. The reaction scheme as proposed for the $\mathrm{SiH}_{4}-\mathrm{HCl}-\mathrm{H}_{2}$ system at temperatures above $925^{\circ} \mathrm{C}$ (part I) can be used with some additional assumptions concerning the species present on the surface. The reaction between silicon adatoms and $\mathrm{SiO}_{2}$ can be neglected below $1000^{\circ} \mathrm{C}[7]$.

If no $\mathrm{HCl}$ is present in the gas phase the following reaction schemes will be used:

a. Gas phase dissociation of $\mathrm{SiH}_{4}$ near the surface [8]

$$
\mathrm{SiH}_{4}(\mathrm{~g}) \underset{\mathrm{k}_{-1}}{\stackrel{\mathrm{k}_{1}}{\rightleftharpoons}} \mathrm{SiH}_{2}(\mathrm{~g})+\mathrm{H}_{2}(\mathrm{~g})
$$




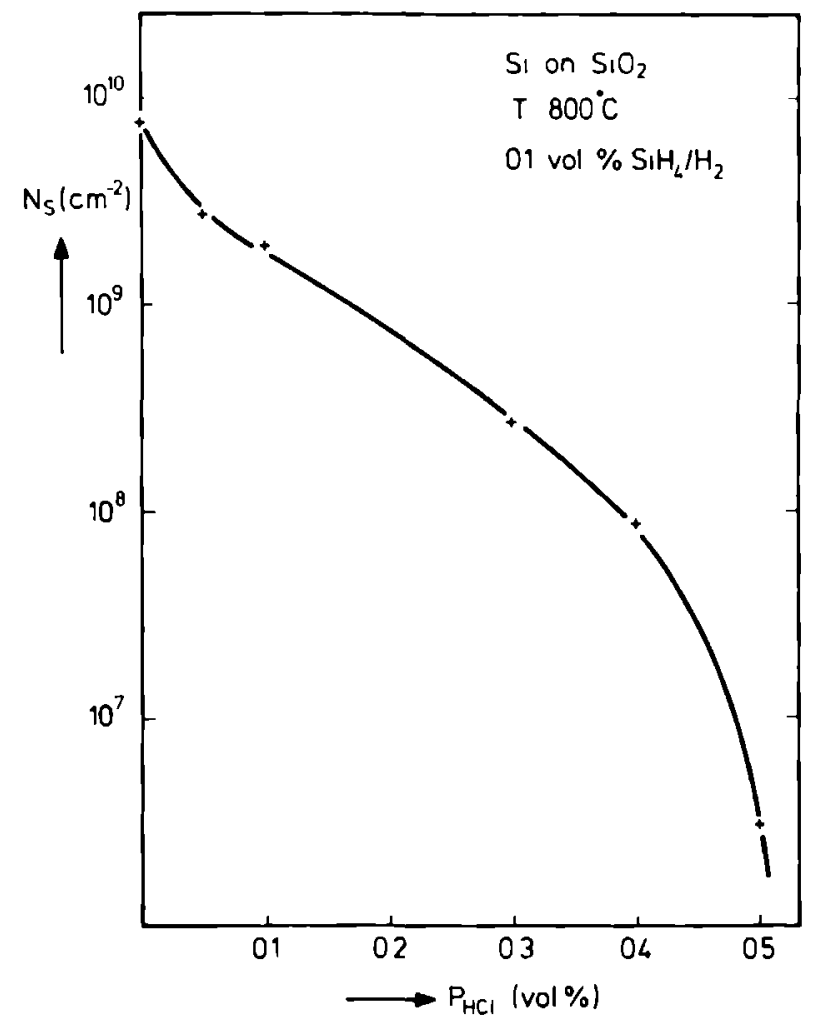

Figure 6.

$N_{S}$ for $\mathrm{SiO}_{2}$ substrates for an input of $0.1 \mathrm{vol}$. \% silane and different input concentrations of hydrogen chlorine in hydrogen as a carrier gas at $800^{\circ} \mathrm{C}$.

b. Adsorption of $\mathrm{SiH}_{2}$ on a free surface site (the latter denoted by *)

$$
\mathrm{SiH}_{2}(\mathrm{~g})+* \underset{\mathrm{k}_{-2}}{\stackrel{\mathrm{k}_{2}}{\rightleftharpoons}} \mathrm{SiH}_{2}^{*}
$$

c. Adsorption of atomic hydrogen

$$
\mathrm{z}_{2} \mathrm{H}_{2}(\mathrm{~g})+\stackrel{*}{\stackrel{\mathrm{k}_{3}}{\rightleftharpoons}} \mathrm{H}_{-3}^{*}
$$

d. Formation of silicon clusters

$$
\mathrm{SiH}_{2} *+\mathrm{SiH}_{2} * \stackrel{\mathrm{k}_{4}}{\rightarrow} \mathrm{Si}_{2} \mathrm{H}_{2} * *+\mathrm{H}_{2}(\mathrm{~g})
$$




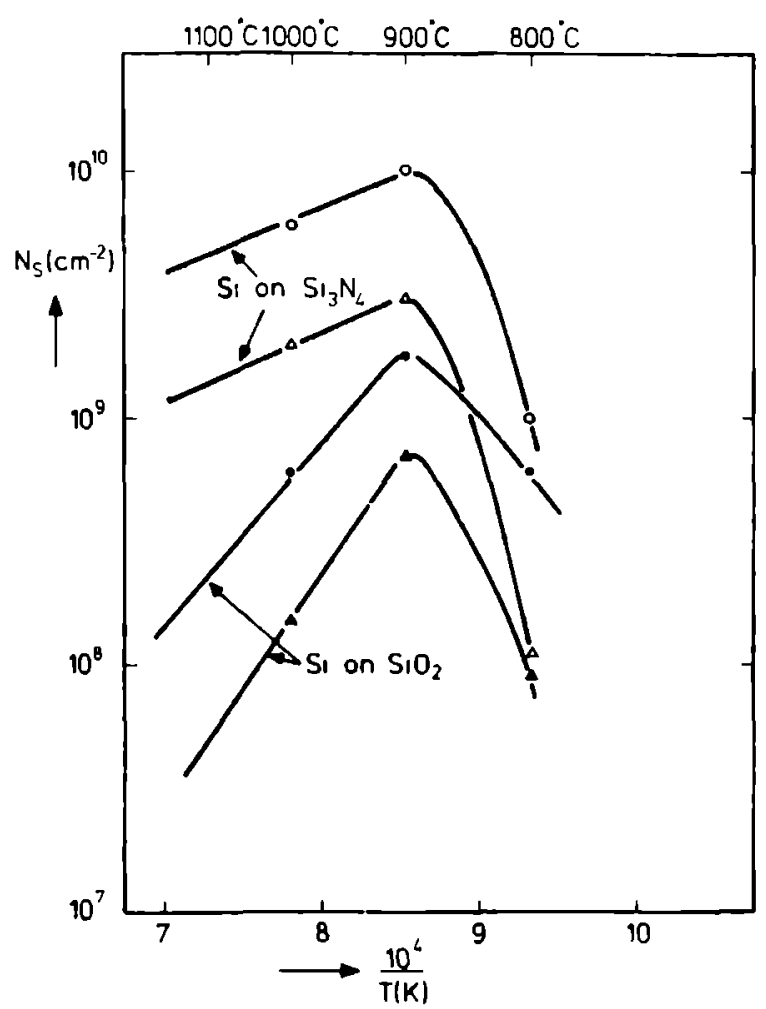

Figure 7.

The saturation nucleus density $\left(\mathrm{N}_{S}\right)$ as a function of temperature for two $\mathrm{Sl}_{2} \mathrm{H}_{4}-\mathrm{HCl}$ mixtures in hydrogen on $\mathrm{SiO}_{2}$ and $\mathrm{Si}_{3} \mathrm{~N}_{4}$ substrates $\left(0, \bullet 0.1\right.$ vol. \% $\mathrm{SiH}_{4}$ and 0.2 vol. \% $\mathrm{HCl} ; \wedge, \triangle 0.1$ vol. \% $\mathrm{SiH}_{4}$ and 0.4 vol. \% $\mathrm{HCl}$.

$$
\mathrm{Si}_{2} \mathrm{H}_{2} * *+\mathrm{SiH}_{2} * \stackrel{\mathrm{k}_{5}}{\rightarrow} \mathrm{Si}_{3} \mathrm{H}_{2} * * *+\mathrm{H}_{2}(\mathrm{~g}), \text { etc. }
$$

The concentrations of the surface species $\left[\mathrm{SiH}_{4}{ }^{*}\right],\left[\mathrm{SiH}_{3}{ }^{*}\right],\left[\mathrm{SiH}^{*}\right]$ and $\left[\mathrm{Si}^{*}\right]$ are assumed to be small compared with the concentration of $\left[\mathrm{SiH}_{2}^{*}\right]$, according to the experimental data concerning the growth of silicon on silicon in the $\mathrm{SiH}_{4}-\mathrm{H}_{2}-\mathrm{N}_{2}$ system at $700^{\circ} \mathrm{C}[9]$. As the $\mathrm{SiO}$ and the $\mathrm{SiN}$ bond strengths are strong compared with the Si-Si bonding (as discussed later), it is likely that nucelation on $\mathrm{SiO}_{2}$ and $\mathrm{Si}_{3} \mathrm{~N}_{4}$ substrates starts with the formation of these bonds. In a steady state situation the concentration of $\mathrm{SiH}_{2}$ admolecules reaches a constant value, which before formation of silicon clusters occurs can be expressed as 


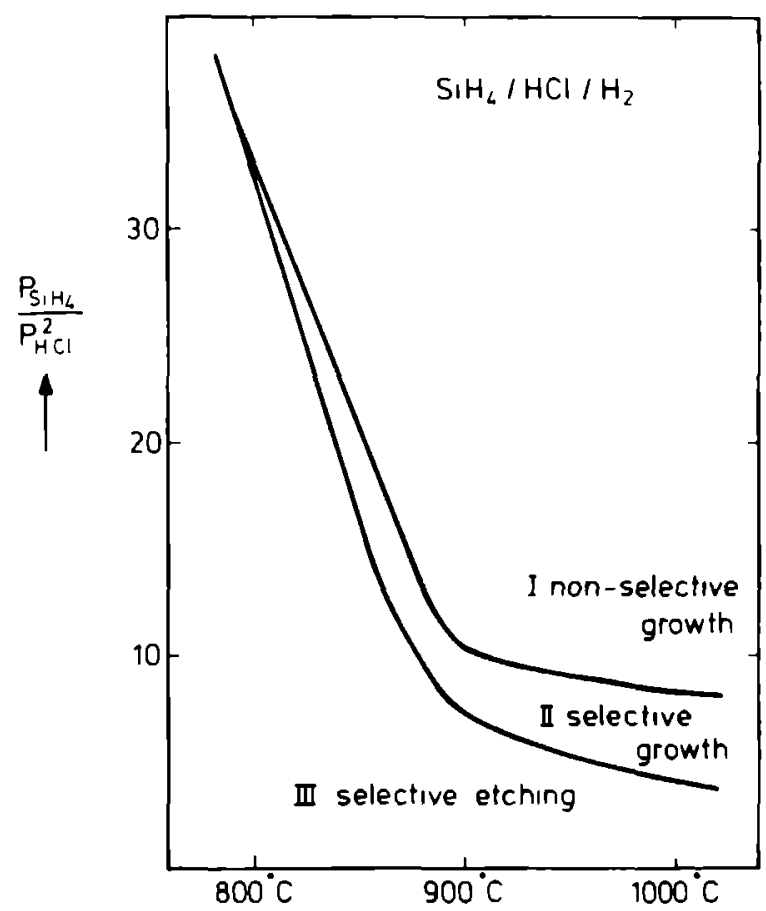

\section{Figure 8.}

The temperature dependence of selective growth of silicon on silicon slices partly coated with oxide or nitride as a function of temperature and supersaturation, expressed as $\mathrm{PSiH}_{4} / P_{\mathrm{HCl}}^{2}$ in hydrogen as a carrier gas.

$\mathbf{n}_{1}=\left[\mathrm{SiH}_{2} *\right]=\frac{\mathrm{K}_{1} \mathrm{~K}_{2} \mathrm{PSiH}_{4}[*]}{\mathrm{PH}_{2}}$

where $[*]$ is the concentration of free surface sites

$$
[*]=\mathbf{n}_{0}-\left[\mathrm{H}^{*}\right]-\left[\mathrm{SiH}_{2}^{*}\right]-- \text {. }
$$

As will be discussed in the section on adsorption, hydrogen and silicon will be adsorbed preferentially at oxygen and nitrogen surface sites on $\mathrm{SiO}_{2}$ and $\mathrm{Si}_{3} \mathrm{~N}_{4}$ substrates, respectively. The expression as obtained by Venables (equation (1)) for $\mathrm{N}_{\mathrm{S}}$ can be compared with the experimental data in the $\mathrm{SiH}_{4}-\mathrm{H}_{2}$ system on $\mathrm{SiO}_{2}$ and $\mathrm{Si}_{3} \mathrm{~N}_{4}$ substrates in the temperature range under discussion. Introducing equation (8) for $n_{1}$ in equation (1) gives 
$\frac{N_{s}}{n_{0}} \cong\left\{\frac{K_{1} K_{2} P_{S i H_{4}}[*]}{n_{0} P_{H_{2}}}\right\}^{\frac{i+1}{2}} \exp \left[\left(E_{i}+E_{m}-E_{d}\right) / 2 k T\right]$.

In order to arrive at an expression describing the experimental data, the following remarks can be made:

i. $\mathrm{N}_{\mathrm{S}}$ is almost equal for $\mathrm{SiO}_{2}$ and $\mathrm{Si}_{3} \mathrm{~N}_{4}$ substrates in the $\mathrm{SiH}_{4}-\mathrm{N}_{2}$ system at 700 ${ }^{\circ} \mathrm{C}$, as discussed before.

Between $800^{\circ}$ and $1100^{\circ} \mathrm{C}$ the $\mathrm{SiH}_{2} \mathrm{Cl}_{2}-\mathrm{N}_{2}$ system showed the same behaviour (part II).

ii. The saturation nucleus density of silicon clusters on $\mathrm{Si}_{3} \mathrm{~N}_{4}$ substrates is in a first approximation inversely proportional to $\mathrm{P}_{\mathrm{H}_{2}}\left(\mathrm{~N}_{\mathrm{S}} \propto \mathrm{P}_{\mathrm{H}_{2}}^{-1}\right)$ (Figure 4).

In the case of $\mathrm{SiO}_{2}$ substrates the hydrogen pressure is observed to have a stronger influence on $\mathrm{N}_{\mathrm{S}}\left(\mathrm{N}_{\mathrm{S}} \propto \mathrm{P}_{\mathrm{H}_{2}}^{-3 / 2}\right)$. In part II it was concluded that adsorption of atomic hydrogen could explain the differences in $\mathrm{N}_{\mathrm{S}}$ between $\mathrm{SiO}_{2}$ and $\mathrm{Si}_{3} \mathrm{~N}_{4}$ in the $\mathrm{SiH}_{2} \mathrm{Cl}_{2} \cdot \mathrm{H}_{2}$ system $\left(\mathrm{N}_{\mathrm{S}} \propto \mathrm{P}_{\mathrm{H}_{2}}^{-1 / 2}\right)$.

iii. The saturation density of silicon clusters on $\mathrm{SiO}_{2}$ and $\mathrm{Si}_{3} \mathrm{~N}_{4}$ substrates is in a first approximation linearly proportional to the input concentration of silane (Figure 5).

The remarks made above lead to the following expression, describing $\mathrm{N}_{\mathrm{S}}$ at a fixed temperature as a function of the gas phase composition

$\mathrm{N}_{\mathrm{S}}=\mathrm{A} \frac{\mathrm{PSiH}_{4}}{\mathrm{P}_{\mathrm{H}_{2}}} \times \frac{1}{\left(1+\mathrm{K}_{3} \mathrm{P}_{\mathrm{H}_{2}}^{1 / 2}\right)}$

where $\mathrm{A}$ is a constant.

Comparison of this expression with the expression as given by equation (10) then leads to a critical cluster with $\mathrm{i}=1$ and $\mathrm{SiH}_{2}$ as the predominant surface species. Further it can be concluded that under the experimental conditions the concentration of the surface species [ $\left.\mathrm{SiH}_{2}{ }^{*}\right]$ is much smaller than the total number of surface sites $\left(n_{0}\right)$ (equation $(9)$ ). This leads to $[*]=n_{0}-\left[H^{*}\right]$, which can be rewritten by using equation (5) to $[*]=n_{0} /\left(1+K_{3} P_{H_{2}}^{1}{ }^{2}\right)$. The differences in nucleation behaviour between $\mathrm{SiO}_{2}$ and $\mathrm{Si}_{3} \mathrm{~N}_{4}$ substrates at temperatures below $900{ }^{\circ} \mathrm{C}$ can be explained by a strong hydrogen adsorption on $\mathrm{SiO}_{2}$ substrates $\left(\mathrm{K}_{3} \mathrm{P}_{\mathrm{H}}^{1}{ }^{2}>1\right)$ and a weak adsorption of atomic hydrogen on $\mathrm{Si}_{3} \mathrm{~N}_{4}$ substrates $\left(\mathrm{K}_{3} \mathrm{P}_{\mathrm{H}_{2}}^{1 / 2}<1\right)$. As will be discussed in the section on adsorption, this is due to a large difference in the bond strength between the $\mathrm{NH}$ and the $\mathrm{OH}$ bond. 
If $\mathrm{HCl}$ is introduced to the $\mathrm{SiH}_{4}-\mathrm{H}_{2}$ system the following reactions are added to the reactions $(a-d)$

e Attack of $\mathrm{S}_{1} \mathrm{H}_{2}$ * by $\mathrm{HCl}$

$$
\mathrm{SlH}_{2} *+2 \mathrm{HCl}(\mathrm{g}) \stackrel{\mathrm{k}_{6}}{\stackrel{\mathrm{k}_{6}}{\rightleftharpoons}} \mathrm{SiCl}_{2} *+2 \mathrm{H}_{2}(\mathrm{~g}) .
$$

f. Desorption of $\mathrm{SiCl}_{2}$

$$
\mathrm{SiCl}_{2} * \stackrel{\mathrm{k}_{7}}{\rightarrow} \mathrm{S}_{1} \mathrm{Cl}_{2}(\mathrm{~g})
$$

g. Adsorption of atomic chlorine

$$
\mathrm{HCl}(\mathrm{g})+2 * \stackrel{\mathrm{k}_{8}}{\rightleftharpoons} \mathrm{Cl}^{*}+\mathrm{H}^{*}
$$

k. Formation of sulicon clusters

$$
\begin{aligned}
& \mathrm{H}_{2}+\mathrm{SiCl}_{2} *+\mathrm{SlH}_{2}^{*} \stackrel{\mathrm{k}_{9}}{\rightarrow} \mathrm{Si}_{2} \mathrm{H}_{2}^{* *}+2 \mathrm{HCl}(\mathrm{g}) \\
& \mathrm{S}_{2} \mathrm{H}_{2} * *+\mathrm{SlCl}_{2} *+\mathrm{H}_{2}(\mathrm{~g}) \stackrel{\mathrm{k}_{10}}{\rightarrow} \mathrm{S}_{3} \mathrm{H}_{2} * * *+2 \mathrm{HCl}(\mathrm{g}) .
\end{aligned}
$$

If $\mathrm{HCl}$ is added to the system, almost all the $\mathrm{SiH}_{2}^{*}$ admolecules will be converted to $\mathrm{SiCl}_{2}$, followed by desorption if no centers for growth are present [part I, 9]. Before silicon clusters are formed the steady state concentration of the $\mathrm{SiH}_{2}^{*}$ surface species can be given by

$$
\mathrm{n}_{1}=\left[\mathrm{S}_{1} \mathrm{H}_{2} *\right]=\frac{\mathrm{K}_{1} \mathrm{k}_{2} \mathrm{P}_{\mathrm{S}_{1} \mathrm{H}_{4}}[*]}{\mathrm{P}_{\mathrm{H}_{2}}\left(\mathrm{k}_{-2}+\mathrm{k}_{6} \mathrm{P}_{\mathrm{HCl}}^{2}\right)}
$$

If silicon clusters are present, etching of these clusters also occurs. According to van der Putte et al. [10] this etch rate can be given by

$$
\mathbf{R}_{\text {etch }}=k_{\text {etch }} \frac{\mathbf{P}_{\mathrm{HCl}}^{2}}{\mathbf{P}_{\mathrm{H}_{2}}} \text {. }
$$

At an etch rate lower than the growth rate of silicon clusters this extra term has no influence on the total number of nucles, but in the opposite case no nucles will be formed. Inserting equation (17) into equation (1) leads to 
$\frac{N_{s}}{n_{0}} \cong\left\{\frac{K_{1} k_{2} P_{S i H_{4}}[*]}{n_{0} P_{H_{2}}\left(k_{-2}+k_{6} P_{H C l}^{2}\right)}\right\}^{\frac{i+1}{2}} \exp \left[\left(E_{i}+E_{m}-E_{d}\right) / 2 k T\right]$.

In part I an extensive discussion is devoted to experimental data on the $\mathrm{SiH}_{4} \cdot \mathrm{HCl}-\mathrm{H}_{2}$ system on $\mathrm{SiO}_{2}$ and $\mathrm{Si}_{3} \mathrm{~N}_{4}$ substrates at temperatures above $925{ }^{\circ} \mathrm{C}$. From plots of $\log \mathrm{N}_{\mathrm{S}}$ versus $\log \mathrm{PSiH}_{4} / \mathrm{P}_{\mathrm{HCl}}^{2}$ it was shown that, if the input concentrations of hydrogen chloride are not too high $\mathbf{N}_{\mathbf{S}}$ is linearly proportional to $\mathrm{PSiH}_{4} / \mathrm{P}_{\mathrm{HCl}}^{2}$, indicating that $\mathrm{j}=1$ and $[*]$ is constant at those temperatures. At higher $\mathrm{HCl}$ concentrations the initial cluster size changes from $\mathrm{i}=1$ to $\mathrm{i}=4$. At temperatures below $925^{\circ} \mathrm{C}, \mathrm{N}_{\mathrm{s}}$ decreases with decreasing temperatures, in contrast to the situation at higher temperatures where the opposite occurs (Figure 7). In order to interpret the experimental data below $900^{\circ} \mathrm{C}$ growth rate measurements for silicon on silicon in the $\mathrm{SiH}_{4} \cdot \mathrm{HCl}-\mathrm{H}_{2}$ system are helpful [11]. At temperatures above $900^{\circ} \mathrm{C}$ the growth rate is gas phase diffusion-controlled and is relatively high compared with the etch rate given by the presence of $\mathrm{HCl}$ for not too high input concentrations of $\mathrm{HCl}$. As discussed in part $\mathrm{I}, \mathrm{N}_{\mathrm{S}}$ is linearly proportional to $\mathrm{PSiH}_{4} / \mathrm{P}_{\mathrm{HCl}}^{2}(\mathrm{i}=1)$ for $\mathrm{PSiH}_{4} / \mathrm{P}_{\mathrm{HCl}}^{2}>50$ ( $\mathrm{p}$ in bars) at temperatures above $925^{\circ} \mathrm{C}$. At lower values of $\mathrm{PSiH}_{4} / \mathrm{P}_{\mathrm{HCl}}^{2}$ the critical cluster size increases and for $\mathrm{PSiH}_{4} / \mathrm{P}_{\mathrm{HCl}}^{2}<8$ no nucleation is observed at these temperatures. At temperatures below $900^{\circ} \mathrm{C}$ the growth rate of silicon on silicon is kinetically or surface-controlled in the $\mathrm{SiH}_{4} \cdot \mathrm{H}_{2}$ system and a strong decrease in the growth rate with decreasing temperatures is apparent. Addition of $\mathrm{HCl}$ to this system at temperatures below $900{ }^{\circ} \mathrm{C}$ leads to an additional lowering of the growth rate as measured in the $\mathrm{SiH}_{4} \cdot \mathrm{H}_{2}$ system, due to the conversion of $\mathrm{SiH}_{2}$ into $\mathrm{SiCl}_{2}$ which easily desorbs [11]. At $800^{\circ} \mathrm{C}$ no nucleation is observed on $\mathrm{SiO}_{2}$ and $\mathrm{Si}_{3} \mathrm{~N}_{4}$ substrates for $\mathrm{PSiH}_{4} / \mathrm{P}_{\mathrm{HCl}}^{2}<30$ (Figures 7 and 8 as will be discussed later in connection with selective growth). In the regime where the growth of silicon on silicon is surfacecontrolled $\left(\mathrm{T}<900^{\circ} \mathrm{C}\right) \mathrm{N}_{\mathrm{S}}$ is linearly proportional to $\mathrm{PSiH}_{4} / \mathrm{P}_{\mathrm{HCl}}^{2}(\mathrm{i}=1)$ only for relatively high values of this parameter $>100$ as obtained from Figure 6). Or, in other words, when hydrogen chloride is added to a certain amount of silane the critical cluster size deviates from $i=1$ for much smaller hydrogen chloride concentrations at $800^{\circ} \mathrm{C}$ than at temperatures above $900^{\circ} \mathrm{C}$. This leads to a decrease in $N_{s}$, the term between the brackets in equation (10) being smaller than unity $\left(n_{1} / n_{0}\right)$. A second possibility which could explain the decrease in $N_{S}$ below $900^{\circ} \mathrm{C}$ as shown in Figure 7 for the $\mathrm{SiH}_{4}-\mathrm{HCl}-\mathrm{H}_{2}$ system is given by a strong adsorption of atomic chlorine. As will be discussed in the section on adsorption, chlorine will be preferentially adsorbed on the silicon surface atoms of the $\mathrm{SiO}_{2}$ and $\mathrm{Si}_{3} \mathrm{~N}_{4}$ substrates, but there is evidence that above $700^{\circ} \mathrm{C}$ the interaction between chlorine and the silicon surface atoms is only weak, leading to a small concentration of chlorine surface atoms $\left(\left[\mathrm{Cl}^{*}\right] \ll \mathrm{n}_{0}\right)$.

According to Figure 8 silicon can be grown selectively on silicon slices partly coated with oxide or nitride at temperatures above $800{ }^{\circ} \mathrm{C}$. As the growth of silicon on 
silicon in the $\mathrm{S}_{1} \mathrm{H}_{4}-\mathrm{HCl}-\mathrm{H}_{2}$ system can be given by $\mathrm{R}=\mathrm{k}_{\mathrm{a}} \mathrm{PS}_{1} \mathrm{H}_{4}-\mathrm{k}_{\mathrm{b}} \mathrm{P}_{\mathrm{HCl}}^{2}$ leadıng to $\mathrm{R}=0$ for $\mathrm{PS}_{\mathrm{S}_{1} \mathrm{H}_{4}} / \mathrm{P}_{\mathrm{HCl}}^{2}=\mathrm{kb}_{\mathrm{b}} / \mathrm{k}_{\mathrm{a}}$, this relation is used as a parameter in Figure 8 In the gas phase diffusion-controlled regime of the growth of slicon on slicon above $900^{\circ} \mathrm{C}$, as discussed above, surface diffusion and incorporation of slicon at the atomic steps are relatively fast compared to the diffusion of reactants towards the surface In the same temperature regime the nucleation of sulicon on slicon is surface-controlled (part I), leadıng to desorption of $\mathrm{SiCl}_{2}$ if no growth centres are present Consequently a selective growth can become apparent

At temperatures below $900^{\circ} \mathrm{C}$ the growth of sucon on sucon becomes surfacecontrolled, the reduction of $\mathrm{SiCl}_{2}$ at the atomuc steps being rate-limiting [9] Nucleation of sulicon on $\mathrm{S}_{1} \mathrm{O}_{2}$ and $\mathrm{S}_{3} \mathrm{~N}_{4}$ in the $\mathrm{S}_{1} \mathrm{H}_{4} \mathrm{H}_{2} \cdot \mathrm{HCl}$ system below $900{ }^{\circ} \mathrm{C}$ is also surface-controlled, as discussed before At low temperatures, therefore, nucleation and growth are both limited by the reduction of $\mathrm{S}_{1} \mathrm{Cl}_{2}$ by hydrogen This explains the loss of selectivity at lower temperatures in the $\mathrm{SI}-\mathrm{H}-\mathrm{Cl}$ system According to Figure 2 some selectinty in the growth of silucon on $\mathrm{SiO}_{2}$ and $\mathrm{S}_{3} \mathrm{~N}_{4}$ can also be expected in the $\mathrm{SiH}_{4}-\mathrm{H}_{2}$ system at low temperatures and low input concentrations of slane.

\section{Adsorption on $\mathrm{SlO}_{2}$ and $\mathrm{Sl}_{3} \mathrm{~N}_{4}$ substrates}

In this section we discuss adsorption of $\mathrm{H}, \mathrm{Cl}, \mathrm{SlH}_{2}$ and $\mathrm{SiCl}_{2}$ in connection with the nucleation experiments on $\mathrm{SiO}_{2}$ and $\mathrm{Sl}_{3} \mathrm{~N}_{4}$ substrates We also give a comparison with adsorptions of the same compounds on slicon The concentration of free surface sites on a $\mathrm{SiO}_{2}$ substrate, $[*]=\left[*_{\mathrm{ox}}\right]+\left[*_{\mathrm{s} 1}\right]$ (where the subscripts $o x$ and $s 1$ refer to the surface atoms oxygen and silicon), can be given by

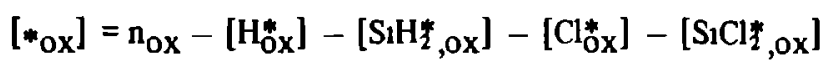

$$
\begin{aligned}
& {\left[*_{\mathrm{S} 1}\right]=\mathrm{n}_{\mathrm{S1}}-\left[\mathrm{H}_{\mathrm{S1}}^{*}\right]-\left[{\mathrm{S} 1 \mathrm{H}_{2}^{*}, \mathrm{S1}}^{*}\right]-\left[\mathrm{Cl}_{\mathrm{S1}}^{*}\right]-\left[\mathrm{SICl}_{2}^{*}, \mathrm{s1}\right]}
\end{aligned}
$$

where $n_{0}=n_{O X}+n_{S 1}$ is the total number of surface sites per unit area The concentration of free surface sites on $\mathrm{Si}_{3} \mathrm{~N}_{4}$ can be given in a similar way Making use of the equilibrium partial pressures of the various species in the gas phase, one can calculate the surface concentrations of the different compounds if values for the adsorption energies of these species are known [9] If no direct measurements are avalable, these adsorption energes $\left(E_{a}\right)$ can best be given by the dissociation energy (D) of the corresponding diatomic molecules Table I gives accepted values for D, according to the JANAF tables [12] for most of the bonds $D$ values for $\mathrm{Si}-\mathrm{O}, \mathrm{O}-\mathrm{Cl}$ and $\mathrm{N}-\mathrm{Cl}$ have been reported by Roberts and Caseno [13], who give average values for polyatomic molecules Since, as far as the authors are aware, no dissociation energy for the single bond of S1-N is known, an estumate of $D_{S_{1 N}}$ can be given by equating $D_{S_{1}-N} / D_{S_{1}-O}=D_{C-N} / D_{C-O}$ Using values for the single bonds denved from measurements on polyatomic molecules [13], this yields $\mathrm{D}_{\mathrm{S}_{1} \mathrm{~N}}=92 \mathrm{kcal} / \mathrm{mole}($ Table I) 


\begin{tabular}{|c|c|c|c|}
\hline \multirow{2}{*}{$\begin{array}{c}\text { adsorbed } \\
\text { atoms }\end{array}$} & \multicolumn{3}{|c|}{ Substrate atoms } \\
\cline { 2 - 4 } & $\mathrm{Si}$ & $\mathrm{O}$ & $\mathrm{N}$ \\
\hline $\mathrm{Si}$ & 70 & 108 & 92 \\
$\mathrm{H}$ & 70 & 102 & 83 \\
$\mathrm{Cl}$ & 90 & 52 & 46 \\
\hline
\end{tabular}

TABLE I: Accepted adsorption energies in $\mathrm{kcal} / \mathrm{mole}[12,13]$.

\section{Adsorption of monoatomic hydrogen}

As discussed before, the nucleation experiments on $\mathrm{SiO}_{2}$ and $\mathrm{Si}_{3} \mathrm{~N}_{4}$ substrates indicate a strong adsorption of atomic hydrogen on $\mathrm{SiO}_{2}$ and a weak adsorption on $\mathrm{Si}_{3} \mathrm{~N}_{4}$. According to Table I this could be due to the differences in bond strengths between $\mathrm{OH}$ and $\mathrm{NH}$. It is therefore also to be expected that adsorption of atomic hydrogen on silicon will be relatively weak, leading to a small coverage with hydrogen atoms [9]. More evidence of a strong hydrogen adsorption on $\mathrm{SiO}_{2}$ comes from the work of Morterra and Low [14] and of Lawrenko et al. [15]. Morterra and Low studied the reaction between porous silica and molecular hydrogen. They found that this silica reacts with molecular hydrogen. Infrared studies have shown that if molecular hydrogen reacts with porous $\mathrm{SiO}_{2}$ at temperatures above $650^{\circ} \mathrm{C}$, silanols ( $\mathrm{Si}-\mathrm{OH}$ ) are formed while $\mathrm{SiH}$ groups are totally absent. Lawrenko et al. studied the adsorption of hydrogen on monocrystalline $\mathrm{SiO}_{2}, \mathrm{Al}_{2} \mathrm{O}_{3}$ and $\mathrm{MgO}$. Measuring the weight losses of the samples by means of a microbalance they found that at temperatures below $900{ }^{\circ} \mathrm{C}$ measurable quantities of hydrogen are adsorbed on the three substrates, indicating the formation of $\mathrm{OH}$ groups. They also observed that the adsorption is reversible. Stein and Wegener [16] found that $\mathrm{CVD} \mathrm{Si}_{3} \mathrm{~N}_{4}$ contains chemically bonded hydrogen. Annealing experiments showed that the $\mathrm{SiH}$ bonds are annealed out more easily than the $\mathrm{NH}$ bonds. It can therefore be concluded that adsorption of atomic hydrogen on $\mathrm{SiO}_{2}$ substrates blocks adsorption sites, leading to a decrease in the saturation density of silicon clusters, whereas in the case of $\mathrm{Si}_{3} \mathrm{~N}_{4}$ and silicon surfaces this adsorption is only weak.

\section{Adsorption of atomic chlorine}

According to Table I, chlorine does not adsorb preferentially on oxygen or nitrogen, and it may therefore be assumed that adsorption of chlorine on $\mathrm{SiO}_{2}$ and $\mathrm{Si}_{3} \mathrm{~N}_{4}$ can be treated as adsorption on the silicon surface atoms. Adsorption of atomic chlorine on silicon has been discussed previously in connection with growth 
rate measurements of silicon on silicon [9] It was concluded there that at temper atures above $700{ }^{\circ} \mathrm{C}$ the fractional surface concentration of atomic chlorine is much smaller than unity, in agreement with evolution measurements reported by Miyamura et al [17]

\section{Adsorption of $\mathrm{SLH}_{2}$ and $\mathrm{SiCl}_{2}$}

Because of the relatively high values of $D_{S_{1}-N}$ and $D_{S_{1}-O}$ in contrast to $D_{S_{1}-S_{1}}$ (Table I) it can be assumed that the surface species $\mathrm{StH}_{2}$ and $\mathrm{SiCl}_{2}$ adsorb predominantly on top of oxygen or nitrogen atoms of the $\mathrm{SiO}_{2}$ or $\mathrm{Sl}_{3} \mathrm{~N}_{4}$ substrates After adsorption of the first monolayer of slicon the surface moblity of further $\mathrm{S}_{1} \mathrm{H}_{2}$ or $\mathrm{SiCl}_{2}$ monomers will be enhanced This postulation could explain the similarity in nucleation densities on $\mathrm{SiO}_{2}$ and $\mathrm{Sl}_{3} \mathrm{~N}_{4}$ with sapphire and spinel substrates as observed by Cullen and coworkers [18]

As discussed before, $\mathrm{N}_{\mathrm{S}}$ is linearly proportional to the input concentration of silane on $\mathrm{SiO}_{2}$ and $\mathrm{Sl}_{3} \mathrm{~N}_{4}$ substrates, indicating a small coverage of $\mathrm{SiH}_{2}$ monomers As discussed previously, the surface concentrations of $\mathrm{SiCl}_{2}$ on silicon in the $\mathrm{S}_{1} \mathrm{H}_{4} \mathrm{HCl}-\mathrm{H}_{2}$ systems are considered to be small [9] A strong adsorption of $\mathrm{SiCl}_{2}$ on $\mathrm{SiO}_{2}$ or $\mathrm{Sl}_{3} \mathrm{~N}_{4}$ substrates cannot be ruled out completely, but according to the experimental data as described in part II (the $\mathrm{S}_{1} \mathrm{H}_{2} \mathrm{Cl}_{2}-\mathrm{H}_{2}$ system) the surface coverage of $\mathrm{SiCl}_{2}$ is much smaller than that of atomuc hydrogen, notably for $\mathrm{SiO}_{2}$ substrates

\section{Conclusions}

In our study of the nucleation of slicon on $\mathrm{SiO}_{2}$ and $\mathrm{Sl}_{3} \mathrm{~N}_{4}$ substrates at temperatures between $600^{\circ}$ and $900^{\circ} \mathrm{C}$ in the $\mathrm{S}_{1} \mathrm{H}_{4}-\mathrm{HCl}-\mathrm{H}_{2}$ system, it was observed that the saturation nucleus density on $\mathrm{S}_{1} \mathrm{O}_{2}$ substrates in the $\mathrm{S}_{1} \mathrm{H}_{4}-\mathrm{H}_{2}$ system shows a maximum at approximately $900{ }^{\circ} \mathrm{C}$, whereas for $\mathrm{Sl}_{3} \mathrm{~N}_{4}$ substrates this density increases sightly with decreasing temperatures Addition of nitrogen to the $\mathrm{SiH}_{4} \cdot \mathrm{H}_{2}$ systems produces a strong increase in the saturation density of sulicon clusters, notably on $\mathrm{S}_{2} \mathrm{O}_{2}$ substrates Analysis of the experimental data suggests that atomic hydrogen is strongly adsorbed because of the formation of $\mathrm{OH}$ bonds, whereas on $\mathrm{Sl}_{3} \mathrm{~N}_{4}$ substrates adsorption of atomc hydrogen leads to only small coverages. The introduction of $\mathrm{HCl}$ strongly reduces the nucleus density, notably at temperatures below $900{ }^{\circ} \mathrm{C}$ It is concluded that this additional reduction at temperatures below $900{ }^{\circ} \mathrm{C}$ is comparable with the decrease in growth rate in the case of silicon on silicon. The adsorption of $\mathrm{H}, \mathrm{Cl}, \mathrm{SiCl}_{2}$ and $\mathrm{SiH}_{2}$ on $\mathrm{SiO}_{2}$ and $\mathrm{Sl}_{3} \mathrm{~N}_{4}$ substrates is discussed and compared with the adsorption of these species on silicon surfaces It is concluded that only adsorption of atomic hydrogen on $\mathrm{SiO}_{2}$ is needed to explain the experimental results this adsorption blocks the adsorption sites, leading to a decrease in the saturation density of silicon clusters 


\section{References}

1 W.A.P. Claassen and J. Bloem, J. Electrochem. Soc. 127, 194 (1980).

2 W.A.P. Claassen and J. Bloem, J. Electrochem. Soc. 127, 1836 (1980).

3 L.J.M. Bollen, unpublished results.

4 E. Sirtl and H. Seiter, Semiconductor Silicon (1969) p. 189 (R.R. Haberecht and E.L. Kern, Editors The Electrochem. Soc.).

5 S.I. Raider, R. Flitsch, J.A. Aboaf and W.A. Pliskin, J. Electrochem. Soc. 123, 560 (1976).

6 J.A. Venables, Phil. Mag. 27, 697 (1973).

7. J. Bloem and L.J. Giling in 'Current Topics in Materials Science', Ed. E. Kaldis, North-Holland Publishing Comp. Vol. I, Chapter 4 (1978).

8 C.G. Newman, H.E. O'Neal, M.A. Ring, F. Leska and N. Shipley, Int. J. Chemical Kinetics XI, 1167 (1979).

9 W.A.P. Claassen and J. Bloem, submitted to J. Cryst. Growth.

10 P. van der Putte, L.J. Giling and J. Bloem, J. Cryst. Growth 41, 133 (1977).

11 J. Bloem and W.A.P. Claassen, J. Cryst. Growth 49, 435 (1980).

12 JANAF Thermochemical Tables 2nd ed. June 1971, NSRDS-NBS-37.

13 J.D. Roberts and M.C. Caserio, 'Modern Organic Chemistry', W.A. Benjamin, Inc. (1967).

14 C. Morterra and M.J.D. Low, J. Catalysis 28, 265 (1973).

15 W.A. Lawrenko, W.L. Tikusch, W.S. Senkov, W.A. Krawez, K.W. Nasarenko and W.M. Werestschak, Z. Phys. Chem. Leipzig 259, 129 (1978).

16 H.J. Stein and H.A.R. Wegener, J. Electrochem. Soc. 124, 908 (1977).

17 M. Miyamura, Y. Sakisaka, M. Nishijma and M. Onchi, Surface Science 72, 243 (1978).

18 G.W. Cullen, J.F. Corboy and J.T. Mc Ginn in 'Semiconductor Silicon', Eds. H.R. Huff and E. Sirtl, The Electrochem. Soc. (1977). 


\title{
CHAPTER IV
}

\section{THE NUCLEATION OF CVD SILICON ON $\mathrm{SiO}_{2}$ AND $\mathrm{Si}_{3} \mathrm{~N}_{4}$ SUBSTRATES}

\author{
II The $\mathrm{SiH}_{2} \mathrm{Cl}_{2}-\mathrm{H}_{2}-\mathrm{N}_{2}$ system
}

\begin{abstract}
A description is given of nucleation experiments with silicon on $\mathrm{S}_{1} \mathrm{O}_{2}$ and $\mathrm{Sl}_{3} \mathrm{~N}_{4}$ substrates in the $\mathrm{S}_{1} \mathrm{H}_{2} \mathrm{Cl}_{2}-\mathrm{H}_{2}-\mathrm{N}_{2}$ system, performed at temperatures between $800^{\circ}$ and $1100^{\circ} \mathrm{C}$. The saturation cluster densities were determined for different mixtures as a function of temperature and could be varied between $10^{5}-10^{10} \mathrm{~cm}^{-2}$. A reaction scheme is proposed in which slicon adatoms reach a steady state concentration before nucleation occurs Comparison of the experimental data with existing nucleation theories gives approximate values for the size of the critical cluster. A strong adsorption of atomic hydrogen, especially on $\mathrm{S}_{1} \mathrm{O}_{2}$ surlaces, may explain the substantial differences in nucleation on $\mathrm{S}_{1} \mathrm{O}_{2}$ and $\mathrm{S}_{3} \mathrm{~N}_{4}$ surfaces at temperatures below $1000^{\circ} \mathrm{C}$
\end{abstract}

\section{Introduction}

Polycrystalline silicon layers are finding extensive application in the fabrication of integrated circuits, e.g. as gate material in MOS (Metal-Oxide-Silicon) field effect transistors [1]. For this purpose $\mathrm{CVD}$ with $\mathrm{SiH}_{4}$ as input gas is most widely used but chlorosilanes too, such as $\mathrm{SiHCl}_{3}$ and $\mathrm{SiCl}_{4}$ and recently $\mathrm{SiH}_{2} \mathrm{Cl}_{2}$ are becoming increasingly important as starting materials for the depositıon of silicon layers [2]. Reports of nucleation experiments with silicon on amorphous, polycrystalline and monocrystalline substrates are relatively scarce. The present authors discuss such experiments in a previous paper dealing with nucleation of silicon on $\mathrm{S}_{1} \mathrm{O}_{2}$ and $\mathrm{Si}_{3} \mathrm{~N}_{4}$ substrates in the $\mathrm{SiH}_{4}-\mathrm{HCl}-\mathrm{H}_{2}$ system [3]. The present paper discusses nucleation in the $\mathrm{SiH}_{2} \mathrm{Cl}_{2}-\mathrm{H}_{2}-\mathrm{N}_{2}$ system on $\mathrm{SiO}_{2}$ and $\mathrm{Si}_{3} \mathrm{~N}_{4}$ substrates. The experimental results are described and compared with existing nucleation theories.

\section{Experimental}

The nucleation experiments were performed in a horizontal R.F. heated reactor, consisting of a rectangular air-cooled fused silica tube, provided with a pyrographite coated carbon susceptor covered with a thin layer of silicon. Nucleation of silicon was performed on silicon slices (wafer 0.5 inch square) covered with an amorphous $1500 \AA$ thick LP-CVD SiO 2 or $\mathrm{Si}_{3} \mathrm{~N}_{4}$ layer. The effective cross-section of the reactor tube was about $11 \mathrm{~cm}^{2}$. The gas system was provided with automatic mass flow controllers for the hydrogen and nitrogen carrier gas and the $\mathrm{SiH}_{2} \mathrm{Cl}_{2}$ source. Some experiments were performed with $\mathrm{SiHCl}_{3}$, in which case the input concentrations were controlled by passing a flow of hydrogen, montored by means of an automatic mass flow controller, through a bubbler filled with $\mathrm{SiHCl}_{3}$ at a constant temperature. The carrier gas was purified; both water vapour and oxygen concentrations were below $1 \mathrm{ppm}$. The slices were cleaned prior to a deposition experiment 
in a $\mathrm{H}_{2} \mathrm{SO}_{4} \cdot \mathrm{H}_{2} \mathrm{O}_{2}$ mixture followed by rinsing in water of ultra-high purity. After spin drying, the slices were further cleaned in the reactor tube with $0.2 \mathrm{vol} . \% \mathrm{HCl}$ in hydrogen at $1000{ }^{\circ} \mathrm{C}$ for five minutes. After this, the reactor was purged by a hydrogen flow, while the substrate temperature was brought to the desired nucleation temperature. Prior to deposition the reactor was flushed with the particular $\mathrm{H}_{2}-\mathrm{N}_{2}$ mixture, which is also used during the nucleation experiment for about five minutes. During the nucleation experiment the $\mathrm{H}_{2}-\mathrm{N}_{2}$ mixture loaded with $\mathrm{SiH}_{2} \mathrm{Cl}_{2}$ was passed over the slices. In order to obtain stable gas llow conditions a room temperature gas velocity of about $60 \mathrm{~cm} / \mathrm{sec}$ was chosen. The temperature of the slices was measured with an optical pyrometer focussed on the surface of an uncoated silicon slice, and the values were corrected for the emissivity of silicon and the absorption and reflection of the system. After termination of the experiment the substrates were cooled without $\mathrm{SiH}_{2} \mathrm{Cl}_{2}$ addition and inspected at room temperature. The density of the nuclei formed was determined from either SEM or TEM photomicrographs.

\section{Experimental results}

\subsection{Introduction}

A series of short depositions was carried out with different concentrations of $\mathrm{SiH}_{2} \mathrm{Cl}_{2}$ in $\mathrm{H}_{2}, \mathrm{~N}_{2}$ or mixtures of $\mathrm{H}_{2}$ and $\mathrm{N}_{2}$ at temperatures between $800^{\circ}$ and $1100^{\circ} \mathrm{C}$. As in the $\mathrm{SiH}_{4} \cdot \mathrm{HCl}-\mathrm{H}_{2}$ system [3], it was found that after an incubation period the density of stable clusters very quickly reached a saturation density of nuclei with respect to exposure time. After this period the clusters merely increased in size until coalescence occurred. The existing clusters showed a very narrow size distribution, from which it may be concluded that the clusters are formed in a very short period of time.

\subsection{Nucleation on a $\mathrm{SiO}_{2}$ substrate}

The experimentally observed saturation densities of $\mathrm{Si}$ clusters in the $\mathrm{SiH}_{2} \mathrm{Cl}_{2} \cdot \mathrm{H}_{2}-\mathrm{N}_{2}$ system have been collected in Table I. In Figure 1 the saturation densities of silicon clusters on $\mathrm{SiO}_{2}$ substrates at $1000{ }^{\circ} \mathrm{C}$ are plotted for 0.1 vol. \% $\mathrm{SiH}_{2} \mathrm{Cl}_{2}$ for some $\mathrm{H}_{2}-\mathrm{N}_{2}$ mixtures, the latter expressed as $\mathrm{PH}_{2} /\left(\mathrm{PH}_{2}+\mathrm{PN}_{2}\right)$. The highest saturation density can be observed for pure nitrogen, while the introduction of hydrogen strongly reduces the saturation density of $\mathrm{Si}$ clusters on $\mathrm{SiO}_{2}$ substrates. Figure 2 gives a plot of the saturation density of nuclei versus the reciprocal temperature in the temperature region $925^{\circ}-1100^{\circ} \mathrm{C}$ (with the exception of nitrogen, where results at $800^{\circ} \mathrm{C}$ are also given). For nitrogen the formation process is barely a function of temperature. If hydrogen is added to the mixture the temperature dependence of the formation process increases with increasing hydrogen concentrations. Figure 3 shows photomicrographs of nucleation on $\mathrm{SiO}_{2}$ substrates at $1000^{\circ} \mathrm{C}$, for an input concentration of $0.1 \mathrm{vol} \% \mathrm{SiH}_{2} \mathrm{Cl}_{2}$ in pure $\mathrm{H}_{2}$ (a) and pure $\mathrm{N}_{2}$ (b). 
TABLE 1. Saturation nucleus density $\left(\mathrm{cm}^{-2}\right)$ for the $\mathrm{SiH}_{2} \mathrm{Cl}_{2}-\mathrm{H}_{2}-\mathrm{N}_{2}$ system on $\mathrm{SiO}_{2}$ substrates between $800^{\circ}$ and $1100{ }^{\circ} \mathrm{C}$. $t$ is the exposure time.

\begin{tabular}{|c|c|c|c|c|c|c|c|c|c|c|c|c|}
\hline \multicolumn{3}{|c|}{ Partial pressure (bar) } & \multicolumn{10}{|c|}{ Temperature } \\
\hline \multirow[t]{2}{*}{$\mathrm{PSiH}_{2} \mathrm{Cl}_{2}$} & \multirow[t]{2}{*}{$\mathrm{P}_{\mathrm{H}_{2}}$} & \multirow[t]{2}{*}{$\mathrm{P}_{\mathrm{N}_{2}}$} & \multicolumn{2}{|c|}{$1100^{\circ} \mathrm{C}$} & \multicolumn{2}{|c|}{$1000^{\circ} \mathrm{C}$} & \multicolumn{2}{|c|}{$925^{\circ} \mathrm{C}$} & \multicolumn{2}{|r|}{$900^{\circ} \mathrm{C}$} & \multicolumn{2}{|r|}{$800^{\circ} \mathrm{C}$} \\
\hline & & & $\begin{array}{c}\mathrm{t} \\
(\mathrm{sec})\end{array}$ & $\underset{\left(\mathrm{cm}^{-2}\right)}{\mathrm{N}_{\mathrm{S}}}$ & $\begin{array}{c}\mathrm{t} \\
(\mathrm{sec})\end{array}$ & $\underset{\left(\mathrm{cm}^{-2}\right)}{\mathrm{N}_{\mathrm{s}}}$ & $\begin{array}{c}\mathfrak{t} \\
(\mathrm{sec})\end{array}$ & $\begin{array}{c}\mathrm{N}_{\mathrm{s}} \\
\left(\mathrm{cm}^{-2}\right)\end{array}$ & $\begin{array}{c}\mathrm{t} \\
(\mathrm{sec})\end{array}$ & $\begin{array}{c}\mathrm{N}_{\mathrm{s}} \\
\left(\mathrm{cm}^{-2}\right)\end{array}$ & $\begin{array}{c}\mathrm{t} \\
(\mathrm{sec})\end{array}$ & $\begin{array}{c}\mathbf{N}_{\mathrm{s}} \\
\left(\mathrm{cm}^{-2}\right)\end{array}$ \\
\hline $1 \times 10^{-3}$ & 1 & - & 10 & $4 \times 10^{8}$ & 10 & $5 \times 10^{7}$ & 120 & $8 \times 10^{6}$ & & - & & - \\
\hline $2 \times 10^{-3}$ & 1 & - & 3 & $9 \times 10^{8}$ & 5 & $1.1 \times 10^{8}$ & 15 & $2.5 \times 10^{7}$ & & - & & - \\
\hline $4 \times 10^{-3}$ & 1 & - & & - & 5 & $1.8 \times 10^{8}$ & 15 & $5 \times 10^{7}$ & & - & & - \\
\hline $1 \times 10^{-3}$ & 0.76 & 0.24 & & - & 5 & $7 \times 10^{7}$ & & - & & - & & - \\
\hline $1 \times 10^{-3}$ & 0.44 & 0.56 & & - & 5 & $4 \times 10^{8}$ & & - & & - & & - \\
\hline $1 \times 10^{-3}$ & 0.18 & 0.82 & 3 & $1.4 \times 10^{9}$ & 5 & $6 \times 10^{8}$ & 15 & $4 \times 10^{8}$ & & - & & - \\
\hline $1 \times 10^{-3}$ & 0.03 & 0.97 & 3 & $4 \times 10^{9}$ & 5 & $3 \times 10^{9}$ & 15 & $2 \times 10^{9}$ & & - & & - \\
\hline $2 \times 10^{-4}$ & - & 1 & & - & 10 & $4 \times 10^{9}$ & & - & & - & & - \\
\hline $5 \times 10^{-4}$ & - & 1 & 5 & $1.1 \times 10^{10}$ & 5 & $1.1 \times 10^{10}$ & 30 & $1.2 \times 10^{10}$ & & - & & - \\
\hline $1 \times 10^{-3}$ & - & 1 & 3 & $1.2 \times 10^{10}$ & 5 & $1.5 \times 10^{10}$ & & - & 15 & $1.3 \times 10^{10}$ & 60 & $1.7 \times 10^{10}$ \\
\hline
\end{tabular}




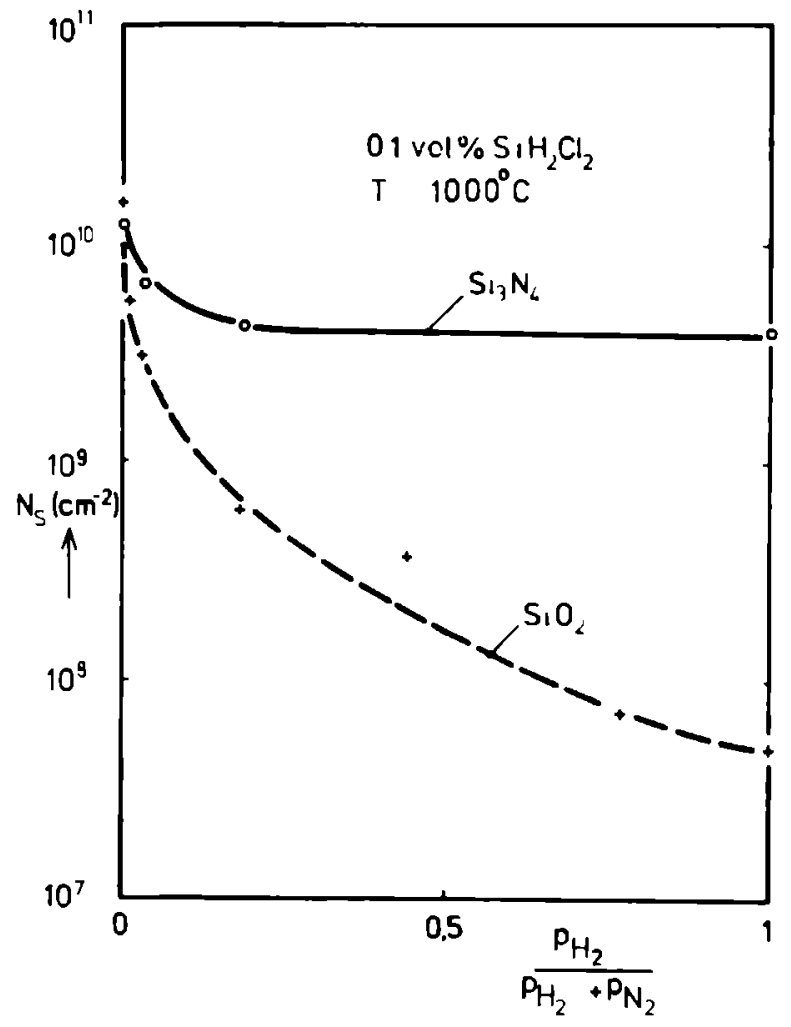

Figure 1.

The saturation nucleus density for some $\mathrm{H}_{2}-\mathrm{N}_{2}$ mixtures and $0.1 \mathrm{vol}$. \% $\mathrm{SiH}_{2} \mathrm{Cl}_{2}$ on $\mathrm{SiO}_{2}$ and $\mathrm{Si}_{3} \mathrm{~N}_{4}$ substrates at $1000^{\circ} \mathrm{C}$.

It will be shown in section 4 that the experimental data on saturation densities of nuclei $\left(\mathrm{N}_{\mathrm{S}}\right.$ ) on a $\mathrm{SiO}_{2}$ substrate at $1100^{\circ} \mathrm{C}$ as a function of gas phase composition can be described by

$\mathrm{N}_{\mathrm{S}}=\frac{\mathrm{A} \mathrm{PSiH}_{2} \mathrm{Cl}_{2} \text { (b) }}{1+\mathrm{B} \mathrm{P}_{\mathrm{H}_{2}^{\prime}{ }^{2}}^{2}}$

where $\mathrm{PSiH}_{2} \mathrm{Cl}_{2}$ (b) is the input concentration of $\mathrm{SiH}_{2} \mathrm{Cl}_{2}$ and $\mathrm{A}$ and $\mathrm{B}$ are constants. For B P $\mathbf{H}_{2}^{1}>1$ a plot of $\log \left(\mathrm{N}_{\mathrm{s}} / \mathrm{PSiH}_{2} \mathrm{Cl}_{2}\right.$ (b) versus $\log \left(\mathrm{P}_{\mathrm{H}_{2}}\right)$ should show a linear dependence, as indicated in Figure 4. For temperatures below 1100 ${ }^{\circ} \mathrm{C}$ the tangent in Figure 4 differs from $1 / 2$ for high hydrogen pressures. In this figure the points at $\mathrm{PH}_{2}$ around $10^{-3}$ represent the saturation densities of nuclei for the $\mathrm{SiH}_{2} \mathrm{Cl}_{2} \cdot \mathrm{N}_{2}$ system (no hydrogen added). As described in section 4 , in a nitrogen medium $\mathrm{SiH}_{2} \mathrm{Cl}_{2}$ decomposes almost completely in the gas phase to 


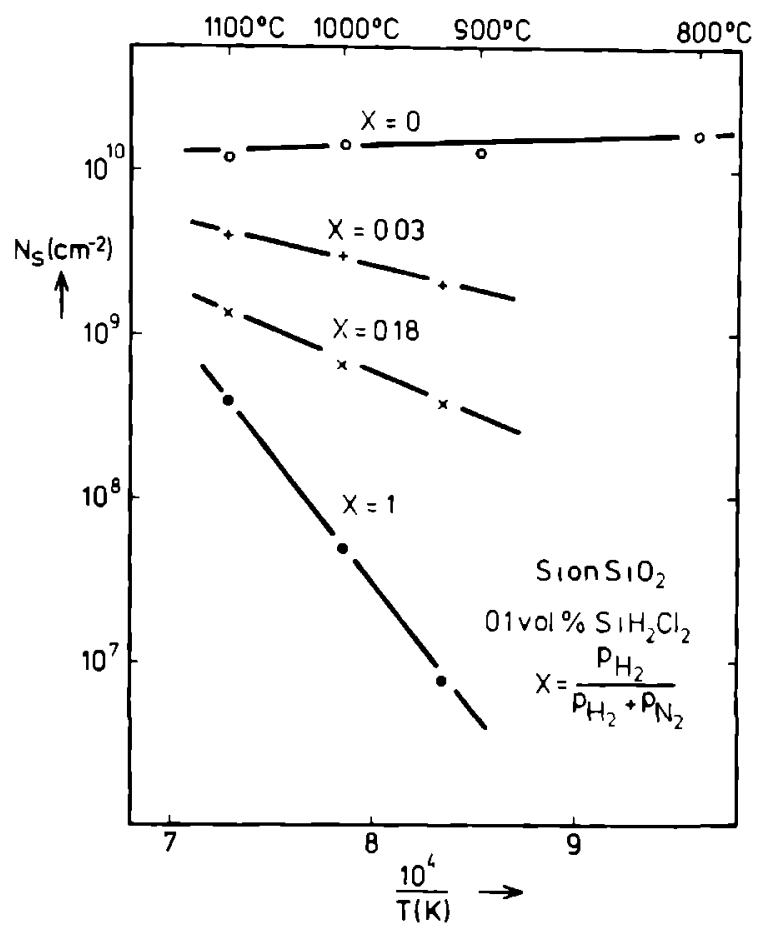

Figure 2.

The saturation nucleus density as a function of temperature on $\mathrm{SiO}_{2}$ substrates for some $\mathrm{H}_{2}-\mathrm{N}_{2}$ mixtures and 0.1 vol. $\% \mathrm{SiH}_{2} \mathrm{Cl}_{2}$.

$\mathrm{SiCl}_{2}$ and $\mathrm{H}_{2}$. This means that an input concentration of 0.1 vol. $\% \mathrm{SiH}_{2} \mathrm{Cl}_{2}$ gives $\mathrm{P}_{\mathrm{H}_{2}} \cong 10^{-3}$ bar.

\subsection{Nucleation on a $\mathrm{Si}_{3} \mathrm{~N}_{4}$ substrate: differences compared with a SiO ${ }_{2}$ substrate}

Table II gives the experimental data for the saturation densities of stable clusters on $\mathrm{Si}_{3} \mathrm{~N}_{4}$ substrates in the $\mathrm{SiH}_{2} \mathrm{Cl}_{2} \cdot \mathrm{H}_{2} \cdot \mathrm{N}_{2}$ system. Figure 1 also shows saturation densities of silicon clusters for $\mathrm{Si}_{3} \mathrm{~N}_{4}$ substrates as a function of $\mathrm{P}_{2} /\left(\mathrm{P}_{2}+\mathrm{PN}_{2}\right)$ at $1000{ }^{\circ} \mathrm{C}$. The difference between $\mathrm{SiO}_{2}$ and $\mathrm{Si}_{3} \mathrm{~N}_{4}$ substrates is remarkable. Introduction of hydrogen to the system reduces the saturation density of nuclei for the $\mathrm{Si}_{3} \mathrm{~N}_{4}$ substrate, but for the $\mathrm{SiO}_{2}$ substrate the variation is much stronger. In Figure 5 saturation densities of nuclei on $\mathrm{Si}_{3} \mathrm{~N}_{4}$ substrates are given for 0.1 vol. \% $\mathrm{SiH}_{2} \mathrm{Cl}_{2}$ in hydrogen and nitrogen as a function of temperature. As for the $\mathrm{SiO}_{2}$ system (Figure 2) the experiments in hydrogen give the lowest density of nuclei and the strongest temperature dependence of the formation process. It appears that if 
TABLE II. Saturation nucleus density $\left(\mathrm{cm}^{-2}\right)$ for the $\mathrm{SiH}_{2} \mathrm{Cl}_{2}-\mathrm{H}_{2}-\mathrm{N}_{2}$ system on $\mathrm{Si}_{3} \mathrm{~N}_{4}$ substrates between $800^{\circ}$ and $1100^{\circ} \mathrm{C}$. $t$ is the exposure time.

\begin{tabular}{|c|c|c|c|c|c|c|c|c|c|c|}
\hline \multicolumn{3}{|c|}{ Partial pressure (bar) } & \multicolumn{8}{|c|}{ Temperature } \\
\hline \multirow{2}{*}{$\mathrm{P}_{\mathrm{SiH}_{2}} \mathrm{Cl}_{2}$} & \multirow{2}{*}{$\mathrm{p}_{\mathrm{H}_{2}}$} & \multirow{2}{*}{$\mathrm{p}_{\mathrm{N}_{2}}$} & \multicolumn{2}{|c|}{$1100^{\circ} \mathrm{C}$} & \multicolumn{2}{|c|}{$1000^{\circ} \mathrm{C}$} & \multicolumn{2}{|c|}{$900^{\circ} \mathrm{C}$} & \multicolumn{2}{|c|}{$800^{\circ} \mathrm{C}$} \\
\hline & & & $\begin{array}{c}t \\
(\mathrm{sec})\end{array}$ & $\underset{\left(\mathrm{cm}^{-2}\right)}{\left.\mathrm{N}_{\mathrm{S}}\right)}$ & $\begin{array}{c}t \\
(\mathrm{sec})\end{array}$ & $\underset{\left(\mathrm{cm}^{-2}\right)}{\mathrm{N}_{\mathrm{S}}}$ & $\begin{array}{c}t \\
(\mathrm{sec})\end{array}$ & $\begin{array}{c}\mathrm{N}_{\mathrm{S}} \\
\left(\mathrm{cm}^{-2}\right)\end{array}$ & $\begin{array}{c}\mathrm{t} \\
(\mathrm{sec})\end{array}$ & $\underset{\left(\mathrm{cm}^{-2}\right)}{\mathrm{N}_{\mathrm{S}}}$ \\
\hline $1 \times 10^{-3}$ & 1 & - & 5 & $6 \times 10^{9}$ & 10 & $4 \times 10^{9}$ & 15 & $1.4 \times 10^{9}$ & 120 & $7 \times 10^{8}$ \\
\hline $1 \times 10^{-3}$ & 0.18 & 0.82 & & - & 5 & $4 \times 10^{9}$ & & - & & - \\
\hline $1 \times 10^{-3}$ & 0.03 & 0.97 & & & 5 & $7 \times 10^{9}$ & & - & & - \\
\hline $5 \times 10^{-4}$ & - & 1 & 5 & $1.1 \times 10^{10}$ & 5 & $1.1 \times 10^{10}$ & & - & & - \\
\hline $1 \times 10^{-3}$ & - & 1 & 3 & $1.1 \times 10^{10}$ & 5 & $1.2 \times 10^{10}$ & 15 & $1.6 \times 10^{10}$ & 60 & $1.7 \times 10^{10}$ \\
\hline
\end{tabular}



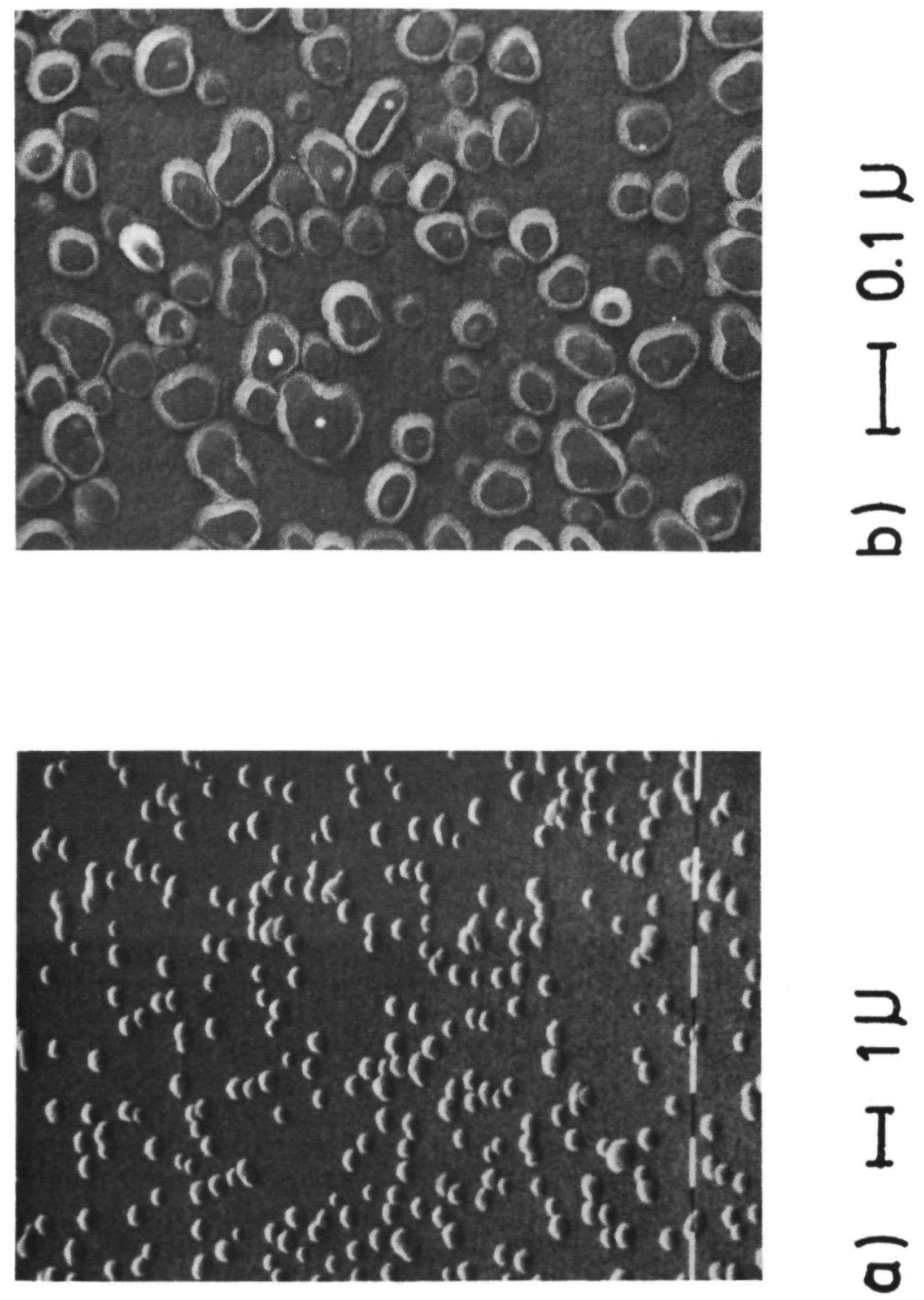

Figure 3.

Photomicrographs of the nucleus density for 0.1 vol. $\% \mathrm{SiH}_{2} \mathrm{Cl}_{2}$ in pure $\mathrm{H}_{2}$ (a) and pure $N_{2}$ (b). 


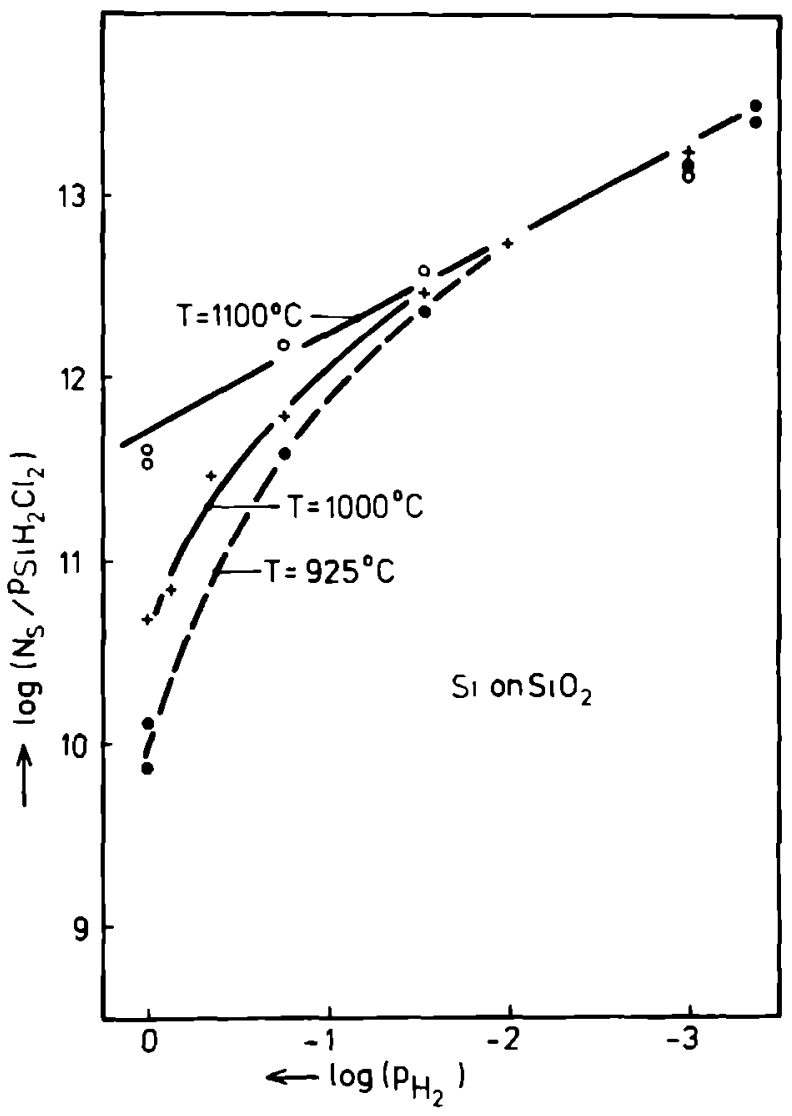

Figure 4.

The saturation nucleus density at $925^{\circ} \mathrm{C}, 1000{ }^{\circ} \mathrm{C}$ and $1100{ }^{\circ} \mathrm{C}$ for different mixtures of $\mathrm{SiH}_{2} \mathrm{Cl}_{2}-\mathrm{H}_{2}-\mathrm{N}_{2}$, expressed as log $\left(\mathrm{N}_{\mathrm{S}} / \mathrm{PSiH}_{2} \mathrm{Cl}_{2}\right)$ versus $\log \left(\mathrm{P}_{\mathrm{H}_{2}}\right)$ on $\mathrm{SiO}_{2}$ substrates.

the hydrogen content is very low there is hardly any difference between a $\mathrm{SiO}_{2}$ and $\mathrm{Si}_{3} \mathrm{~N}_{4}$ substrate. The experimentally found expression for the saturation density of stable clusters (eq. 1) as a function of temperature and gas phase composition could also be used for $\mathrm{Si}_{3} \mathrm{~N}_{4}$ substrates. In Figure $6 \log \left(\mathrm{N}_{\mathrm{S}} / \mathrm{PSiH}_{2} \mathrm{Cl}_{2}\right)$ versus $\log \left(\mathrm{P}_{\mathrm{H}_{2}}\right)$ is plotted at $1000^{\circ} \mathrm{C}$ for $\mathrm{Si}$ on $\mathrm{Si}_{3} \mathrm{~N}_{4}$, giving a linear dependence between the two parameters. Further it can be observed that the tangent in this figure is smaller than $1 / 2$, indicating that the assumption $\mathrm{BP}_{\mathrm{H}_{2}}^{1 / 2}>1$ is not acceptable in this case. 


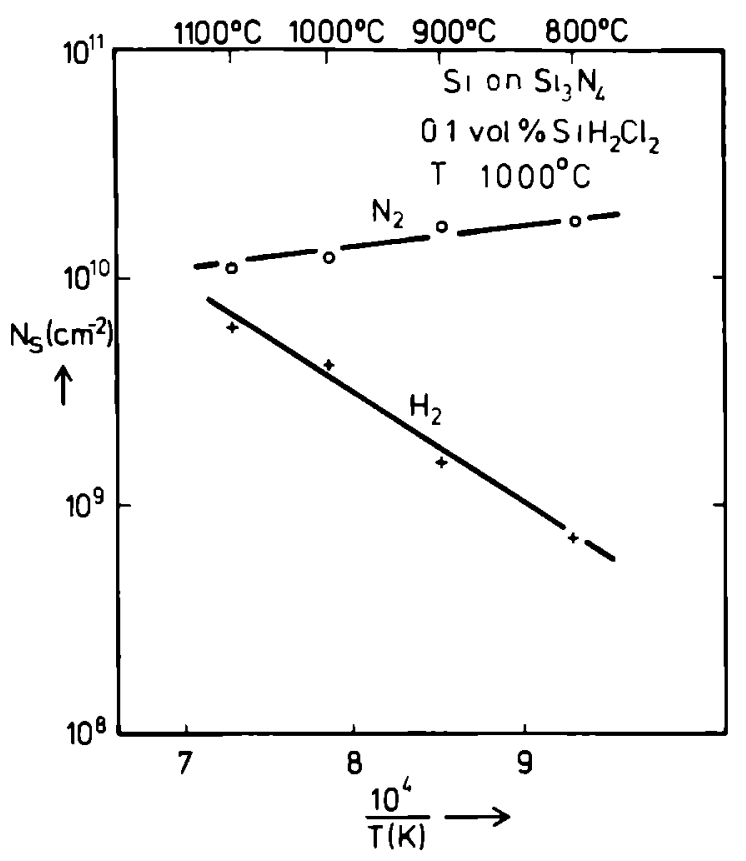

Figure 5.

The saturation nucleus density on $\mathrm{Si}_{3} \mathrm{~N}_{4}$ substrates for $0.1 \mathrm{vol} \% \mathrm{SiH}_{2} \mathrm{Cl}_{2}$ in pure $\mathrm{H}_{2}(\mathrm{H})$ and pure $\mathrm{N}_{2}(\mathrm{o})$ as a function of temperature.

\subsection{Nucleation of Si on $\mathrm{SiO}_{2}$ and $\mathrm{Si}_{3} \mathrm{~N}_{4}$ substrates: comparison of the} $\mathrm{SiH}_{2} \mathrm{Cl}_{2}-\mathrm{H}_{2}$ system with other silicon-containing compounds in hydrogen

Figures 7 and 8 give saturation densities of silicon clusters for $\mathrm{SiO}_{2}$ and $\mathrm{Si}_{3} \mathrm{~N}_{4}$ substrates, respectively, as a function of temperature for $\mathrm{SiH}_{4}$ [3], $\mathrm{SiH}_{2} \mathrm{Cl}_{2}$ and $\mathrm{SiHCl}_{3}$ (all concentrations about $0.1 \mathrm{vol} . \%$ ) in hydrogen as a carrier gas. The difference in the saturation nucleus density between $\mathrm{SiH}_{4}$ and $\mathrm{SiH}_{2} \mathrm{Cl}_{2}$ as the silicon containing compounds for both substrates is remarkable.The saturation density of nuclei in the $\mathrm{SiH}_{4}-\mathrm{H}_{2}$ system increases with decreasing temperatures, whereas for the other systems the opposite occurs. On $\mathrm{SiO}_{2}$ substrates $\mathrm{SiHCl}_{3}$ behaves in much the same way as $\mathrm{SiH}_{2} \mathrm{Cl}_{2}$ whereas on $\mathrm{Si}_{3} \mathrm{~N}_{4}$ substrates this is only true at high temperatures (Figure 8). It was observed that the growth rate of silicon on silicon for a mixture of $0.1 \mathrm{vol} . \% \mathrm{SiH}_{4}$ and $0.2 \mathrm{vol}$. \% $\mathrm{HCl}$ is almost equal to that of $0.1 \mathrm{vol} . \% \mathrm{SiH}_{2} \mathrm{Cl}_{2}$, both systems having hydrogen as a carrier gas and a temperature of $1000^{\circ} \mathrm{C}$ [4]. It is therefore interesting to compare the saturation densities of nuclei on $\mathrm{SiO}_{2}$ and $\mathrm{Si}_{3} \mathrm{~N}_{4}$ substrates in the $\mathrm{SiH}_{2} \mathrm{Cl}_{2} \cdot \mathrm{H}_{2}$ system with the results of nucleation experiments in the $\mathrm{SiH}_{4}-\mathrm{HCl}-\mathrm{H}_{2}$ system. In Figure 9 saturation densities of silicon clusters are given for $\mathrm{SiO}_{2}$ and $\mathrm{Si}_{3} \mathrm{~N}_{4}$ substrates as a function of temperature for 


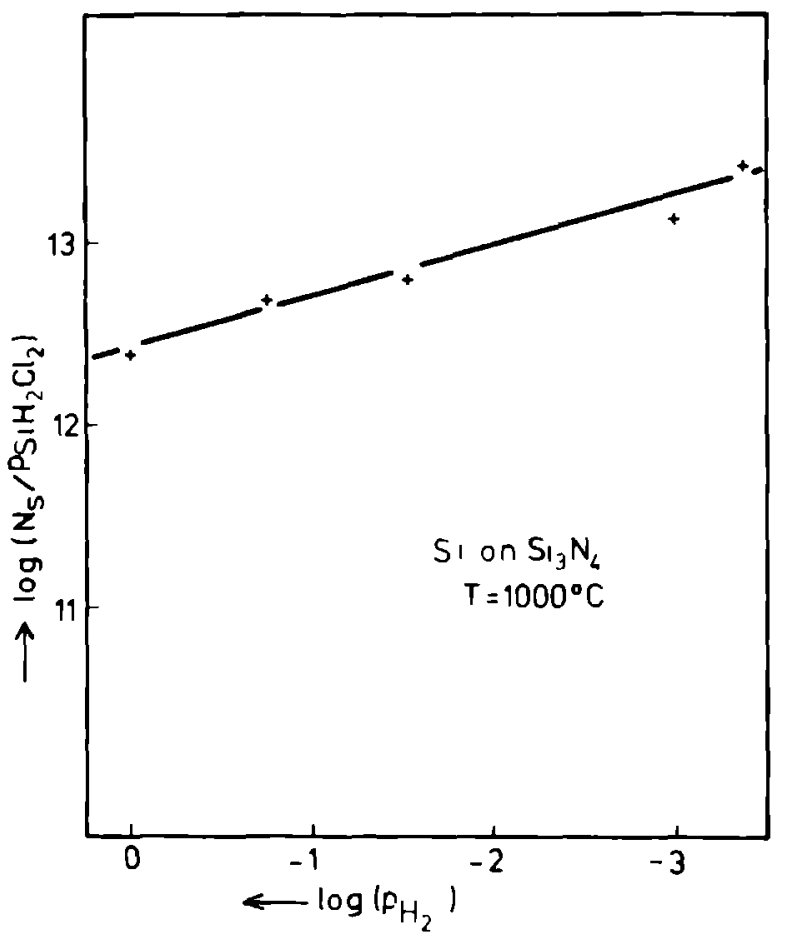

Figure 6.

$\log \left(\mathrm{N}_{\mathrm{S}} / \mathrm{PSiH}_{2} \mathrm{Cl}_{2}\right)$ versus $\log \left(\mathrm{P}_{\mathrm{H}_{2}}\right)$ at $1000^{\circ} \mathrm{C}$ for Sion $\mathrm{Si}_{3} \mathrm{~N}_{\mathrm{A}}$.

0.1 vol. \% $\mathrm{SiH}_{2} \mathrm{Cl}_{2}$ and a mixture of 0.1 vol. $\% \mathrm{SiH}_{4}$ and 0.2 vol. \% $\mathrm{HCl}$ [4], both systems in a hydrogen medium. It can be observed on both substrates that for the $\mathrm{SiH}_{2} \mathrm{Cl}_{2} \cdot \mathrm{H}_{2}$ mixture the saturation density of nuclei decreases with decreasing temperature, whereas for the $\mathrm{SiH}_{4} \cdot \mathrm{HCl}-\mathrm{H}_{2}$ mixture the opposite occurs.

\section{Discussion}

\subsection{Adatom concentration and surface coverage}

In order to arrive at an expression describing the adatom concentration of silicon on the substrate it would be very helpful to have thermochemical data of the $\mathrm{Si}-\mathrm{H}-\mathrm{N}-\mathrm{Cl}$ system. With this in view thermochemical data of the $\mathrm{Si}-\mathrm{H}-\mathrm{Cl}$ and $\mathrm{Si}-\mathrm{N}-\mathrm{Cl}$ systems have been calculated for $\mathrm{Cl} / \mathrm{H}_{2}=10^{-3}$ and $\mathrm{Cl} / \mathrm{N}_{2}=10^{-3}$, respectively, in the temperature range of $900-1400 \mathrm{~K}$, using the procedure reported by Van der Putte et al. [5] (Figure 10). In equilibrium with solid silicon the most abundant species are $\mathrm{H}_{2}, \mathrm{HCl}, \mathrm{SiCl}_{2}, \mathrm{SiH}_{2} \mathrm{Cl}_{2}, \mathrm{SiCl}_{4}$ and $\mathrm{SiHCl}_{3}$, in accordance with mass 


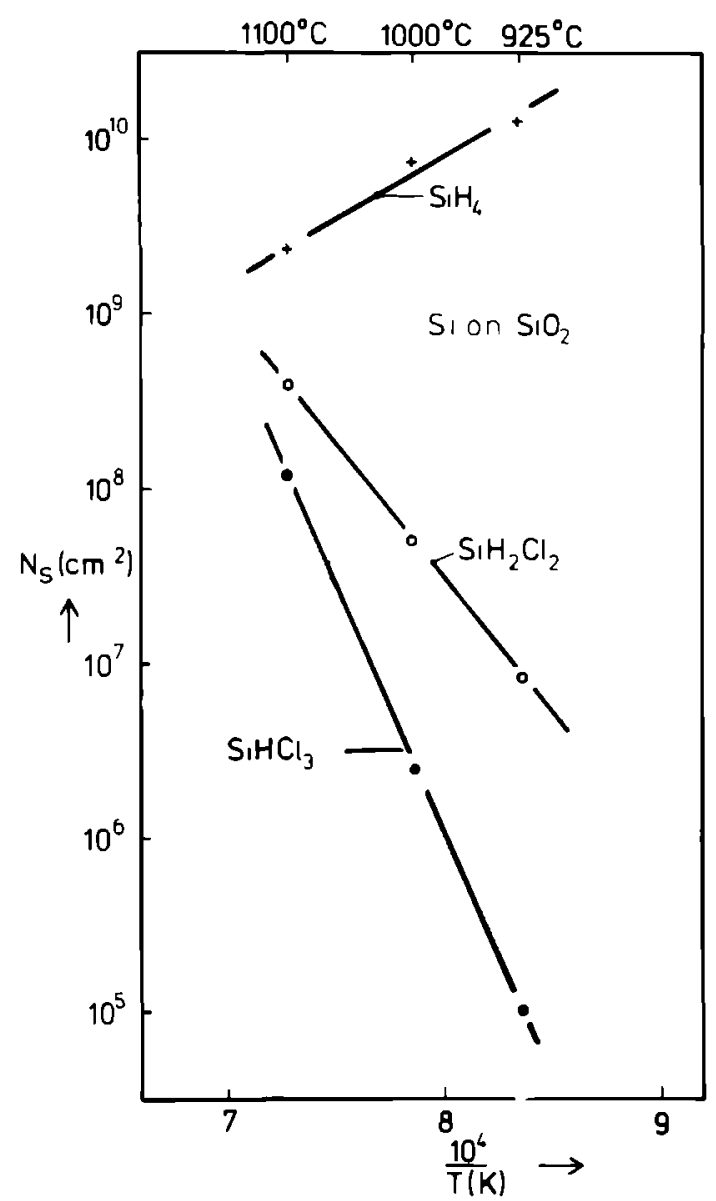

Figure 7.

Saturation densities on $\mathrm{SiO}_{2}$ substrates as a function of temperature for $\mathrm{SiH}_{4}$, $\mathrm{SiH}_{2} \mathrm{Cl}_{2}$ and $\mathrm{SiHCl}_{3}$ (all concentrations about $0.1 \mathrm{vol} \%$ ) in $\mathrm{H}_{2}$ as a carrier gas.

spectrometric analysis results reported by Ban and Gilbert [6]. With the aid of the thermochemical data a number of reactions that can take place on or near the substrate are summarized in the Appendix. As discussed in the Appendix, reasonable assumptions could be made for the initial states of nucleation, leading to an expression for the silicon adatom concentration (A-15):

$\frac{\mathrm{n}_{1}}{\mathrm{n}_{0}}=\frac{\mathrm{K}_{3} \mathrm{PSiCl}_{2}}{\mathrm{k}_{\mathrm{B}}\left(1+\mathrm{K}_{3} \mathrm{PSiCl}_{2}+\mathrm{K}_{10} \mathrm{P}_{\left.\mathrm{H}_{2}{ }^{2}\right)}^{2}\right.}$. 


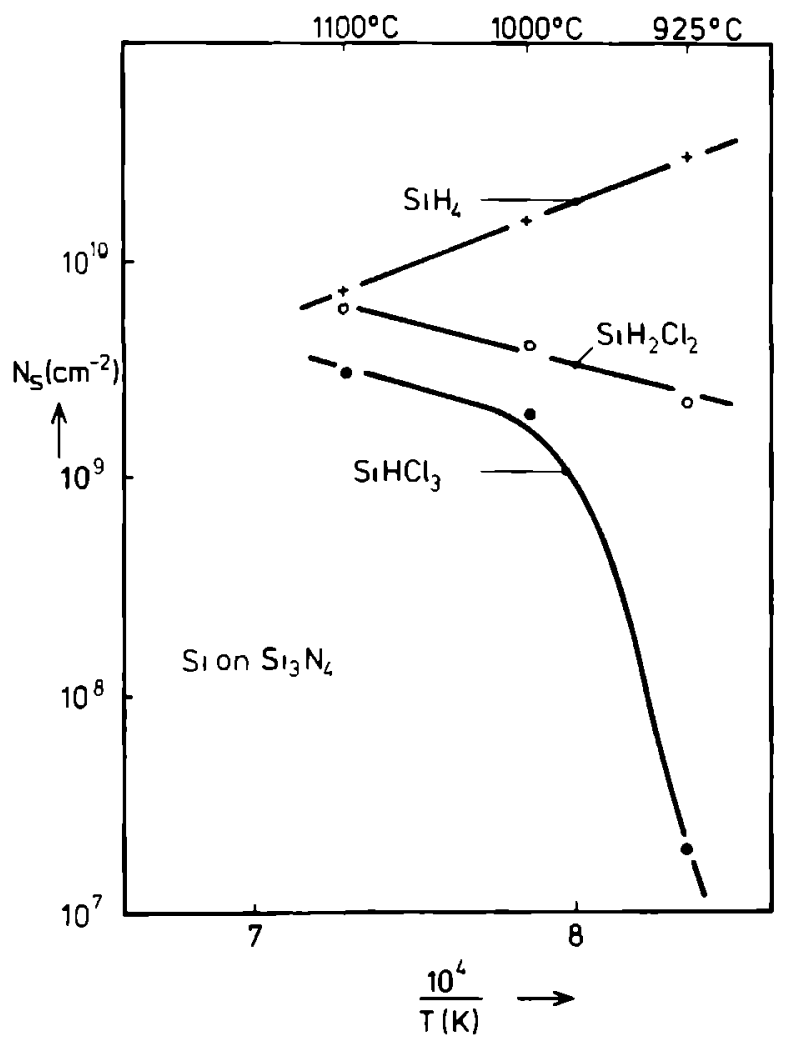

Figure 8

Saturation densittes on $\mathrm{St}_{3} \mathrm{~N}_{4}$ substrates for $\mathrm{SLH}_{4}, \mathrm{SLH}_{2} \mathrm{Cl}_{2}$ and $\mathrm{SLHCl}_{3}$ in $\mathrm{H}_{2}$ as a carrier gas (all concentrations about $01 \mathrm{vol} \%$ ) as a function of temperature

The dissociation of $\mathrm{SiH}_{2} \mathrm{Cl}_{2}$ to $\mathrm{SiCl}_{2}$ and $\mathrm{H}_{2}$ (A-1) followed by a very strong adsorption of $\mathrm{SiCl}_{2}$ compared to $\mathrm{SiH}_{2} \mathrm{Cl}_{2}$ plays an important role in obtaining this expression The decomposition parameter $\alpha$ of reaction $\mathrm{A}-1$ can be defined by

$$
\begin{aligned}
& \mathrm{PS}_{\mathrm{S}_{2}} \mathrm{Cl}_{2}=(1-\alpha) \mathrm{PSiH}_{2} \mathrm{Cl}_{2} \text { (b) }
\end{aligned}
$$

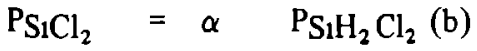

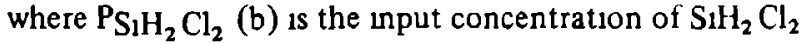
If the equilibrium partial pressure of $\mathrm{SiCl}_{2}$ is much higher than that of $\mathrm{SiH}_{2} \mathrm{Cl}_{2}$ it can be assumed that the decomposition of $\mathrm{SiH}_{2} \mathrm{Cl}_{2}$ into $\mathrm{SiCl}_{2}$ and $\mathrm{H}_{2}$ is almost complete $\left(\alpha \cong 1\right.$ ) (Figure 10 ) For a $\mathrm{H}_{2} \cdot \mathrm{N}_{2}$ mxxture we obtain, by introducing the decomposition parameter $\alpha$ into equation (2) 


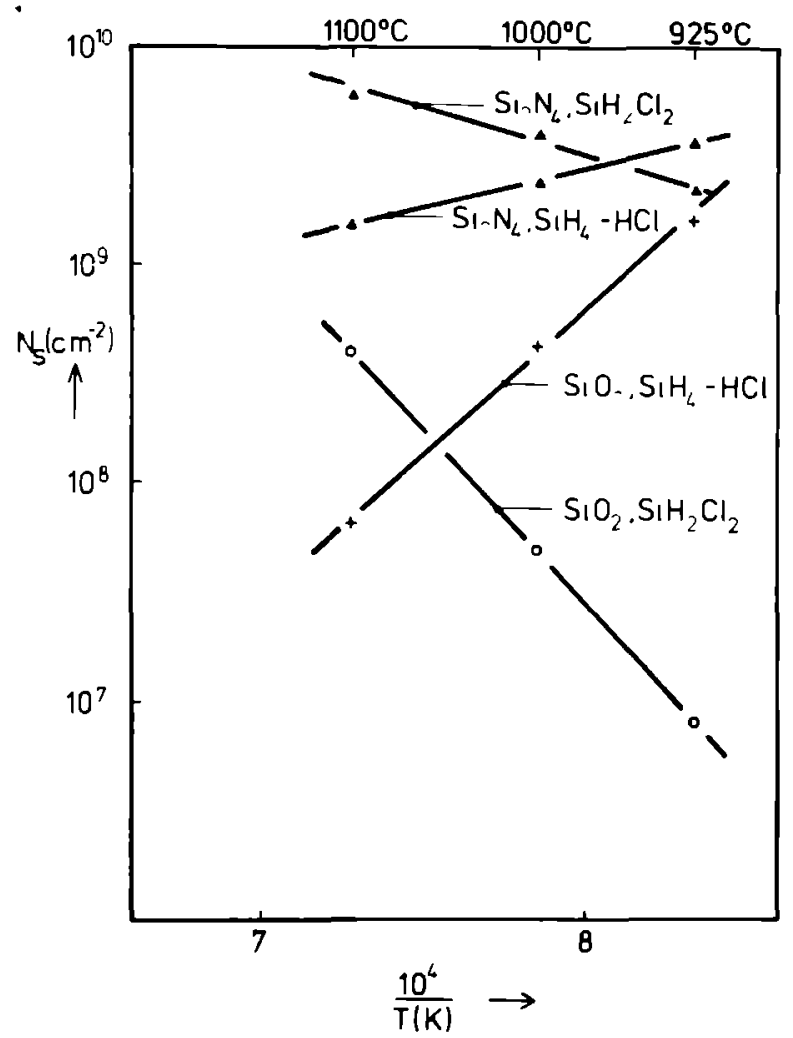

Figure 9.

Saturation nucleus densities on $\mathrm{SiO}_{2}$ and $\mathrm{Si}_{3} \mathrm{~N}_{4}$ substrates as a function of temperature for $0.1 \mathrm{vol}$. \% $\mathrm{SiH}_{2} \mathrm{Cl}_{2}$ and a mixture of $0.1 \mathrm{vol}$. \% $\mathrm{SiH}_{4}$ and $0.2 \mathrm{vol}$. $\% \mathrm{HCl}$.

$$
\frac{n_{1}}{n_{0}}=\frac{A \alpha P_{S_{i H}} C l_{2}(b)}{\left(1+K_{3} \alpha P_{S_{i H}} C l_{2}(b)+K_{10} P_{H_{2}^{1 / 2}}\right)}
$$

where $A=K_{3} / k_{8}$.

Equation (4) for the silicon adatom concentration can also be used if no $\mathrm{H}_{2}$ is added deliberately. In that case $\mathbf{P}_{\mathbf{H}_{2}}$ is given by the equilibrium partial pressure of $\mathrm{H}_{2}$ (proportional to $\alpha \mathrm{PSiH}_{2} \mathrm{Cl}_{2}$ (b)). 

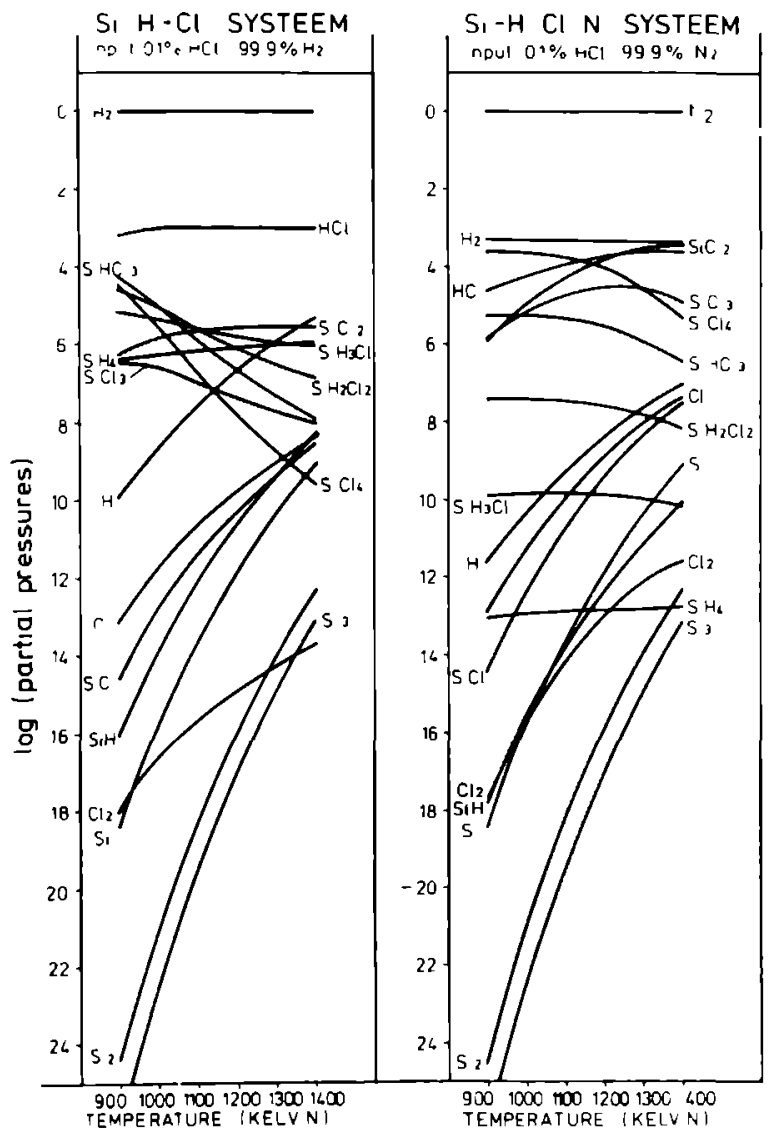

Figure 10

Thermodynamic data for the $\mathrm{St}_{t} \mathrm{HCl}$ and the $\mathrm{St} \mathrm{N}-\mathrm{HCl}$ systems as a function of temperature and an input of $1 \mathrm{vol} \% \mathrm{HCl}$

\section{Interpretation of results}

\section{The $\mathrm{SiH}_{2} \mathrm{Cl}_{2} \cdot \mathrm{H}_{2} \cdot \mathrm{N}_{2}$ system}

It was concluded that expressions given by Venables $[3,7]$ can be used to characterize the saturation density of stable clusters $\left(\mathrm{N}_{S}\right)$ in the present case where incomplete condensation of silicon has to be assumed Because of the exustence of an uncubation period before the actual nucleation starts, it is thought probable that an equlibrium concentration of silicon adatoms can buld up prior to the first nucleation In this period therefore a strong imcomplete condensation regime applies For this situation the relevant expression given by Venables can be rewritten as 
$\frac{N_{s}}{n_{0}} \cong\left(\frac{n_{1}}{n_{0}}\right)^{\frac{i+1}{2}} \exp \left[\left(E_{i}+E_{m}-E_{d}\right) / 2 k T\right]$

where $i$ is the number of atoms in the initial cluster, $n_{1}$ the monomer or adatom concentration and $n_{0}$ denotes the number of surface sites $\left(\cong 10^{14} \mathrm{~cm}^{-2}\right)$. $E_{i}$ is the heat of formation of a cluster consisting of $i$ atoms, $E_{m}$ is the activation energy for surface diffusion of mobile clusters and $E_{d}$ is the activation energy for surface diffusion of adatoms. As discussed in section $4.1, n_{1} / n_{0}$ can be given as a first approximation by equation (4), leading to

$\frac{\mathrm{n}_{1}}{\mathrm{n}_{0}}=\left\{\frac{\mathrm{A} \alpha \mathrm{PSiH}_{2} \mathrm{Cl}_{2}(\mathrm{~b})}{\left(\left(1+\mathrm{K}_{3} \alpha \mathrm{PSiH}_{2} \mathrm{Cl}_{2}(\mathrm{~b})+\mathrm{K}_{10} \mathrm{P}_{\left.\mathrm{H}_{2}{ }^{\prime 2}\right)}^{2}\right.\right.}\right\}^{\frac{\mathrm{i}+1}{2}} \exp \left[\left(\mathrm{E}_{\mathrm{i}}+\mathrm{E}_{\mathrm{m}}-\mathrm{E}_{\mathrm{d}}\right) / 2 \mathrm{kT}\right]$

where $\mathrm{A}$ is a constant, $\alpha$ is the decomposition parameter and $\mathrm{PSiH}_{2} \mathrm{Cl}_{2}(\mathrm{~b})$ is the input concentration of $\mathrm{SiH}_{2} \mathrm{Cl}_{2}$, the other parameters being as defined before (equation (5)). Starting with the experiments done on $\mathrm{SiO}_{2}$ substrates, it can be observed in Table I that $\mathrm{N}_{\mathrm{S}}$ in the $\mathrm{SiH}_{2} \mathrm{Cl}_{2} \cdot \mathrm{H}_{2}$ system is almost proportional to $\mathrm{PSiH}_{2} \mathrm{Cl}_{2}$ (b). It can thus be concluded that in eq. (6) $\mathrm{K}_{3} \alpha \mathrm{PSiH}_{2} \mathrm{Cl}_{2}$ (b) $<$ $\left(1+\mathrm{K}_{10} \mathrm{P}_{\mathrm{H}_{2}}{ }^{2}\right)$, and moreover $\mathrm{i}=1$ for the temperature range between $925^{\circ}-$ $1100^{\circ} \mathrm{C}$. If $\mathrm{i}=1$ for the $\mathrm{SiH}_{2} \mathrm{Cl}_{2} \cdot \mathrm{H}_{2}$ system, it is acceptable that in all other cases where the saturation nucleus density is higher one will also have $\mathrm{i}=1$. If furthermore $\mathrm{K}_{3} \propto \mathrm{PSiH}_{2} \mathrm{Cl}_{2}$ (b) $<\left(1+\mathrm{K}_{10} \mathrm{P}_{\mathrm{H}_{2}}^{1}{ }^{2}\right)$ for all $\mathrm{H}_{2}-\mathrm{N}_{2}$ mixtures we obtain, from equation (6), for a fixed temperature

$\frac{N_{s}}{n_{0}}=\frac{A \alpha P_{S i H_{2}} C l_{2} \text { (b) }}{1+K_{10} P_{\mathrm{H}_{2}}^{1 / 2}}$

The experimental data given in Figure 4 by plotting $\log \left(\mathrm{N}_{\mathrm{S}} / \mathrm{PSiH}_{2} \mathrm{Cl}_{2}\right.$ (b)) versus $\log$ $\left(\mathrm{P}_{2}\right)$ can now be analysed. At $1100^{\circ} \mathrm{C}$ we observe a tangent which is almost $1 / 2$ for all $\mathrm{H}_{2}-\mathrm{N}_{2}$ mixtures, from which it may be concluded that adsorption of atomic hydrogen plays an important role in nucleation kinetics on $\mathrm{SiO}_{2}$ substrates $\left(\mathrm{K}_{10} \mathrm{P}_{\mathrm{H}_{2}}^{1 / 2}>1\right)$. Equation (7) can be used for the $\mathrm{SiH}_{2} \mathrm{Cl}_{2}-\mathrm{N}_{2}$ system by introducing the equilibrium partial pressure of $\mathrm{H}_{2}$. This is done in Figure 4, and the results show that $\alpha$ is close to unity in accordance with the thermochemical data in Figure $10\left(\mathrm{PH}_{2} \cong \mathrm{PSiH}_{2} \mathrm{Cl}_{2}\right.$ (b)). At lower temperatures the tangent in Figure 4 is only $1 / 2$ for the lowest hydrogen pressures and the deviation from the slope $1 / 2$ is strongest at $925^{\circ} \mathrm{C}$. Especially at the lower temperatures the assumption $\mathrm{K}_{10} \mathrm{P}_{\mathrm{H}_{2}}^{\mathbf{2}_{2}}>$ $\left(1+\mathrm{K}_{3} \propto \mathrm{PSiH}_{2} \mathrm{Cl}_{2}\right.$ (b)) remains acceptable. For $\mathrm{SiO}_{2}$ substrates an additional decrease in $\mathrm{N}_{\mathrm{S}}$ then has to be found in a lower value of $\alpha$. At lower temperatures and the highest hydrogen pressures, therefore, hydrogen adsorption is no longer the 
only factor that determines the saturation density. According to Figure 10, the dissociation of $\mathrm{SiH}_{2} \mathrm{Cl}_{2}$ into $\mathrm{SiCl}_{2}$ and $\mathrm{H}_{2}$ becomes more difficult under these experimental conditions, leading to the smaller value of $\alpha$. If the decrease in saturation density is only caused by a decrease in $\alpha$ and if $\alpha \cong 1$ at $1000^{\circ} \mathrm{C}$, we calculate an effective value of $\alpha=10^{-2}$ at $925^{\circ} \mathrm{C}$ using Figure 4 .

For the $\mathrm{Si}_{3} \mathrm{~N}_{4}$ substrates equation (6) can also describe the experimental data given in Figures 1, 5 and 6. If we compare Figures 2 and 5, where the saturation nucleus density is plotted for hydrogen and nitrogen as a carrier gas, on $\mathrm{SiO}_{2}$ and $\mathrm{Si}_{3} \mathrm{~N}_{4}$ substrates, it can be observed that hydrogen adsorption on $\mathrm{Si}_{3} \mathrm{~N}_{4}$ substrates could play a role but to a lesser degree than on $\mathrm{SiO}_{2}$ substrates. By plotting log $\left(\mathrm{N}_{\mathrm{S}} / \mathrm{PSiH}_{2} \mathrm{Cl}_{2}\right.$ (b)) versus $\log \left(\mathrm{P}_{\mathrm{H}_{2}}\right)$ (Figure 6) we observe that the tangent in this figure is less than $1 / 2$ at $1000^{\circ} \mathrm{C}$, leading to the conclusion that the assumption $\mathrm{K}_{10} \mathrm{P}_{\mathrm{H}_{2}}^{1 / 2}>\left(1+\mathrm{K}_{3} \alpha \mathrm{PSiH}_{2} \mathrm{Cl}_{2}(\mathrm{~b})\right)$ is not acceptable in this case, adsorption of $\mathrm{SiCl}_{2}$ thus cannot be neglected.

It may be concluded that the difference in saturation nucleus densities between $\mathrm{SiO}_{2}$ and $\mathrm{Si}_{3} \mathrm{~N}_{4}$ substrates in a hydrogen medium is caused by strong adsorption of atomic hydrogen, especially on $\mathrm{SiO}_{2}$ substrates. According to the JANAF tables [8] the $\mathrm{OH}$ bond energy is stronger than the $\mathrm{NH}$ bond by about $20 \mathrm{kcal} / \mathrm{mole}$. This difference in bond energy is sufficient to explain the experimental data.

4.2.2 Comparison between different silicon-containing compounds in a $\mathrm{H}_{2}$ medium

Figures 7 and 8 give saturation densities of silicon clusters for $\mathrm{SiO}_{2}$ and $\mathrm{Si}_{3} \mathrm{~N}_{4}$ substrates, respectively for $\mathrm{SiH}_{4}, \mathrm{SiH}_{2} \mathrm{Cl}_{2}$ and $\mathrm{SiHCl}_{3}$ (all concentrations about 0.1 vol. \%) in hydrogen as a carrier gas. If we start with the $\mathrm{SiO}_{2}$ substrate a remarkable difference between the $\mathrm{SiH}_{4}-\mathrm{H}_{2}$ and the $\mathrm{SiH}_{2} \mathrm{Cl}_{2}-\mathrm{H}_{2}$ system is observed. As discussed in section 4.2.1., the presence of hydrogen hampers the dissociation of $\mathrm{SiH}_{2} \mathrm{Cl}_{2}$, and moreover adsorption of atomic hydrogen on $\mathrm{SiO}_{2}$ blocks the adsorption for silicon species, as a consequence of which the saturation density decreases with decreasing temperature. In the $\mathrm{SiH}_{4}-\mathrm{H}_{2}$ system, hydrogen adsorption does not determine nucleation kinetics in the temperature range under discussion. At temperatures below $900^{\circ} \mathrm{C}$ hydrogen adsorption also becomes important for $\mathrm{SiH}_{4}$ on $\mathrm{SiO}_{2}$ substrates, which results in a decrease of the saturation density with de. creasing temperatures for the $\mathrm{SiH}_{4} \cdot \mathrm{H}_{2}$ system as well [3]. The $\mathrm{SiHCl}_{3} \cdot \mathrm{H}_{2}$ system behaves like the $\mathrm{SiH}_{2} \mathrm{Cl}_{2}$ system, but shows a lower saturation nucleus density than the former system. Nucleation is more difficult than for the $\mathrm{SiH}_{2} \mathrm{Cl}_{2} \cdot \mathrm{H}_{2}$ system, due to a smaller decomposition parameter. For $\mathrm{Si}_{3} \mathrm{~N}_{4}$ substrates the difference between the $\mathrm{SiH}_{2} \mathrm{Cl}_{2}-\mathrm{H}_{2}$ system and the $\mathrm{SiH}_{4}-\mathrm{H}_{2}$ system is smaller than for the $\mathrm{SiO}_{2}$ substrates (Figure 8). This can be understood because we have seen that hydrogen adsorption plays a less important role on $\mathrm{Si}_{3} \mathrm{~N}_{4}$ substrates in the $\mathrm{SiH}_{2} \mathrm{Cl}_{2} \cdot \mathrm{H}_{2}$ system, and in the $\mathrm{SiH}_{4} \cdot \mathrm{H}_{2}$ system hydrogen adsorption does not come into play. The strong decrease of the saturation density at temperatures 
below $1000{ }^{\circ} \mathrm{C}$ in the $\mathrm{SiHCl}_{3}-\mathrm{H}_{2}$ system also has to be explained by a decrease of the $\mathrm{SiCl}_{2}$ concentration in the gas phase.

Introduction of $\mathrm{HCl}$ to the $\mathrm{SiH}_{4}-\mathrm{H}_{2}$ system decreases the saturation nucleus density, but down to $900{ }^{\circ} \mathrm{C}$ this density still increases with decreasing temperature (Figure 9). In the $\mathrm{SiH}_{4} \cdot \mathrm{HCl}-\mathrm{H}_{2}$ system etching of $\mathrm{Si}$ adatoms by $\mathrm{HCl}$ occurs, whereas in the $\mathrm{SiH}_{2} \mathrm{Cl}_{2}-\mathrm{H}_{2}$ system as discussed in the Appendix, hardly any free $\mathrm{HCl}$ is present before the onset of nucleation. The greater critical cluster size, which varies from 1 to approximately 4 for the $\mathrm{SiH}_{4} \cdot \mathrm{HCl} \cdot \mathrm{H}_{2}$ system, could also be explained in terms of the etching of $\mathrm{Si}$ adatoms by $\mathrm{HCl}$ giving $\mathrm{SiCl}_{2}$ [3]. The difference in nucleation on $\mathrm{SiO}_{2}$ and $\mathrm{Si}_{3} \mathrm{~N}_{4}$ substrates in the $\mathrm{SiH}_{4}-\mathrm{HCl}-\mathrm{H}_{2}$ and $\mathrm{SiH}_{2} \mathrm{Cl}_{2}$ systems are ultimately traced back to the difference in the steady state concentration of silicon adatoms on the substrates prior to the actual nucleation.

\section{Conclusions}

In an attempt to understand and be able to monitor the crystallite size of polycrystalline silicon layers we have studied the nucleation of silicon on various substrates for different silicon-containing compounds as a function of gas phase composition and temperature. Experiments with nucleation of silicon on $\mathrm{SiO}_{2}$ and $\mathrm{Si}_{3} \mathrm{~N}_{4}$ substrates were reported for the $\mathrm{SiH}_{2} \mathrm{Cl}_{2} \cdot \mathrm{H}_{2} \cdot \mathrm{N}_{2}$ system in the temperature range of $800^{\circ}-1100^{\circ} \mathrm{C}$. The differences and conformities between the $\mathrm{SiH}_{4} \cdot \mathrm{H}_{2} \cdot \mathrm{HCl}, \mathrm{SiHCl}_{3} \cdot \mathrm{H}_{2}$ and the $\mathrm{SiH}_{2} \mathrm{Cl}_{2} \cdot \mathrm{H}_{2}$ systems were also discussed. As far as the $\mathrm{SiH}_{2} \mathrm{Cl}_{2} \cdot \mathrm{H}_{2} \cdot \mathrm{N}_{2}$ system is concerned it is observed that the saturation nucleus densities on $\mathrm{SiO}_{2}$ and $\mathrm{Si}_{3} \mathrm{~N}_{4}$ substrates are almost the same for nitrogen as a carrier gas, and these densities are barely a function of temperature. Introduction of hydrogen strongly reduces the saturation nucleus density and this decrease is much stronger for $\mathrm{SiO}_{2}$ than for $\mathrm{Si}_{3} \mathrm{~N}_{4}$ substrates, resulting in a decrease of the saturation nucleus density with decreasing temperatures. Further the temperature dependence of the formation process increases with increasing hydrogen pressures. The experimental data can be explained from an analysis of the silicon adatom concentration on the surface as a function of gas phase composition and temperature. Application of an expression for the saturation nucleus density as obtained by Venables gives an indication of the size of the critical cluster, which seems to be 1 for all $\mathrm{SiH}_{2} \mathrm{Cl}_{2}$ mixtures under discussion. The differences between the $\mathrm{SiH}_{4}-\mathrm{H}_{2} \cdot \mathrm{HCl}$, the $\mathrm{SiH}_{4}-\mathrm{H}_{2}$ the $\mathrm{SiHCl}_{3} \cdot \mathrm{H}_{2}$ and the $\mathrm{SiH}_{2} \mathrm{Cl}_{2} \cdot \mathrm{H}_{2}$ systems are remarkable. For $\mathrm{SiHCl}_{3}$ and $\mathrm{SiH}_{2} \mathrm{Cl}_{2}$ the saturation density of silicon clusters decreases with decreasing temperature, whereas for the $\mathrm{SiH}_{4} \cdot \mathrm{HCl}-\mathrm{H}_{2}$ and $\mathrm{SiH}_{4}-\mathrm{H}_{2}$ systems the opposite occurs. Formation of $\mathrm{SiCl}_{2}$ by dissociation of $\mathrm{SiH}_{2} \mathrm{Cl}_{2}$ or $\mathrm{SiHCl}_{3}$ becomes more difficult at decreasing temperatures, leading to a smaller steady state concentration of silicon adatoms at lower temperatures.

\section{Acknowledgements}

The authors wish to thank $H$. Haanstra and members of his group for the SEM and TEM photomicrographs. 


\section{APPENDIX:}

\section{REACTION SCHEME FOR THE $\mathrm{SiH}_{2} \mathrm{Cl}_{2}-\mathrm{H}_{2}-\mathrm{N}_{2}$ SYSTEM}

According to the thermochemical data in Figure 10 the main processes which take place on or near the surface can be summarized as follows:

a. Supply of $\mathrm{SiH}_{2} \mathrm{Cl}_{2}$ by means of gas phase diffusion:

$$
\mathrm{SiH}_{2} \mathrm{Cl}_{2} \text { (b) } \stackrel{\mathrm{k}_{\mathrm{a}}}{\rightarrow} \mathrm{SiH}_{2} \mathrm{Cl}_{2}(\mathrm{~g})
$$

$\mathrm{SiH}_{2} \mathrm{Cl}_{2}$ (b) is the input concentration of $\mathrm{SiH}_{2} \mathrm{Cl}_{2}$ and $\mathrm{SiH}_{2} \mathrm{Cl}_{2}$ (g) is the concentration of $\mathrm{SiH}_{2} \mathrm{Cl}_{2}$ near the surface.

b. Dissociation of $\mathrm{SiH}_{2} \mathrm{Cl}_{2}$ in the gas phase:

$$
\mathrm{SiH}_{2} \mathrm{Cl}_{2}(\mathrm{~g}) \underset{\mathrm{k}_{-1}}{\stackrel{\mathrm{k}_{1}}{\rightleftharpoons}} \mathrm{SiCl}_{2}(\mathrm{~g})+\mathrm{H}_{2}(\mathrm{~g})
$$

c. Adsorption of $\mathrm{SiH}_{2} \mathrm{Cl}_{2}$ and $\mathrm{SiCl}_{2}$ on a free surface site (denoted by *) and dissociation of $\mathrm{SiH}_{2} \mathrm{Cl}_{2}$ *:

$$
\begin{aligned}
& *+\mathrm{SiH}_{2} \mathrm{Cl}_{2}(\mathrm{~g}) \underset{\mathrm{k}_{-2}}{\stackrel{\mathrm{k}_{2}}{\rightleftharpoons}} \mathrm{SiH}_{2} \mathrm{Cl}_{2} * \\
& *+\mathrm{SiCl}_{2}(\mathrm{~g}) \stackrel{\mathrm{k}_{3}}{\stackrel{\mathrm{k}_{-3}}{\rightleftharpoons}} \mathrm{SiCl}_{2}^{*} \\
& \mathrm{SiH}_{2} \mathrm{Cl}_{2} * \underset{\mathrm{k}_{4}}{\stackrel{\mathrm{k}_{4}}{\rightleftharpoons}} \mathrm{SiCl}_{2} *+\mathrm{H}_{2}(\mathrm{~g}) .
\end{aligned}
$$

d. Formation of Si adatoms on the surface:

$$
\begin{aligned}
& \mathrm{SiH}_{2} \mathrm{Cl}_{2} \stackrel{\stackrel{\mathrm{k}_{5}}{\rightleftharpoons}}{\stackrel{\mathrm{k}_{5}}{\rightleftharpoons}} \mathrm{Si}^{*}+2 \mathrm{HCl}(\mathrm{g}) \\
& \mathrm{SiCl}_{2} *+\mathrm{H}_{2}(\mathrm{~g}) \underset{\mathrm{k}_{-6}}{\stackrel{\mathrm{k}_{6}}{\rightleftharpoons}} \mathrm{Si}^{*}+2 \mathrm{HCl}(\mathrm{g}) .
\end{aligned}
$$


e. Formation of stable silicon clusters by diffusion of Si adatoms on the surface:

$$
\mathrm{Si}^{*} \stackrel{\mathrm{k}_{7}}{\rightleftharpoons} \mathrm{Si}(\mathrm{s}) \text {. }
$$

f. Reaction of Si adatoms with hydrogen:

$$
\mathrm{Si}^{*}+\mathrm{H}_{2} \underset{\mathrm{k}_{-8}}{\stackrel{\mathrm{k}_{\beta}}{\rightleftharpoons}} \mathrm{SiH}_{2}^{*}
$$

g. Adsorption of hydrogen and chlorine:

$$
\begin{aligned}
& *+\mathrm{HCl}(\mathrm{g}) \underset{\mathrm{K}_{-9}}{\stackrel{\mathrm{k}_{9}}{\rightleftharpoons}} \mathrm{Cl}^{*}+1 / 2 \mathrm{H}_{2}(\mathrm{~g}) \\
& 1 / 2 \mathrm{H}_{2}(\mathrm{~g})+\underset{\mathrm{k}_{-10}}{\stackrel{\mathrm{k}_{10}}{\rightleftharpoons}} \mathrm{H}^{*} .
\end{aligned}
$$

Formation of chlorosilanes other than $\mathrm{SiCl}_{2}$, such as $\mathrm{SiHCl}_{3}$ and $\mathrm{SiCl}_{4}$, can be left out of consideration, at least in the initial stage of nucleation, where practically no $\mathrm{HCl}$ is present. The notation ( $\mathrm{g}$ ) will only be used when comparison with bulk values of the vapour pressure is made.

The total number of reactions can be decreased by judging the various parameters in view of experimental results and thermochemical data. The following assumptions can be made.

a. Because hardly any $\mathrm{HCl}$ is present in the initial stage of nucleation, the back reaction $\mathrm{k}_{-5}$ and $\mathrm{k}_{-6}$ can be neglected and also $\left[\mathrm{Cl}^{*}\right]$ can be treated as small.

b. Nucleation and growth experiments in the $\mathrm{SiH}_{4} \cdot \mathrm{HCl} \cdot \mathrm{H}_{2}$ system lead to the conclusion that silicon adatoms [ $\mathrm{Si}^{*}$ ] are needed to arrive at nucleation [3] .

c. Gas phase dissociation of $\mathrm{SiH}_{2} \mathrm{Cl}_{2}$ to $\mathrm{SiCl}_{2}$ and $\mathrm{H}_{2}$ occurs at temperatures above $800^{\circ} \mathrm{C}$. This is according to Smith and Sedgwick [9] who performed in situ measurements using inelastic light scattering and obtained spectra of $\mathrm{SiCl}_{2}$ in a R.F. heated reactor in the $\mathrm{SiH}_{2} \mathrm{Cl}_{2} \cdot \mathrm{H}_{2}$ system.

d. The nucleation starts via the adsorption of $\mathrm{SiCl}_{2}$ or via adsorption of $\mathrm{SiH}_{2} \mathrm{Cl}_{2}$ In order to discriminate between adsorption of $\mathrm{SiH}_{2} \mathrm{Cl}_{2}$ and $\mathrm{SiCl}_{2}$ we have to notice that $\mathrm{SiH}_{2} \mathrm{Cl}_{2}$ is a fully coordinated molecule with four atoms bonded in a tetrahedral configuration. If $\mathrm{SiH}_{2} \mathrm{Cl}_{2}$ adsorbs without dissociation, then a peripheral hydrogen or chlorine atom has to come into contact with the surface. In the non-linear $\mathrm{SiCl}_{2}$ molecule the silicon atom is not sterically blocked from the surface of the substrate, and the presence of the unbonded electrons on the silicon greatly enhances its adsorption by interaction with the dangling bonds on 
the surface [10]. It can therefore be concluded that the adsorption energy of $\mathrm{S}_{1} \mathrm{H}_{2} \mathrm{Cl}_{2}$ is much smaller than that of $\mathrm{SiCl}_{2}$ This means that (A-2), (A-4) and (A-5) can be left out of consideration With the above approximations the steady state concentrations of $\left[\mathrm{Si}^{*}\right]$ and $\left[\mathrm{SiCl}_{2}^{*}\right]$ will be given by

$$
\begin{aligned}
& \mathrm{n}_{1}=\left[\mathrm{S}^{*}\right]=\frac{\mathrm{k}_{6}\left[\mathrm{~S}_{1 C_{2}}{ }^{*}\right] \mathrm{P}_{\mathrm{H}_{2}}+\mathrm{k}_{-8}\left[\mathrm{~S}_{1} \mathrm{H}_{2}{ }^{*}\right]}{\mathrm{k}_{7}+\mathrm{k}_{8} \mathrm{P}_{\mathrm{H}_{2}}} \\
& {\left[\mathrm{~S}_{1} \mathrm{Cl}_{2}{ }^{*}\right]=\frac{\mathrm{k}_{3} \mathrm{PS}_{\mathrm{SCl}_{2}}[*]}{\mathrm{k}_{.3}+\mathrm{k}_{6} \mathrm{PH}_{2}}}
\end{aligned}
$$

As for the $\mathrm{S}_{1} \mathrm{H}_{4}-\mathrm{HCl}-\mathrm{H}_{2}$ system [3] the nucleus density very quickly reaches a saturation density, with respect to exposure tume, after an incubation period On the basis of these experiments it was assumed that the time needed to attain the population of adatoms is small, giving a constant value of $n_{1}$ before nucleation occurs. This means that $k_{7}$ can be omitted until nucleation takes place. The second term in the nominator, the indirect formation of $\mathrm{Si}^{*}$, can be assumed to be small compared to the first term and can be neglected. The sulicon adatom concentration will be much smaller than the concentration of adsorbed $\mathrm{SiCl}_{2}$ molecules, therefore it can be assumed that $\mathrm{k}_{-3}>\mathrm{k}_{6} \mathrm{P}_{\mathrm{H}_{2}}$. With these approximations one obtains

$$
\mathrm{n}_{1}=\frac{\mathrm{k}_{6} \mathrm{~K}_{3} \mathrm{P}_{\mathrm{SlCl}_{2}}[*]}{\mathrm{k}_{\mathrm{B}}}
$$

For the concentration of free surface sites we can wnte

$$
[*]=\mathrm{n}_{0}-\left[\mathrm{Si}^{*}\right]-\left[\mathrm{S}_{1} \mathrm{Cl}_{2}{ }^{*}\right]-\left[\mathrm{H}^{*}\right]-\left[\mathrm{S}_{1} \mathrm{H}_{2}^{*}\right]
$$

where $n_{0}$ is the total number of sites per unit area

With $\left[\mathrm{H}^{*}\right]=\mathrm{K}_{10} \mathrm{P}_{\mathrm{H}_{2}}^{1}{ }^{2}[*], \mathrm{K}_{10}=\mathrm{k}_{10} / \mathrm{k}_{-10},\left[\mathrm{~S}_{1} \mathrm{Cl}_{2}{ }^{*}\right]=\mathrm{K}_{3} \mathrm{P}_{\mathrm{S}_{1} \mathrm{Cl}_{2}}[*], \mathrm{K}_{3}=\mathrm{k}_{3} / \mathrm{k}_{.3}$ and $\left[\mathrm{Si}^{*}\right],\left[\mathrm{S}_{1} \mathrm{H}_{2}{ }^{*}\right] \leqslant\left[\mathrm{S}_{1} \mathrm{Cl}_{2}^{*}\right]$, this leads to

$$
[*]=\frac{n_{0}}{\left(1+K_{3} P_{S_{1} C l}+K_{10} P_{H_{2}}^{1 / 2}\right)} \text {. }
$$

The silicon adatom concentration can now be given by

$$
\frac{n_{1}}{n_{0}}=\frac{K_{3} k_{6} P_{S_{1} C_{2}}}{k_{8}\left(1+K_{3} P_{S_{1} C_{2}}+K_{10} P_{H_{2}^{1 / 2}}^{1 / 2}\right)}
$$




\section{References}

1 See for example: T.I. Kamins, IEEE Trans. PHP. 10, 221 (1974).

2 P.H. Robinson and N. Goldsmith, J. Elec. Mat. 4, 313 (1975). V.S. Ban, J. Electrochem. Soc. 122, 1398 (1975).

3 W.A.P. Claassen and J. Bloem, J. Electrochem. Soc. 127, 194 (1980).

4 J. Bloem and W.A.P. Claassen, J. Cryst. Growth, in press.

5 P. van der Putte, L.J. Giling and J. Bloem, J. Cryst. Growth 41, 133 (1977).

6 V.S. Ban and S.L. Gilbert, J. Electrochem. Soc. 122, 1382 (1975).

7 J.A. Venables, Phil. Mag. 27, 697 (1973).

8 JANAF Thermochemical Tables 2nd ed. June 1971, NSRDS-NBS-37.

9 J.E. Smith Jr., and T.O. Sedgwick, Thin Solid Films 40, 1 (1977).

10 A.A. Chernov, J. Cryst. Growth 42, 55 (1977). 


\title{
CHAPTER V
}

\section{RATE-DETERMINING REACTIONS AND SURFACE SPECIES IN CVD OF SILICON}

\author{
I The $\mathrm{SiH}_{4}-\mathrm{HCl}-\mathrm{H}_{2}$ system
}

\author{
Summary
}

CVD of silicon from 0.1 volume percent $\mathrm{SiH}_{4}$ in hydrogen shows a growth rate that does not change significantly on addition of $0.4 \% \mathrm{HCl}$ to the gas phase for growth temperatures above $1000^{\circ} \mathrm{C}$. Below $1000^{\circ} \mathrm{C}$, however, this addition causes a vastly reduced growth rate compared to the growth from $\mathrm{SiH}_{4}$ alone. This behaviour produces experimental information on the possible rate-limiting steps in the lower temperature region. It is concluded that, for $\mathrm{SiH}_{4}$ without $\mathrm{HCl}$, surface diffusion of silicon-containing species and the incorporation on steps on the surface constitutes the rate-determining reaction. At lower temperatures the concentrations of these species increase far above the equilibrium values. The introduction of $\mathrm{HCl}$ then changes the adatoms ( $\mathrm{Si}$ and $\mathrm{SiH}_{2}$ ) into $\mathrm{SiCl}_{2}$, subsequent desorption of $\mathrm{SiCl}_{2}$ is responsible for the reduction in growth rate. The mechanism is discussed in terms of recent calculations reported by Chernov et al. [2] on the adsorption of different species on the silicon surface.

\section{Introduction}

In CVD of silicon for the production of monocrystalline silicon layers on silicon substrates the quality of the resulting layers is of prime importance. In order to achieve a deposit of higher quality deposition temperatures above $1050^{\circ} \mathrm{C}$ are generally used. Under these circumstances the surface reactions are sufficiently rapid and it is the supply of reactants that determines the growth rate via gas phase diffusion. Hydrogen is preferred as a carrier gas, to bring about the reduction of silicon halides, to reduce homogeneous gas phase nucleation of $\mathrm{SiH}_{4}$ and to minimize the undesired effects of oxygen on nucleation and growth. This hightemperature regime has been the subject of much study, and reasonable models are available to explain the growth rate in this regime [1]. As to the situation at temperatures below $900-1000^{\circ} \mathrm{C}$ there is less confidence in our knowledge, and speculative models are used to describe the growth, which is controlled by surface reactions of unknown origin. Recently, Chemov et al. [2] calculated the adsorption energy of $\mathrm{H}, \mathrm{Cl}, \mathrm{SiCl}_{2}$ and other species that could be present on the silicon surface. They found an extremely high surface coverage of especially $\mathrm{H}$ and $\mathrm{Cl}$ ( $~ 99 \%$ ), because of their high energy of adsorption of 71.4 and about $100 \mathrm{kcal}$ / mole respectively. It was stressed by Chernov [2] that this high surface coverage could hamper the diffusion of adatoms on the silicon surface. The influence of this adsorption on crystal growth could be one of the reasons why layers grown below $900{ }^{\circ} \mathrm{C}$ in a hydrogen ambient tend to become polycrystalline whereas in a $\mathrm{He}$ ambient or at reduced pressures still monocrystalline layers can be produced. This is the more so at UHV conditions where the growth of monocrystalline layers is still possible at appreciably lower temperatures [3]. In these UHV systems not only 
hydrogen adsorption is minimized, it is also much easier to control the presence of oxide on the silicon surface The reason is found in the extremely low background oxygen and water vapour pressures possible at UHV conditions

Experiments were therefore planned to obtain information on the low temperature growth kinetics, mainly by studying growth and etching in the $\mathrm{SiH}_{4} \mathrm{HCl}$ system It will be shown in the present study that experiments at lower temperatures give indications on the specific surface reaction responsible for the reduced growth rate below $1000{ }^{\circ} \mathrm{C}$

\section{Experımental results}

It has been shown [4] that, at high temperatures where chemical equllbrium at the slucon surface can be expected, growth by $\mathrm{SiH}_{4}$ and etching by $\mathrm{HCl}$ can be taken to proceed independently of each other The growth rate could be given as

$\mathrm{R}=\mathrm{k}_{\mathrm{a}} \mathrm{PS}_{\mathrm{S}} \mathrm{H}_{4}-\mathrm{k}_{\mathrm{b}} \mathrm{P}_{\mathrm{HCl}}^{2}$

The quadratic term in $\mathrm{P}_{\mathrm{HCl}}$ is caused by the main reaction product being $\mathrm{S}_{1} \mathrm{Cl}_{2}$ and the circumstances that only a fraction of the $\mathrm{HCl}$ that is present reacts to form $\mathrm{SiCl}_{2}$ It has been shown by Van der Putte et al [5] that the etching of slicon proceeds via the attack by $\mathrm{HCl}$ on surface steps and the subsequent diffusion and desorption of $\mathrm{SiCl}_{2}$ molecules The experimental evidence shows that 01 volume percent $\mathrm{SiH}_{4}$ in hydrogen shows a growth rate of about $03 \mu \mathrm{m} / \mathrm{mm}$ at $1000^{\circ} \mathrm{C}$, whereas $04 \% \mathrm{HCl}$ in hydrogen gives an etch rate of only $002 \mu \mathrm{m} / \mathrm{min}$ at $100{ }^{\circ} \mathrm{C}$ For a muxture with an input concentration of slane of $01 \%$ and a fourfold $\mathrm{HCl}$ concentration (resembling the input of $\mathrm{SiCl}_{4}$ in hydrogen) the growth rate at $100{ }^{\circ} \mathrm{C}$ within a few percent equals the growth rate given by $\mathrm{SiH}_{4}$ alone It was assumed at that time that these results could be extrapolated to temperatures below $900{ }^{\circ} \mathrm{C} \mathrm{[6]}$ The present experments were performed in a conventional air cooled, RF-heated fused slica reactor The silicon slices were heated on a $\mathrm{S} 1 \mathrm{C}$ coated graphite susceptor A typical gas flow rate of $60 \mathrm{~cm} / \mathrm{sec}$ was used in order to obtain stable laminar flow conditions The hydrogen carner gas was punfied by means of a conventional gas punfier to a water and oxygen content below $1 \mathrm{ppm}$ The carner gas as well as the reactants (electronic grade $\mathrm{HCl}$ and $5 \% \mathrm{~S}_{1} \mathrm{H}_{4} \mathrm{in}_{2}$ ) were introduced va automatic flow controllers Growth and etch rates were determuned by means of IR interference measurements on grown layers or from the decrease in thickness of layers with accurately known thuckness Temperature measurements were done by optical pyrometry using the surface temperature of slicon slices, after correction for the emissivity of sulicon and the absorption of the reactor wall Pror to the growth or etchung experuments the slicon wafers were treated at $1100^{\circ} \mathrm{C}$ for 3 minutes with $04 \% \mathrm{HCl}$ in $\mathrm{H}_{2}$ to remove $005 \mu \mathrm{m}$ from the surface Firstly the growth rate of slicon as a function of temperature was remeasured for an input concentration of $\mathrm{SiH}_{4}$ of 01 volume percent with hydrogen 


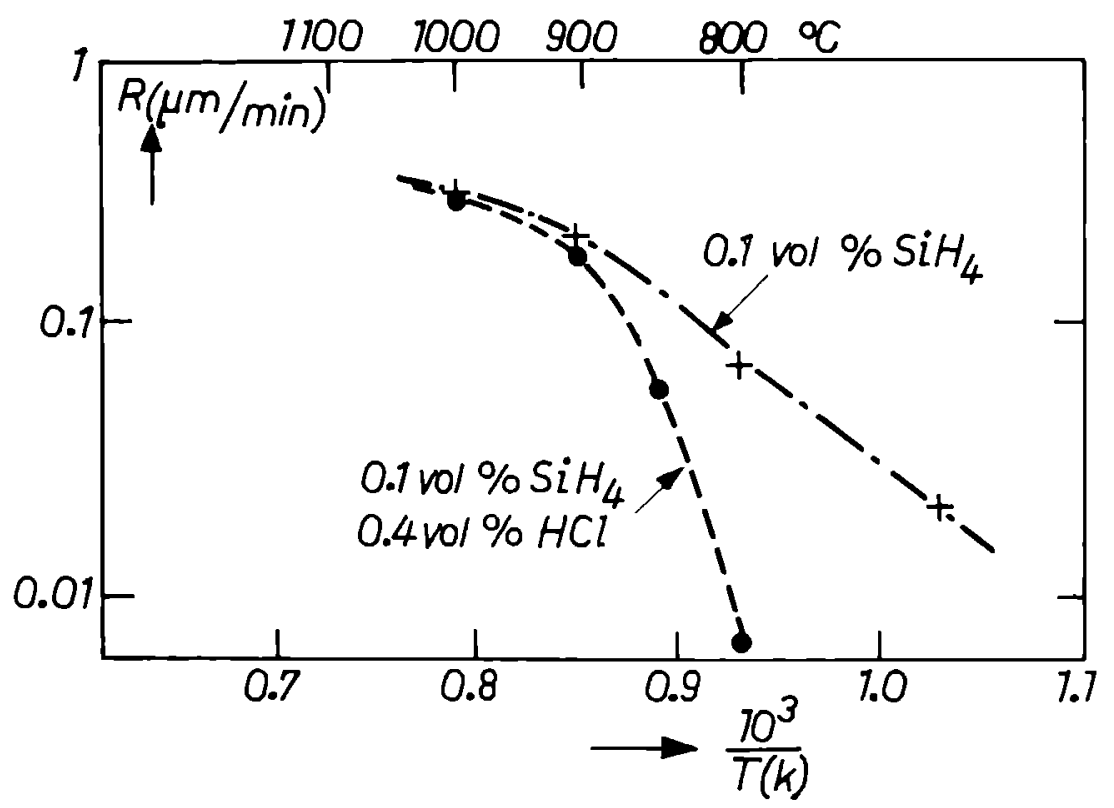

Figure 1.

Growth rate given by a mixture of $0.1 \% \mathrm{SiH}_{4}$ and $0.4 \% \mathrm{HCl}$ in hydrogen as a function of temperature, compared with the growth rate shown by silane without $\mathrm{HCl}$ addition, the drawn curve for $\mathrm{SiH}_{4}$ according to Van den Brekel [7], the data points are from the present study.

as carrier gas. Figure 1 gives the result, which is in accordance with the result of previous investigations $[1,7]$, showing the high temperature region where growth is limited by the supply of reactant via gas phase diffusion, and below $900^{\circ} \mathrm{C}$ the decrease in growth rate because of the onset of a rate-limiting surface reaction of unknown origin. The results given in Figure 1 for $\mathrm{SiH}_{4}$ are exactly comparable to those of Van den Brekel [7] measured at the centre part of the susceptor. The upper curve of fig. 1 is according to ref. 7 , the data points are from the present study. Figure 2 shows the etch rate of silicon given by 0.4 and 1.0 volume percent $\mathrm{HCl}$ in hydrogen as a function of temperature. Here, too, the etch rate is temperature-independent until well below $900^{\circ} \mathrm{C}$ where a strong decrease is observed. This has been reported beiore $[8,9]$. It was noticed that, even at the lowest temperatures $\left(800^{\circ} \mathrm{C}\right)$, no incubation time for the etch rate could be observed. Figure 3 shows the etch rate of silicon at $1000^{\circ} \mathrm{C}$ as a function of the input concentration of $\mathrm{HCl}$, confirming the variation of the etch rate with $\mathrm{P}_{\mathrm{HCl}}^{2}$. A mixture of $\mathrm{SiH}_{4}$ $(0.1 \%)$ and $\mathrm{HCl}(0.4 \%)$ gives the result shown in the lower curve of figure 1. Down to $900^{\circ} \mathrm{C}$ the small difference is equal to the etch rate given by $\mathrm{HCl}$ alone (see eq. 1). Below $900{ }^{\circ} \mathrm{C}$, however, the growth rate falls off rapidly. The difference 


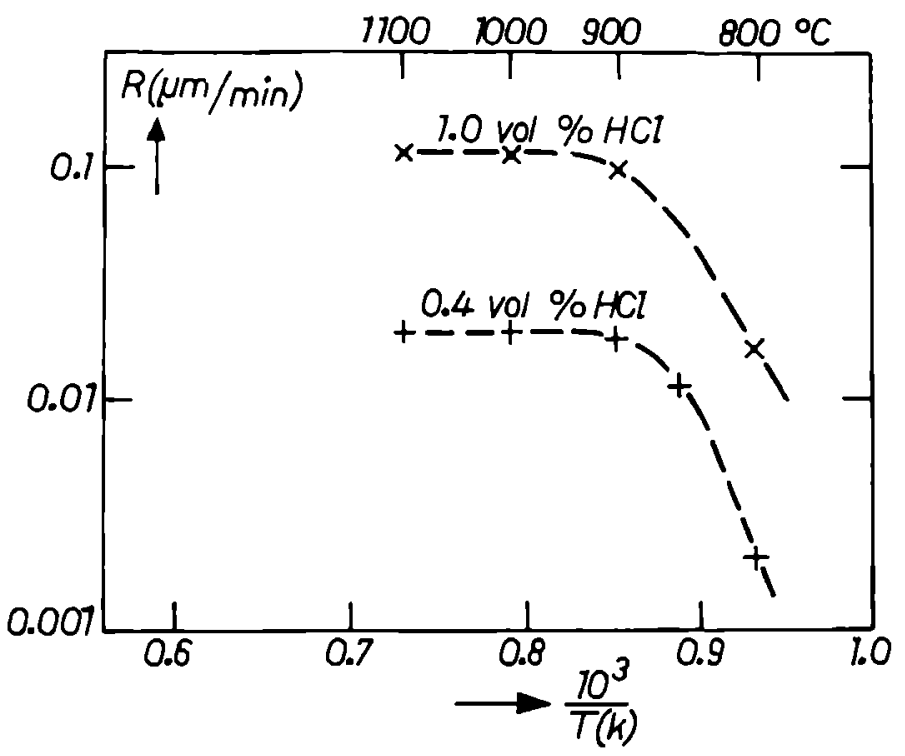

Figure 2.

The etch rate of silicon in hydrogen with 0.4 and 0.1 volume percent $\mathrm{HCl}$ as a function of temperature.

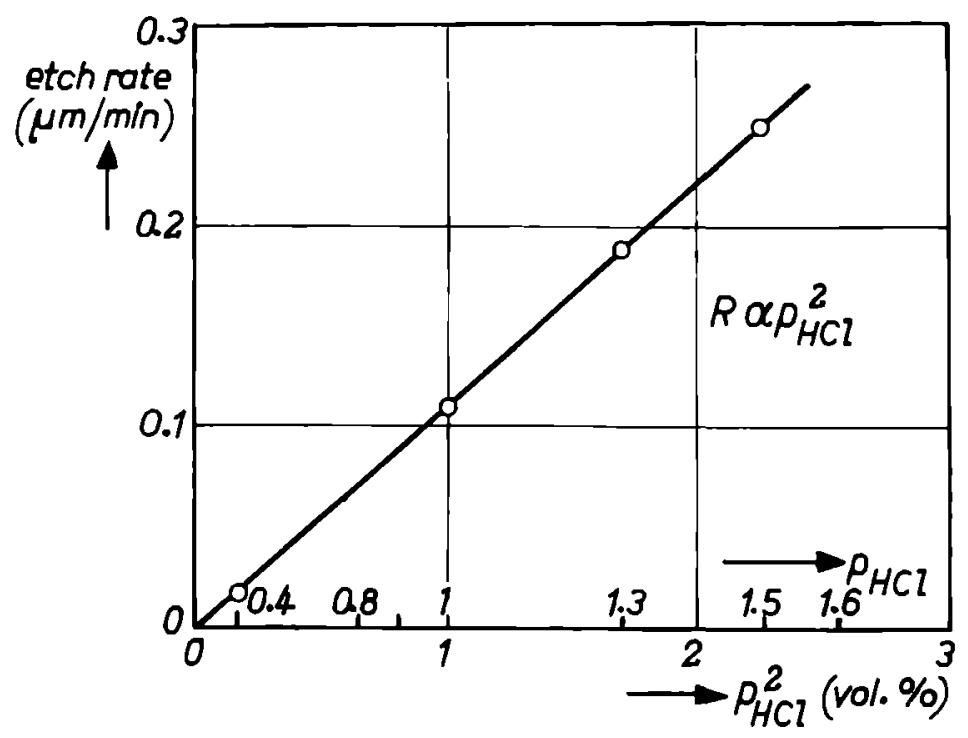

Figure 3.

The etch rate of silicon at $1000^{\circ} \mathrm{C}$ as a function of the input concentration of $\mathrm{HCl}$ with hydrogen as the carrier gas. 


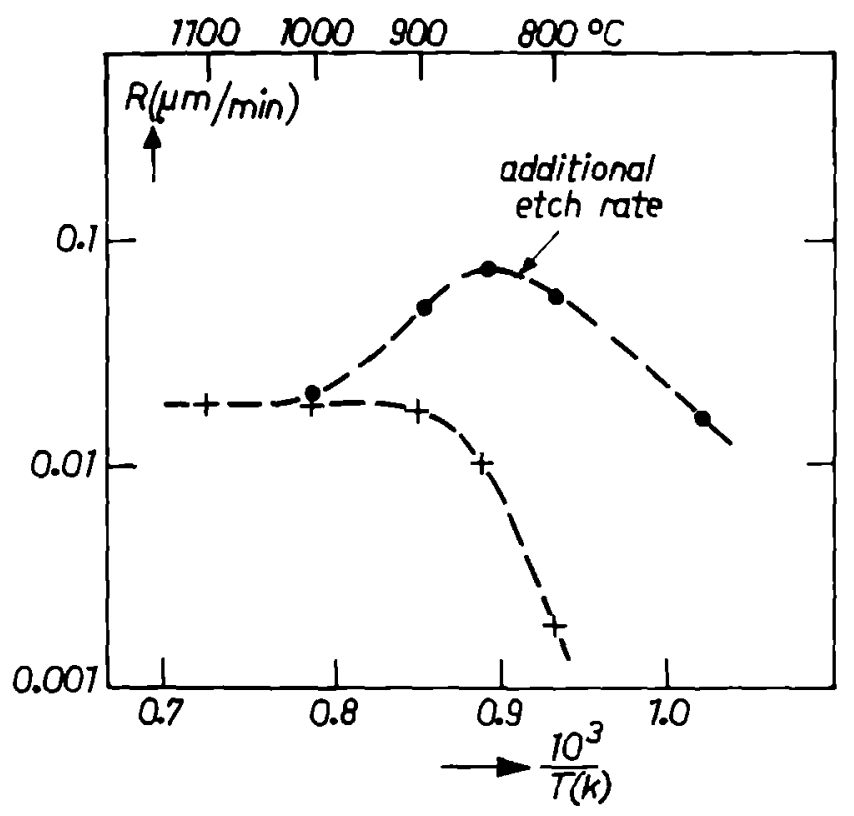

Figure 4.

The difference in growth rate shown by $0.1 \% \mathrm{SiH}_{4}$ and that of a mixture of $0.1 \%$ $\mathrm{SiH}_{4}$ and $0.4 \% \mathrm{HCl}$ can be interpreted as an apparent etch rate of $\mathrm{HCl}$. This apparent etch rate is shown in the upper curve and is compared with the etch rate of $\mathrm{HCl}$ alone as given in figure 2.

between the upper and lower curve in figure 1 reflects the influence of the addition of $\mathrm{HCl}$ and can be interpreted as an etch rate. This etch rate, however, is much greater than the etch rate given by the same concentration of $\mathrm{HCl}$ without $\mathrm{SiH}_{4}$ being present. In figure 4 the apparent etch rate of $\mathrm{HCl}$ in the mixture is given, calculated from the difference in the curve for $\mathrm{SiH}_{4}$ and for $\mathrm{SiH}_{4}+4 \mathrm{HCl}$. The difference curve below $900{ }^{\circ} \mathrm{C}$ shows an etch rate appreciably higher than that given by $\mathrm{HCl}$ alone (lower curve). Figure 5 shows the temperature dependence of the growth rate for $0.1,0.2$ and 0.4 volume percent of $\mathrm{SiH}_{4}$ mixed with 0.4 volume percent of $\mathrm{HCl}$. For all silane concentrations a rapid decrease in growth rate below $900^{\circ} \mathrm{C}$ is observed.

In order to study the influence of the amount of $\mathrm{HCl}$ in the mixture, experiments were done with $0.1 \%$ silane and increasing amounts of $\mathrm{HCl}$ at temperatures of $1000^{\circ} \mathrm{C}, 900^{\circ} \mathrm{C}$ and $800^{\circ} \mathrm{C}$. The results are given in figure 6 . The curve at $1000^{\circ} \mathrm{C}$ shows the behaviour given in eq. (1): $\mathrm{R}=\mathrm{k}_{\mathrm{a}} \mathrm{PSSiH}_{4}-\mathrm{kb}_{\mathrm{b}} \mathrm{P}_{\mathrm{HCl}}^{2}$. At $900^{\circ} \mathrm{C}$, however, the first addition of $\mathrm{HCl}$ gives rise to a rapid initial decrease in growth rate 


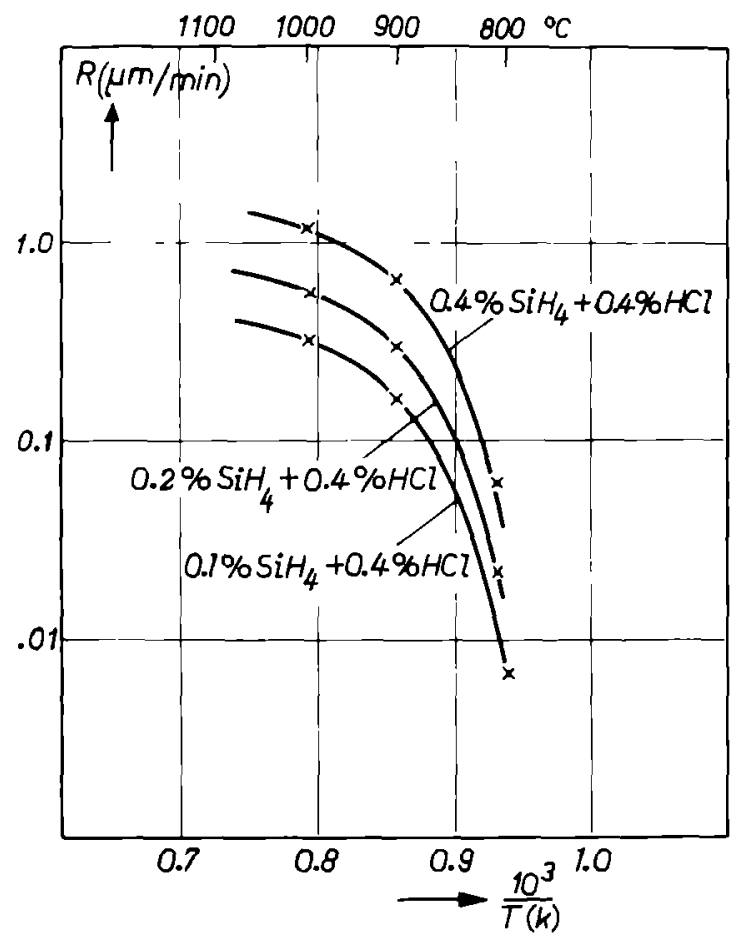

Figure 5.

Temperature dependence of the growth rate of mixtures of $\mathrm{SiH}_{4}$ and $0.4 \% \mathrm{HCl}$, for $\mathrm{SiH}_{4}$ input concentrations of $0.1,0.2$ and 0.4 volume \% in hydrogen.

followed by a slower fall-off at a lower level. This effect is even better perceivable at $800{ }^{\circ} \mathrm{C}$. Plotting the growth rate of $\mathrm{SiH}_{4}-\mathrm{HCl}$ mixtures for constant $\mathrm{PSiH}_{4}$ as a function of $\mathrm{P}_{\mathrm{HCl}}^{2}$ one obtains the results given in figure 7 , confirming the rapid decrease of the growth rate on the first addition of small amounts of $\mathrm{HCl}$ and indicating a subsequent reduction in growth rate proportional to $\mathrm{P}_{\mathrm{HCl}}^{2}$. The same kind of experiments for other silane input concentrations show the same behaviour. This is shown in figure 8 and figure 9 for growth rates at 900 and $800^{\circ} \mathrm{C}$ respectively as a function of $\mathrm{P}_{\mathrm{HCl}}^{2}$. In all cases an initial decrease in growth rate is observed followed by a slower fall off proportional to $\mathrm{P}_{\mathrm{HCl}}^{2}$. The decrease in growth rate appears to be proportional to the input concentration of $\mathrm{PSiH}_{4}$, or, in other words both the initial growth rate without $\mathrm{HCl}$ and the growth rate after the rapid initial decrease are proportional to $\mathrm{PSiH}_{4}$. The resulting growth rate after introduction of $\mathrm{HCl}$ can be extrapolated to $\mathrm{P}_{\mathrm{HCl}}=0$, this value $\left(\mathrm{R}_{2}\right)$ is plotted in figure 10 as a function of $\mathrm{PSiH}_{4}$ together with the growth rate without $\mathrm{HCl}\left(\mathrm{R}_{1}\right)$. 


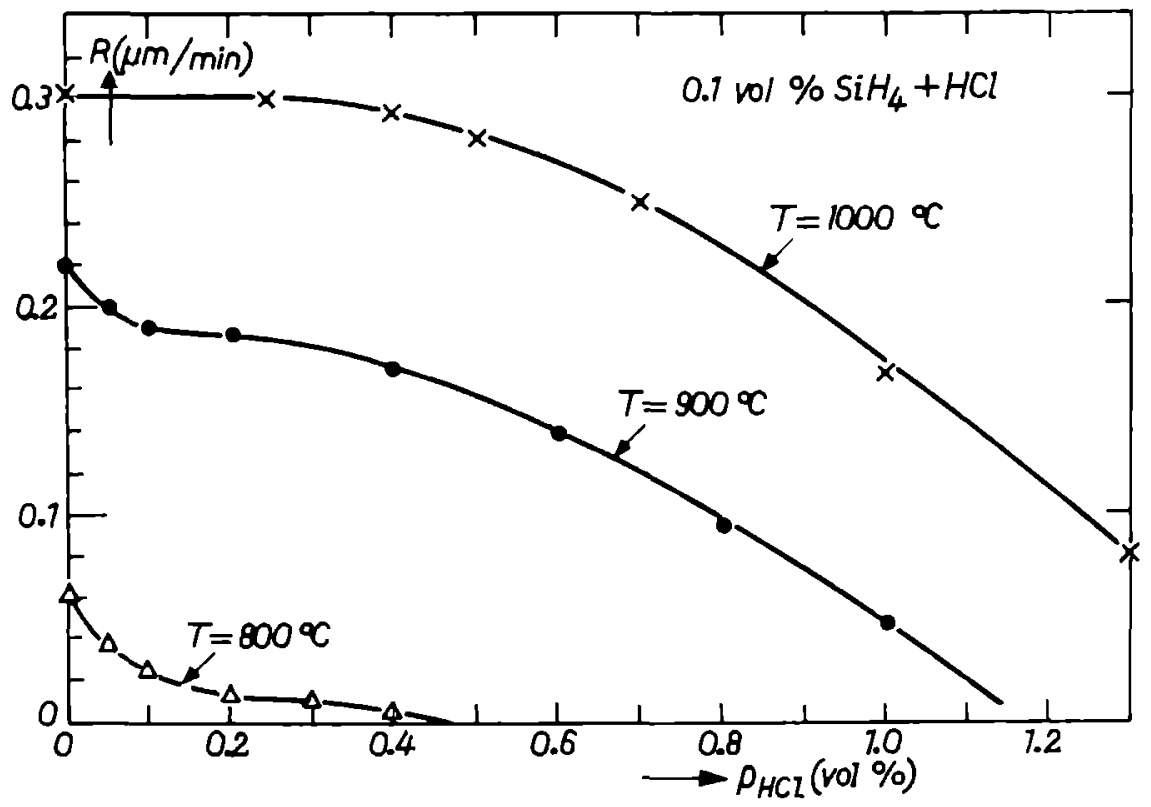

Figure 6.

Growth rates shown by mixtures of 0.1 vol. \% $\mathrm{SiH}_{4}$ and increasing amounts of $\mathrm{HCl}$ at 1000,900 and $800^{\circ} \mathrm{C}$.

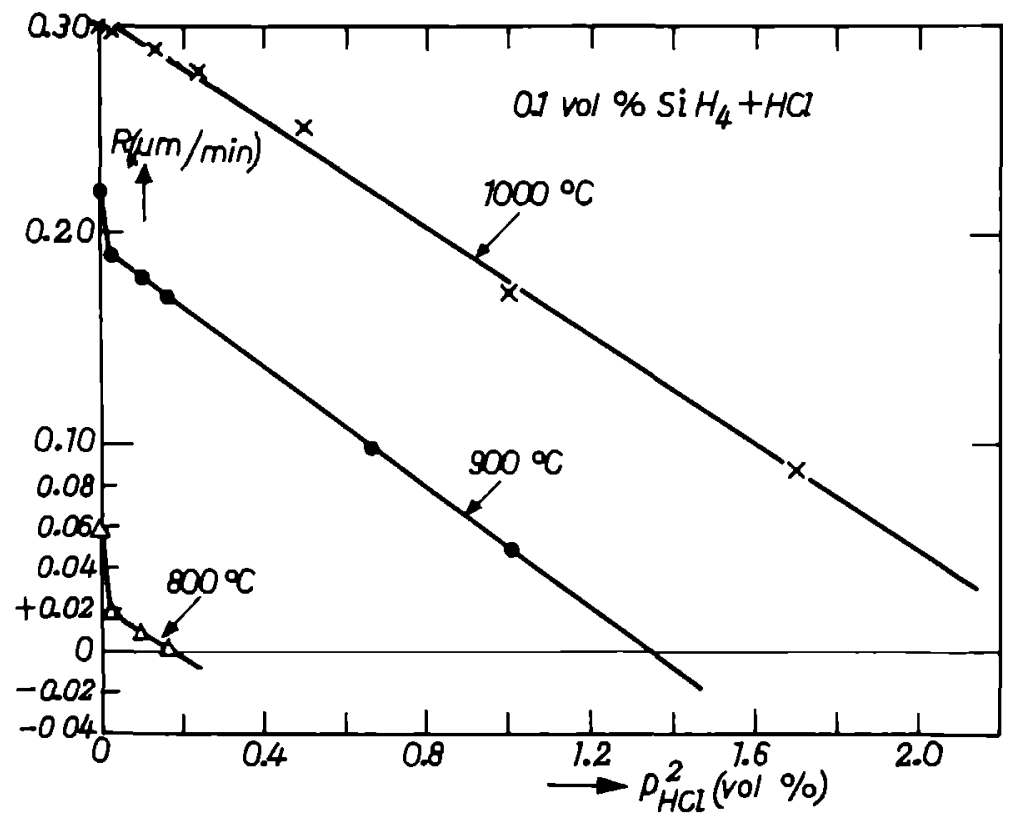

Figure 7.

The growth rate shown by mixtures of 0.1 vol. $\% \mathrm{SiH}_{4}$ and $\mathrm{HCl}$ plotted as a function of $P_{H C T}^{2}$ 


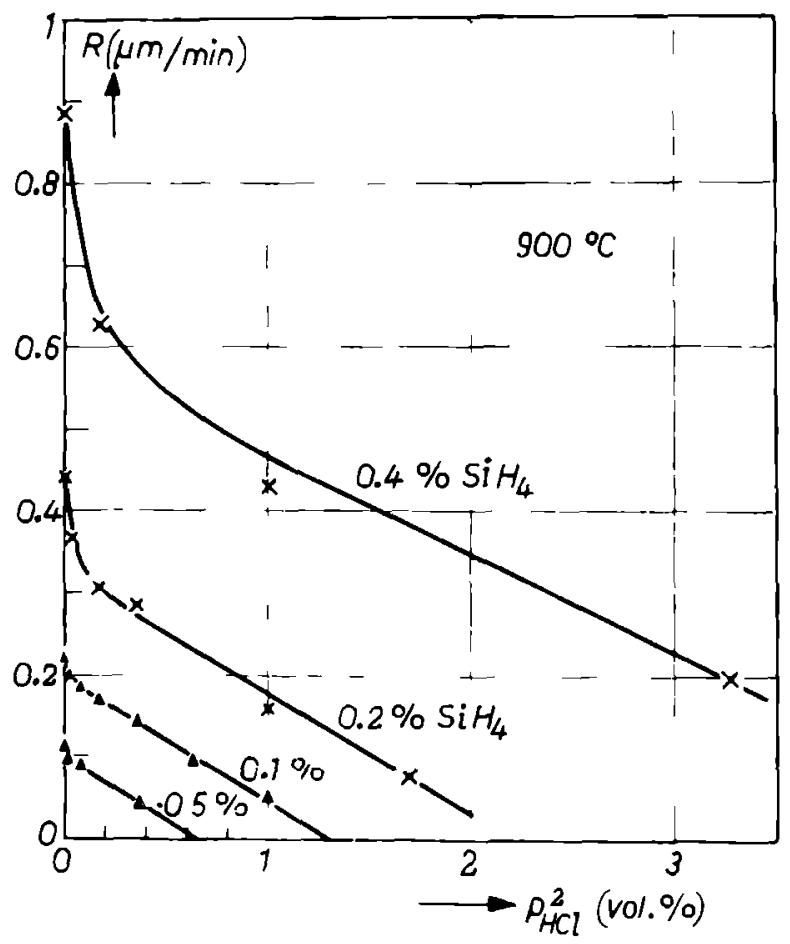

Figure 8.

Growth rates at $900^{\circ} \mathrm{C}$ for $0.05,0.1,0.2$ and 0.4 volume $\% \mathrm{SiH}_{4}$ as a function of the $\mathrm{HCl}$ concentrations, plotted as $\mathrm{P}_{\mathrm{HCt}}^{2}$

The ratio $R_{2} / R_{1}$ is about 0.8 at $900{ }^{\circ} \mathrm{C}$ and 0.25 at $800^{\circ} \mathrm{C}$. The growth rate for $\mathbf{R}_{2}$ thus can be expressed as

$$
\mathbf{R}_{2}=\mathbf{k}_{\mathrm{c}} \mathrm{PSiH}_{4}-\mathrm{kb}_{\mathrm{b}} \mathrm{P}_{\mathrm{HCl}}^{2}
$$

The etching term $\mathrm{kb}_{\mathrm{HCl}}^{2}$ is nearly equal to the etch rate of silicon by $\mathrm{HCl}$ alone (figure 2).

\section{Discussion}

In the high temperature regime above $1000^{\circ} \mathrm{C}$ the silicon surface can be assumed to be in local chemical equilibrium with the gas phase in contact with that surface.

Surface adatoms and adsorbed molecules are present, moving over the surface until they are incorporated in the lattice at specific sites. According to the crystal growth theory given by Burton, Cabrera and Frank [10], steps on the surface provide the sinks for the moving adatoms and this surface diffusion is the slowest step on the 


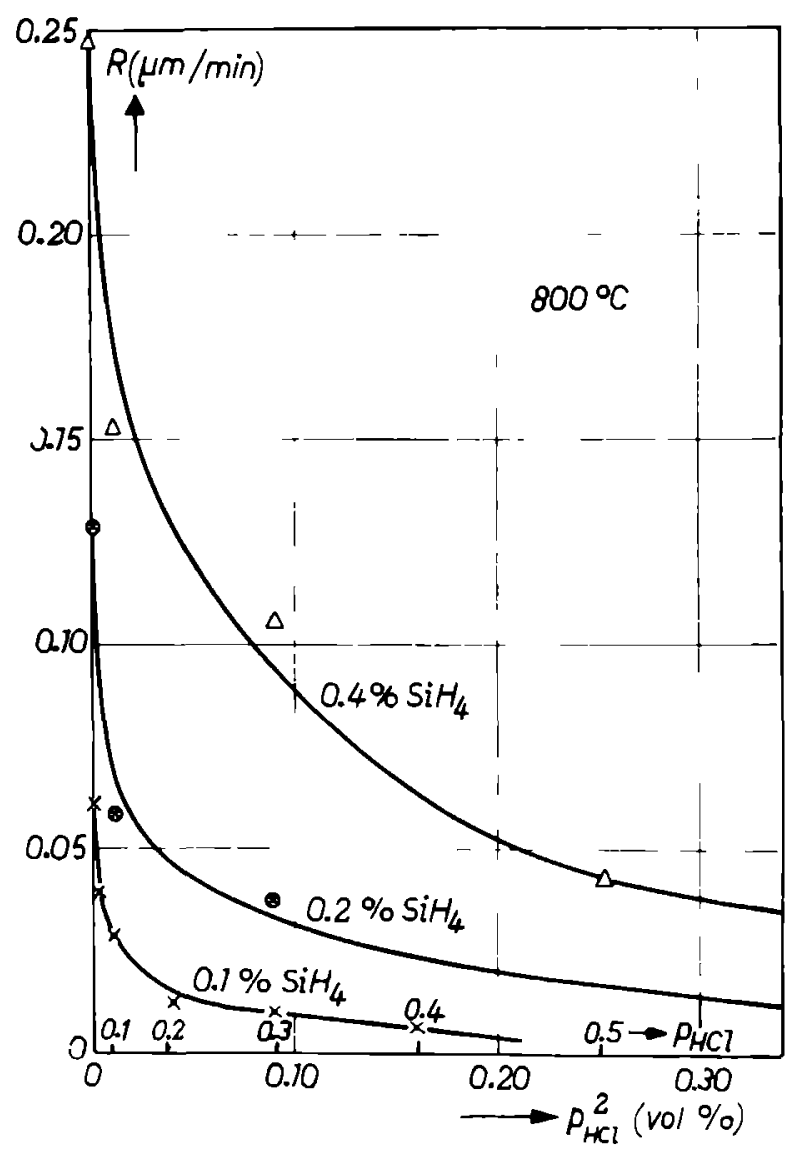

Figure 9.

Growth rates at $800^{\circ} \mathrm{C}$ for $0.1,0.2$ and $0.4 \% \mathrm{SiH}_{4}$ in hydrogen as a function of $P_{H C t}^{2}$

surface. The adatoms and molecules that can be visualized as present on the surface, are $\mathrm{SiH}_{2}{ }^{*}, \mathrm{Si}^{*}$ and $\mathrm{SiCl}_{2}{ }^{*}$. The asterisks denote that we are dealing with adsorbed species not yet incorporated into the crystal lattice. This incorporation proceeds via surface diffusion, incorporation on the steps and subsequent removal of $\mathrm{H}$ and $\mathrm{Cl}$ atoms by chemical reactions. At high temperatures $\left(\mathrm{T}>1000^{\circ} \mathrm{C}\right)$ these surface processes occur so easily that the transport of reactants from the gas phase becomes the rate-determining step. At temperatures below $1000^{\circ} \mathrm{C}$ the surface kinetics become slower and gas phase diffusion no longer constitutes the slowest step. According to Chernov [2] the surface diffusion coefficient of adatoms $\left(D_{\mathbf{s}}\right)$ is given by 


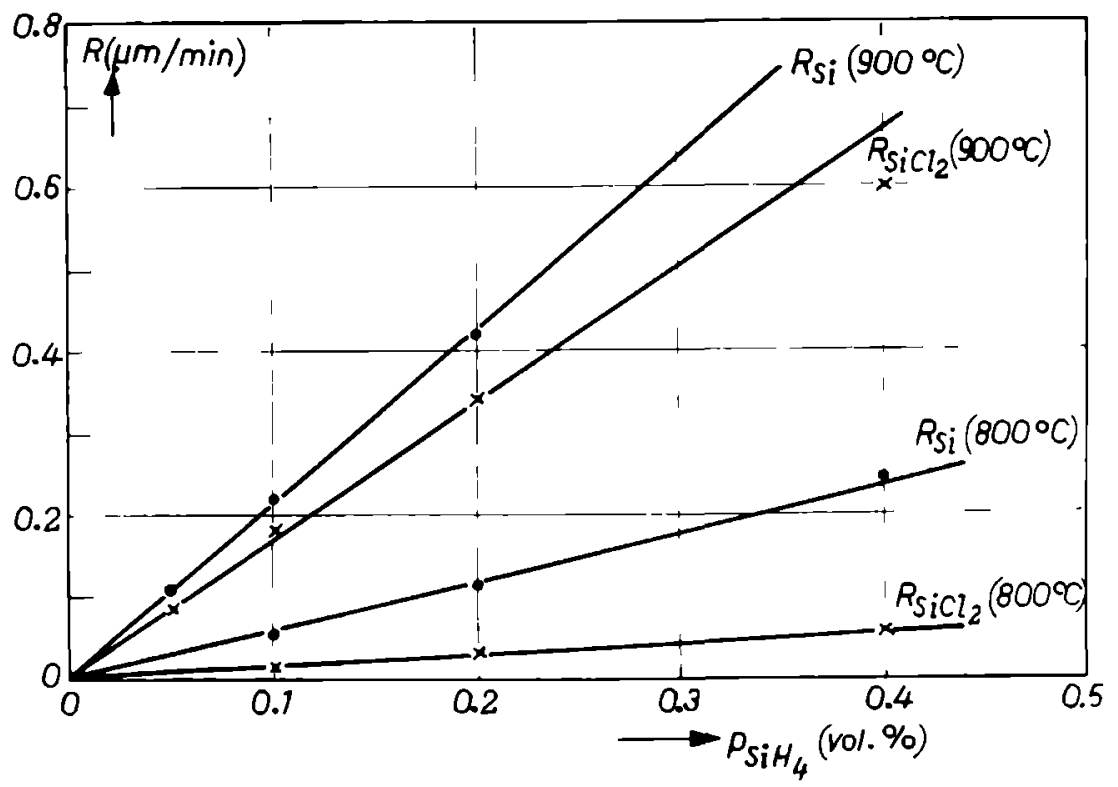

Figure 10.

The growth rate of silicon as a function of input concentration of silane at $800^{\circ}$ and $900^{\circ} \mathrm{C} . R_{1}$ shows the growth rate for $\mathrm{SiH}_{4}$ without $\mathrm{HCl}, R_{2}$ is the growth rate in the presence of $\mathrm{HCl}$, extrapolated to $P_{H C l}=0 . R_{1}=R_{S i} ; R_{2}=R_{S i C l}$.

$\mathrm{D}_{\mathrm{S}}=\mathrm{D}_{\mathrm{S}}^{0} \theta \exp \left(-\mathrm{E}_{\mathrm{D}} / \mathrm{kT}\right)$

in which $E_{D}$ is the activa+ion energy for diffusion, $D_{s}^{0}$ is a constant and $\theta$ is the fraction of free surface sites needed to make surface diffusion possible. Chernov also made it clear that especially adsorption of $\mathrm{HCl}$ is important. Around $100{ }^{\circ} \mathrm{C}$ at least $99 \%$ of the surface sites could be filled with atomic hydrogen or chlorine. It seems probable, therefore, that the diffusion of adatoms is the main rate-limiting step in the growth of silicon at lower temperatures. Experiments done by Van der Putte et al. [5] showed that in the case of etching with $\mathrm{HCl}$ the diffusion of $\mathrm{SiCl}_{2}$ away from the steps where it has been formed constitutes the rate-limiting reaction. Nucleation experiments $[11,12]$ also are explained on the basis of surface diffusion of adatoms. Returning to the experiments cited above, we note that the temperature independent etch rate given in figure 2 is in accordance with the analysis reported by Van der Putte for $\mathrm{T}>900^{\circ} \mathrm{C}$. The sharp decrease at temperatures below $900^{\circ} \mathrm{C}$ can be caused by the influence of trace amounts of oxygen and water vapour. The results of Rijks et al. [9] clearly show that $\mathrm{SiO}_{2}$ can be formed on the surface, effectively hampering the etching reaction. At $900^{\circ} \mathrm{C}$ already $0.2 \mathrm{ppm}$ of 


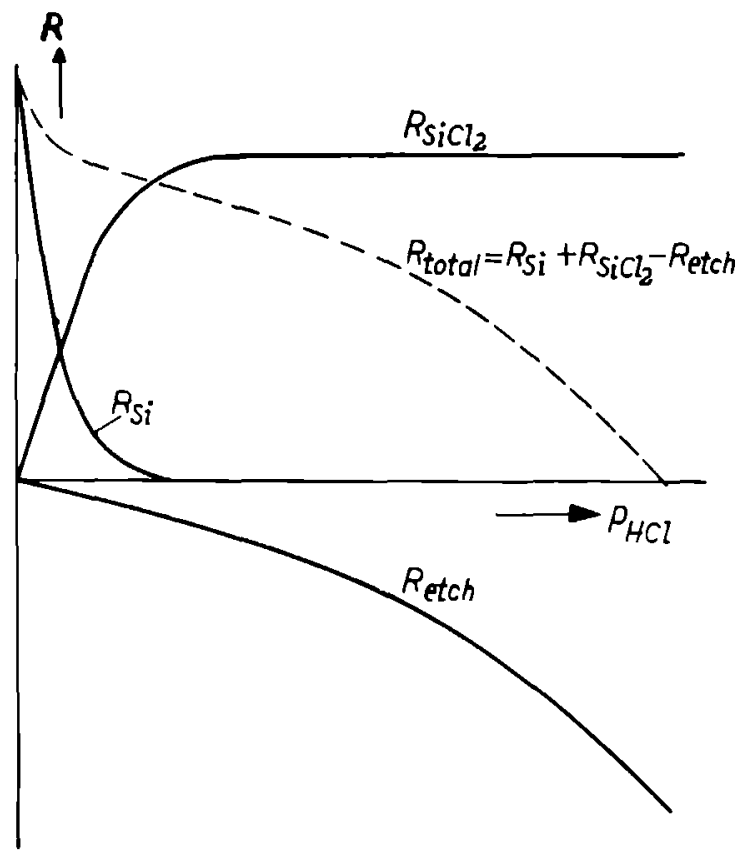

Figure 11.

Schematic representation of the growth rate of silicon via $\mathrm{Si}^{*}$ and $\mathrm{SiCl}_{2}{ }^{*}\left(\mathrm{R}_{\mathrm{Si}}\right.$ and $\mathrm{RSiCl}_{2}$ ) as a function of $\mathrm{PHCl}_{\mathrm{HC}}$

The total growth rate is composed of the sum of $\mathrm{RSi}_{\mathrm{S}}$ and $\mathrm{RSiCl}_{2}$ minus the etch rate given by $\mathrm{HCl}$.

oxygen or water vapor in $\mathrm{H}_{2}$ or in $\mathrm{N}_{2}$ is sufficient to create a stable $\mathrm{SiO}_{2}$ phase, well within the range of gas purity in the present system. In figure 7 it is seen that etching is still possible in the $\mathrm{SiH}_{4}-\mathrm{HCl}-\mathrm{H}_{2}$ system. The reduction in growth rate at 800 and $900^{\circ} \mathrm{C}$ gives the same slope of $\mathrm{R}$ vs. $\mathrm{P}_{\mathrm{HCl}}^{2}$ after the initial rapid decrease in growth rate. The influence of trace amounts of oxygen or water vapour is thus apparently reduced, probably by a gas phase reaction between $\mathrm{SiH}_{4}$ and oxygen.

The growth of silicon from silane (figure 1) is in good agreement with earlier observations: below $900^{\circ} \mathrm{C}$ surface reactions become rate-determining. The mixture of $\mathrm{SiH}_{4}+4 \mathrm{HCl}$ however, shows an appreciably lower growth rate below $900^{\circ} \mathrm{C}$. The reduction of the growth rate in this region will be dependent on the surface reactions that occur in the kinetic region. Figure 4 shows that indeed the start of the kinetic region coincides with the reduction in growth rate, which further decreases with decreasing temperature, as it can not surpass the growth rate of pure $\mathrm{SiH}_{4}$ at the same temperature. 
In a more detailed discussion of the process, the distinction between the high and low temperature regimes has to be stressed. The high temperature behaviour gives a growth rate (eq. 1) composed of a growth term and an etching term. In the growth term diffusion of $\mathrm{SiH}_{4}$ from the bulk of the gas phase (b) towards the surface is the main kinetic barrier

$\mathrm{SiH}_{4}(\mathrm{~b}) \rightleftharpoons \mathrm{SiH}_{4}(\mathrm{~g})$

The addition ( $\mathrm{g}$ ) denotes the concentration near the silicon surface. The etching term in eq. (1) is caused by the etching of silicon by $\mathrm{HCl}$ on steps present on the surface via the overall reaction

$$
2 \mathrm{HCl}(\mathrm{g})+\mathrm{Si}(\mathrm{cr}) \rightleftharpoons \mathrm{SiCl}_{2}(\mathrm{~g})+\mathrm{H}_{2}(\mathrm{~g})
$$

A surface catalyzed gas phase reaction can be given as:

$$
\mathrm{SiH}_{4}(\mathrm{~g})+2 \mathrm{HCl}(\mathrm{g}) \rightleftharpoons \mathrm{SiCl}_{2}(\mathrm{~g})+3 \mathrm{H}_{2}(\mathrm{~g})
$$

At the higher temperatures $\mathrm{SiCl}_{2}$ is the main reaction product [5], going to lower temperatures also the presence of $\mathrm{SiHCl}_{3}$ has to be considered. The fully coordinated species as $\mathrm{SiH}_{4}, \mathrm{SiHCl}_{3}$, and $\mathrm{SiCl}_{4}$ have low adsorption energies compared with $\mathrm{Si}^{*}, \mathrm{SiCl}_{2}{ }^{*}$ and $\mathrm{SiH}_{2}{ }^{*}$ [2], this will influence the adsorption-desorption equilibria and the various surface reactions. In the present experiments it is not possible to separate the contribution of $\mathrm{Si}^{*}$ and $\mathrm{SiH}_{2}{ }^{*}$. According to Chernov they have nearly equal adsorption energies and could have nearly equal concentrations in a hydrogen ambient. Therefore in the following only $\mathrm{Si}^{*}$ will be considered in the calculations. The main rate-limiting reaction has to be found between the various surface reactions like the adsorption of silane, the chemical reaction to form adatoms, the diffusion of surface species to reactive sites and the incorporation of silicon on the steps. As discussed above, the rate-limiting step can best be correlated with the surface diffusion and the incorporation at the atomic steps of the adatoms. In both cases the steady state concentrations of $\mathrm{Si}^{*}$ and $\mathrm{SiCl}_{2}{ }^{*}$ will be increased. As $\mathrm{Si}^{*}$ is a reactive species, addition of $\mathrm{HCl}$ will reduce its concentrations converting it to $\mathrm{SiCl}_{2}{ }^{*}$. It has to be realised that, whatever the surface species present, the growth rate will be the same when a condition of complete condensation prevails. When $\mathrm{SiCl}_{2}{ }^{*}$ is present at the surface and the incorporation reaction is the rate determining step, then the $\mathrm{SiCl}_{2}$ * concentration between the steps will be increased. This supersaturation will promote the desorption of $\mathrm{SiCl}_{2}$ and the formation of $\mathrm{SiHCl}_{3}$ by reaction of $\mathrm{SiCl}_{2}$ with $\mathrm{HCl}$.The occurrence of these alternative reactions is the reason for a reduction in growth rate. A number of surface reactions and the steady state concentrations of $\mathrm{Si}^{*}$ and $\mathrm{SiCl}_{2}$ * are given in the Appendix, where also general expressions for the growth of silicon are calculated in terms of the input concentrations of $\mathrm{HCl}$ and $\mathrm{SiH}_{4}$ and of the rate constants of the various surface reactions. A comparison of the experimentally found relations and the theoretical 
expression for the growth rates gives rise to the following points

I The first observation concerns the main surface species present In a system without $\mathrm{HCl}$ sllicon adatoms are formed, incorporation of $\mathrm{Sl}^{*}$ at the surface steps constitutes the layer growth of slicon $\mathrm{On}$ the addition of $\mathrm{HCl}$ the results can only be explained for $\mathrm{SiCl}_{2}$ * as the predominant surface species The intro duction of some $\mathrm{HCl}$ already decreases the concentration of $\mathrm{Si}^{*}$ (and $\mathrm{SiH}_{2}{ }^{*}$ ) to insignificant amounts and diffusion and incorporation via $\mathrm{SiCl}_{2}$ * has to take over (see figure 11)

u The desorption rate of $\mathrm{SiCl}_{2}$ causes the reduction of the growth rate as a consequence of $\mathrm{HCl}$ addition

w From the present experiments it has to be concluded that the introduction of $\mathrm{HCl}$ at temperatures below $900{ }^{\circ} \mathrm{C}$ leads to an increased concentration of surface species $\left(\mathrm{SlCl}_{2}{ }^{*}\right)$ The rate-determining step therefore has to be found at the end of the chain of reactions These are the diffusion and incorporation of $\mathrm{SiCl}_{2}$ at surface steps together with the chemical reaction needed to remove $\mathrm{Cl}$ atoms from the step site Additional information is needed to decide between these possibulities

IV It has been shown that especially at lower temperatures, nucleation becomes difficult as soon as some $\mathrm{HCl}$ is present, nucleation experuments [12] indicate that $\mathrm{S}_{1}$ * adatoms are needed to come to nucleation In addition it was found that, under conditions where such a nucleation on a foreign surface or on a perfect sucon facet meets with difficulties, growth of silicon on a stepped silicon substrate still remains possible This experimental result can now be explained by the possibility of growth via $\mathrm{SiCl}_{2}$ in the latter case, the reaction is more readily acheved at an atomic step than from an isolated $\mathrm{SiCl}_{2}$ molecule adsorbed on the slicon surface between the steps

$v$ The general picture obtained is that of a predominant occurrence of $\mathrm{SlCl}_{2}$ on the silicon surface as soon as some $\mathrm{HCl}$ is present in the gas phase In this respect the growth of slicon as described here and the etching of silicon by $\mathrm{HCl}$ as descnbed in ref 5 show a perfect match In both cases diffusion and reaction of $\mathrm{SiCl}_{2} *$ is the rate-limiting step The perfect analogy is also present in the morphology and the defects introduced on growth or etching $[13,14$, 15]

\section{Conclusion}

The growth and etchung of silicon in CVD has been studied and a companson with recent nucleation studies leads to a consistent picture of the atomic processes during nucleation and growth of slicon

In the nucleation experments it was ascertauned that slicon adatoms ( $\left.\mathrm{S}_{1}{ }^{*}\right)$ are responsible for the initial nucleation of slicon on foreign substrates 
The present expenments on the growth of slicon on silicon substrates shows that, at temperatures below $900^{\circ} \mathrm{C}$, the man surface species responsible for growth is $\mathrm{SiCl}_{2}{ }^{*}$, as soon as some $\mathrm{HCl}$ is present in the gas phase because $\mathrm{S}_{1}{ }^{*}$ rapidly reacts to form $\mathrm{SiCl}_{2}{ }^{*}$ Growth now has to proceed via $\mathrm{SlCl}_{2}{ }^{*}$, this appears to be only possible on a slicon surface provided with atomic steps, on a foreign surface the nucleation barrier is more difficult to surpass $\mathrm{S}_{1} \mathrm{Cl}_{2}{ }^{*}$ diffuses over the slicon surface and is incorporated at steps on the surface after which the $\mathrm{Cl}$ atoms have to desorb in order to give a positive growth rate At hugher temperatures above 1000 ${ }^{\circ} \mathrm{C}$ the surface reactions become so rapid that the supply of reactants by gas phase diffusion becomes rate-limiting 


\section{APPENDIX}

a The following redctions can be distinguished

1. Gas phase transport of $\mathrm{S}_{1} \mathrm{H}_{4}$ and $\mathrm{HCl}$ from the bulk of the gas phase (b) to the region near the silicon surface $(\mathrm{g})$

$\mathrm{S}_{1} \mathrm{H}_{4}(\mathrm{~b}) \underset{\mathrm{k}_{-1}}{\stackrel{\mathrm{k}_{1}}{\rightleftharpoons}} \mathrm{S}_{1} \mathrm{H}_{4}(\mathrm{~g})$

$\mathrm{HCl}(\mathrm{b}) \underset{\mathrm{k}_{-2}}{\stackrel{\mathrm{k}_{2}}{\rightleftharpoons}} \mathrm{HCl}(\mathrm{g})$

2. Adsorption reactions

(* denotes a free surface site)

$\mathrm{S}_{1} \mathrm{H}_{4}(\mathrm{~g})+* \underset{\mathrm{k}_{-3}}{\stackrel{\mathrm{k}_{3}}{\rightleftharpoons}} \mathrm{Si}^{*}+2 \mathrm{H}_{2}(\mathrm{~g})$

$\mathrm{HCl}(\mathrm{g})+* \underset{\mathrm{k}_{\mathcal{A}}}{\stackrel{\mathrm{k}_{4}}{\rightleftharpoons}} \mathrm{Cl} \mathrm{l}^{*}+1 / 2 \mathrm{H}_{2}(\mathrm{~g})$

$1 / 2 \mathrm{H}_{2}+\underset{\mathrm{k}_{-5}}{\stackrel{\mathrm{k}_{5}}{\rightleftharpoons}} \mathrm{H}^{*}$

3. Surface reactions

$\mathrm{Sl}^{*}+2 \mathrm{HCl}(\mathrm{g}) \underset{\mathrm{k}_{-6}}{\stackrel{\mathrm{k}_{6}}{\rightleftharpoons}} \mathrm{SiCl}_{2} *+\mathrm{H}_{2}(\mathrm{~g})$

$\mathrm{SiCl}_{2} \underset{\mathrm{k}_{-7}}{\stackrel{\mathrm{k}_{7}}{\rightleftharpoons}} \mathrm{SiCl}_{2}(\mathrm{~g})+$ *

$\mathrm{SiCl}_{2} *+\mathrm{HCl}(\mathrm{g}) \underset{\mathrm{k}_{-8}}{\stackrel{\mathrm{k}_{8}}{\rightleftharpoons}} \mathrm{S}_{1} \mathrm{HCl}_{\mathrm{3}}(\mathrm{g})+$ *

4. The incorporation of slicon into the lattice, represented by the surface diffusion of $\mathrm{Si}^{*}$ and $\mathrm{SiCl}_{2}$ * to the atomic steps and the incorporation reaction at the step.

$\mathrm{Sl}_{1} * \underset{\mathrm{k}_{-9}}{\stackrel{\mathrm{k}_{9}}{\rightleftharpoons}} \mathrm{S} 1$ (st) 


$$
\begin{aligned}
& \mathrm{Si}(\mathrm{st}) \underset{\mathrm{k}_{-10}}{\stackrel{\mathrm{k}_{10}}{\rightleftharpoons}} \mathrm{SI}(\mathrm{cr}) \\
& \mathrm{SiCl}_{2}{ }_{\mathrm{k}_{-11}}^{\stackrel{\mathrm{k}_{11}}{=} \mathrm{SiCl}_{2}(\mathrm{st})} \\
& \mathrm{SiCl}_{2}(\mathrm{st})+\mathrm{H}_{2}(\mathrm{~g}) \underset{\mathrm{k}_{-12}}{\stackrel{\mathrm{k}_{12}}{\rightleftharpoons}} \mathrm{Si}(\mathrm{cr})+2 \mathrm{HCl}(\mathrm{g})
\end{aligned}
$$

The fraction of free surface sites $(\theta)$ follows from

$$
1=\theta+\left[\mathrm{H}^{*}\right]+\left[\mathrm{Cl}^{*}\right]+\left[\mathrm{SiCl}_{2}^{*}\right]+
$$

with eq (4), (5) and (7) this leads to

$$
\theta=\frac{1}{1+\mathrm{K}_{9} \mathrm{P}_{\mathrm{H}_{2}}^{12}+\mathrm{K}_{4} \mathrm{P}_{\mathrm{HCl}} / \mathrm{P}_{\mathrm{H}_{2}^{\prime}}^{12}+\mathrm{K}_{7} \mathrm{P}_{\mathrm{SICl}_{2}}}
$$

where $k_{4} / k_{.4}=K_{4}$ etc

In the following the notation (g) will only be used when companson with bulk values of the vapour pressures is made

In a steady state situation it is possible to calculate the $\mathrm{S}_{1}$ * and $\mathrm{SiCl}_{2}{ }^{*}$ concentrations by equating all the ways to produce and to eliminate these species This gives for $\mathrm{S}^{*}$

$$
\begin{aligned}
& \frac{\mathrm{d}\left[\mathrm{S}_{1}^{*}\right]}{\mathrm{dt}}=0=\mathrm{k}_{3} \mathrm{PS}_{\mathrm{S}_{4}} \theta+\mathrm{k}_{-6}\left[\mathrm{~S}_{1} \mathrm{Cl}_{2} *\right] \mathrm{P}_{\mathrm{H}_{2}}+\mathrm{k}_{-9}[\mathrm{~S}(\mathrm{st})]-\left[\mathrm{S}_{1}^{*}\right]\left(\mathrm{k}_{-3} \mathrm{P}_{\mathrm{H}_{2}}^{2}+\right. \\
& \left.+\mathrm{k}_{6} \mathrm{P}_{\mathrm{HCl}}^{2}+\mathrm{k}_{9}\right)
\end{aligned}
$$

The rate constants $k_{.6}$ and $k_{-9}$ (the reverse reactions of $k_{6}$ and $k_{9}$ ) are expected to be small, thus

$$
\left[\mathrm{Sl}^{*}\right]=\frac{\mathrm{k}_{3} \mathrm{P}_{\mathrm{S}_{1} \mathrm{H}_{4}} \cdot \theta}{\left(\mathrm{k}_{.3} \mathrm{P}_{\mathrm{H}_{2}}^{2}+\mathrm{k}_{6} \mathrm{P}_{\mathrm{HCl}}^{2}+\mathrm{k}_{9}\right)}
$$

Equilibrum between solid sulicon and hydrogen gas gives a value of $\mathrm{PS}_{\mathrm{S}_{1}} \mathrm{H}_{4}$ near to $10^{-6}$ bar at temperatures between 700 and $1100^{\circ} \mathrm{C}[12]$ In the kinetic region $\mathrm{P}_{\mathrm{S}_{1} \mathrm{H}_{4}}(\mathrm{~g}) \approx \mathrm{P}_{\mathrm{S}_{1} \mathrm{H}_{4}}(\mathrm{~b})$ this means that the surface concentration of $\mathrm{S}_{1}^{*}$ can be a factor of 1000 higher than the equilibrium value for an input concentration of $\mathrm{SiH}_{4}$ of $10^{-3}$ bar $\left(01\right.$ volume percent of $\mathrm{SiH}_{4}$ in $\left.\mathrm{H}_{2}\right)$ as used in the present expenments 
In the presence of $\mathrm{HCl}$ the term $\mathrm{k}_{6} \mathrm{P}_{\mathrm{HCl}}^{2}$ will soon dominate leading to

$$
\left[\mathrm{Sl}^{*}\right]=\frac{\mathrm{k}_{3} \mathrm{P}_{\mathrm{S}_{1} \mathrm{H}_{4}} \cdot \theta}{\mathrm{k}_{6} \mathrm{P}_{\mathrm{HCl}}^{2}}
$$

Along the same lines for $\mathrm{SiCl}_{2}{ }^{*}$ we find

$$
\left[\mathrm{SlCl}_{2}{ }^{*}\right]=\frac{\mathrm{k}_{6}\left[\mathrm{~S}_{1}^{*}\right] \mathrm{P}_{\mathrm{HCl}}^{2}+\mathrm{k}_{7} \mathrm{PS}_{\mathrm{SlCl}_{2}} \cdot \theta+\mathrm{k}_{-11}\left[\mathrm{SiCl}_{2}(\mathrm{st})\right]}{\mathrm{k}_{7}+\mathrm{k}_{6} \mathrm{P}_{\mathrm{H}_{2}}+\mathrm{k}_{\mathrm{B}} \mathrm{P}_{\mathrm{HCl}}+\mathrm{k}_{11}},
$$

for small values of $\mathrm{k}_{-6}, \mathrm{k}_{-11}$ and $\mathrm{PS}_{\mathrm{SiCl}_{2}}$ we obtain, using A-15,

$$
\left[\mathrm{S}_{1 C_{2}}^{*}\right]=\frac{\mathrm{k}_{3} \mathrm{P}_{\mathrm{S}_{1} \mathrm{H}_{4}} \cdot \theta}{\mathrm{k}_{7}+\mathrm{k}_{8} \mathrm{P}_{\mathrm{HCl}}+\mathrm{k}_{11}}
$$

For $\mathrm{S}_{1}(\mathrm{st})$ we have

$$
\left[S_{1}(s t)\right]=\frac{k_{9}\left[S^{*}\right]}{k_{10}+k_{.9}} .
$$

In the present experiments it is not possible to discriminate between $k_{.9}$ and $k_{10}$, it will be assumed that $k_{10}$ is large, thus

$\left[\mathrm{S}_{1}(\mathrm{st})\right]=\mathrm{k}_{9}\left[\mathrm{~S}_{1}^{*}\right] / \mathrm{k}_{10}$

For $\mathrm{SiCl}_{2}$ (st) we find

$$
\left[\mathrm{S}_{1 C l}(\mathrm{st})\right]=\frac{\mathrm{k}_{11}\left[\mathrm{SlCl}_{2}{ }^{*}\right]}{\mathrm{k}_{.11}+\mathrm{k}_{12} \mathrm{P}_{\mathrm{H}_{2}}}
$$

Growth via $\mathrm{Sl}_{1}$ is now found from

$$
\mathrm{R}_{\mathrm{S}_{1}}=\mathrm{k}_{10}\left[\mathrm{~S}_{1}(\mathrm{st})\right]=\frac{\mathrm{k}_{9} \mathrm{k}_{3} \mathrm{P}_{\mathrm{StH}_{4}} \cdot \theta}{\left(\mathrm{k}_{3} \mathrm{P}_{\mathrm{H}_{2}}^{2}+\mathrm{k}_{6} \mathrm{P}_{\mathrm{HCl}}^{2}+\mathrm{k}_{9}\right)}
$$

Without $\mathrm{HCl}$ we could have ( $\mathrm{k}_{9}$ large)

$$
\mathrm{R}_{\mathrm{S}_{1}}=\mathrm{k}_{3} \mathrm{PS}_{\mathrm{S}_{1} \mathrm{H}_{4}} \cdot \theta
$$

In the presence of $\mathrm{HCl}$ then

$$
\mathrm{R}_{\mathrm{S}_{1}}=\frac{\mathrm{k}_{9} \mathrm{k}_{3} \cdot \mathrm{P}_{\mathrm{S}_{1} \mathrm{H}_{4}} \cdot \theta}{\mathrm{k}_{6} \mathrm{P}_{\mathrm{HCl}}^{2}}
$$


In that case the route via eq. (A-12) becomes possible leading to the chemical reaction of $\mathrm{SiCl}_{2}$ with $\mathrm{H}_{2}$ at the steps giving

$\mathrm{R}_{\mathrm{SiCl}_{2}}=\mathrm{k}_{12} \mathrm{P}_{\mathrm{H}_{2}}\left[\mathrm{SiCl}_{2}(\mathrm{st})\right]=\frac{\mathrm{k}_{12} \mathrm{P}_{\mathrm{H}_{2}} \mathrm{k}_{11} \mathrm{k}_{3} \mathrm{PSiH}_{4} \cdot \theta}{\left(\mathrm{k}_{12} \mathrm{P}_{\mathrm{H}_{2}}+\mathrm{k}_{-11}\right)\left(\mathrm{k}_{7}+\mathrm{k}_{8} \mathrm{P}_{\mathrm{HCl}}+\mathrm{k}_{11}\right)}$,

For a slow desorption of $\mathrm{SiCl}_{2}$ from the steps (small value of $\mathrm{k}_{-11}$ ) we have a growth reaction limited by surface diffusion of $\mathrm{SiCl}_{2}$

$\mathrm{R}_{\mathrm{SiCl}_{2}}=\frac{\mathrm{k}_{11} \mathrm{k}_{3} \mathrm{PSiH}_{4} \cdot \theta}{\left(\mathrm{k}_{7}+\mathrm{k}_{8} \mathrm{P}_{\mathrm{HCl}}+\mathrm{k}_{11}\right)}$.

A slow chemical reaction $\left(\mathrm{k}_{12} \mathrm{P}_{\mathrm{H}_{2}}<\mathrm{k}_{-11}\right)$ leads to

$$
\mathrm{R}_{\mathrm{SiCl}_{2}}=\frac{\mathrm{k}_{12} \mathrm{P}_{\mathrm{H}_{2}} \cdot \mathrm{k}_{11} \mathrm{k}_{3} \mathrm{PSiH}_{4} \cdot \theta}{\left(\mathrm{k}_{7}+\mathrm{k}_{8} \mathrm{P}_{\mathrm{HCl}}+\mathrm{k}_{11}\right)} .
$$

Additional experiments are needed to discriminate between (A-23) and (A-24). Both reactions lead to an increased $\mathrm{SiCl}_{2}$ * concentration between the steps. The foregoing expressions have to be compared with the experimentally observed behaviour of a rapid decrease in growth rate on the introduction of $\mathrm{HCl}$ followed by a relation of the type

$$
\mathrm{R}_{2}=\mathrm{k}_{\mathrm{c}} \mathrm{PSiH}_{4}-\mathrm{k}_{\mathrm{b}} \mathrm{P}_{\mathrm{HCl}}^{2}
$$

The initial decrease can be explained by the growth rate via $\mathrm{Si}^{*}$, rapidly decreasing with increasing $\mathrm{HCl}$ concentration (A-22). The growth then remains via the $\mathrm{SiCl}_{2}$ route, the negative term in $\mathrm{P}_{\mathrm{HCl}}^{2}$ describes the etching on the steps. We obtain then

$$
R_{\mathrm{SiCl}_{2}}=\frac{k_{12} P_{\mathrm{H}_{2}}}{\left(\mathrm{k}_{.11}+\mathrm{k}_{12} \mathrm{P}_{\mathrm{H}_{2}}\right)} \cdot \frac{\mathrm{k}_{11} \mathrm{k}_{3} \mathrm{PSiH}_{4} \cdot \theta}{\left(\mathrm{k}_{11}+\mathrm{k}_{8} \mathrm{P}_{\mathrm{HCl}}+\mathrm{k}_{7}\right)}-k_{b} \frac{\mathrm{P}_{\mathrm{HCl}}^{2}}{\mathrm{P}_{\mathrm{H}_{2}}} .
$$

In (A-23 and A-24) the expected growth rate via $\mathrm{SiCl}_{2}$ is given. Comparison with the experimental growth rate equation shows that $k_{B}$ has to be small, the main desorption process has to be correlated with $\mathrm{k}_{1}$.

In order to come to the origin of the initial rapid decrease in growth rate on the introduction of $\mathrm{HCl}$, the growth via $\mathrm{Si}^{*},(\mathrm{~A}-21)$ has to be compared with the growth via $\mathrm{SiCl}_{2}{ }^{*}$, e.g. via eq. (A-23)

$\frac{\mathrm{R}_{\mathrm{SiCl}_{2}}}{\mathrm{R}_{\mathrm{Si}}}=\frac{\mathrm{k}_{11}}{\mathrm{k}_{11}+\mathrm{k}_{7}} \cdot \frac{\theta_{\mathrm{Cl}}}{\theta_{\mathrm{H}}}$. 
The value of $\theta$ could be different in $\mathrm{H}_{2}$ and $\mathrm{H}_{2}+\mathrm{HCl}$ as the heat of adsorption of $\mathrm{Cl}$ is higher than that of $\mathrm{H}$.

Between $\mathrm{Cl}$ adatoms repulsive forces are present however, which is not the case for $\mathrm{H}$ [2]. Because of the repulsive effect the heat of adsorption of $\mathrm{Cl}$ and $\mathrm{H}$ come close to each other. In a first approximation it is therefore assumed that the value of $\theta$ is not greatly different when we compare a $\mathrm{H}_{2}$ ambient to $\mathrm{H}_{2}+\mathrm{HCl}$.

The ratio of growth rates expected via $\mathrm{SiCl}_{2}{ }^{*}$ and $\mathrm{Si}^{*}$ then becomes

$$
\frac{\mathrm{RSiCl}_{2}}{\mathrm{R}_{\mathrm{Si}}}=\frac{\mathrm{k}_{11}}{\mathrm{k}_{11}+\mathrm{k}_{7}} \text {. }
$$

It is seen that, for comparable values of $\theta_{\mathrm{Cl}}$ and $\theta_{\mathrm{H}}$, the desorption of $\mathrm{SiCl}_{2}$ via $\mathrm{k}_{7}$ is the main reason for the decrease in growth rate on introduction of $\mathrm{HCl}$.

At high temperatures the surface diffusion term $\left(\mathrm{k}_{11}\right)$ is so large that the growth rate is the same via the two routes.

At lower temperatures the value of $\mathrm{k}_{11}$ decreases, the increased adatom concentration between the steps then promotes the desorption.

The temperature dependence of the ratio $\mathrm{RSiCl}_{2} / \mathrm{R}_{\mathrm{Si}}$ is governed by the activation energies for surface diffusion of $\mathrm{SiCl}_{2}$ compared with the heat of desorption of $\mathrm{SiCl}_{2}$. The diffusion of $\mathrm{SiCl}_{2}$ depends on the activation energy for diffusion of $\mathrm{SiCl}_{2}$ plus the activation energy to break the $\mathrm{Si}-\mathrm{H}$ bond needed to create a vacant surface site (eq. 2). $\mathrm{k}_{7}$ depends on the heat of adsorption of $\mathrm{SiCl}_{2}$. The ratio $\mathrm{RSiCl}_{2} / \mathrm{R}_{\mathrm{Si}}$ then has an activation energy

$$
E_{R}=E_{11}-E_{7}=E_{\text {diff.SiCl}}+E_{\text {des.H }}-E_{\text {des.SiCl}}
$$

From the experiments (figure 10) $\mathrm{E}_{\mathrm{R}}$ can be calculated to be close to $30 \mathrm{kcal} / \mathrm{mole}$. As the heats of desorption of $\mathrm{H}$ and $\mathrm{SiCl}_{2}$ are nearly equal and $\mathrm{E}\left(\mathrm{diff} . \mathrm{SiCl}_{2}\right)=32$ $\mathrm{kcal} /$ mole according to Van der Putte et al [13] the present effect shows the right order of magnitude. 


\section{References}

1 For a review see J. Bloem and L.J. Giling in Current Topics in Materials Science Volume 1, ch. 4, edited by E. Kaldis (North Holland Publishing Company) (1978).

2 A.A. Chernov, J. Cryst. Growth 42, (1977) 55

A.A. Chernov and M.P. Rusaikin, J. Cryst. Growth 45, (1978) 73.

3 Y. Shiraki, Y. Katayama, K.L. Kobayashi and K.F. Komatsubara, J. Cryst. Growth 45 (1978) 287.

4 J. Bloem, J. Cryst. Growth 18 (1973) 70.

5 P. van der Putte, L.J. Giling and J. Bloem, J. Cryst. Growth 41, (1977), 133.

6 J. Bloem, J. Cryst. Growth 31, (1975) 256.

7 C.H.J. van den Brekel, Thesis, University of Nijmegen, 1978.

8 L.V. Gregor, P. Balk and F J. Campagna, IBM J. Res. Dev. 9, (1965) 327.

9 H.J. Rijks, J. Bloem and L.J. Giling, J. Appl. Phys. 50, (1979) 1370.

10 W.K. Burton, N. Cabrera and F.C. Frank, Phil. Trans. Roy. Soc. 243 (1951) 299.

11 J. Nishizawa, T. Terasaki and M. Shimbo, J. Cryst. Growth 17, (1972) 241.

12 J. Bloem and W.A.P. Claassen, to be published.

13 P. van der Putte, W. van Enckevort, L.J. Giling and J. Bloem, J. Cryst. Growth 43 (1978) 659.

14 J. Burmeister, J. Cryst. Growth 11 (1971) 131.

15 A.G. Revesz and R.J. Evans, Trans. Metall. Soc. AIME 230 (1964) 581.

16 JANAF Thermochemical Tables 2nd ed. June 1971, NSRDS-NBS-37. 


\title{
CHAPTER VI
}

\section{RATE-DETERMINING REACTIONS AND SURFACE SPECIES IN CVD OF SILICON}

\author{
II The $\mathrm{SiH}_{2} \mathrm{Cl}_{2}-\mathrm{H}_{2}-\mathrm{N}_{2} \cdot \mathrm{HCl}$ system
}

\section{Summary}

The growth rate of CVD silicon from $\mathrm{SiH}_{2} \mathrm{Cl}_{2}$-nitrogen-hydrogen mixlures is found to be $d$ linear function of the partial pressure of hydrogen at temperdures between $800^{\circ}$ and $1000^{\circ} \mathrm{C}$ Al temperatures below $900^{\circ} \mathrm{C}$, the $\mathrm{SiH}_{2} \mathrm{Cl}_{2}-\mathrm{N}_{2}$ system shows a saturation in growth rate for input concentrations above 0.5 volume percent. This is at variance with the $\mathrm{S}_{1} \mathrm{H}_{2} \mathrm{Cl}_{2}-\mathrm{N}_{2}$ system, which shows a linear dependence between the growth rate and the input concentration of $\mathrm{SiH}_{2} \mathrm{Cl}_{2}$ at $800^{\circ} \mathrm{C}$. Addition of $\mathrm{HCl}$ to the $\mathrm{SiH}_{2} \mathrm{Cl}_{2}-\mathrm{H}_{2}$ system reduces the growth rate d temperatures below $100{ }^{\circ} \mathrm{C}$ due to the lormation of $\mathrm{S}_{1} \mathrm{HCl}_{3}$ in the gas phase. The formation of $\mathrm{SiHCl}_{3}$ is directly related to the dissociation of $\mathrm{SiH}_{2} \mathrm{Cl}_{2}$ in the gas phase into $\mathrm{SiCl}_{2}$ and $\mathrm{H}_{2}$. It is concluded that in a $\mathrm{S}_{1}-\mathrm{H}-\mathrm{N}-\mathrm{Cl}$ system the surface concentration of $\mathrm{SiCl}_{2}$ is always much larger than the $\mathrm{S}_{1}$ adatom concentration. The reduction of $\mathrm{SiCl}_{2}$ dt step sites is proposed to be the rate-limiting reaction, leading to a surface concentration of $\mathrm{SiCl}_{2}$ lar above the equilibrium concentration and favourung desorption of $\mathrm{SiCl}_{2}$. The high $\mathrm{SiCl}_{2}$ concentration accounts for the saturation in growth rate as a function of input concentration of $\mathrm{SiH}_{2} \mathrm{Cl}_{2}$ in hydrogen; the linear increase in growth rate when nitrogen is used as a carrer gas can also be explained along these lines.

\section{Introduction}

In a previous paper [1] (referred to as part I in the following) the rate-determining reactions in the $\mathrm{SiH}_{4}-\mathrm{HCl}-\mathrm{H}_{2}$ system were described at temperatures below 1000 ${ }^{\circ} \mathrm{C}$. It was demonstrated there that $\mathrm{SiCl}_{2}$ is the main surface species in a $\mathrm{Si}-\mathrm{Cl}-\mathrm{H}$ system. It was concluded that candidates for the rate-determining surface reactions below $1000^{\circ} \mathrm{C}$ could be either the surface diffusion of $\mathrm{SiCl}_{2}$ to atomic steps or the chemical reaction at the silicon step to remove the chlorine atoms from the attached $\mathrm{SiCl}_{2}$ molecules. No preference could be given between these possibilities based on the data available at that time. The present paper reports on additional experiments directed at resolving this dilemma, for which purpose the chlorosilanes can be used. Dichlorosilane was selected because unlike other homologues, it decomposes without hydrogen addition. As a consequence, the kinetics of decomposition can be studied with and without either hydrogen or hydrogen chloride being present in the gas phase, thus providing information on rate-limiting steps.

\section{Experimental}

The experiments were performed in a horizontal air-cooled R.F. heated reactor. Most of the experimental conditions have been described in part I, but some additional information is given below. The gas system was provided with automatic mass-flow controllers for the carrier gases hydrogen and nitrogen and the reactants $\mathrm{SiH}_{2} \mathrm{Cl}_{2}$ and $\mathrm{HCl}$ (both electronic grade). The carrier gases were purified to bring 
water and oxygen concentrations below $1 \mathrm{ppm}$. Monocrystalline silicon slices, covered with a $1500 \AA$ thick LPCVD Si ${ }_{3} \mathrm{~N}_{4}$ layer, were used as substrates. In order to avord nucleation difficulties [2] the substrates were covered prior to deposition with a thin polycrystalline silicon layer (about $1000 \AA$ ), using 0.1 vol $\% \mathrm{SiH}_{4}$ in hydrogen for 20 seconds at $1000^{\circ} \mathrm{C}$.

The growth rate of silicon on silicon as a function of temperature from $\mathrm{SiH}_{2} \mathrm{Cl}_{2}$ in hydrogen shows a kinetically controlled regime at temperatures below $1000^{\circ} \mathrm{C}$ and a gas phase diffusion-controlled regime above this temperature [3]. The experiments reported in this paper relate to the kinetically controlled temperature region. Figure 1 shows the growth rate of silicon at an input concentration of $0.4 \mathrm{vol} . \%$ $\mathrm{SiH}_{2} \mathrm{Cl}_{2}$ for different mixtures of hydrogen and nitrogen at 800,900 and 1000 ${ }^{\circ} \mathrm{C}$. As can be seen, the growth rate depends linearly on the partial pressure of hydrogen. The growth rate as a function of the input concentration of $\mathrm{SiH}_{2} \mathrm{Cl}_{2}$ in a hydrogen atmosphere is given in Figure 2 at temperatures between $800^{\circ}$

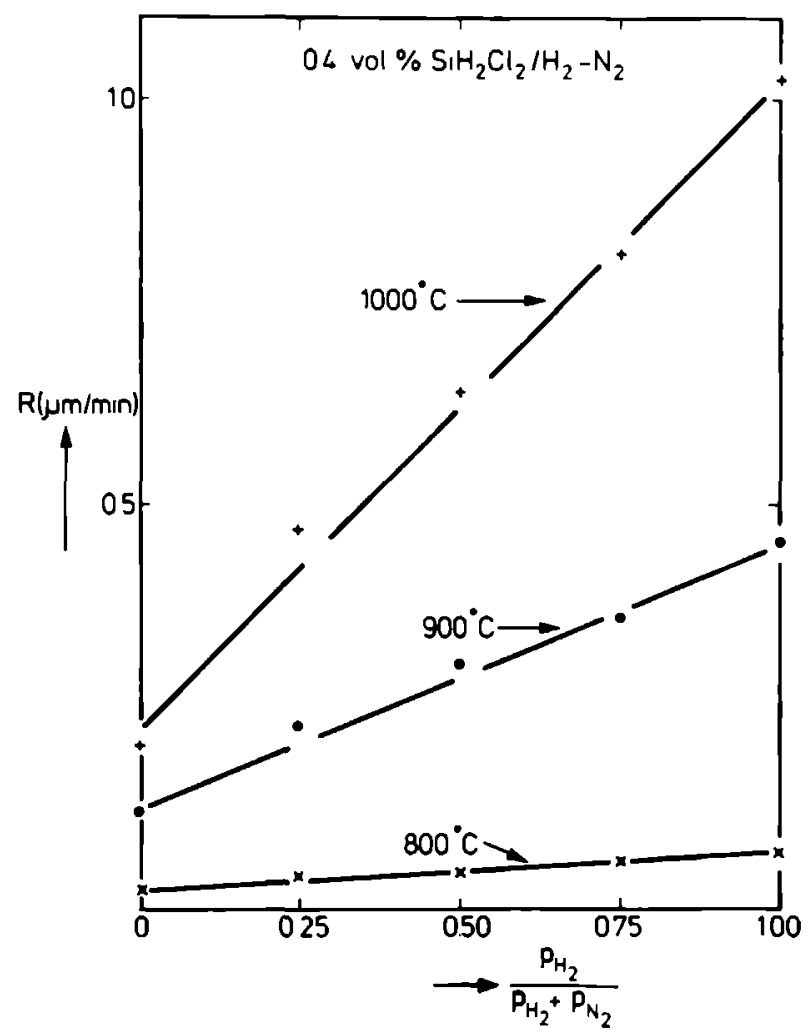

Figure 1.

Growth rate versus the content of $\mathrm{H}_{2}$ of mixtures of $\mathrm{H}_{2}-\mathrm{N}_{2}-\mathrm{SiH}_{2} \mathrm{Cl}_{2}$, for $0.4 \mathrm{vol}$. \% $\mathrm{SiH}_{2} \mathrm{Cl}_{2}$ at 800,900 and $1000^{\circ} \mathrm{C}$. 


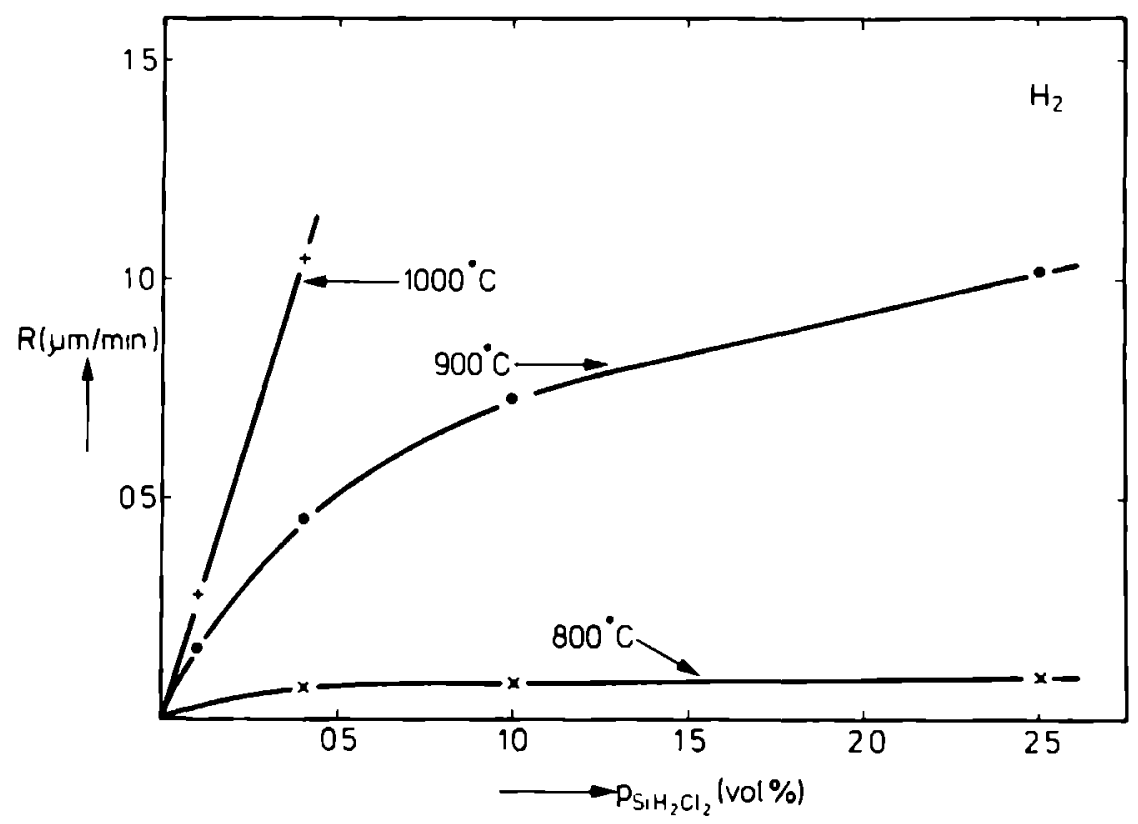

Figure 2.

Growth rate as a function of input concentration of $\mathrm{SiH}_{2} \mathrm{Cl}_{2}$ at 800,900 and $1000^{\circ} \mathrm{C}$ in a $\mathrm{H}_{2}$ ambient.

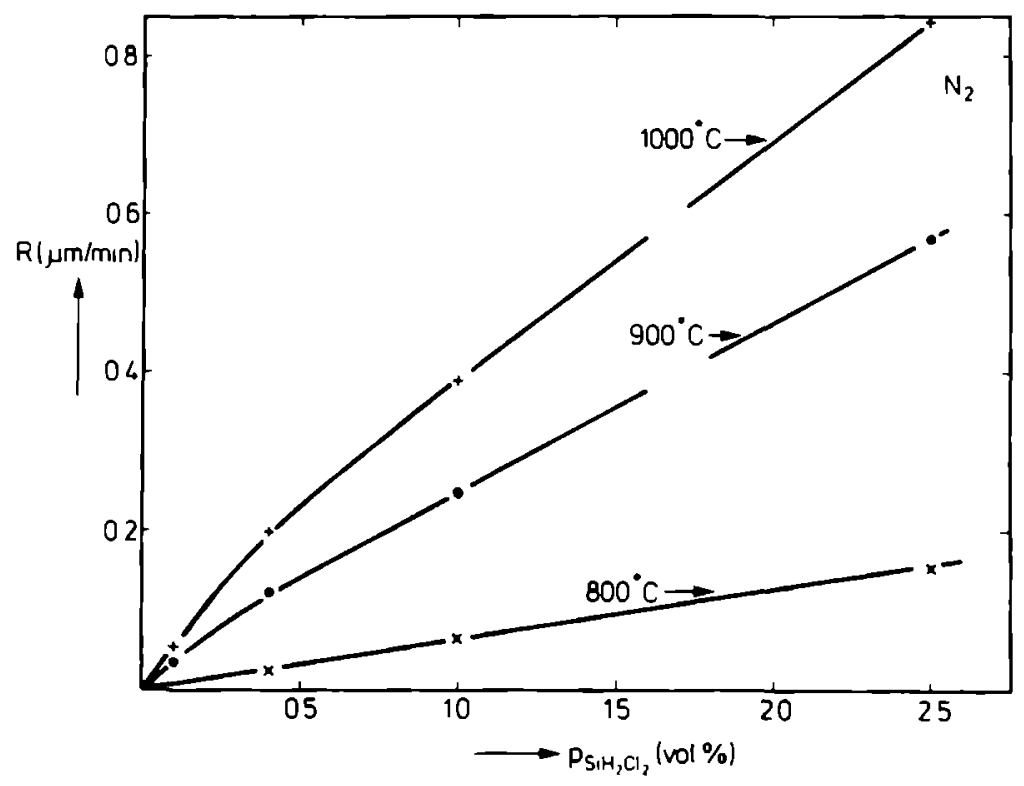

Figure 3.

The growth in a $N_{2}$ atmosphere at 800,900 and $1000^{\circ} \mathrm{C}$ as a function of the input concentrations of $\mathrm{SiH}_{2} \mathrm{Cl}_{2}$. 


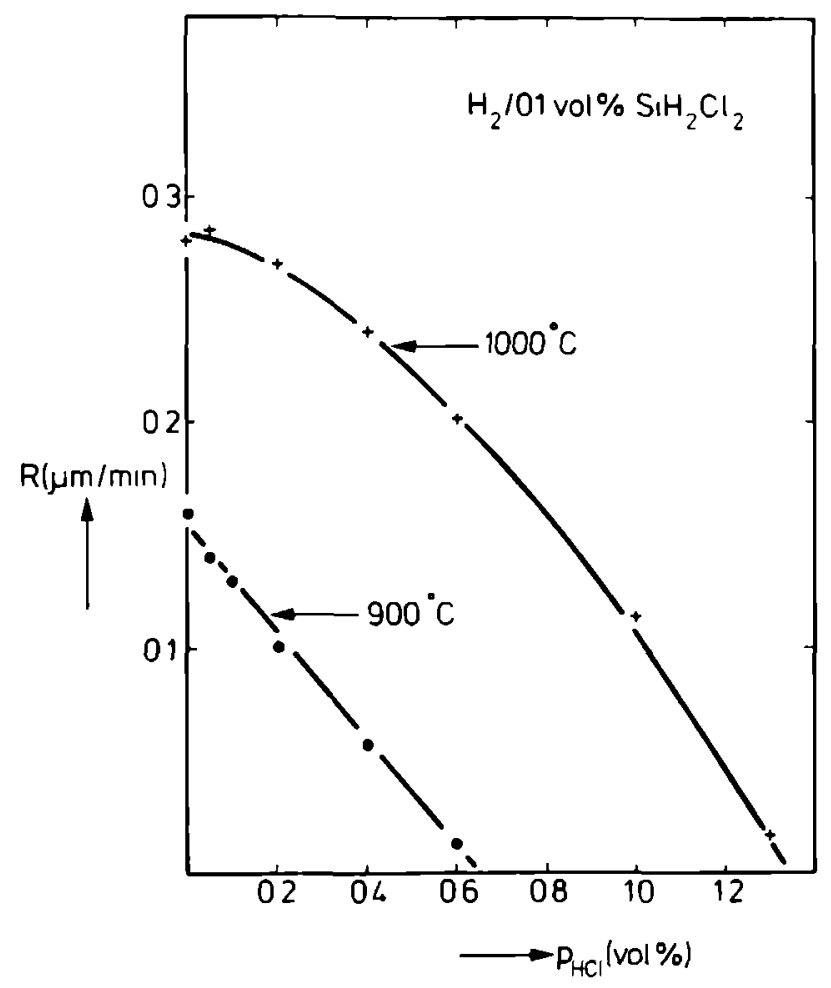

Figure 4.

Influence of addition of $\mathrm{HCl}$ on the growth rate of 0.1 vol. \% $\mathrm{SiH}_{2} \mathrm{Cl}_{2}$ in $\mathrm{H}_{2}$ at 900 and $1000^{\circ} \mathrm{C}$.

and $1000^{\circ} \mathrm{C}$. It can be observed from Figure 2 that the growth rate deviates from linearity, notably at the lowest temperatures. Figure 3 gives the growth rate as a function of the input concentration of $\mathrm{SiH}_{2} \mathrm{Cl}_{2}$ in nitrogen. Contrary to the experimental data of Figure 2, there is no saturation effect observable at $800^{\circ} \mathrm{C}$, while at temperatures above $800^{\circ} \mathrm{C}$ the growth rate becomes non-linear. Addition of $\mathrm{HCl}$ to the $\mathrm{SiH}_{2} \mathrm{Cl}_{2} \cdot \mathrm{H}_{2}$ system results in a growth rate behaviour as shown in Figures 4 and 5 . Figure 4 gives data for the growth rate as a function of $\mathrm{HCl}$ added to 0.1 vol. $\% \mathrm{SiH}_{2} \mathrm{Cl}_{2}$ at 900 and $1000^{\circ} \mathrm{C}$. At $1000^{\circ} \mathrm{C}$ the decrease in the growth rate is almost a quadratic function of the input concentration of $\mathrm{HCl}$ while at $900{ }^{\circ} \mathrm{C}$ addition of $\mathrm{HCl}$ gives rise to a decrease in the growth rate, which is almost linear with $\mathrm{PHCl}_{\mathrm{H}}$. This linear relation between the growth rate of silicon and the input concentration of hydrogen chloride can also be observed in Figure 5, which gives the results of experiments performed with $0.4 \mathrm{vol} . \% \mathrm{SiH}_{2} \mathrm{Cl}_{2}$ at 800 and $900{ }^{\circ} \mathrm{C}$. The addition of $\mathrm{HCl}$ to the $\mathrm{SiH}_{2} \mathrm{Cl}_{2}-\mathrm{N}_{2}$ system at 800,900 and $1000^{\circ} \mathrm{C}$ 


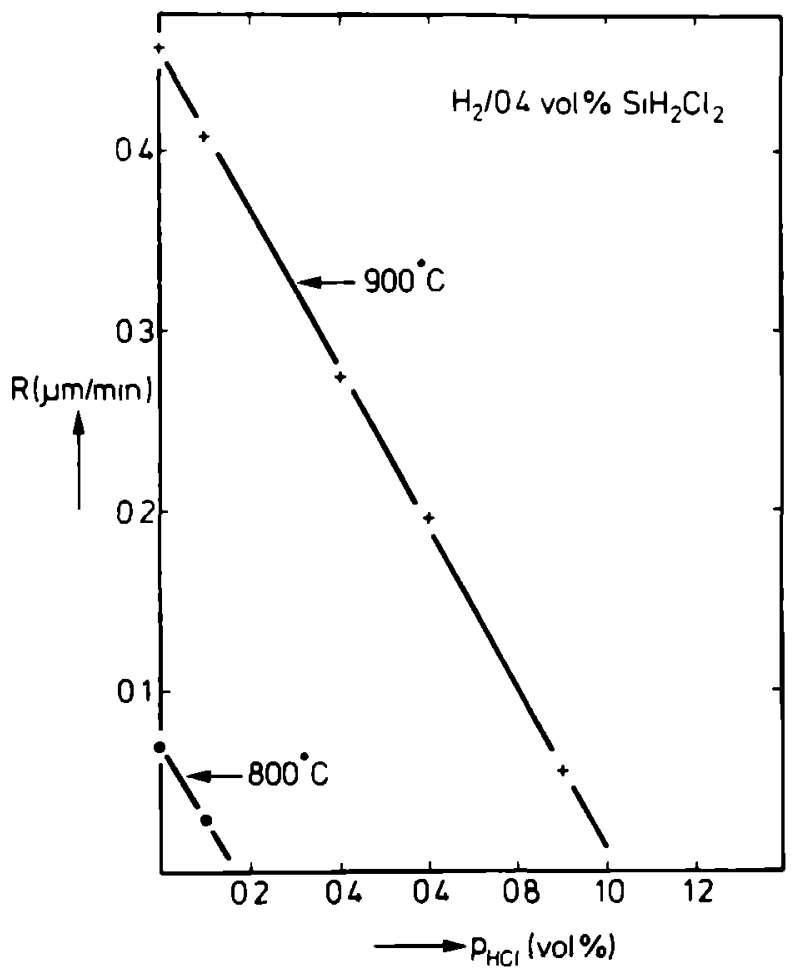

Figure 5 .

The growth rate of $0.4 \mathrm{voL} \% \mathrm{SiH}_{2} \mathrm{Cl}_{2}$ at 800 and $900{ }^{\circ} \mathrm{C}$ as a function of the input concentration of $\mathrm{HCl}$ in hydrogen as a carrier gas.

shows the results as given in Figure 6. In this temperature range and for an input of 0.1 vol. $\% \mathrm{SiH}_{2} \mathrm{Cl}_{2}$ the growth rate varies linearly with the input concentration of $\mathrm{HCl}$. The slopes of these lines decrease with decreasing temperature.

\section{Discussion}

\subsection{Introduction}

In order to arrive at an expression that describes the growth rate of silicon in the $\mathrm{SiH}_{2} \mathrm{Cl}_{2} \cdot \mathrm{H}_{2} \cdot \mathrm{HCl}$ system it is necessary to consider a number of possible reactions that can take place on or near the surface. These are summarized in the Appendix. The following steps should be considered:

a. Supply of $\mathrm{SiH}_{2} \mathrm{Cl}_{2}$ through gas phase diffusion.

b. Gas phase reactions, such as dissociation of $\mathrm{SiH}_{2} \mathrm{Cl}_{2}$ into $\mathrm{SiCl}_{2}$ and $\mathrm{H}_{2}$ and formation of $\mathrm{SiHCl}_{3}$. 


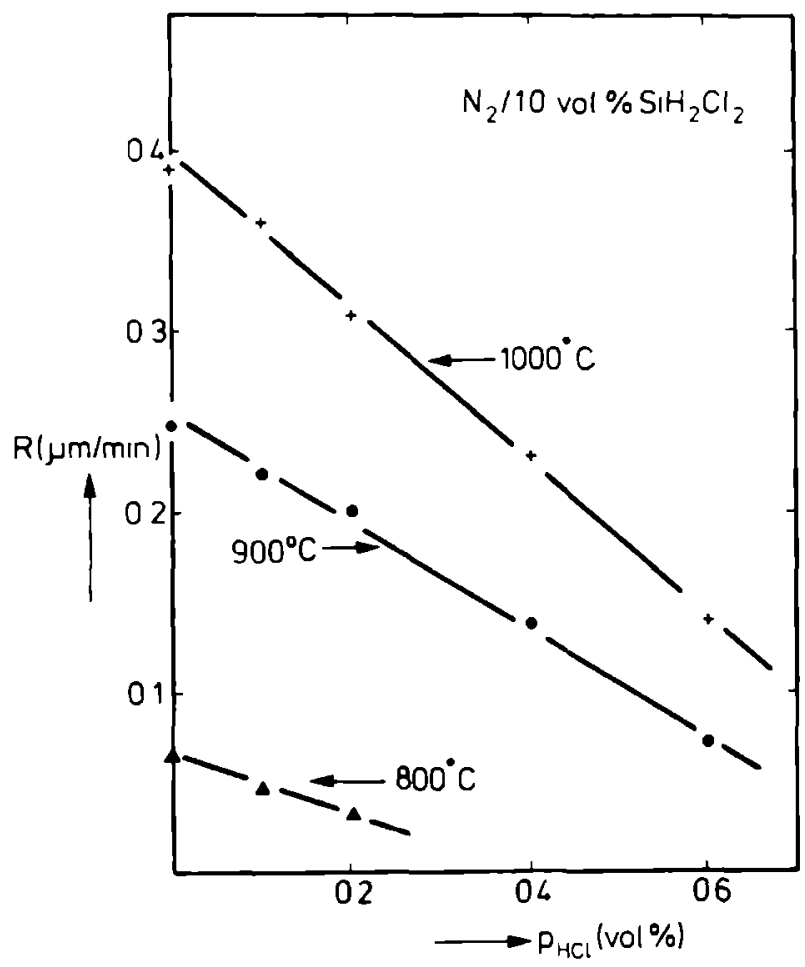

Figure 6.

Growth rate as a function of increasing amounts of $\mathrm{HCl}$ in mixtures of $1.0 \mathrm{vol} . \%$ $\mathrm{SiH}_{2} \mathrm{Cl}_{2}$ in $\mathrm{N}_{2}$ at 800,900 and $1000^{\circ} \mathrm{C}$.

c. Adsorption of different species on the surface, such as $\mathrm{SiCl}_{2}$, chlorine and hydrogen .

d. Surface reactions followed by incorporation of silicon at the steps.

For the silicon growth rate the following expression is found (by introducing A-19 and $\mathrm{A}-20$ into $\mathrm{A}-18$ ):

$\mathrm{R}=\frac{\mathrm{k}_{4} \mathrm{k}_{14} \mathrm{k}_{15} \mathrm{P}_{\mathrm{H}_{2}} \mathrm{PSiCl}_{2} \theta}{\left(\mathrm{k} .4_{.4}+\mathrm{k}_{14}\right)\left(\mathrm{k}_{.14}+\mathrm{k}_{15} \mathrm{P}_{\mathrm{H}_{2}}\right)}-\frac{\mathrm{K}_{\mathrm{e}} \mathrm{P}_{\mathrm{HCl}}^{2}}{\mathrm{P}_{\mathrm{H}_{2}}}$

with the fraction of free surface sites $\theta$ given by equation (A-22):

$\theta=\frac{1}{1+\mathrm{K}_{4} \mathrm{PSiCl}_{2}+\mathrm{K}_{5} \mathrm{P}_{\mathrm{HCl}} / \mathrm{P}_{\mathrm{H}_{2}}^{1 / 2}+\mathrm{K}_{6} \mathrm{P}_{\mathrm{H}_{2}}^{1 / 2}}$. 
The first term of equation (1) describes the growth via reduction of $\mathrm{SiCl}_{2}$ species adsorbed on step sites of the silicon surface The negative term stems from etching reactions caused by gaseous hydrogen chlonde With the and of the assumptions made in the Appendux rate-limiting reactions can be classified In Table I these ratelimiting reactions are given in the case that no $\mathrm{HCl}$ is added and assuming complete gas phase dissociation of $\mathrm{SiH}_{2} \mathrm{Cl}_{2}$ into $\mathrm{SiCl}_{2}$ and $\mathrm{H}_{2}$ Comparison with the exper1mental results indicates that $e$ is the most probable rate-limiting reaction in which $\theta$ is constant over a wide range of experimental conditions The assumptions made in order to obtain equation (1) and Table I will be discussed in the following sections

\section{TABLE I}

Possible rate-limiting reactions for the growth of slicon from $\mathrm{S}_{1} \mathrm{H}_{2} \mathrm{Cl}_{2}$ in $\mathrm{H}_{2}-\mathrm{N}_{2}$ muxtures Complete dissociation of $\mathrm{SiH}_{2} \mathrm{Cl}_{2}$ into $\mathrm{SiCl}_{2}$ and $\mathrm{H}_{2}$ is assumed and the reactions, as given in the Appendix are used $R_{1}$ gives an expression for the growth rate when the corresponding reaction is rate-limiting $\mathrm{P}_{\mathrm{SiH}_{2}}^{\mathrm{O}} \mathrm{Cl}_{2}$ is the input concentration of $\mathrm{S}_{1} \mathrm{H}_{2} \mathrm{Cl}_{2}$

\begin{tabular}{|c|c|c|}
\hline \multicolumn{2}{|c|}{ Reaction } & $R_{1}$ for 1 as rate-limiting reaction \\
\hline a & gas phase diffusion (eq (A-0)) & $\mathrm{R}_{\mathrm{a}}=\mathrm{k}_{\mathrm{a}} \mathrm{P}_{\mathrm{S}_{1} \mathrm{H}_{2} \mathrm{Cl}_{2}}^{\mathrm{O}}$ \\
\hline $\mathrm{b}$ & $\begin{array}{l}\text { gas phase dissociation of } \mathrm{S}_{1} \mathrm{H}_{2} \mathrm{Cl}_{2} \\
\text { (eq (A-1)) }\end{array}$ & $\mathrm{R}_{\mathrm{b}}=\mathrm{kb}_{\mathrm{b}} \mathrm{P}_{\mathrm{S}_{1} \mathrm{H}_{2} \mathrm{Cl}_{2}}^{\mathrm{O}}$ \\
\hline c & adsorption of $\mathrm{SICl}_{2}($ eq $(\mathrm{A}-4))$ & $\mathrm{R}_{\mathrm{c}}=\mathrm{k}_{\mathrm{c}} \mathrm{P}_{\mathrm{S}_{1} \mathrm{H}_{2} \mathrm{Cl}_{2}}^{0}$ \\
\hline $\mathrm{d}$ & $\begin{array}{l}\text { incorporation of } \mathrm{SiCl}_{2} \text { at an } \\
\text { atomic step (eq }(\mathrm{A}-14) \text { ) }\end{array}$ & $\mathrm{R}_{\mathrm{d}}=\mathrm{k}_{\mathrm{d}} \mathrm{P}_{\mathrm{SiH}_{2} \mathrm{Cl}_{2}}^{\mathbf{0}}$ \\
\hline e & $\begin{array}{l}\text { reduction of } \mathrm{SiCl}_{2} \text { at an } \\
\text { atomic step }(\mathrm{eq}(\mathrm{A}-15))\end{array}$ & $\mathrm{R}_{\mathrm{e}}=\mathrm{k}_{\mathrm{e}} \mathrm{P}_{\mathrm{H}_{2}} \mathrm{P}_{\mathrm{S}_{1} \mathrm{H}_{2} \mathrm{Cl}_{2} \theta}^{\circ}$ \\
\hline
\end{tabular}

The expenmental growth rate is given by

$\mathrm{R}_{\exp }=\mathrm{kexp}_{\exp } \mathrm{P}_{2} \mathrm{P}_{\mathrm{SiH}_{2} \mathrm{Cl}_{2}}^{\mathrm{O}}$ (eq (6))

\section{Interpretation of results}

\section{The $\mathrm{SiH}_{2} \mathrm{Cl}_{2}-\mathrm{H}_{2}-\mathrm{N}_{2}-\mathrm{HCl}$ system}

For the slicon growth rate ( $R$ ) equation (1) can be used For not too high input concentrations of $\mathrm{SiH}_{2} \mathrm{Cl}_{2}$, and without deliberate addition of $\mathrm{HCl}$, as discussed 
later, all terms containing $\mathrm{P} \mathrm{HCl}$ can be neglected This approximation leads to

$$
\mathrm{R}=\frac{\mathrm{k}_{4} \mathrm{k}_{14} \mathrm{k}_{15} \mathrm{P}_{\mathrm{H}_{2}} \mathrm{PS}_{1 C_{2}}}{\left(\mathrm{k}_{.4}+\mathrm{k}_{14}\right)\left(\mathrm{k}_{.14}+\mathrm{k}_{15} \mathrm{P}_{\mathrm{H}_{2}}\right)} \times \frac{1}{\left(1+\mathrm{K}_{4} \mathrm{PS}_{1} \mathrm{Cl}_{2}+\mathrm{K}_{6} \mathrm{P}_{\mathrm{H}_{2}^{1}}{ }^{2}\right)}
$$

In the surface-controlled regime of the growth $\left(\mathrm{T}<1000^{\circ} \mathrm{C}\right)$ it is convenient to introduce the decomposition parameter $(\alpha)$ for the gas phase reaction of $\mathrm{SiH}_{2} \mathrm{Cl}_{2}$ (A-1)

$\mathrm{SiH}_{2} \mathrm{Cl}_{2} \stackrel{\mathrm{K}_{1}}{=} \mathrm{SICl}_{2}+\mathrm{H}_{2}$

in which $\mathrm{PS}_{1} \mathrm{H}_{2} \mathrm{Cl}_{2}=(1-\alpha) \mathrm{P}_{\mathrm{S}_{1} \mathrm{H}_{2} \mathrm{Cl}_{2}}^{\mathrm{O}}$

$$
\mathrm{P}_{\mathrm{S}_{1 C l}}=\alpha \mathrm{P}_{\mathrm{S}_{1} \mathrm{H}_{2} \mathrm{Cl}_{2}}^{\mathrm{O}}
$$

If no extra hydrogen is added

$\mathrm{P}_{\mathrm{H}_{2}}=\alpha \mathrm{P}_{\mathrm{S}_{1} \mathrm{H}_{2}}^{\mathrm{O}} \mathrm{Cl}_{2}$

$\mathrm{P}_{\mathrm{S}_{1} \mathrm{H}_{2} \mathrm{Cl}_{2}}^{\mathrm{I}}$ is the input concentration of $\mathrm{SiH}_{2} \mathrm{Cl}_{2}$

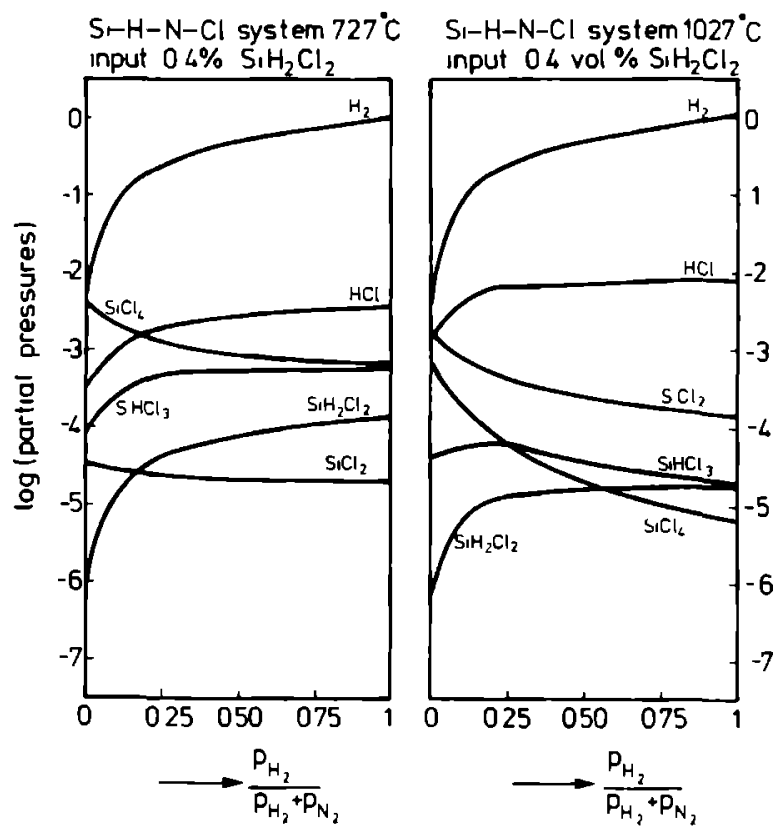

Figure 7

Thermochemical data for the St-H-Cl and the St-N-H-Cl systems at 727 and $1027^{\circ} \mathrm{C}$ and an input of $\mathrm{O} 4 \mathrm{vol} \% \mathrm{SuH}_{2} \mathrm{Cl}_{2}$ 

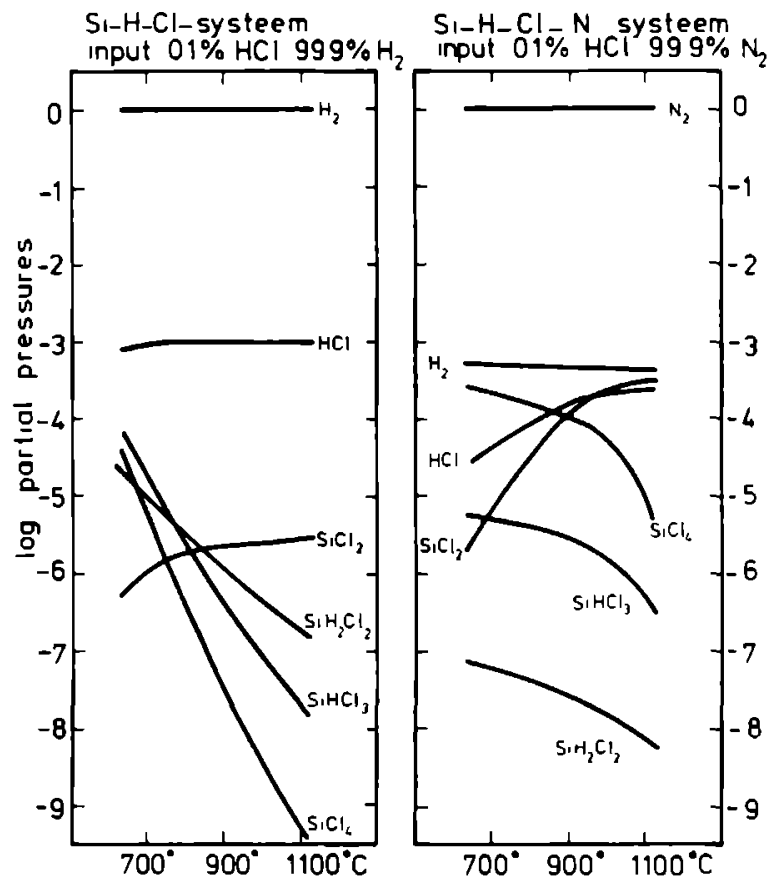

Figure 8.

Thermochemical data for the Si-H-Cl and the Si-H-N-Cl systems as a function of temperature and an input of $0.1 \mathrm{vol} . \% \mathrm{HCl}$.

In order to give an estimate of $\alpha$ thermochemical data on the Si-H-N-Cl system as a function of gas phase composition and temperature are given in Figures 7 and 8. The procedure reported by Van der Putte et al [4] was used. The most abundant species are depicted in Figure 7 as a function of the composition of the hydrogennitrogen mixture at $727^{\circ}$ and $1027^{\circ} \mathrm{C}$ and an input of $0.4 \mathrm{vol} . \% \mathrm{SiH}_{2} \mathrm{Cl}_{2}$, and in Figure 8 as a function of temperature in hydrogen and nitrogen and an input of $0.1 \mathrm{vol} . \% \mathrm{HCl}$. From these thermodynamic data it can be deduced that the $\alpha$ values are in general close to unity for the gas phase decomposition of $\mathrm{SiH}_{2} \mathrm{Cl}_{2}$ both in nitrogen and in hydrogen. At low temperatures in hydrogen, however, the value of $\alpha$ becomes appreciably smaller. This follows from the equilibrium constant $K_{1}$ and equation (3):

$$
\mathrm{K}_{1}=\frac{\mathrm{PSiCl}_{2} \mathrm{P}_{2}}{\mathrm{PSiH}_{2} \mathrm{Cl}_{2}}=\frac{\alpha \mathrm{PH}_{2}}{(1-\alpha)}
$$


thus $\alpha=\frac{\mathrm{K}_{1}}{\mathrm{~K}_{1}+\mathrm{P}_{\mathrm{H}_{2}}}$

According to the thermochemical data [5] the value of $K_{1}$ is 61 at $100{ }^{\circ} \mathrm{C}$ and $66 \times 10^{-2}$ at $700^{\circ} \mathrm{C}$ At the lower temperatures $\alpha$ can best be considered equal to $\mathrm{K}_{1} / \mathrm{PH}_{2}$ in contrast to the situation at higher temperatures or the situation where $\mathrm{P}_{\mathrm{H}_{2}}$ is small (inert gas or reduced pressure) giving $\alpha=1$

For the growth rate of silicon in a hydrogen ambient it follows from equations (2), (3) and (4) that

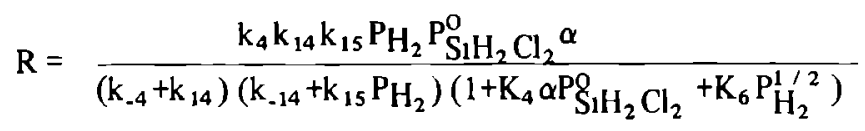

According to Figure 1 the expenimentally found growth rate can be expressed as

$$
\mathrm{R}_{\exp }=\mathrm{K}_{\exp } \mathrm{PH}_{2} \mathrm{P}_{\mathrm{S}_{1} \mathrm{H}_{2} \mathrm{Cl}_{2}}^{\mathrm{O}}
$$

Companson of equations (5) and (6) leads to the following conclusions For relatively low input concentrations of $\mathrm{S}_{1} \mathrm{H}_{2} \mathrm{Cl}_{2}$ and $\alpha$ close to unity (above $900^{\circ} \mathrm{C}$, according to equation (4) and thermochemical data at those temperatures) it may be concluded that $\mathrm{k}_{-14}>\mathrm{k}_{15} \mathrm{P}_{2}$ and $\mathrm{K}_{4} \alpha \mathrm{P}_{\mathrm{S}_{1} \mathrm{H}_{2} \mathrm{Cl}_{2}}^{\mathrm{O}}+\mathrm{K}_{6} \mathrm{P}_{\mathrm{H}_{2}}^{1 / 2}<1$ According to Figure 1 at $800^{\circ} \mathrm{C}$ the growth rate found is nearly independent of the presence of hydrogen This point can be understood from the smaller values of $\alpha$ (equation (4)) at these lower temperatures $\left(\alpha=\mathrm{K}_{1} / \mathrm{P}_{\mathrm{H}_{2}}\right)$ in combination with $\mathrm{k}_{.14}>\mathrm{k}_{15} \mathrm{P}_{\mathrm{H}_{2}}$ and

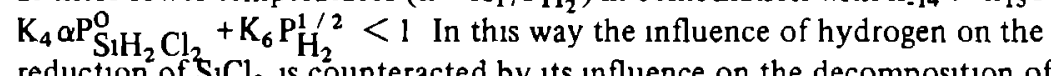
reduction of $\mathrm{SlCl}_{2}$ is counteracted by its influence on the decomposition of $\mathrm{S}_{1} \mathrm{H}_{2} \mathrm{Cl}_{2}$ to form $\mathrm{SiCl}_{2}$ In conclusion it can be said that $\mathrm{k}_{.14}$ has to be larger than $\mathrm{k}_{15} \mathrm{P}_{\mathrm{H}_{2}}$, which means that the chemical reaction at the steps constitutes the slowest and rate determining step in the chan of reactions Also interesting is the conclusion that $\mathrm{K}_{6} \mathrm{P}_{\mathrm{H}_{2}}^{12}$ has to be smaller than unity, which leads to a smaller surface concentration of monoatomic hydrogen than postulated by Chernov [6] Equation (5) indicates that saturation of the growth rate as a function of the input concentration of $\mathrm{SiH}_{2} \mathrm{Cl}_{2}$ can be expected if $\mathrm{K}_{4} \alpha \mathrm{P}_{\mathrm{S}_{1} \mathrm{H}_{2} \mathrm{Cl}_{2}}^{\mathrm{i}}$ is greater than $\left(1+\mathrm{K}_{6} \mathrm{P}_{\mathrm{H}_{2}}^{1 / 2}\right)$ This is seen to be the case in Figure 2 at the lower femperature, indicating that the adsorption of $\mathrm{SiCl}_{2}$ on the silicon surface is much more pronounced than the adsorption of monoatomic hydrogen

The experiments given in Figure 3 (growth in nitrogen) show a nearly linear variation of the growth rate with increasing input concentration of $\mathrm{S}_{1} \mathrm{H}_{2} \mathrm{Cl}_{2}$ at $800^{\circ} \mathrm{C}$ Saturation does not occur as it does in hydrogen (Figure 2) In the 
$\mathrm{S}_{1} \mathrm{H}_{2} \mathrm{Cl}_{2} \cdot \mathrm{N}_{2}$ system this can readily be explained with the ald of equation (2) Again $\mathrm{K}_{15} \mathrm{P}_{\mathrm{H}_{2}}<\mathrm{K}_{-14}$ and $\mathrm{K}_{6} \mathrm{P}_{\mathrm{H}_{2}}^{\prime}<\mathrm{K}_{4} \mathrm{PS}_{\mathrm{SICl}_{2}}$ is assumed Now according to equation (3), $\mathrm{P}_{\mathrm{H}_{2}}$ is equal to $\alpha \mathrm{P}_{\mathrm{S}_{1} \mathrm{H}_{2}}^{\mathrm{O}} \mathrm{Cl}_{2}$ and equation (2) becomes

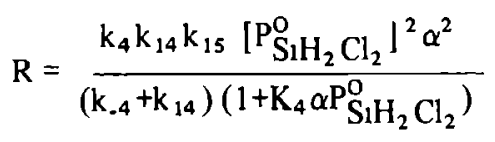

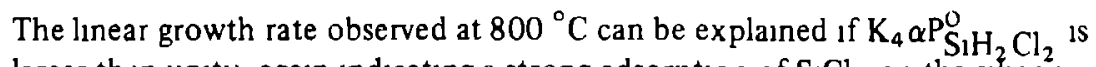
larger than unity, again indicating a strong adsorption of $\mathrm{SiCl}_{2}$ on the silicon surface At temperatures above $800^{\circ} \mathrm{C}$ there is a gradual change to the situation above $1000^{\circ} \mathrm{C}$ where the supply of reactants from the gas phase determines the growth rate $\mathrm{At}$ the higher growth rates more $\mathrm{HCl}$ is formed as a reaction product Notably at higher input concentrations of $\mathrm{SiH}_{2} \mathrm{Cl}_{2}$, therefore, the full equation (1) has to be considered, leading to a lowering of the growth rate and a deviation from linearity because of the back-etching effect of hydrogen chloride As the etching is proportional to $\mathrm{P}_{\mathrm{HCl}}^{2} / \mathrm{PH}_{2}$ [4] increased etch rates are found in an inert medium with a low value of $\mathrm{P}_{2}$ Indeed, for the $\mathrm{S}_{1} \mathrm{H}_{2} \mathrm{Cl}_{2} \cdot \mathrm{N}_{2}$ system the deviation from lineanty is much larger than for the $\mathrm{SiH}_{2} \mathrm{Cl}_{2} \cdot \mathrm{H}_{2}$ system (Figures 2 and 3 at $1000^{\circ} \mathrm{C}$ )

In the $\mathrm{S}_{1} \mathrm{H}_{2} \mathrm{Cl}_{2} \cdot \mathrm{H}_{2}$ system a deviation from linearity in the growth rate of silicon can be expected for high input concentrations of $\mathrm{SiH}_{2} \mathrm{Cl}_{2}$, as observed by Robinson and Goldsmith [7]

Experımentally the growth rate depends strongly on the partial pressure of hydrogen In order to find out whether the type of inert gas influences the growth rate, we performed a growth expenment at $1000^{\circ} \mathrm{C}$ in helium as a carner gas and an input of $04 \mathrm{vol} \% \mathrm{SiH}_{2} \mathrm{Cl}_{2}$ With this mixture the growth rate is $024 \mu \mathrm{m} / \mathrm{min}$ With nitrogen as a carrier gas, the growth rate at otherwise similar conditions, was $020 \mu \mathrm{m} / \mathrm{min}$ The conclusion is therefore that the growth rate is not determined by the hydrodynamics of the gas flow but by chemical reactions at the surface

\section{$322 \mathrm{The} \mathrm{S}_{2} \mathrm{H}_{2} \mathrm{Cl}_{2} \cdot \mathrm{H}_{2} \cdot \mathrm{HCl}$ system}

The experimental data on the addition of $\mathrm{HCl}$ to the $\mathrm{SlH}_{2} \mathrm{Cl}_{2} \mathrm{H}_{2}$ system are given in Figures 4 and 5 These figures show the growth rate for two input concentrations of $\mathrm{S}_{1} \mathrm{H}_{2} \mathrm{Cl}_{2}$ at temperatures between 800 and $1000^{\circ} \mathrm{C}$ Comparison of these data with those of the $\mathrm{SiH}_{4}-\mathrm{HCl}-\mathrm{H}_{2}$ system (part I) leads to the following conclusions

At $1000{ }^{\circ} \mathrm{C}$ in the diffusion limited high temperature regime the $\mathrm{S}_{1} \mathrm{H}_{4} \cdot \mathrm{H}_{2} \cdot \mathrm{HCl}$ and the $\mathrm{S}_{1} \mathrm{H}_{2} \mathrm{Cl}_{2} \cdot \mathrm{HCl} \cdot \mathrm{H}_{2}$ systems show a nearly simular behavour The surface processes occur easuly and the supply of reactants from the gas phase determines the combined effect of growth and etching Closer inspection, however, shows a larger 
decrease in growth rate for the $\mathrm{S}_{1} \mathrm{H}_{2} \mathrm{Cl}_{2}$ system, compared to the $\mathrm{S}_{1} \mathrm{H}_{4}-\mathrm{H}_{2} \mathrm{HCl}$ system at $1000^{\circ} \mathrm{C}$ Another term, linear in $\mathrm{P}_{\mathrm{HCl}}$ has to be added

At temperatures below $1000{ }^{\circ} \mathrm{C}$ surface reactions constitute the rate-limiting step and typical differences between the $\mathrm{S}_{1} \mathrm{H}_{2} \mathrm{Cl}_{2} \cdot \mathrm{H}_{2} \cdot \mathrm{HCl}$ system and the $\mathrm{S}_{1} \mathrm{H}_{4}-\mathrm{H}_{2}-\mathrm{HCl}$ system show up At 800 and $900{ }^{\circ} \mathrm{C}$ the addition of $\mathrm{HCl}$ to $\mathrm{S}_{1} \mathrm{H}_{4}-\mathrm{H}_{2}$ causes a rapid decrease in growth rate and this decrease is proportional to $\mathrm{P}_{\mathrm{HCl}}^{2}$ The rapid initial decrease is followed by a slower decrease in growth rate, which is also proportional to $\mathrm{P}_{\mathrm{HCl}}^{2}$ (part I) In the $\mathrm{SiH}_{2} \mathrm{Cl}_{2}-\mathrm{H}_{2}-\mathrm{HCl}$ system a linear dependence is found between the decrease in growth rate and the amount of $\mathrm{HCl}$ added (Figures 4 and 5) In the $\mathrm{SiH}_{4}-\mathrm{H}_{2} \mathrm{HCl}$ system the rapid decrease in growth rate is explained in terms of the conversion of the reactive $\mathrm{Si}$ or $\mathrm{SiH}_{2}$ surface species into $\mathrm{SiCl}_{2}$ on the addition of small amounts of $\mathrm{HCl}$ (part I) The absence of a rapid initial decrease in growth rate in the $\mathrm{S}_{1} \mathrm{H}_{2} \mathrm{Cl}_{2}-\mathrm{H}_{2}-\mathrm{HCl}$ system leads to the conclusion that the concentration of $\mathrm{S}_{1}$ is small compared to the concentration of $\mathrm{SiCl}_{2}$ adsorbed on the surface Even without the addition of $\mathrm{HCl}$, the main mobile species on the surface is expected to be the $\mathrm{SiCl}_{2}$ molecule The linear decrease in growth rate with input concentration of $\mathrm{HCl}$ at temperatures below $1000^{\circ} \mathrm{C}$ is supposed to be caused by the formation of $\mathrm{SiHCl}_{3}$ in the gas phase (reaction $\mathrm{A} \mathrm{1,} \mathrm{A-2)}$

$\begin{aligned} & \mathrm{SiH}_{2} \mathrm{Cl}_{2} \stackrel{\mathrm{k}_{1}}{\rightleftharpoons} \mathrm{k}_{-1} \mathrm{SlCl}_{2}+\mathrm{H}_{2} \\ & \mathrm{~S}_{1} \mathrm{Cl}_{2}+\mathrm{HCl} \stackrel{\mathrm{k}_{2}}{\rightarrow} \mathrm{S}_{1} \mathrm{HCl}_{3}\end{aligned}$

Since $\mathrm{S}_{1} \mathrm{H}_{2} \mathrm{Cl}_{2}$ readily dissociates into $\mathrm{SlCl}_{2}$ and $\mathrm{H}_{2}$ the formation of $\mathrm{SiHCl}_{3}$ from $\mathrm{S}_{1} \mathrm{Cl}_{2}$ and $\mathrm{HCl}$ in the gas phase has to be expected at the lower temperatures in hydrogen, as may be seen from Figures 7 and 8 Combination of equation (A-1) and (A-2) leads to

$\mathrm{P}_{\mathrm{SiCl}_{2}}=\frac{\mathrm{k}_{1} \mathrm{PS}_{\mathrm{S}} \mathrm{H}_{2} \mathrm{Cl}_{2}}{\mathrm{k}_{2} \mathrm{P}_{\mathrm{HCl}}+\mathrm{k}_{-1} \mathrm{P}_{\mathrm{H}_{2}}}$

Inserting this equation into equation (1) we obtain an expression describing the growth rate Addition of $\mathrm{HCl}$ will lower the partial pressure of $\mathrm{S}_{1} \mathrm{Cl}_{2}$ and consequently cause a linear decrease in the growth rate The term $\mathrm{KeP}_{\mathrm{e}}^{2} \mathrm{HCl}^{2} / \mathrm{P}_{\mathrm{H}_{2}}$ in equation (1) is of minor importance under the expenmental conditions, according to measured etch rates of sulicon by $\mathrm{HCl}$ in hydrogen (part I) The formation of $\mathrm{SiHCl}_{3}$ did not play any role in the $\mathrm{SiH}_{4}-\mathrm{H}_{2}-\mathrm{HCl}$ system In that case $\mathrm{SiCl}_{2}$ is a reaction product of the surface reactions between silicon and hydrogen chlonde The concentration of $\mathrm{S}_{1} \mathrm{Cl}_{2}$ in the gas phase is small and, according to $\mathrm{Van}$ der Putte et al [4], desorption of $\mathrm{SiCl}_{2}$ is not rate-limiting These circumstances 
guarantee that possible gas phase reactions wll not influence the growth rate in the $\mathrm{S}_{1} \mathrm{H}_{4}-\mathrm{H}_{2} \mathrm{HCl}$ system

Formation of $\mathrm{SiCl}_{4}$ as a reaction product is also possible according to the thermo chemical data as shown in Figures 7 and 8 From the experimental results, however, no evidence can be obtained that formation of $\mathrm{SiCl}_{4}$ contributes to the growth of silicon The reason for this is that $\mathrm{SiCl}_{4}$ has to be formed on the surface via additional, rather complicated reactions and it is therefore understandable that the resulting $\mathrm{S}_{1} \mathrm{Cl}_{4}$ concentration remains small, in accordance with mass spectrometric analysis performed by Ban and Gilbert [8]

\section{The $\mathrm{SlH}_{2} \mathrm{Cl}_{2} \mathrm{~N}_{2}-\mathrm{HCl}$ system}

Figure 6 gives the growth rate for an input concentration of 10 vol $\% \mathrm{~S}_{1} \mathrm{H}_{2} \mathrm{Cl}_{2}$ and increasing amounts of $\mathrm{HCl}$ at 800,900 and $1000^{\circ} \mathrm{C}$ At all three temperatures the growth rate depends linearly on the $\mathrm{HCl}$ input concentration but this effect de creases with decreasing temperature

The experments described so far all show gas phase diffusion-limited growth rates at temperatures of $1000{ }^{\circ} \mathrm{C}$ and above This is also expected in the $\mathrm{S}_{1} \mathrm{H}_{2} \mathrm{Cl}_{2}-\mathrm{N}_{2}$ system Still on addition of $\mathrm{HCl}$, a linear decrease in the growth rate with increasing values of $\mathrm{PHCl}$ is found at $1000^{\circ} \mathrm{C}$ (Figure 6) According to Van der Putte et al [4] the etch rate of slicon by $\mathrm{HCl}$ is proportional to the equilibrium concentration of $\mathrm{SiCl}_{2}$ on the surface, being proportional to $\mathrm{PHCl}_{\mathrm{HC}}^{2} / \mathrm{PH}_{2}$ In the present case no extra hydrogen is added to the gas mixture The etching is described by

$\mathrm{S}+2 \mathrm{KCl} \stackrel{\mathrm{a}_{\mathrm{a}}}{\rightleftharpoons} \mathrm{SiCl}_{2}+\mathrm{H}_{2}, \quad \mathrm{~K}_{\mathrm{a}}=\frac{\mathrm{PSICl}_{2} \mathrm{P}_{\mathrm{H}_{2}}}{\mathrm{P}_{\mathrm{HCl}}^{2}}$

The overall reaction shows that $\mathrm{PSICl}_{2}$ will be nearly equal to $\mathrm{P}_{\mathrm{H}_{2}}$ in an inert ambient and $\mathrm{PSICl}_{2}$ and $\mathrm{P}_{\mathrm{H}_{2}}$ will both be proportional to $\mathrm{K}_{\mathrm{a}}^{1 / 2} \mathrm{PHCl}_{\mathrm{HCl}}$, leading to an etch rate in an inert gas proportional to $\mathrm{P}_{\mathrm{HCl}}$, in agreement with experimental data [4 9] The growth rate of slicon can now be given by equation (1) by introducing equation (7) for the first term and $\mathrm{Ke}_{\mathrm{e}} \mathrm{PCl}$ for the second term At temperatures below $1000^{\circ} \mathrm{C}$, Figure 6 shows a linear decrease in growth rate for increasing input values of $\mathrm{HCl}$, the same as found at $1000{ }^{\circ} \mathrm{C}$ The slopes of the lines become less steep going to lower temperatures This effect can be attributed to a lower etch rate at lower temperatures Etching experiments with slicon etched by $02 \mathrm{vol} \% \mathrm{HCl}$ in nitrogen showed etch rates of 020,012 and $007 \mu \mathrm{m} / \mathrm{min}$ at temperatures of 1100 , 1000 and $900{ }^{\circ} \mathrm{C}$ respectively [9] These etch rates are sufficient to explain the decrease in growth rate found experimentally in the presence of $\mathrm{SiH}_{2} \mathrm{Cl}_{2}$ Forma toon of $\mathrm{S}_{1} \mathrm{HCl}_{3}$ in the gas phase cannot be excluded but is not directly apparent from the expenmental data $\ln$ this connection Figures 7 and 8 show that in an inert ambient the concentration of $\mathrm{S}_{1} \mathrm{HCl}_{3}$ is indeed relatively low 


\section{Conclusion}

In an attempt to understand the nature of the slowest step in the growth of silicon on silicon we have studied the $\mathrm{S}_{1} \mathrm{H}_{2} \mathrm{Cl}_{2}-\mathrm{H}_{2}-\mathrm{N}_{2} \mathrm{HCl}$ system, comparing the experımental data with those obtained on the $\mathrm{S}_{1} \mathrm{H}_{4}-\mathrm{HCl}-\mathrm{H}_{2}$ system The experiments on the latter system led to the conclusion that the incorporation of silicon at surface steps or the diffusion of $\mathrm{SiCl}_{2}$ on the silicon surface is the slowest step in the chain, but no choice could be made between them By measuring the growth rate, for a constant input concentration of $\mathrm{S}_{1} \mathrm{H}_{2} \mathrm{Cl}_{2}$ at temperatures between 800 and $1000^{\circ} \mathrm{C}$, as a function of the composition of $\mathrm{H}_{2}$ and $\mathrm{N}_{2}$ in the gas-mixture we were able to show that the incorporation of silicon at the step determines the growth rate Further we could explain the observation that the growth rate of silicon at low temperatures $\left(<900^{\circ} \mathrm{C}\right)$ saturates in a hydrogen medium, and not in a nitrogen medium $\left(800^{\circ} \mathrm{C}\right)$, as a function of the input concentration of $\mathrm{SiH}_{2} \mathrm{Cl}_{2}$ Introduction of $\mathrm{HCl}$ to the $\mathrm{S}_{1} \mathrm{H}_{2} \mathrm{Cl}_{2} \cdot \mathrm{H}_{2}$ system shows that $\mathrm{S}_{1} \mathrm{HCl}_{3}$ is formed in the gas phase and it also confirms that the $S_{1}$ adatom concentration is always small compared with the $\mathrm{SiCl}_{2}$ surface concentration in the $\mathrm{Si}-\mathrm{H} \cdot \mathrm{N}-\mathrm{Cl}$ system As a consequence of the conclusion that equation (A-15) constitutes the rate-limiting reaction it follows that the foregoing reactions lead to a quası equilibrium concentration of surface species The surface concentration of $\mathrm{SiCl}_{2}{ }^{*}$ and $\mathrm{SiCl}_{2}$ (st) therefore reflect the supersaturation in the gas phase, no large additional enhancement is expected

\section{Acknowledgement}

The authors wish to thank Dr L J Gling for help with the thermochemical calculations and $\mathrm{Mr} J$ Goonssen for the critical reading of the manuscript 


\section{References}

1 J. Bloem and W.A.P. Claassen, J. Cryst. Growth, in press.

2 W.A.P. Claassen and J. Bloem, to be published.

3 For a review see J. Bloem and L.J. Giling in 'Current Topics in Materials Science', Ed. E. Kaldis North-Holland publishing Comp., Vol. I, Chapter 4 (1978).

4 P. van der Putte, L.J. Giling and J. Bloem, J. Cryst. Growth 41, 133 (1977).

5 JANAF Thermochemical Tables 2nd ed. June 1971, NSRDS-NBS-37.

6 A.A. Chernov, J. Cryst. Growth 42, 55 (1977).

7 P.H. Robinson and N. Goldsmith, J. Elec. Mat. 4, 313 (1975).

8 V.S. Ban and S.L. Gilbe it, J. Electrochem. Soc. 122, 1382 (1975).

9 W.A.P. Claassen, unpublished results.

10 J.E. Smith Jr. and T.O. Sedgwick, Thin Solid Films 40, 1 (1977). 


\section{APPENDIX}

The following reactions can be distinguished:

a. Supply of $\mathrm{SiH}_{2} \mathrm{Cl}_{2}$

$\mathrm{SiH}_{2} \mathrm{Cl}_{2}$ (b) $\stackrel{\mathrm{k}_{\mathrm{a}}}{\rightarrow} \mathrm{SiH}_{2} \mathrm{Cl}_{2}$ (g).

$\mathrm{S}_{1} \mathrm{H}_{2} \mathrm{Cl}_{2}$ (b) is the input concentration of $\mathrm{SiH}_{2} \mathrm{Cl}_{2}$ and $\mathrm{SiH}_{2} \mathrm{Cl}_{2}$ (g) the concentration of $\mathrm{SiH}_{2} \mathrm{Cl}_{2}$ near the silicon surface.

b. Gas phase reactions

$$
\begin{aligned}
& \mathrm{S}_{1} \mathrm{H}_{2} \mathrm{Cl}_{2}(\mathrm{~g}) \underset{\mathrm{k}_{-1}}{\stackrel{\mathrm{k}_{1}}{\rightleftharpoons}} \mathrm{S}_{1} \mathrm{Cl}_{2}(\mathrm{~g})+\mathrm{H}_{2}(\mathrm{~g}) \\
& k_{2} \\
& \mathrm{SiCl}_{2}(\mathrm{~g})+\mathrm{HCl}(\mathrm{g})-\mathrm{S}_{1} \mathrm{HCl}_{3}(\mathrm{~g}) \text {. }
\end{aligned}
$$

c. Adsorption (* denotes a free surface site)

$$
\begin{aligned}
& \mathrm{SiH}_{2} \mathrm{Cl}_{2}(\mathrm{~g})+\underset{\mathrm{k}_{-3}}{\stackrel{\mathrm{k}_{3}}{\rightleftharpoons}} \mathrm{S}_{2} \mathrm{H}_{2} \mathrm{Cl}_{2} * \\
& \mathrm{SiCl}_{2}(\mathrm{~g})+* \underset{\mathrm{k}_{-4}}{\stackrel{\mathrm{k}_{4}}{\rightleftharpoons}} \mathrm{SiCl}_{2} * \\
& \mathrm{HCl}(\mathrm{g})+\underset{\mathrm{k}_{-5}}{\stackrel{\mathrm{k}_{5}}{\rightleftharpoons}} \mathrm{Cl}+1 / 2 \mathrm{H}_{2}(\mathrm{~g}) \\
& 1 / 2 \mathrm{H}_{2}(\mathrm{~g})+* \underset{\mathrm{k}_{-6}}{\stackrel{\mathrm{k}_{6}}{\rightleftharpoons}} \mathrm{H}^{*} .
\end{aligned}
$$

d. Surface reactions

$$
\mathrm{S}_{1} \mathrm{H}_{2} \mathrm{Cl}_{2} \stackrel{\mathrm{k}_{7}}{\stackrel{\mathrm{k}_{-7}}{\rightleftharpoons}} \mathrm{S}_{1} *+2 \mathrm{HCl}(\mathrm{g})
$$




$$
\begin{aligned}
& \mathrm{SiH}_{2} \mathrm{Cl}_{2} \stackrel{\stackrel{\mathrm{k}_{8}}{\rightleftharpoons}}{\rightleftharpoons} \mathrm{SiCl}_{-8} *+\mathrm{H}_{2}(\mathrm{~g}) \\
& \mathrm{SiCl}_{2} *+\mathrm{H}_{2}(\mathrm{~g}) \stackrel{\mathrm{k}_{9}}{\rightleftharpoons} \mathrm{Sl}_{-9}^{*}+2 \mathrm{HCl}(\mathrm{g}) \\
& \mathrm{SiCl}_{2}^{*}+\mathrm{HCl}(\mathrm{g}) \stackrel{\mathrm{k}_{10}}{\rightarrow} \mathrm{SiHCl}_{3}(\mathrm{~g})+* \\
& \mathrm{SiCl}_{2} *+\mathrm{SiCl}_{2}(\mathrm{~g}) \stackrel{\mathrm{k}_{11}}{\rightarrow} \mathrm{SiCl}_{4}(\mathrm{~g})+\mathrm{Sl}(\mathrm{cr})
\end{aligned}
$$

e Growth reactions

((st) denotes a position at an atomic step on the surface, $\mathrm{Sl}$ (cr) means that the silicon has found a stable position as part of the crystal)

$$
\begin{aligned}
& \mathrm{Sl}_{1} * \underset{\mathrm{k}_{-12}}{\stackrel{\mathrm{k}_{12}}{\rightleftharpoons}} \mathrm{Sl}(\mathrm{st}) \\
& \mathrm{Sl}(\mathrm{st}) \underset{\mathrm{k}_{-13}}{\stackrel{\mathrm{k}_{13}}{\rightleftharpoons}} \mathrm{Sl}(\mathrm{cr}) \\
& \mathrm{SiCl}_{2} * \underset{\mathrm{k}_{-14}}{\stackrel{\mathrm{k}_{14}}{\rightleftharpoons}} \mathrm{SlCl}_{2}(\mathrm{st}) \\
& \mathrm{SlCl}_{2}(\mathrm{st})+\mathrm{H}_{2}(\mathrm{~g}) \underset{\mathrm{k}_{-15}}{\stackrel{\mathrm{k}_{15}}{\rightleftharpoons}} \mathrm{Si}(\mathrm{cr})+2 \mathrm{HCl}(\mathrm{g}) .
\end{aligned}
$$

In the following the notation (g) will only be used when companson with bulk values of the vapour pressure is made (e $\mathrm{g} \mathrm{P} \mathrm{PSiH}_{2} \mathrm{Cl}_{2}=\mathrm{PS}_{\mathrm{S}_{1}} \mathrm{H}_{2}$ (g)) In order to simplify the total number of expressions it is possible to judge the weight of the vanous parameters using the expenmental results and the thermochemical data given in Figures 7 and 8 As discussed in section 32 , companson of the $\mathrm{S}_{1} \mathrm{H}_{2} \mathrm{Cl}_{2}-\mathrm{H}_{2}-\mathrm{N}_{2}-\mathrm{HCl}$ system with the $\mathrm{SiH}_{4}-\mathrm{HCl}-\mathrm{H}_{2}$ system (part I) leads to the following conclusions

1 In a $\mathrm{S}-\mathrm{H}-\mathrm{N}-\mathrm{Cl}$ system the concentration of $\mathrm{S}_{1}{ }^{*}$ is always much smaller than the concentration of $\mathrm{S}_{1} \mathrm{Cl}_{2}$ * This means that in a first approximation (A-7), (A-9), (A-12) and (A-13) can be neglected

u Formation of $\mathrm{SlHCl}_{3}$ (reaction (A-10)) and $\mathrm{SiCl}_{4}$ (reaction (A-11)), which both take place on the silicon surface, can be left out of account Under the operating conditions $\mathrm{S}_{1} \mathrm{HCl}_{3}$ will only be formed in the gas phase (equation (A-2)) 
Two growth routes can be distınguished, one via $\mathrm{PSICl}_{2}$ and the other via $\mathrm{PS}_{\mathrm{S}_{1}} \mathrm{H}_{2} \mathrm{Cl}_{2}$ In order to discrimınate between these two routes the following remarks are helpful According to Chernov [6] the fully coordinated $\mathrm{SiH}_{2} \mathrm{Cl}_{2}$ molecule has a low adsorption energy compared with that of the non-linear $\mathrm{SiCl}_{2}$ molecule The adsorption of $\mathrm{S}_{1} \mathrm{Cl}_{2}$ is greatly enhanced by the presence of residual unbonded electrons on the silicon atom in this molecule which can interact with the dangling bonds on the surface It is therefore likely that the reaction starts with the ad. sorption of $\mathrm{SiCl}_{2}$ (equation (A-4)) if $\mathrm{SiCl}_{2}$ is formed by dissociation of $\mathrm{S}_{1} \mathrm{H}_{2} \mathrm{Cl}_{2}$ This is the case according to themochemical data (Figures 7 and 8) and exper1ments reported by Smith and Sedgwick [10], who measured $\mathrm{SiCl}_{2}$ with an inelastic Light scattering method in the $\mathrm{S}_{1} \mathrm{H}_{2} \mathrm{Cl}_{2}-\mathrm{H}_{2}$ system This means that $\mathrm{K}_{3}$ and $\mathrm{K}_{8}$ are also small, so that the corresponding reactions $\mathrm{A}-3$ and $\mathrm{A}-8$ can be neglected.

The concentrations of the various species on the surface, using the reactions given above and introducing the concept of a steady-state situation, can now be given With the above approximations the steady-state concentration of $\left[\mathrm{SiCl}_{2}{ }^{*}\right]$ and $\left[\mathrm{SiCl}_{2}(\mathrm{st})\right]$ will be given by

$\left[\mathrm{SiCl}_{2}^{*}\right]=\frac{\mathrm{k}_{4} \theta \mathrm{PS}_{\mathrm{Sl}_{2}}+\mathrm{k}_{-14}\left[\mathrm{SiCl}_{2}(\mathrm{st})\right]}{\mathrm{k}_{-4}+\mathrm{k}_{14}}$

$\left[\mathrm{S}_{1 C l}(\mathrm{st})\right]=\frac{\mathrm{k}_{14}\left[\mathrm{SiCl}_{2}{ }^{*}\right]+\mathrm{k}_{.15} \mathrm{P}_{\mathrm{HCl}}^{2}}{\mathrm{k}_{-14}+\mathrm{k}_{15} \mathrm{P}_{\mathrm{H}_{2}}}$

As described in part I for the $\mathrm{S}_{1} \mathrm{H}_{4}-\mathrm{HCl}-\mathrm{H}_{2}$ system, it can be assumed that the growth and etching of slicon can be treated as being independent of each other

$R=R_{\text {growth }}-R_{\text {etch }}$

For a positive growth rate the reactions $\mathrm{k}_{-14}$ and $\mathrm{k}_{-15}$ can be neglected compared with reaction $k_{4}$ and $k_{14}$ respectively in the numerator of equations (A.16) and (A-17), leading to

$\mathbf{R}_{\text {growth }}=\mathrm{k}_{15} \mathrm{PH}_{2}\left[\mathrm{~S}_{1} \mathrm{Cl}_{2}(\mathrm{st})\right]=\frac{\mathrm{k}_{4} \mathrm{k}_{14} \mathrm{k}_{15} \mathrm{P}_{\mathrm{H}_{2}} \mathrm{PS}_{\mathrm{SCl}_{2}} \theta}{\left(\mathrm{k}_{-4}+\mathrm{k}_{14}\right)\left(\mathrm{k}_{-14}+\mathrm{k}_{15} \mathrm{P}_{\mathrm{H}_{2}}\right)}$

The term Retch in (A-18) has been given by Van der Putte et al [4] According to these authors, who measured etch rates of slicon by $\mathrm{HCl}$ in hydrogen and argon, Retch can be given by

$\mathrm{R}_{\mathrm{etch}}=\frac{\mathrm{K}_{\mathrm{e}} \mathrm{P}_{\mathrm{HCl}}^{2}}{\mathrm{P}_{\mathrm{H}_{2}}}$ 
where $\mathrm{PHCl}_{\mathrm{HCl}} \mathrm{P}_{\mathrm{H}_{2}}$ are equilibrium values and $\mathrm{K}_{\mathrm{e}}$ is a constant.

The sum of the fractions of free and occupied surface sites gives

$1=\theta+\left[\mathrm{H}^{*}\right]+\left[\mathrm{Cl}^{*}\right]+\left[\mathrm{SiCl}_{2}^{*}\right]+$.

With $\left[\mathrm{H}^{*}\right]=\mathrm{K}_{6} \mathrm{P}_{\mathrm{H}_{2}}^{1 / 2} \theta,\left[\mathrm{Cl}^{*}\right]=\mathrm{K}_{5} \mathrm{P}_{\mathrm{HCl}} \theta / \mathrm{P}_{\mathrm{H}_{2}}^{1 / 2}$

and $\left[\mathrm{SiCl}_{2}{ }^{*}\right]=\mathrm{K}_{4} \mathrm{PS}_{\mathrm{SlCl}_{2}} \theta$ we obtain

$\theta=\frac{1}{\left(1+\mathrm{K}_{4} \mathrm{P}_{\mathrm{S}_{1} \mathrm{Cl}_{2}}+\mathrm{K}_{5} \mathrm{P}_{\mathrm{HCl}} / \mathrm{P}_{\mathrm{H}_{2}}^{1 / 2}+\mathrm{K}_{6} \mathrm{P}_{\mathrm{H}_{2}{ }^{\prime 2}}\right.}$

Here $k_{6} / k_{.6}=K_{6}$ etc. 


\title{
CHAPTER VII
}

\section{RATE-DETERMINING REACTIONS AND SURFACE SPECIES IN CVD OF SILICON}

\author{
III The $\mathrm{SiH}_{4}-\mathrm{H}_{2}-\mathrm{N}_{2}$ system
}

\section{Summary}

At a temperature of $700{ }^{\circ} \mathrm{C}$ the growth rate of slicon in the $\mathrm{S} \mathrm{H}_{4}-\mathrm{H}_{3}-\mathrm{N}_{2}$ system is found to be inversely proportional to the partial pressure of hydrogen and linearly proportional to the input concentration of sldane (up to $04 \mathrm{vol} \%$ ) Analysis of the experimental data shows that $\mathrm{SiH}_{2}$ is the most abundant surface species and hydrogen adsorption does not influence the growth rate Addition of hydrogen chloride to the $\mathrm{S}_{1} \mathrm{H}_{4}-\mathrm{H}_{2}-\mathrm{N}_{2}$ system results in a reduction of the growth rate, due to the conversion of $\mathrm{SiH}_{2}$ into $\mathrm{SiCl}_{2}$ This reduction in the growth rate is most pronounced in an inert medium Adsorption on the silicon surtace is discussed and it is concluded that $\mathrm{H}, \mathrm{Cl}, \mathrm{S}_{1} \mathrm{Cl}_{2}$ and $\mathrm{S}_{1} \mathrm{H}$, are present as surface species among which, however, hydrogen and chlorine are only of minor importance

\section{Introduction}

Polycrystalline silicon layers, which are widely used in the electronics industry [1], are usually grown by pyrolysis of silane under atmospheric pressure (CVD) or reduced pressure (LPCVD) In both systems hydrogen or an inert gas can be used as a carrier gas It is known that at temperatures below $800^{\circ} \mathrm{C}$ the growth rate of sulicon in an inert medium is much higher than in hydrogen [2,3,4] Bryant [2] discussed experimental data given by several authors for the growth rate of slicon from silane in hydrogen or in an inert medium Plotting different authors' measurements in a single figure and analysing the results, Bryant concluded that hydrogen desorption controlled the reaction around $700{ }^{\circ} \mathrm{C}$ if an inert gas was used as a carrier gas In a hydrogen medium the chemical reaction on the surface was thought to be rate-limiting The procedure followed by Bryant could lead to erroneous conclusions, however, the picture could be distorted because of differences in experimental conditions, as will be discussed later

Relatively little has been published on the growth rate of slicon using mixtures of hydrogen and inert gases or reduced pressures of hydrogen Yasuda et al [3] measured growth rates of silicon given by 005 vol \% silane in mixtures of argon and hydrogen (pure argon, $\mathrm{Ar} \quad \mathrm{H}_{2}=75 \quad 25$ and $\mathrm{Ar} \quad \mathrm{H}_{2}=50 \quad 50$ ) at temperatures between 600 and $800{ }^{\circ} \mathrm{C}$ From these experimental results a growth rate proportional to $\mathrm{P}_{\mathrm{H}_{2}}^{-1}$ can be deduced Duchemin et al [4] measured growth rates of silicon for different silicon-containing compounds at reduced pressures in a hydrogen ambient and temperatures between 800 and $1050{ }^{\circ} \mathrm{C}$ From indirect expenments they found a $\mathrm{P}_{\mathrm{H}_{2}}^{-1 / 2}$ dependence at low hydrogen pressures while at higher hydrogen pressures the growth rate of slicon becomes inversely proportional to the hydrogen pressure $\left(\mathrm{R}^{\circ} \mathrm{P}_{\mathrm{H}_{2}}^{-1}\right)$ At $1025^{\circ} \mathrm{C}$ Manasevit [5] measured the growth rate of slicon from 25 vol \% silane in a hydrogen - helium mixture For 
hydrogen concentrations up to $30 \%$ he found a growth rate proportional to the hydrogen pressure $\left(\mathrm{R}^{\circ} \mathrm{P}_{\mathrm{H}_{2}}\right)$ and observed a saturation in the growth rate at higher hydrogen concentrations However, in Manasevits' expenments the walls of the reactor became heavily contaminated caused by gas phase nucleation Thermo diffusion in a cold wall apparatus leads to deposit of clusters on the cold walls, reducing the apparent growth rate on the heated slicon slice Therefore these expenmental results cannot be considered to be representative for the silicon growth but merely reflect a lower gas phase nucleation in a hydrogen ambient [6]

We have carried out systematic experiments with silane in mixtures of hydrogen and nitrogen at $700^{\circ} \mathrm{C}$ This could give more information about surface species and rate-limiting steps in the growth of sulicon In this paper adsorption of different species is considered in connection with two foregong papers [7 8] where ratedetermining reactions are described in the $\mathrm{SiH}_{4} \cdot \mathrm{H}_{2} \mathrm{HCl}$ system and the $\mathrm{SiH}_{2} \mathrm{Cl}_{2}-\mathrm{H}_{2}-\mathrm{N}_{2}-\mathrm{HCl}$ system, respectively (referred to as part I and part II in the following) In addition we study the influence of the addition of $\mathrm{HCl}$ to the $\mathrm{S}_{1} \mathrm{H}_{4} \cdot \mathrm{H}_{2}-\mathrm{N}_{2}$ mixture

\section{Experimental}

A horizontal air-cooled R F heated reactor was used for the expenments The carrier gases hydrogen and nitrogen were purified to a water and oxygen concentration below $1 \mathrm{ppm}$ The slane and hydrogen chloride used were both electronic grade For all gases automatic gas flow controllers were used The temperature was measured on a silıcon slice by means of a calibrated radiation thermometer The rest of the experimental conditions were as described in part I and part II [ [ $\left.\begin{array}{ll}7 & 8\end{array}\right]$

Figure 1 shows the growth rate of silicon at $700^{\circ} \mathrm{C}$ for an input concentration of $02 \mathrm{vol} \% \mathrm{SiH}_{4}$ and different mixtures of hydrogen and nitrogen, the latter expressed as $\mathrm{PH}_{2} /\left(\mathrm{PH}_{2}+\mathrm{PN}_{2}\right)$ It can be observed that the growth rate strongly decreases when small amounts of hydrogen are added to the silane nitrogen mixture The experimental data, in this figure, can be described by an expression in which the growth rate of slicon on silicon at $700{ }^{\circ} \mathrm{C}$ is inversely proportional to the hydrogen pressure

$R_{\exp }=\frac{A P_{S_{1} H_{4}}^{O}}{1+\mathrm{BP}_{H_{2}}}$

where $\mathrm{P}_{\mathrm{S}_{1} \mathrm{H}_{4}}^{\mathrm{O}}$ is the input concentration of silane, $\mathrm{P}_{\mathrm{H}_{2}}$ the hydrogen pressure while $\mathrm{A}$ and $\mathrm{B}$ are constants According to equation (1) $\left(\mathrm{P}_{\mathrm{S}_{1} \mathrm{H}_{4}}^{\mathrm{d}} / \mathrm{R}\right)$ plotted versus $\mathrm{P}_{\mathrm{H}_{2}}$ should give a straight line relationship This is shown to be the case in Figure 2 for different input concentrations of sulane at $700^{\circ} \mathrm{C}$ Figure 3 gives the growth rate of slicon on silicon at $700^{\circ} \mathrm{C}$ as a function of the input concentration of slane up to 


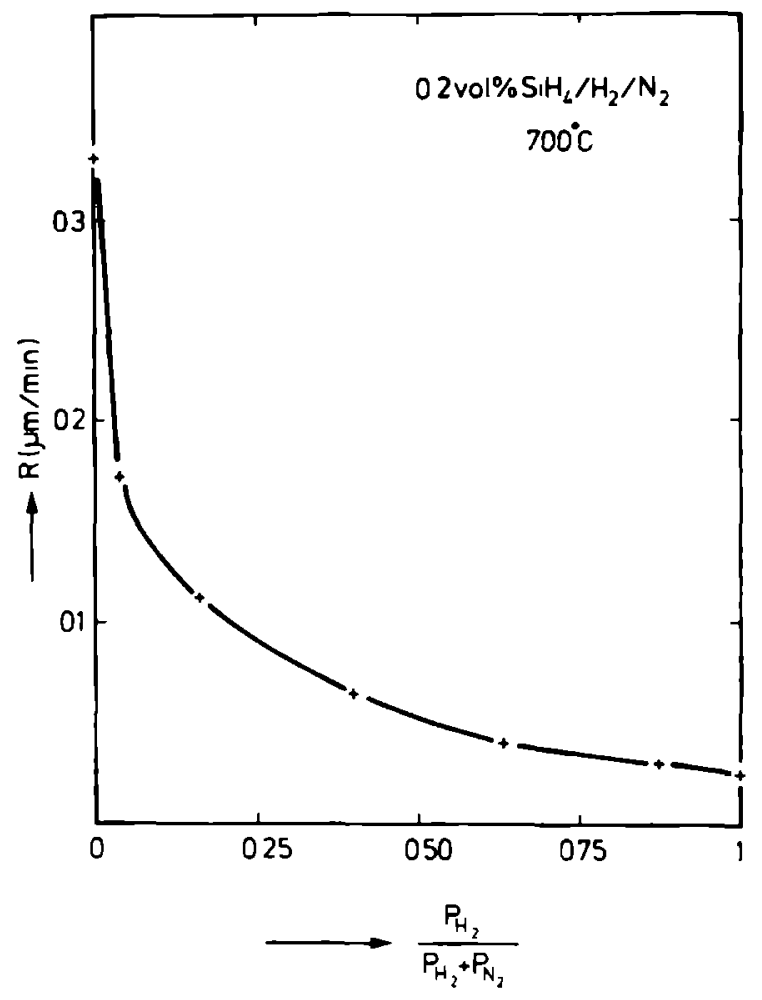

Figure 1.

The growth rate of silicon at $700^{\circ} \mathrm{C}$, for $0.2 \mathrm{vol} \% \mathrm{SiH}_{4}$ and different hydrogennitrogen mixtures.

$0.4 \mathrm{vol} . \%$ and different combinations of hydrogen and nitrogen as a carrier gas. A linear relation between the growth rate and the input concentrations of silane can be observed for hydrogen and the hydrogen-nitrogen mixture. In nitrogen as a carrier gas the deviation from linearity is caused by gas phase nucleation, as evidenced by a contamination of the reactor walls for an input concentration exceeding 0.2 vol. \% of silane. In all other cases gas phase nucleation can be neglected. Van der Meer [9] also found a linear dependence between the growth rate of silicon and the input concentration of silane (up to $1.0 \mathrm{vol} . \%$ ) in hydrogen as a carrier gas and temperatures between 600 and $800^{\circ} \mathrm{C}$. In Figure 4 the growth rate is given as a function of the input concentration of silane at $700^{\circ} \mathrm{C}$ in inert gases, as given by Adamczewska and Budzynski [10], Wells et al. [11] and Seto [12]. The experimental results of Wells and Seto formed the basis of Bryant's analysis [2]. The log-log plot of these data gives a slope equal to 0.5 , leading to the conclusion that desorption of hydrogen is rate-limiting if an inert gas is used as a carrier gas. However, log-log plots of the experimental data of Adamczewska 


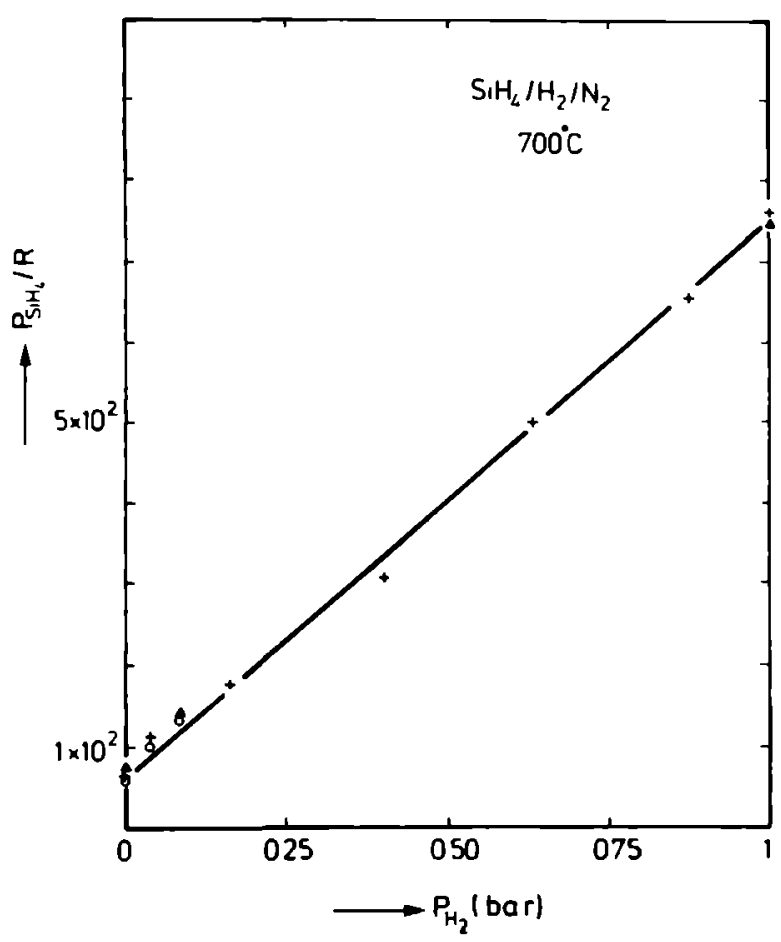

Figure 2.

The growth rate of silicon on silicon at $700^{\circ} \mathrm{C}$ for different mixtures of $\mathrm{SiH}_{4}-\mathrm{H}_{2}-\mathrm{N}_{2}$, expressed as $\left(\mathrm{PSiH}_{4} / \mathrm{R}\right)$ versus $\left(\mathrm{PH}_{2}\right): 00.1$ vol. \% $\mathrm{SiH}_{4} ;+0.2$ vol. $\% \mathrm{SiH}_{4}$ and $\triangle 0.4 \mathrm{vol}$. \% $\mathrm{SiH}_{4}$.

and our results gives, for low input concentrations of silane a linear dependence between the growth rate and the input concentration of silane. The large discrepancy between these results and those of Wells and Seto could be explained by a low Peclet number for small linear gas velocities, as indicated in Figure 4, leading to depletion of silane in the gas phase and a deviation from linearity in the growth rate as a function of the input concentration of silane. The addition of $\mathrm{HCl}$ to the $\mathrm{SiH}_{4}-\mathrm{H}_{2} \cdot \mathrm{N}_{2}$ system results in a strong decrease in the growth rate, as shown in Figure 5. In this figure growth rates are given as a function of $\mathrm{P}_{\mathrm{HCl}}^{2}$ for an input concentration of $0.2 \mathrm{vol} . \% \mathrm{SiH}_{4}$ in a mixture of hydrogen and nitrogen $(4 \%$ hydrogen) and in a hydrogen ambient at $700^{\circ} \mathrm{C}$. It can be observed that the initial decrease in growth rate is strongest for the lower hydrogen concentration. There is a typical difference in growth rate after the rapid initial decrease on addition of $\mathrm{HCl}$; the growth rate remains higher at a low hydrogen concentration in the carrier gas. 


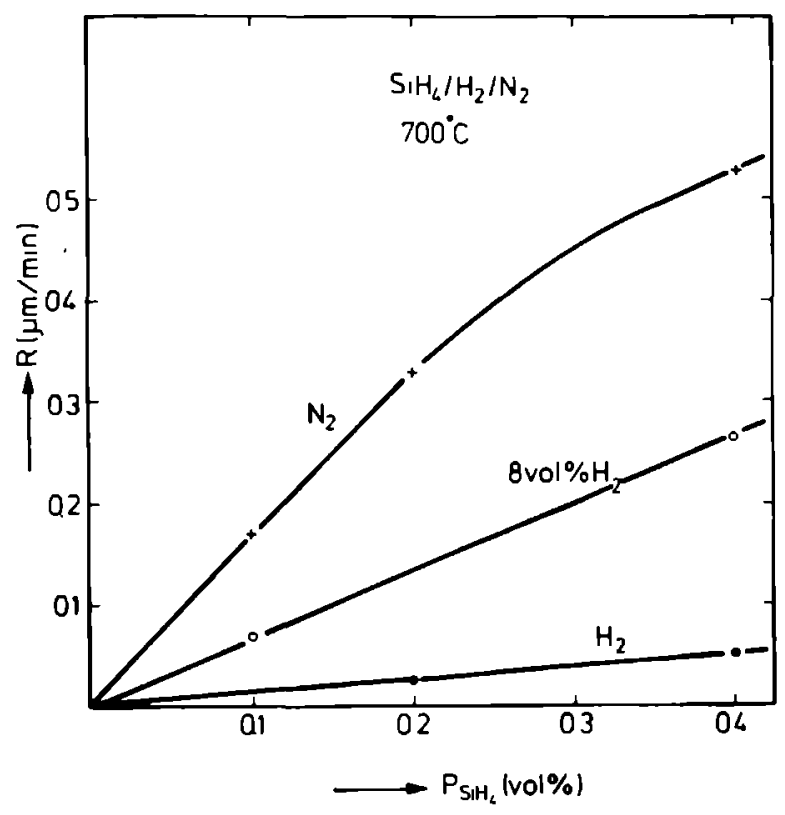

Figure 3.

The growth rate at $700{ }^{\circ} \mathrm{C}$ for silane concentrations up to 0.4 vol. \% and different mixtures of carrier gases.

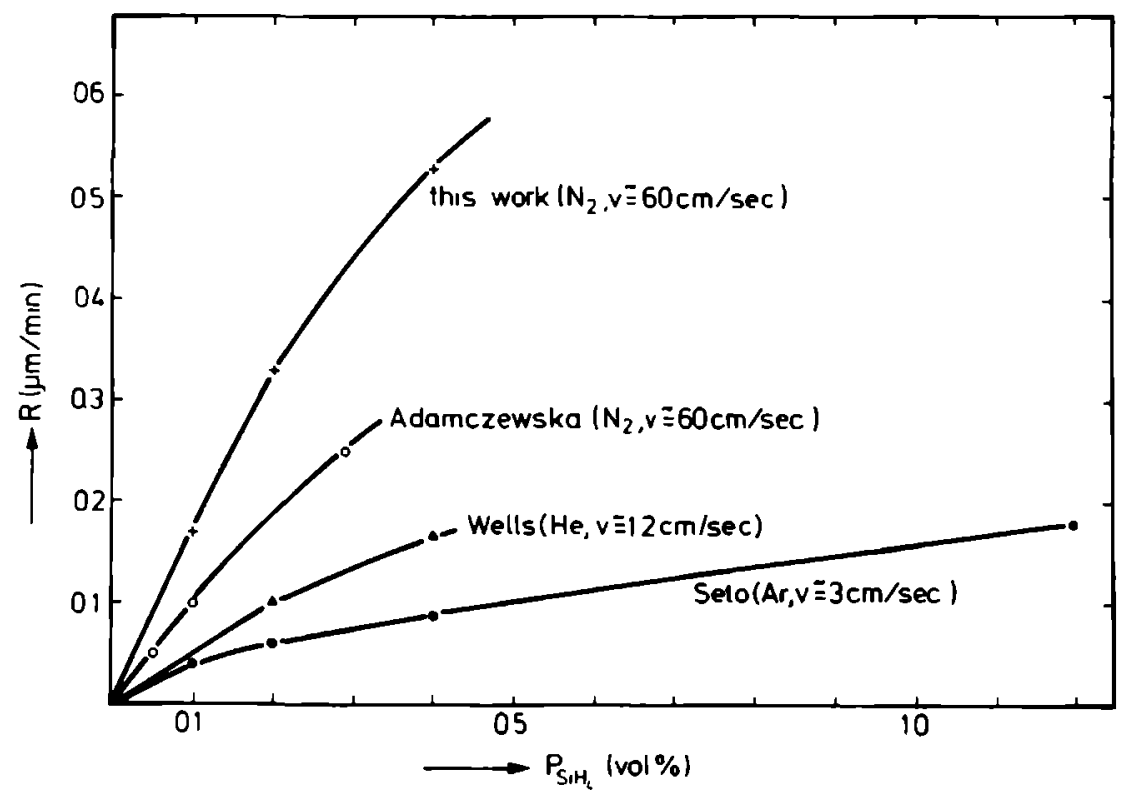

Figure 4.

The growth rate of silicon at $700^{\circ} \mathrm{C}$ from silane in an inert ambient: + this work, o ref. $10, \wedge$ ref. $11, \bullet$ ref. 12 . 


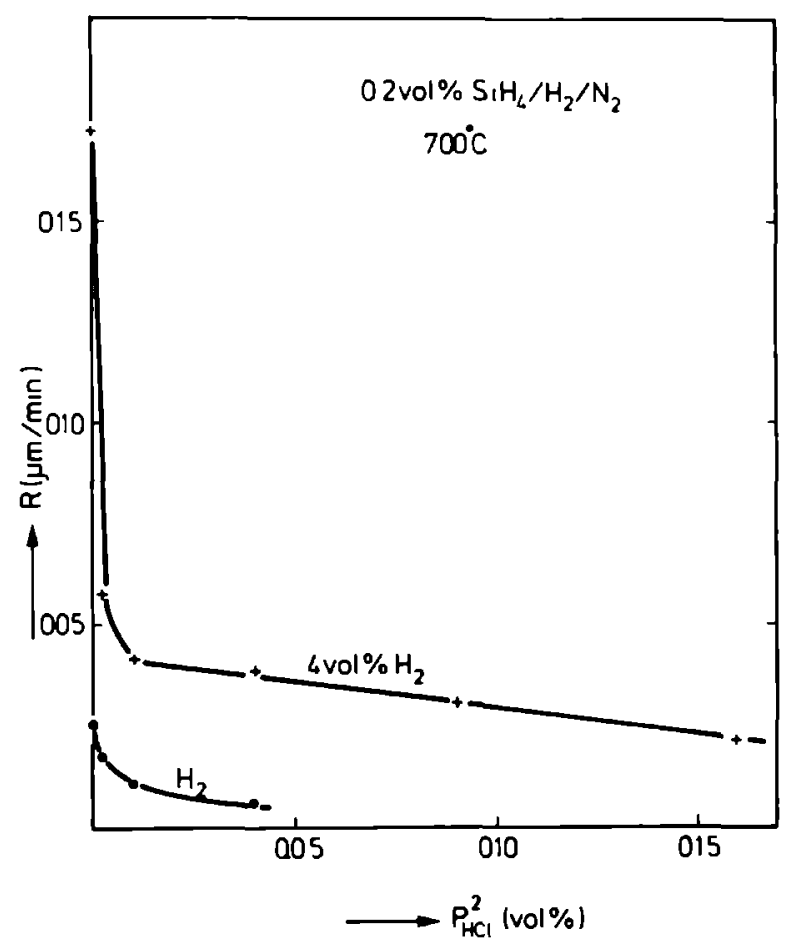

Figure 5.

Growth rate as shown by 0.2 vol. $\% \mathrm{SiH}_{4}$ in hydrogen and a mixture of hydrogen and nitrogen and increasing amounts of $\mathrm{HCl}$ at $700^{\circ} \mathrm{C}$.

\section{Discussion}

\subsection{Reaction scheme for the $\mathrm{SiH}_{4}-\mathrm{H}_{2}-\mathrm{N}_{2}$ system}

In order to arrive at an expression describing the growth of silicon on silicon in the $\mathrm{SiH}_{4}-\mathrm{H}_{2} \cdot \mathrm{N}_{2}$ system, the reaction scheme as proposed in the Appendix of part I [7] will be followed with some additional assumptions concerning the species present on the silicon surface. The following steps could be taken into account:

a. Gas phase diffusion towards the surface

$$
\mathrm{SiH}_{4}(\mathrm{~b}) \underset{\mathrm{k}_{-1}}{\stackrel{\mathrm{k}_{1}}{\rightleftharpoons}} \mathrm{SiH}_{4}(\mathrm{~g}) \text {. }
$$

(b) refers to bulk concentrations and (g) to concentrations near the surface. 
b. Decomposition of silane near the surface

$$
\mathrm{SiH}_{4}(\mathrm{~g}) \underset{\mathrm{k}_{-2}}{\stackrel{\mathrm{k}_{2}}{\rightleftharpoons}} \mathrm{SiH}_{\mathrm{n}}(\mathrm{g})+\frac{4-\mathrm{n}}{2} \mathrm{H}_{2}(\mathrm{~g}) .
$$

c. Chemisorption of a $\mathrm{SiH}_{\mathrm{n}}$ compound on a free surface site (denoted by $*$ )

$$
\mathrm{SiH}_{\mathrm{n}}(\mathrm{g})+\underset{\mathrm{k}_{.3}}{\stackrel{\mathrm{k}_{3}}{\rightleftharpoons}} \mathrm{SiH}_{\mathrm{n}}^{*}
$$

d. Surface diffusion of $\mathrm{SiH}_{\mathrm{n}}$ * to an atomic step

$$
\mathrm{SiH}_{\mathrm{n}} *+* \underset{\mathrm{k}_{.4}}{\stackrel{\mathrm{k}_{4}}{\rightleftharpoons}} \mathrm{SiH}_{\mathrm{n}}{ }^{*}+*
$$

e. Attachment on a free step site (denoted by $*_{s}$ )

$$
\mathrm{SiH}_{\mathrm{n}}{ }^{*}+* \mathrm{~s}_{\mathrm{K}_{-5}}^{\stackrel{\mathrm{k}_{5}}{\rightleftharpoons}} \mathrm{SiH}_{\mathrm{n}}^{* * \mathrm{~s}} \text {. }
$$

f. Incorporation by desorption of hydrogen

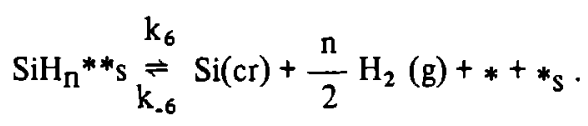

Adsorption of atomic hydrogen can be described as:

$$
\begin{aligned}
& \mathrm{k}_{7} \\
& *+1 / 2 \mathrm{H}_{2}(\mathrm{~g}) \underset{\mathrm{k}_{-7}}{\stackrel{\mathrm{F}}{\rightleftharpoons}} \mathrm{H}^{*} \\
& *_{\mathrm{s}}+1 / 2 \mathrm{H}_{2}(\mathrm{~g}) \underset{\mathrm{k}_{.8}}{\stackrel{\mathrm{k}_{8}}{\rightleftharpoons}} \mathrm{H}^{*} \mathrm{~s}
\end{aligned}
$$

The fraction of free surface sites $\theta$ and free step sites $\theta_{\text {St }}$ can be given by

$$
\begin{aligned}
& \theta=1-\left[\mathrm{H}^{*}\right]-\left[\mathrm{SiH}_{\mathrm{n}}{ }^{*}\right] \\
& \theta_{\mathrm{St}}=1-\left[\mathrm{H}^{*} \mathrm{~s}\right]
\end{aligned}
$$


There is a difference between both terms in (10) as $\mathrm{SiH}_{n}$ adsorbed on a step site cannot be distinguished from $\mathbf{n}$ adsorbed $\mathrm{H}$ atoms If equilibrium conditions are assumed for the adsorption of atomic hydrogen, and if the adsorption is dominant $\theta$ and $\theta_{\text {st }}$ can be given as

$$
\theta=\frac{1}{1+\mathrm{K}_{7} \mathrm{P}_{\mathrm{H}_{2}{ }^{2}}^{{ }^{2}}}
$$

$\theta_{\mathrm{st}}=\frac{1}{1+\mathrm{K}_{8} \mathrm{P}_{\mathrm{H}_{2}{ }^{2}}^{2}}$

It is assumed that nucleation on the silicon surface is not a problem, such that sufficient step sites are present on a real surface One of the reactions (2)-(7) is then rate-limiting, the-reactions preceding the slowest reaction are assumed to be in equilibrium, while the reactions after the slowest step are fast These rate-limiting reactions are collected in Table I, where it is assumed that equilibrium conditions exist for hydrogen adsorption Expressions for the growth rate are given corresponding to the specific rate-limiting reaction

\section{Comparison with experiment}

The experimental data as given in Fig 1,2 and 3 can be described by equation (1)

$$
\mathrm{R}_{\exp }=\frac{\mathrm{AP}_{\mathrm{S}_{1} \mathrm{H}_{4}}^{\mathrm{O}}}{1+\mathrm{BP}_{\mathrm{H}_{2}}}
$$

This expression has to be compared with the rate limiting reactions as given by $\mathrm{R}_{\mathrm{a}}-\mathrm{R}_{\mathrm{f}}$ (Table 1) From this table it can be deduced that in the $\mathrm{S}_{1} \mathrm{H}_{4}-\mathrm{H}_{2} \mathrm{~N}_{2}$ system rate limitation by gas phase diffusion of silane towards the surface $\left(\mathrm{R}_{\mathrm{a}}\right.$ and gas phase dissociation of $\mathrm{S}_{1} \mathrm{H}_{4}\left(\mathrm{R}_{b}\right)$ cannot explain the experimental data The ratelimiting reactions have to be found in one of the surface reactions $\mathrm{c}$ to $f$ Two solutions can be distinguished, depending on the magnitude of the hydrogen adsorption on the slicon surface

1 For a strong hydrogen adsorption $\left[\left(\theta, \theta_{\mathrm{st}} \ll 1\right),\left(\left[\mathrm{H}^{*}\right],\left[\mathrm{H}^{*} \mathrm{~s}\right] \cong 1\right)\right]$ the fraction of free surface sites and step sites can be given by $\theta=1 / \mathrm{K}_{7} \mathrm{P}_{\mathrm{H}_{2}}^{1}{ }^{2}$ and $\theta_{\mathrm{st}}=$ $1 / \mathrm{K}_{8} \mathrm{P}_{\mathrm{H}_{2}}^{1}$, as obtained by using equation (11) The expenmental results then lead to a value of $n$ equal to four, giving $\mathrm{S}_{1} \mathrm{H}_{4}$ as the main slicon-containing surface species When for statistical reasons only one $\theta$ has to be included then $\mathrm{n}=3$, leading to $\mathrm{SiH}_{3}$ as the most important sulicon-containing surface species 11 For a moderate hydrogen adsorption the values of $\theta$ and $\theta_{\text {st }}$ are close to unity $\left[\left(\theta, \theta_{\text {st }} \cong 1\right),\left(\left[\mathrm{H}^{*}\right],\left[\mathrm{H}^{*} \mathrm{~s}\right] \ll 1\right)\right]$ and $\mathrm{n}$ becomes equal to 2 , indicating $\mathrm{S}_{1} \mathrm{H}_{2}$ as the most important surface species, both in hydrogen as well as in a nitrogen ambient 


\section{TABLE I}

Rate-limiting reactions for the growth of silicon from silane, according to the equations (2-7). The growth rate $\mathrm{R}_{\mathrm{i}}$ corresponds to these rate-limiting reactions. $\mathrm{P}_{\mathrm{SiH}_{4}}^{\mathrm{O}}$ denotes the input partial pressure of silane.

\begin{tabular}{l|l}
\hline Reaction & $\mathrm{R}_{\mathrm{i}}$ for $\mathrm{i}$ as rate-limiting reaction \\
\hline a. gas phase diffusion (eq. (2)) & $\mathrm{R}_{\mathrm{a}}=\mathrm{k}_{\mathrm{a}} \mathrm{P}_{\mathrm{SiH}}^{\mathrm{O}}$ \\
b. gas phase dissociation (eq. (3)) & $\mathrm{R}_{\mathrm{b}}=\mathrm{k}_{\mathrm{b}} \mathrm{P}_{\mathrm{SiH}_{4}}^{\mathrm{O}}$ \\
c. chemisorption (eq. (4)) & $\mathrm{R}_{\mathrm{c}}=\mathrm{k}_{\mathrm{c}} \mathrm{P}_{\mathrm{SiH}_{4}}^{\mathrm{O}} \theta /\left(\mathrm{P}_{\mathrm{H}_{2}}\right)^{(4-\mathrm{n}) / 2}$ \\
d. surface diffusion* (eq. (5)) & $\mathrm{R}_{\mathrm{d}}=\mathrm{k}_{\mathrm{d}} \mathrm{P}_{\mathrm{SiH}_{4}}^{\mathrm{O}} \theta^{2} /\left(\mathrm{P}_{\mathrm{H}_{2}}\right)^{(4-\mathrm{n}) / 2}$ \\
e. step incorporation (eq. (6)) & $\mathrm{R}_{\mathrm{e}}=\mathrm{k}_{\mathrm{e}} \mathrm{P}_{\mathrm{SiH}_{4}}^{\mathrm{O}} \theta \cdot \theta_{\mathrm{st}} /\left(\mathrm{P}_{\mathrm{H}_{2}}\right)^{(4-n) / 2}$ \\
f. silicon formation (eq. (7)) & $\mathrm{R}_{\mathrm{f}}=\mathrm{k}_{\mathrm{f}} \mathrm{P}_{\mathrm{SiH}_{4}}^{\mathrm{O}} \theta \cdot \theta \mathrm{st} /\left(\mathrm{P}_{\mathrm{H}_{2}}\right)^{(4-n) / 2}$ \\
\hline
\end{tabular}

* For a directional diffusion a BCF expression can be used. Diffusion limited by surface adsorption then leads to

$$
\mathrm{R}_{\mathrm{d}}=\mathrm{k}_{\mathrm{d}} \mathrm{PSiH}_{4} \cdot \theta^{3 / 2} / \mathrm{P}_{\mathrm{H}_{2}}(4-\mathrm{n}) / 2
$$

As will be discussed in the section on adsorption, the concentration of adsorbed atomic hydrogen is thought to be small and therefore $\mathrm{SiH}_{2}$ is considered to be the most abundant silicon-containing species on the surface. The great difference in adsorption probabilities between the full coordinated $\mathrm{SiH}_{4}$ molecule and the nonlinear $\mathrm{SiH}_{2}$ molecule [13] and single-pulse shock tube experiments of Newman et al. [14], in which $\mathrm{H}_{2}$ and $\mathrm{SiH}_{2}$ are formed when $\mathrm{SiH}_{4}$ decomposes, leads to the same conclusions. Formation of $\mathrm{SiH}_{3}$ can be eliminated, as the single bond rupture process, $\mathrm{SiH}_{4} \rightarrow \mathrm{SiH}_{3}+\mathrm{H}$ needs a high activation energy ( $93 \mathrm{Kcal} / \mathrm{mole}$ [14]) compared to molecular hydrogen elimination from silane. As can be observed in Fig. 3, the growth rate of silicon on silicon in the $\mathrm{SiH}_{4}-\mathrm{N}_{2}$ system is linearly proportional to the input concentration of silane for relatively low input concentrations. For concentrations above $0.2 \mathrm{vol}$ \% the reactor becomes contaminated because of gas phase nucleation, leading to a deviation from linearity of the growth rate as a function of the input concentration of silane. Under the above-mentioned conditions the growth rates obtained in nitrogen are so high that gas phase diffusion can be assumed to be rate-limiting $\left(\mathrm{R}_{\mathrm{a}}\right)$ even at $700^{\circ} \mathrm{C}$. 


\section{The $\mathrm{StH}_{4}-\mathrm{H}_{2}-\mathrm{N}_{2}$ system}

The addition of $\mathrm{HCl}$ to the $\mathrm{SiH}_{4}-\mathrm{H}_{2}$ system at temperatures between 800 and $1000^{\circ} \mathrm{C}$ has been described in part I [7] At a temperature below $900{ }^{\circ} \mathrm{C}$ a rapid decrease in growth rate was observed, proportional to $\mathrm{P}_{\mathrm{HCl}}^{2}$, when small amounts of $\mathrm{HCl}$ were added, followed by a much smaller decrease in the growth rate, also proportional to $\mathrm{P}_{\mathrm{HCl}}^{2}$. The same behaviour can be observed in the $\mathrm{SiH}_{4}-\mathrm{H}_{2}-\mathrm{N}_{2}$ system This can be seen in Figure 5, which shows the influence of the addition of $\mathrm{HCl}$ on the growth rate of slicon for an input concentration of $02 \mathrm{vol} \% \mathrm{~S}_{1} \mathrm{H}_{4}$ and $4 \mathrm{vol} \% \mathrm{H}_{2}$ in nutrogen at $700^{\circ} \mathrm{C}$ (growth rate versus $\mathrm{P}_{\mathrm{HCl}}^{2}$ ) This figure also gives the growth rate at $700{ }^{\circ} \mathrm{C}$ for an input concentration of $02 \mathrm{vol} \% \mathrm{SiH}_{4}$ in a hydrogen ambient In order to discuss the influence of the addition of $\mathrm{HCl}$ to the system some additional remarks have to be made. Besides the reactions $(a-f)$ the following steps can be distınguished after addition of $\mathrm{HCl}$ to the system

$f$ Conversion of $\mathrm{SiH}_{2} *$ into $\mathrm{SiCl}_{2}$ *

$$
\mathrm{S}_{1} \mathrm{H}_{2} *+2 \mathrm{HCl}(\mathrm{g}) \underset{\mathrm{k}_{-9}}{\stackrel{\mathrm{k}_{9}}{\rightleftharpoons}} \mathrm{SiCl}_{2} *+2 \mathrm{H}_{2}(\mathrm{~g})
$$

h Surface diffusion of $\mathrm{SiCl}_{2}$ *

$$
\mathrm{S}_{1} \mathrm{Cl}_{2} *+\underset{\mathrm{k}_{-10}}{\stackrel{\mathrm{k}_{10}}{\rightleftharpoons}} \mathrm{SiCl}_{2} *+*
$$

1 Incorporation on a free step site

$$
\mathrm{SiCl}_{2} *+* \mathrm{~s} \underset{\mathrm{k}_{-11}}{\stackrel{\mathrm{k}_{11}}{\rightleftharpoons}} \mathrm{SiCl}_{2} * \mathrm{~s}_{\mathrm{s}} \text {. }
$$

J Reduction of $\mathrm{SiCl}_{2}$ at the step site

$$
\mathrm{SiCl}_{2} * *_{\mathrm{s}}+\mathrm{H}_{2}(\mathrm{~g}) \stackrel{\mathrm{k}_{12}}{\rightleftharpoons} \mathrm{Sl}(\mathrm{cr})+2 \mathrm{HCl}(\mathrm{g})
$$

k Desorption of $\mathrm{SiCl}_{2}$

$$
\mathrm{SICl}_{2} \stackrel{\mathrm{k}_{13}}{\rightarrow} \mathrm{SiCl}_{2}(\mathrm{~g})
$$


1 Formation of $\mathrm{S}_{1} \mathrm{H}_{2} \mathrm{Cl}_{2}$

$$
\mathrm{SiCl}_{2} *+\mathrm{H}_{2}(\mathrm{~g}) \stackrel{\mathrm{k}_{14}}{\rightarrow} \mathrm{S}_{1} \mathrm{H}_{2} \mathrm{Cl}_{2}(\mathrm{~g})
$$

m Adsorption of chlorine

$$
\begin{aligned}
& \mathrm{HCl}(\mathrm{g})+* \underset{\mathrm{k}_{-15}}{\stackrel{\mathrm{k}_{15}}{\rightleftharpoons}} \mathrm{Cl}^{*}+1 / 2 \mathrm{H}_{2}(\mathrm{~g}) \\
& \mathrm{HCl}(\mathrm{g})+* *_{\mathrm{s}} \underset{\mathrm{k}_{-16}}{\stackrel{\mathrm{k}_{16}}{\rightleftharpoons}} \mathrm{Cl}^{*} \mathrm{~s}+1 / 2 \mathrm{H}_{2}(\mathrm{~g})
\end{aligned}
$$

If $\left[\mathrm{H}^{*}, \mathrm{H}^{*} \mathrm{~s}\right] \ll 1$ and $\left[\mathrm{S}_{1} \mathrm{H}_{2}{ }^{*}\right] \ll 1$, as discussed before, the fraction of free surface sites $\theta$ and free step sites $\theta_{\text {St }}$ can now be given by

$\theta=1-\left[\mathrm{Cl}^{*}\right]-\left[\mathrm{SiCl}_{2}{ }^{*}\right]$

$\theta_{\mathrm{st}}=1-\left[\mathrm{Cl}{ }^{*} \mathrm{~s}\right]$.

As discussed in part II [8], the rate-limiting reaction has to be found in the reduction of $\mathrm{SiCl}_{2}$ at the step site $\left(\mathrm{k}_{12} \mathrm{P}_{\mathrm{H}_{2}}<\mathrm{k}_{-11}\right)$ After conversion of $\mathrm{SiH}_{2}$ into $\mathrm{SiCl}_{2}$ (equation (12)), further addition of $\mathrm{HCl}$ leads to attack of the silicon lattice itself According to Van der Putte et al [15] and discussed in part II, this etch rate can be given as

$\mathrm{R}_{\text {etch }}=\mathrm{k}_{\mathrm{etch}} \mathrm{P}_{\mathrm{HCl}}^{2} / \mathrm{P}_{\mathrm{H}_{2}}$.

The resulting growth rate, after the initial decrease, can now be given as

$$
\mathrm{R}=\mathrm{k}_{12} \mathrm{P}_{\mathrm{H}_{2}}\left[\mathrm{~S}_{1 C l}{ }^{* *} \mathrm{~s}\right]-\mathrm{ketch} \mathrm{P}_{\mathrm{HCl}}^{2} / \mathrm{P}_{\mathrm{H}_{2}}
$$

where $\mathrm{k}_{12} \mathrm{P}_{\mathrm{H}_{2}}\left[\mathrm{~S}_{1 C_{2}}{ }^{* *} \mathrm{~s}\right]=\mathrm{RS}_{\mathrm{SICl}}$, as defined in part I The steady state concentration of $\left[\mathrm{SiCl}_{2}{ }^{* *} \mathrm{~s}\right]$ can be described in a simular way as described in part $\mathrm{I}$, leading with $\mathrm{k}_{12} \mathrm{P}_{\mathrm{H}_{2}}<\mathrm{k}_{-11}$ to

$$
\begin{aligned}
R= & \frac{K_{1} k_{2} k_{3} k_{4} k_{11} k_{12} P_{H_{2}} P_{H C l}^{2} P_{S_{1} H_{4}}^{O} \theta \theta_{s t}}{\left(k_{.2} P_{H_{2}}+k_{3} \theta\right)\left(k_{9} P_{H_{C l}}^{2}+k_{.3}\right)\left(k_{11} \theta_{s t}+k_{.9} P_{H_{2}}^{2}+k_{13}+k_{14} P_{H_{2}}\right)} \\
& -k_{\text {etch }} \frac{P_{\mathrm{HCl}}^{2}}{P_{H_{2}}} .
\end{aligned}
$$


The expenmental data as given in Figure 5 can now be compared with this expression $\mathrm{RS}_{1} \mathrm{Cl}_{2}$ can be considered to be independent of $\mathrm{PHCl}_{\mathrm{HCl}}$ as the reduction in growth rate on further addition of $\mathrm{HCl}$ equals the expected etch rate with $\mathrm{HCl}$ only According to Figure 5, $\mathrm{RS}_{\mathrm{SCl}_{2}}=0042 \mu \mathrm{m} / \mathrm{min}$ for an input of $02 \mathrm{vol} \% \mathrm{~S}_{1} \mathrm{H}_{4}$ in d carrier gas containing 4 vol \% hydrogen at $700^{\circ} \mathrm{C}$ in hydrogen as a carrier gas the initial reduction of the growth rate is less steep than for the $\mathrm{H}_{2} \mathrm{~N}_{2}$ mixture, due to a less complete conversion of $\mathrm{S}_{1} \mathrm{H}_{2}{ }^{*}$ into $\mathrm{SiCl}_{2}{ }^{*}$ for the $\mathrm{HCl}$ input concentration used (equation 12). Therefore $\mathrm{RSiCl}_{2}\left(700^{\circ} \mathrm{C}\right.$ ) for this mixture cannot be obtained from Figure 5 and an indirect way is necessary In part I [7] values of $\mathrm{RS}_{\mathrm{SiCl}}$ are given for an input of $02 \mathrm{vol} \% \% \mathrm{SiH}_{4}$ in hydrogen as a carrier gas at 800 and $900{ }^{\circ} \mathrm{C}$, being 0030 and $034 \mu \mathrm{m} / \mathrm{mm}$ respectively $\mathrm{RSICl}_{2}\left(700^{\circ} \mathrm{C}\right)$ can now be calculated by assuming a $1 / \mathrm{T}$ behaviour leading to $00017 \mu \mathrm{m} / \mathrm{min}$ The values of $\mathrm{RS}_{1 C_{2}}$ at $700{ }^{\circ} \mathrm{C}$ for $\mathrm{P}_{\mathrm{H}_{2}}=1$ bar and $\mathrm{P}_{\mathrm{H}_{2}}=004$ bar are thus shown to be proportional to $\mathrm{P}_{\mathrm{H}_{2}}^{-1}$. The expenmental growth rate after the initial decrease can now be given by

$\mathrm{R}=\mathrm{kSICl}_{2} \frac{\mathrm{P}_{\mathrm{S}_{1} \mathrm{H}_{4}}^{\mathrm{O}}}{\mathbf{P}_{\mathrm{H}_{2}}}-k_{\text {etch }} \frac{\mathbf{P}_{\mathrm{HCl}}^{2}}{\mathbf{P}_{\mathrm{H}_{2}}}$

Comparison of this equation with the expression as given by equation (23) leads to the following solutions depending on the magnitude of chlorine adsorption

I For a strong chlorine adsorption, and chlorine being the most abundant surface species, the concentrations of free surface sites $\theta$ and free step sites $\theta_{\text {st }}$ can be given by

$$
\theta=\frac{\mathrm{P}_{\mathbf{H}_{2}^{\prime}}^{1 / 2}}{\mathrm{~K}_{13} \mathrm{P}_{\mathrm{HCl}}}, \quad \theta_{\mathrm{St}}=\frac{\mathrm{P}_{\mathrm{H}_{2}}^{1 / 2}}{\mathrm{~K}_{14} \mathrm{P}_{\mathrm{HCl}}}
$$

For strong chlonne adsorption the value $\theta$ and $\theta_{\text {st }}$ in equation (25) is introduced in equation (23), giving the disappearance of the $\mathrm{P}_{\mathrm{HCl}}^{2}$ term and the introduction of $\mathrm{P}_{\mathrm{H}_{2}}^{2}$ in the numerator of the first term $\left(\mathrm{R}_{\mathrm{SiCl}_{2}}\right)$

The expenmental data then suggests a model $\mathrm{I}$ in which $\mathrm{k}, \mathrm{P}_{\mathrm{H}_{2}}^{2}>\left(\mathrm{k}_{11} \theta_{\text {st }}+\right.$ $+\mathrm{k}_{13}+\mathrm{k}_{14} \mathrm{P}_{\mathrm{H}_{2}}$ ), $\mathrm{k}_{9} \mathrm{P}_{\mathrm{HCl}}^{2}<\mathrm{k}_{-3}$ and $\mathrm{k}_{-2} \mathrm{P}_{\mathrm{H}_{2}}^{2}>\mathrm{k}_{3} \theta$, in order to arrive at the result of equation (24).

For $\theta$ and $\theta_{\text {st }}$ values close to unity two solutions are possible, in both cases $\mathrm{k}_{9} \mathrm{P}_{\mathrm{HCl}}^{2}>\mathrm{k}_{-3}$ has to be assumed

II If $\mathrm{k}_{-2} \mathrm{P}_{\mathrm{H}_{2}}<\mathrm{k}_{3} \theta$ then $\mathrm{k}_{.9} \mathrm{P}_{\mathrm{H}_{2}}^{2}>\left(\mathrm{k}_{11} \theta_{\mathrm{St}}+\mathrm{k}_{13}+\mathrm{k}_{14} \mathrm{P}_{\mathrm{H}_{2}}\right)$

III If $\mathrm{k}_{-2} \mathrm{P}_{\mathrm{H}_{2}}>\mathrm{k}_{3} \theta$ then $\mathrm{k}_{14} \mathrm{P}_{\mathrm{H}_{2}}>\left(\mathrm{k}_{-9} \mathrm{P}_{\mathrm{H}_{2}}^{2}+\mathrm{k}_{11} \theta_{s t}+\mathrm{k}_{13}\right)$ 
As will be discussed in the section on adsorption, the fractional surface concentration of chlorine is assumed to be small compared to unity at temperatures above $700{ }^{\circ} \mathrm{C}$, excluding model I In order to discriminate between models II and III it can be mentioned that assumptions made in model II are less probable because a relatively hugh value of $\mathrm{k}_{-9} \mathrm{P}_{\mathrm{H}_{2}}^{2}$ is needed and formation of $\mathrm{S}_{1} \mathrm{H}_{2} \mathrm{Cl}_{2}$ is more likely than reduction of $\mathrm{SiCl}_{2}$ to $\mathrm{SiH}_{2}$ Because the rate-limiting step has to be found in the reduction of $\mathrm{SICl}_{2}$ on the step (equation (15)) a surface concentration of $\mathrm{SiCl}_{2}$ much higher than the equilibrium concentration can be expected This leads to a desorption of $\mathrm{S}_{1} \mathrm{Cl}_{2}$ or, according to thermodynamic data at $700{ }^{\circ} \mathrm{C}$ of the $\mathrm{S}-\mathrm{H}-\mathrm{N}-\mathrm{Cl}$ system (part II), to formation of $\mathrm{S}_{1} \mathrm{H}_{2} \mathrm{Cl}_{2}$ (equation 17))

The experimental data can therefore best be described by model III, giving

$\mathrm{R}=\frac{\mathrm{K}_{1} \mathrm{~K}_{2} \mathrm{~K}_{3} \mathrm{~K}_{11} \mathrm{k}_{12} \mathrm{P}_{\mathrm{S}_{1} \mathrm{H}_{4}}^{\mathrm{O}}}{\mathrm{k}_{14} \mathrm{P}_{\mathrm{H}_{2}}}-\mathrm{k}_{\text {etch }} \frac{\mathrm{P}_{\mathrm{HCl}}^{2}}{\mathrm{P}_{\mathrm{H}_{2}}}$

Finally, according to equation (20) a strong adsorption of $\mathrm{SiCl}_{2}$ should lead to a small value of $\theta$ notably for the lowest hydrogen pressures, in contradiction with the experimental data as given in Figure 5 This point will be further discussed in the following section on adsorption

\section{Adsorption on the sllicon surface}

In this section the adsorption of $\mathrm{H}, \mathrm{Cl}, \mathrm{SiCl}_{2}$ and $\mathrm{SiH}_{2}$ wll be discussed, because these species are considered to be the most important representatives on the slicon surface At the start of the present series of experuments we expected to find a strong influence of the adsorption of monoatomic hydrogen and chlorine on the growth rate of slicon, as suggested by Chernov [13] The fraction of free surface sites can be given by

$\theta=1-\theta \mathrm{H}-\theta \mathrm{Cl}-\theta \mathrm{S}_{1} \mathrm{H}_{2}-\theta \mathrm{SiCl}_{2}$

and an analogous expression can be given for the fraction of free step sites, with the remark that $\mathrm{SiCl}_{2}{ }^{*}$ and $\mathrm{SiH}_{2}{ }^{*}$ adsorbed on a step cannot be distınguished from adsorbed $\mathrm{H}^{*}$ and $\mathrm{Cl}^{*}$ atoms In adsorption equilibrium an expression can be found for every species as for $\theta_{H}[16]$

$$
\theta_{\mathrm{H}}=\frac{\mathrm{k}_{\mathrm{H}} \mathrm{P}_{\mathrm{H}}}{1+\sum_{\mathrm{u}} \mathrm{k}_{\mathrm{u}} \mathrm{P}_{\mathrm{u}}} \quad \mathrm{u}=\mathrm{H}, \mathrm{Cl}, \mathrm{S}_{1} \mathrm{Cl}_{2}, \mathrm{~S}_{1} \mathrm{H}_{2}
$$

$$
\text { with } k_{u}=\frac{\exp \left[E_{a, u} / k T\right]}{n_{O} \nu_{u} \sqrt{ } 2 \pi m_{u} k T}
$$


where $P_{u}$ is the partial pressure of species $u$ in the gas phase, $m_{u}$ the mass of the adsorbed molecule, $k$ is Boltzmann's constant, $T$ the absolute temperature, $E_{a, u}$ the heat of adsorption of $u, v_{u}$ the stretching vibration of the $\mathrm{Si}$ - $\mathrm{U}$ bond and $\mathrm{n}_{\mathrm{O}}$ is the total number of surface sites per unit area. In a first approximation $\nu_{u}$ is inversely proportional to the square root of the molecular mass of the adsorbed atom or molecule, which leads to

$\frac{\theta_{H}}{\theta_{u}}=\frac{P_{H}}{P_{u}} \exp \left(E_{a, H}-E_{a, u}\right) / k T$

where $u=\mathrm{H}, \mathrm{Cl}, \mathrm{SiCl}_{2}$ or $\mathrm{SiH}_{2}$. Using this equation relative surface concentrations of the various adsorbing species can be calculated if values for $E_{a}$ and $P_{u}$ are available. The partial pressures can be obtained from thermochemical data for the $\mathrm{Si}-\mathrm{H}-\mathrm{N}-\mathrm{Cl}$ system, as given in part II. The heat of adsorption $\mathrm{E}_{\mathrm{a}}$ is normally taken to be nearly equal to the dissociation energies (D) or bond strengths of the corresponding diatomic molecules ( $\mathrm{SiH}, \mathrm{SiCl}, \mathrm{Si}_{2}$ ). The JANAF tables recommend values of $90 \pm 15 \mathrm{kcal} / \mathrm{mole}$ for $\mathrm{D}_{\mathrm{SiCl}}, 70 \mathrm{kcal} / \mathrm{mole}$ for $\mathrm{DSiH}_{\mathrm{SiH}}$ and $73 \mathrm{kcal} / \mathrm{mole}$ for $\mathrm{DS}_{2}$ [17]. Kecently Farber and Srivastava [18] have used Knudsen effusion mass spectroscopy to study the reaction between $\mathrm{SiCl}_{4}(\mathrm{~g})$ and solid or liquid silicon. From the experimental results they deduced for $\mathrm{SiCl}$ a dissociation energy of $88.6 \pm 0.6$ $\mathrm{kcal} / \mathrm{mole}$. In the following we will accept a value of $90 \mathrm{kcal} / \mathrm{mole}$ for the heat of adsorption of chlorine, and take $70 \mathrm{kcal} / \mathrm{mole}$ for the adsorption of atomic hydrogen.

\section{Adsorption of monoatomic hydrogen}

As discussed before, the growth rate of silicon in the $\mathrm{SiH}_{4}-\mathrm{H}_{2}-\mathrm{N}_{2}$ system is proportional to $\mathrm{P}_{\mathrm{H}_{2}}^{-1}$. This could be explained by a small surface concentration of atomic hydrogen if $\mathrm{SiH}_{2}$ is the most abundant species on the surface, or by a concentration of free surface sites proportional to $\mathrm{P}_{\mathrm{H}_{2}}^{-1 / 2}$ combined with $\mathrm{SiH}_{4}$ as the most important silicon-containing surface species.

Evidence for the importance of $\mathrm{H}^{*}$ comes from nucleation experiments in the $\mathrm{SiH}_{4}$ system [19] and the $\mathrm{SiH}_{2} \mathrm{Cl}_{2}$ system [20]. Below $1100{ }^{\circ} \mathrm{C}$ the nucleation on $\mathrm{SiO}_{2}$ substrates in the latter system strongly depends on the hydrogen content of the gas phase. The density of nuclei varied proportionally with $\mathrm{P}_{\mathrm{H}_{2}}^{-1 / 2}$, as expected for the adsorption of atomic hydrogen on the $\mathrm{SiO}_{2}$ substrate blocking adsorption sites. In the $\mathrm{SiH}_{4}$ system the same behaviour was observed, but only at temperatures below $900^{\circ} \mathrm{C}$. For the $\mathrm{Si}_{3} \mathrm{~N}_{4}$ substrates, hydrogen adsorption also reduces the nucleus density, but this effect is much less pronounced than for the $\mathrm{SiO}_{2}$ substrates. According to the JANAF tables [17] the bond strength between oxygen and hydrogen is $102 \mathrm{kcal} / \mathrm{mole}$, between nitrogen and hydrogen $83 \mathrm{kcal} / \mathrm{mole}$, while for the $\mathrm{Si}-\mathrm{H}$ bond $70 \mathrm{kcal} / \mathrm{mole}$ is reported. The same sequence can be 
expected to apply to the heats of adsorption of hydrogen on oxides, nitrides and silicon. The nucleation results may then be compared with the results of the growth experiments, and the adsorption of atomic hydrogen on silicon can be neglected above $700{ }^{\circ} \mathrm{C}$. Another indication is found from the properties of amorphous hydrogenated silicon films [21]. In these materials $\left(=\mathrm{SiH}_{2}\right)$ and $(\equiv \mathrm{SiH})$ centers are found when amorphous silicon is prepared from silane in a glow discharge or by sputtering of silicon in the presence of hydrogen at temperatures below $300^{\circ} \mathrm{C}$. Annealing of these materials above $300{ }^{\circ} \mathrm{C}$ gives evolution of $\mathrm{H}_{2}$ (one peak near $375^{\circ} \mathrm{C}$ due to the decomposition of $\left(=\mathrm{SiH}_{2}\right)$ and the other around $600{ }^{\circ} \mathrm{C}$, associated with the decomposition of $(\equiv \mathrm{SiH})$. It is therefore to be expected in the CVD of silicon, too, that the surface concentrations of atomic hydrogen $\left(\mathrm{H}^{*}\right)$ will be small. At low temperatures the dissociation of hydrogen is too difficult and at temperatures above $600^{\circ} \mathrm{C}$ the $\mathrm{SiH}$ bonds decompose easily.

\section{Adsorption of $\mathrm{SiH}_{2}$}

Adamczewska and Budzynski [10] observed a saturation in the growth rate from $\mathrm{SiH}_{4}$ at $500{ }^{\circ} \mathrm{C}$ with nitrogen as a carrier gas. Under reduced pressures and at $625^{\circ} \mathrm{C}$ the same behaviour was observed by Van den Brekel and Bollen [22]. Under these circumstances, therefore, a high $\mathrm{SiH}_{2}$ surface concentration could be expected. In the present series of experiments at $700{ }^{\circ} \mathrm{C}$, however, no saturation in the growth rate is observed for input concentrations up to $0.4 \mathrm{vol}$. \%, leading to the conclusion that under those circumstances $\theta \mathrm{SiH}_{2}$ is much smaller than unity. As discussed before, the deviation from linearity in nitrogen as a carrier gas (Figure 3) can be explained by gas phase nucleation of silane.

\section{Adsorption of atomic chlorine}

In the $\mathrm{Si}-\mathrm{H}-\mathrm{N}-\mathrm{Cl}$ system $\mathrm{SiH}_{2}$ will be converted into $\mathrm{SiCl}_{2}$, as previously discussed, and in this case, too, adsorption of chlorine comes into play. Most interesting in this respect is the reduction in growth rate in the $\mathrm{SiH}_{4}-\mathrm{HCl}-\mathrm{H}_{2}-\mathrm{N}_{2}$ system, where the first addition of $\mathrm{HCl}$ gives a strong reduction in growth rate (part I and Figure 5). This reduction could be caused by a strong adsorption of chlorine and subsequent reduction of adsorption possibilities for silane (model I). The experimental data in the $\mathrm{SiH}_{4} \cdot \mathrm{H}_{2} \cdot \mathrm{N}_{2} \cdot \mathrm{HCl}$ system as well as in the $\mathrm{SiH}_{2} \mathrm{Cl}_{2} \cdot \mathrm{H}_{2} \cdot \mathrm{HCl}$ system (part II) [8] can be explained readily without resorting to chlorine adsorption. Evidence for a fractional chlorine surface concentration much smaller than unity, at least at temperatures above $700{ }^{\circ} \mathrm{C}$, comes from the work of Miyamura et al. [23], who studied the adsorption of $\mathrm{HCl}$ on thermally cleaned $\mathrm{Si}$ (111) surfaces by Auger electron spectroscopy, electron energy loss spectroscopy, electron impact desorption and work-function change measurements. Equation (28) can be used to calculate the relative concentrations of $\mathrm{Cl}^{*}$ and $\mathrm{H}^{*}$. With a $\mathrm{SiH}$ bond strength of $70 \mathrm{kcal} / \mathrm{mole}$ and realistic values of $\mathrm{PH}_{\mathrm{H}}$ and $\mathrm{PCl}$ at $700{ }^{\circ} \mathrm{C}$ it is found that a decrease in the heat of adsorption of chlorine of $10 \mathrm{kcal} /$ mole is sufficient to obtain a con- 
centration of chlonne smaller than the concentration of atomic hydrogen $\mathrm{A}$ heat of adsorption of $90 \mathrm{kcal} / \mathrm{mole}$ for chlonne seems therefore to be too high when compared with the adsorption energy of atomic hydrogen $(70 \mathrm{kcal} / \mathrm{mole})$

\section{Adsorption of $\mathrm{SiCl}_{2}$}

As discussed in part II [8] , a strong adsorption of $\mathrm{SiCl}_{2}$ has to be assumed in order to explain the experimental data on growth of silicon from $\mathrm{SiH}_{2} \mathrm{Cl}_{2}$ both in hydrogen and in nitrogen The saturation in the growth rate in the $\mathrm{S}_{1} \mathrm{H}_{2} \mathrm{Cl}_{2}-\mathrm{H}_{2}$ system at $800^{\circ} \mathrm{C}$ shows that the concentration of $\mathrm{S}_{1} \mathrm{Cl}_{2}$ molecules on the surface is much higher than the atomic hydrogen concentration Using equation (28) a minımum heat of adsorption of $\mathrm{SiCl}_{2}$ can be calculated by putting $\theta \mathrm{S}_{1} \mathrm{Cl}_{2}=\theta_{\mathrm{H}}$ In the growth via $\mathrm{S}_{1} \mathrm{H}_{2} \mathrm{Cl}_{2}$ in nitrogen as a carrier gas, the value of $\mathrm{PSICl}_{2}$ is nearly equal to the input concentration of $\mathrm{S}_{1} \mathrm{H}_{2} \mathrm{Cl}_{2}$ It can be calculated that a heat of adsorption for $\mathrm{SiCl}_{2}$ on slicon higher than $30 \mathrm{kcal} / \mathrm{mole}$ is sufficient to give an appreciable concentration of $\mathrm{SiCl}_{2}{ }^{*}$ This value is quite reasonable, but it has to be pointed out that desorption of $\mathrm{S}_{1} \mathrm{Cl}_{2}$ is found to occur after conversion of $\mathrm{S}_{1} \mathrm{H}_{2}$ into $\mathrm{S}_{1} \mathrm{Cl}_{2}$ We therefore expect $\mathrm{E}_{\mathrm{SICl}_{2}}<\mathrm{E}_{\mathrm{S}_{1} \mathrm{H}_{2}} \cong \mathrm{E}_{\mathrm{SI}}$ In the $\mathrm{SiH}_{4}-\mathrm{HCl}-\mathrm{H}_{2}-\mathrm{N}_{2}$ system the value of $\mathrm{PS}_{\mathrm{Sl}_{2}}$ is always smaller than the equilibnum concentration of $\mathrm{SiCl}_{2}$ Therefore in this $\mathrm{S}_{1} \mathrm{H}_{4}-\mathrm{H}_{2}-\mathrm{N}_{2}-\mathrm{HCl}$ system a surface concentration of $\mathrm{S}_{1} \mathrm{Cl}_{2}$ can be expected to be much smaller than in the $\mathrm{S}_{1} \mathrm{H}_{2} \mathrm{Cl}_{2}-\mathrm{H}_{2}-\mathrm{N}_{2}$ system for equal input concentrations, other things being equal, as evidenced by the results in Figure 5

\section{Conclusions}

The growth of silicon on silicon has been studied at $700{ }^{\circ} \mathrm{C}$ in the $\mathrm{S}_{1} \mathrm{H}_{4}-\mathrm{H}_{2}-\mathrm{N}_{2} \mathrm{HCl}$ system Without addition of $\mathrm{HCl}$ the highest growth rates are obtained when nitrogen is used as a carrier gas Addition of hydrogen to the $\mathrm{SiH}_{4} \mathrm{~N}_{2}$ system leads to a reduction in the growth rate, which is inversely proportional to the hydrogen pressure Analysis of the experimental data leads to the conclusion that the equilibnum reaction, $\mathrm{SiH}_{4}=\mathrm{S}_{1} \mathrm{H}_{2}+\mathrm{H}_{2}$, plays a dominant role The rate-lımiting step has to be found between subsequent surface reactions The adsorption of atomic hydrogen at surface sites or step sites can be assumed to be of minor importance A fraction of free surface sites close to unity gives the best fit with the expenmental data This observation is in agreement with hydrogen evolution measurements in amorphous hydrogenated silicon [21] Addition of $\mathrm{HCl}$ to the $\mathrm{S}_{1} \mathrm{H}_{4} \mathrm{H}_{2}-\mathrm{N}_{2}$ system gives a strong decrease in growth rate, due to conversion of $\mathrm{S}_{1} \mathrm{H}_{2}$ into $\mathrm{SiCl}_{2}$ In nitrogen-hydrogen muxtures this reduction in the growth rate is larger than in the $\mathrm{SiH}_{4}-\mathrm{H}_{2}$ system The adsorption of $\mathrm{H}, \mathrm{Cl}, \mathrm{SiCl}_{2}$ and $\mathrm{SiH}_{2}$ has been discussed using the experimental data of the $\mathrm{S}_{1} \mathrm{H}_{4} \mathrm{H}_{2}-\mathrm{N}_{2}-\mathrm{HCl}$ system and the $\mathrm{S}_{1} \mathrm{H}_{2} \mathrm{Cl}_{2} \cdot \mathrm{H}_{2}-\mathrm{N}_{2} \cdot \mathrm{HCl}$ system It is concluded that a high surface concentration of $\mathrm{S}_{1} \mathrm{Cl}_{2}$ can be expected, notably in the $\mathrm{SiH}_{2} \mathrm{Cl}_{2} \cdot \mathrm{H}_{2}-\mathrm{N}_{2}$ system Chlorine adsorption cannot be excluded completely, but there are strong indications that chlorine ad- 
sorption does not have a major influence on the kinetics of the growth of silicon on silicon. It has to be expected that the crystallinity of the grown layer is disturbed by small surface coverage of hydrogen and chlorine, the growth rate however remains the same whether monocrystalline or polycrystalline material is formed. 


\section{References}

1 T.I. Kamins, IEEE Trans. PHP 10, 221 (1974).

T.I. Kamins, M.M. Mandurah and K.C. Saraswat, J. Electrochem. Soc. 125, 927 (1978).

2 W.A. Bryant, Thin Solid Films 60, 19 (1979).

3 Y. Yasuda, K. Hirabayashi and T. Moriya, Suppl J. Jap. Soc. Appl. Phys. 43, 400 (1974).

4 M.J. Duchemin, M.M. Bonnet and M.F. Koelsch, J. Electrochem. Soc. 125, 637 (1978).

5 H.M. Manasevit, J. Electrochem. Soc. 126, 1785 (1979).

6 F.C. Eversteyn, Philips Res. Rep. 29, 45 (1974).

7 J. Bloem and W.A.P. Claassen, J. Cryst. Growth 49, 435 (1980).

8 W.A.P. Claassen and J. Bloem, to be published in J. Cryst. Growth.

9 P.L.A.Chr.M. van der Meer, unpublished results.

10 J. Adamczewska and T. Budzynski, Thin Solid Films 56, 267 (1979).

11 V.A. Wells, B.O. Seraphin and L.S. Raymond, in G.F. Wakefield and J.M. Blocker, Jr. (eds)., Proc. 4th Int. Conf. on Chemical Vapor Deposition, The Electrochemical Society, Princeton, N.J. 1973, p. 512.

12 J.Y.W. Seto, J. Electrochem. Soc. 122, 701 (1975).

13 A.A. Chernov, J. Cryst. Growth 42, 55 (1977).

14 C.G. Newman, H.E. O’Neal, M.A. Ring, F. Leska and N. Shipley, International J. Chemical Kinetics, XI, 1167 (1979).

15 P. van der Putte, L.J. Giling and J. Bloem, J. Cryst. Growth 41, 133 (1977).

16 J.H. de Boer, The Dynamical Character of Adsorption (Clarendon Press, Oxford, 1953).

17 JANAF Thermochemical Tables 2nd ed. June 1971, NSRDS-NBS-37.

18 M. Farber and R.D. Srivastava, J.C.S. Faraday Transactions I 73, 1672 (1977).

19 W.A.P. Claassen and J. Bloem, J. Electrochem. Soc. 127, 194 (1980).

20 W.A.P. Claassen and J. Bloem, J. Electrochem. Soc. 127, 1836 (1980).

21 J.A. McMillan and E.M. Peterson, J. Appl. Phys. 50, 5238 (1979).

22 C.H.J. van den Brekel and L.J.M. Bollen, to be published.

23 M. Miyamura, Y. Sakisaka, M. Nishijima and M. Onchı, Surface Science 72, 243 (1978). 


\title{
CHAPTER VIII
}

\section{KINETIC STUDIES ON THE NUCLEATION AND GROWTH OF SILICON VIA CHEMICAL VAPOUR DEPOSITION}

\author{
Abstract \\ Chemical vapour deposition (CVD) of silicon on various substrates is a well-know technique in \\ semiconductor technology
}

An experimental study has been made of the nucleation of silicon on $\mathrm{SiO}_{2}$ and $\mathrm{Si}_{3} \mathrm{~N}_{4}$ substrates together with a search tor rate-limiting steps in the grow th of slicon from silane $\left(\mathrm{S}_{1} \mathrm{H}_{4}\right)$ and chlorosulanes

Analysis of the experimental data shows that the nucleation depends on the concentration of sulicon adatoms on the surface, $\left(S_{1}^{*}\right)$ After formation of stable nucles and coalescence of the growing domains, further growth of sulicon on slicon proceeds

For the growth of slicon via slane the rate-limiting reaction could not be indicated exactly, addition of some $\mathrm{HCl}$ results in a rapid change of the surface species into $\mathrm{SiCl}_{2}{ }^{*}$, indicating that the rate-limiting step has to be found at the end of the chain of surface reactions This conclusion is confurmed by experiments with an input of $\mathrm{SiH}_{2} \mathrm{Cl}_{2}$, in which case the $\mathrm{SiCl}_{2}{ }^{*}$ surtace species predominates Reduction to slicon is then found to be the rate-limiting reaction The reduction or desorption of chlorne probably takes place at specific sites on the surface, such as atomic surface steps where an adsorbed $\mathrm{S}_{1} \mathrm{Cl}_{2}$ molecule can form a second silicon-silicon bond

The adsorption of monoatomic hydrogen and chlorine on the slicon surface has been analysed and the conclusion is drawn that these surface species are not present in a sufficient concentration to turn the initial adsorption or the surface diffusion of slicon-containing compounds into rate-lımiting reactions

\section{Introduction}

The chemical vapour deposition of slicon is widely used in semiconductor technology for the growth of monocrystalline, polycrystalline or amorphous silicon layers

Monocrystalline layers are grown on monocrystallune substrates in the production of bipolar and MOS (metal-oxide-semiconductor) devices and integrated circuits Polycrystallıne sulicon is mostly used as gate matenal in MOS transistors. Amorphous silicon has at tracted attention as a possible base material for solar cells

In the growth of silicon from the vapour phase via CVD gaseous slicon compounds such as silane $\left(\mathrm{SiH}_{4}\right)$ and the chlorosilanes $\mathrm{S}_{1} \mathrm{H}_{2} \mathrm{Cl}_{2}, \mathrm{~S}_{1} \mathrm{HCl}_{3}$ and $\mathrm{SiCl}_{4}$ are used Hydrogen mostly performs the dual function of reducing agent and carrier gas

A typical apparatus used for the production of monocrystalline (so-called epitaxial) 
layers on monocrystalline substrates (silıcon, sapphire or spinei) is shown in figure 1.

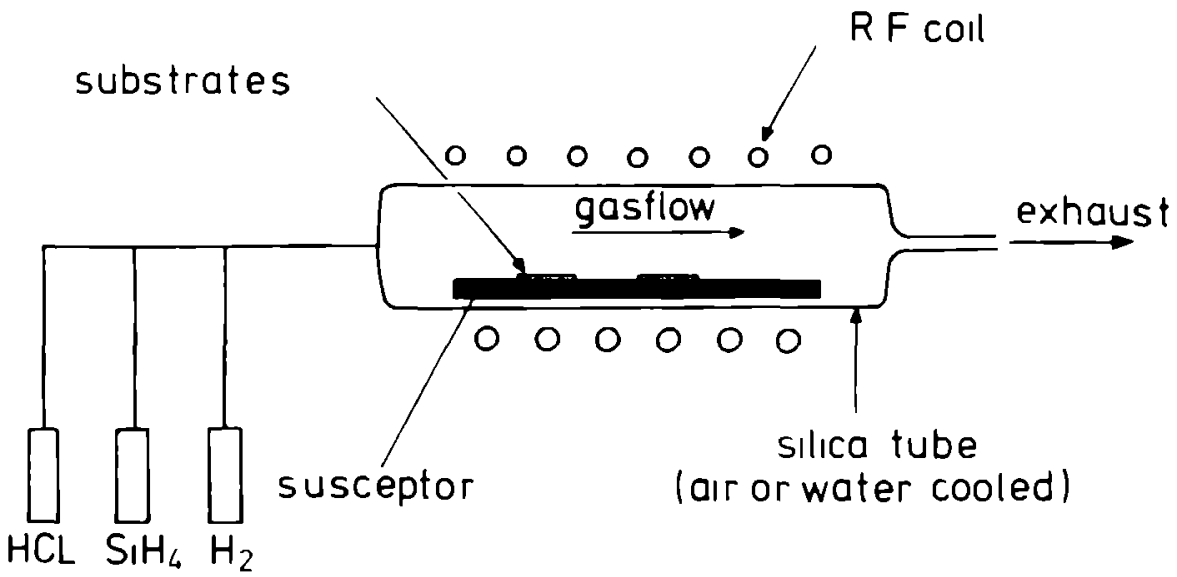

Figure 1.

$A$ horizontal CVD reactor. An $R F$ field is used to heat the graphite susceptor and the silicon wafers to the desired temperature.

A high frequency generator is used to heat the graphite susceptor. On the susceptor the substrate slices are positioned and the carrier gas mixed with a small concentration of silane or chlorosilane is passed over the slices.

At temperatures above $1000^{\circ} \mathrm{C}$ monocrystalline layers can be grown at a rate of around $1 \mu \mathrm{m} / \mathrm{min}$. In the cold-wall aparatus of figure 1 a temperature difference exists in the gas phase between the heated susceptor and the cold wall. As the viscosity of the gas increases with increasing temperature a boundary layer is developed; diffusion of silicon containing compounds through this boundary layer now determines the growth rate of the layer. The growth rate as a function of temperature for a constant input concentration of silane in hydrogen is depicted in figure 2 . It is seen that at temperatures above $1000^{\circ} \mathrm{C}$ the growth rate is hardly temperature-dependent as one would expect for a growth rate determined by the supply of reactant. The diffusion coefficients in the gas phase depend only slightly on temperature, thus explaining the growth behavour in region 1 of figure 2 .

At high growth temperatures the surface reactions are rapid and chemical equilibrium can be established at the silicon surface. These surface reactions, however, do not always lead to growth of a silicon layer. This is shown in figure 3 for the case of $\mathrm{SiCl}_{4}$ as silicon compound.

It is seen that initially the growth rate increases linearly with increasing input concentration of $\mathrm{SiCl}_{4}$; it then goes through a maximum, and at very high input concentrations, around 20 volume percent, the growth rate decreases to zero again. 


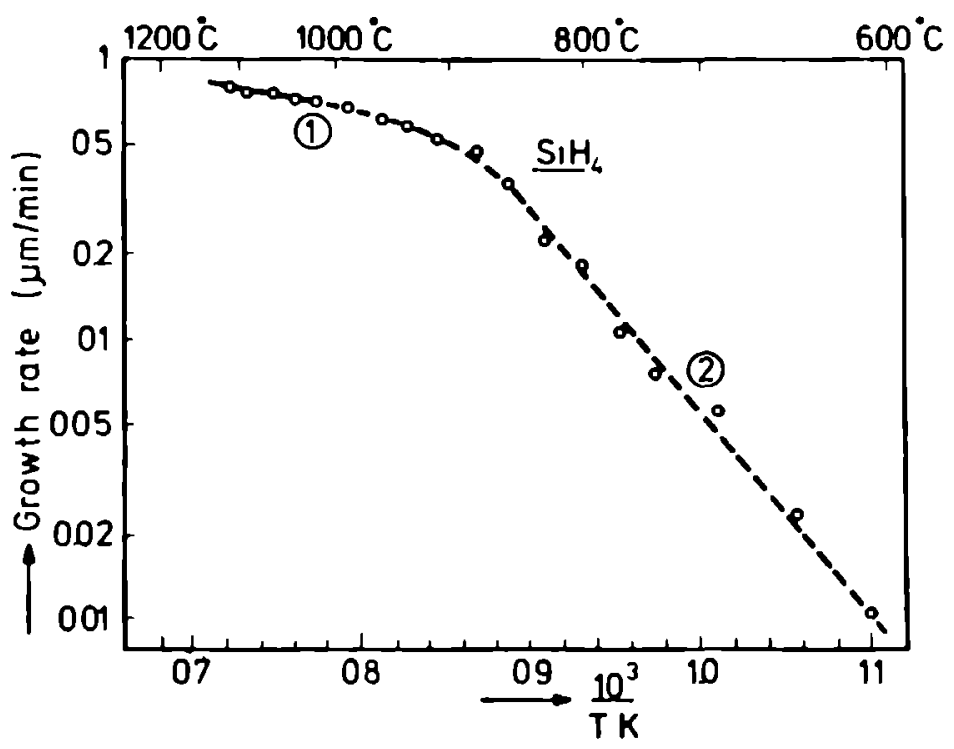

Figure 2.

Silicon growth rate as a function of temperature for a silane concentration of 0.1 volume percent in hydrogen. The low and high temperature regions are clearly visible.

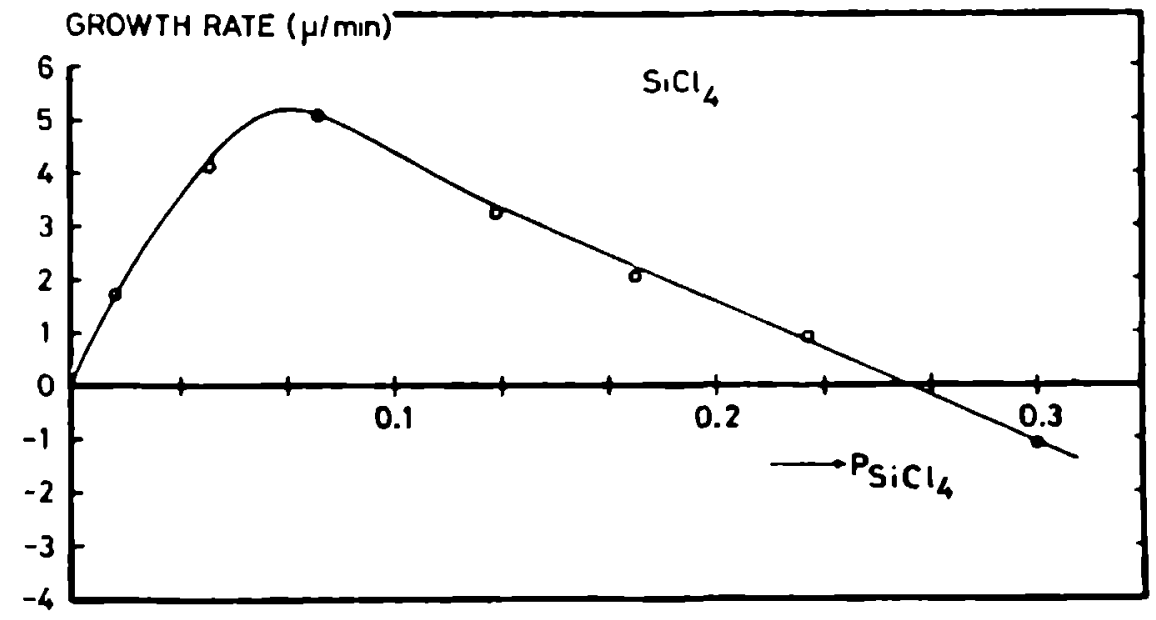

Figure 3.

The growth rate of silicon as a function of input concentration of $\mathrm{SiCl}_{4}$ in hydrogen as a carrier gas. 
This behaviour can be explained on the basis of thermodynamic equilibrium between two competing reactions:

$$
\begin{aligned}
& \mathrm{SiCl}_{4}+2 \mathrm{H}_{2} \rightleftharpoons \mathrm{Si}(\mathrm{cr})+4 \mathrm{HCl} \text { (growth) } \\
& 2 \mathrm{HCl}+\mathrm{Si}(\mathrm{cr}) \rightleftharpoons \mathrm{SiCl}_{2}+\mathrm{H}_{2} \text { (etching) }
\end{aligned}
$$

At higher input concentrations the second reaction is dominant giving the result shown in figure 3. For $\mathrm{SiH}_{2} \mathrm{Cl}_{2}$ and $\mathrm{SiHCl}_{3}$ the reduction in growth rate on increasing the input concentration is much smaller; no maximum in the growth rate versus concentration is found, only a deviation from linearity is observed [1].

Going to lower growth temperatures (region 2 in figure 2) a much stronger temperature dependence of the growth rate is found and surface reactions are thought to limit the growth. In such a situation the surface concentration of silicon species no longer corresponds to a chemical equilibrium. High surface concentrations of species occur, waiting for the next step in the chain of reactions. It can be visualized that such a sequence could consist of the following elements:

1. supply of reactant by gas phase diffusion,

2. adsorption of silicon compounds on the surface,

3. chemical reaction to form stable surface species,

4. surface diffusion to a suitable surface site,

5 . incorporation of silicon in the lattice,

6. surface diffusion of reaction products,

7. desorption of reaction products,

8. gas phase diffusion of products away from the interface.

The first step constitutes the rate-limiting reaction at high temperature, as discussed previously.

In the etching of silicon by gaseous $\mathrm{HCl}$ it has been shown by Van der Putte [2] that the rate-determining reaction is given by 6 . and 8 ., the reaction product being $\mathrm{SiCl}_{2}$.

It has been suggested by Chernov [3] that adsorption of monoatomic hydrogen and chlorine are of great importance. He calculated a dense population of $\mathrm{H}$ and $\mathrm{Cl}$ atoms (denoted $\mathrm{H}^{*}$ and $\mathrm{Cl}^{*}$ ) under equilibrium conditions, even at temperatures above $1000^{\circ} \mathrm{C}$. These adatoms could hamper the adsorption of silanes on the surface, and also could slow down the surface diffusion of reaction species towards specific surface sites. We will come back to this point and conclude that the equilibrium adsorption of $\mathrm{H}^{*}$ and $\mathrm{Cl}^{*}$ is of less importance.

Points 1. to 8. mentioned above are the result of theoretical work done by Kossel and Stranski, and later extended by Burton, Cabrera and Frank [4] . A schematic representation is given in figure 4 . It can be thought that molecules adsorb on the 


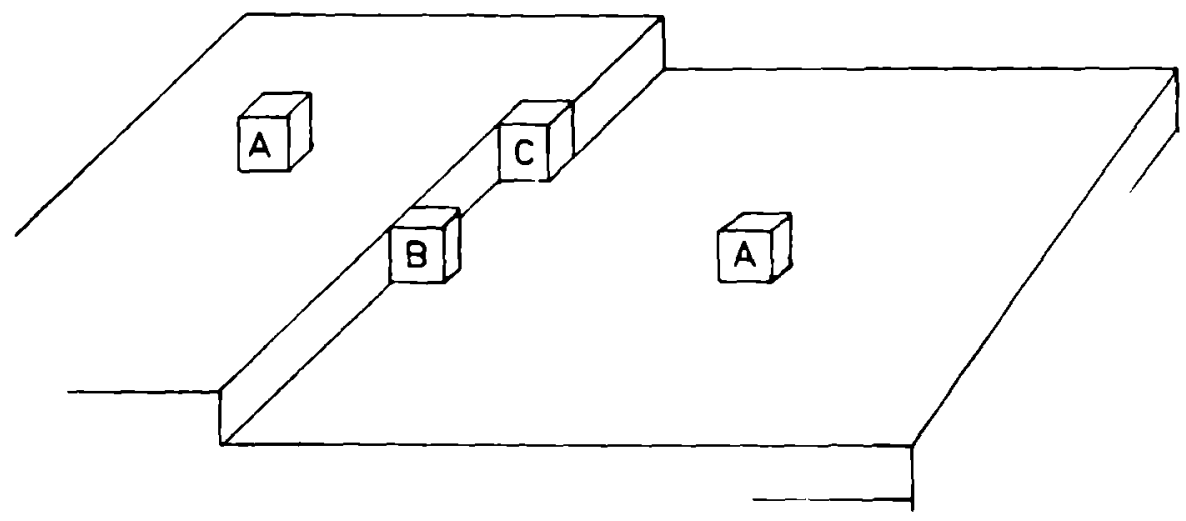

Figure 4.

Surface model with adatoms $(A)$, atoms on atomic steps (ledge position $B$ ) and the stable kink position (C). (terrace-ledge-kink model) $[4]$.

surface, followed by a chemical reaction to produce silicon adatoms that diffuse to a step and find a stable position on a so-called kink site. In this concept a kink site is energetically more attractive than an adatom position and diffusion is easily possible on the low-index perfect lattice plane between the steps.

At somewhat lower temperatures the surface diffusion of the adatoms becomes more difficult and nucleation of new centres between the steps becomes possible when the cohesive forces between the adatoms are stronger than the adhesive forces between adatom and substrate. This leads to less perfect growth and eventually to the growth of a polycrystalline layer. At still lower temperatures surface diffusion is so slow that an adatom has not yet diffused away before the next one arrives at the same lattice site. This leads to the formation of an amorphous layer, in which only short range interactions are present; reheating at higher temperatures can bring the layer to recrystallization [5].

The nucleation of silicon on a silicon substrate has mainly been studied in ultra high vacuum $\left(10^{-10}\right.$ torr) [6]. The surface has to be heated above $1250^{\circ} \mathrm{C}$ in order to be cleaned and a slight misorientation is preferred in order to promote the formation of a well-defined array of atomic steps. It has been shown [7] that on such a surface the lateral movement of the steps brings about the layer growth. In the growth of monocrystalline layers, therefore, a misorientation of about 3 degrees from the (111) orientation in the direction of the nearest (110) is generally used to optimise the growth of defect-free layers. Three degrees misorientation corresponds to an average step separation of about 20 lattice parameters. At temperatures below $100{ }^{\circ} \mathrm{C}$ polycrystalline growth is observed for growth at atmospheric pressure, 
whereds amorphous growth is found below $700{ }^{\circ} \mathrm{C}$ The change in growth habit depends on the growth rate and on the ambient pressure, low growth rates and reduced pressures allowing lower transition temperatures Nucleation of silicon on monocrystalline sapphire and spinel substrates has been studied by Abrahams and Blanc [8] and by Cullen [9] They demonstrated that the first nucleation leads to small islands that grow out unttl coalescence occurs Kamıns [10] reported that growth of slicon on amorphous $\mathrm{SiO}_{2}$ shows an incubation time that depends on temperature and slane input concentration The growth of slicon on amorphous $\mathrm{S}_{1} \mathrm{O}_{2}$ and $\mathrm{Sl}_{3} \mathrm{~N}_{4}$ layers onto silicon slices is an important process in the semicon ductor industry, leading to polycrystalline layers of high resistivity The grain size of the polycrystalline layer is the main parameter that determines the electrical resistivity The grain size in turn depends on the nucleation and growth conditions Since the kınetics of growth between 700 and $1000{ }^{\circ} \mathrm{C}$ and the nucleation of silicon on a foreign substrate as $\mathrm{SiO}_{2}$ and $\mathrm{Si}_{3} \mathrm{~N}_{4}$ are both unknown, a systematic study has been initiated in order to explore this area

\section{Nucleation of silicon on $\mathrm{SiO}_{2}$ and $\mathrm{Si}_{3} \mathrm{~N}_{4}$ substrates}

From nucleation experiments with silicon on a foreign substrate it has been deduced [11] that nucleation is preceded by the formation of a steady state con centration of monomers, dependent on the rate of adsorption and the rates of desorption or chemical reaction The following step is the formation of silicon clusters on the surface that grow and decay until a critical size is exceeded (the cntical cluster), when these clusters begin to grow by attracting neighbounng ad atoms This process can proceed so fast that the surface concentration of silicon adatoms between the growing nucleı becomes depleted, preventing further nucleation [12] This type of behaviour is illustrated in figure 5, which gives a picture of

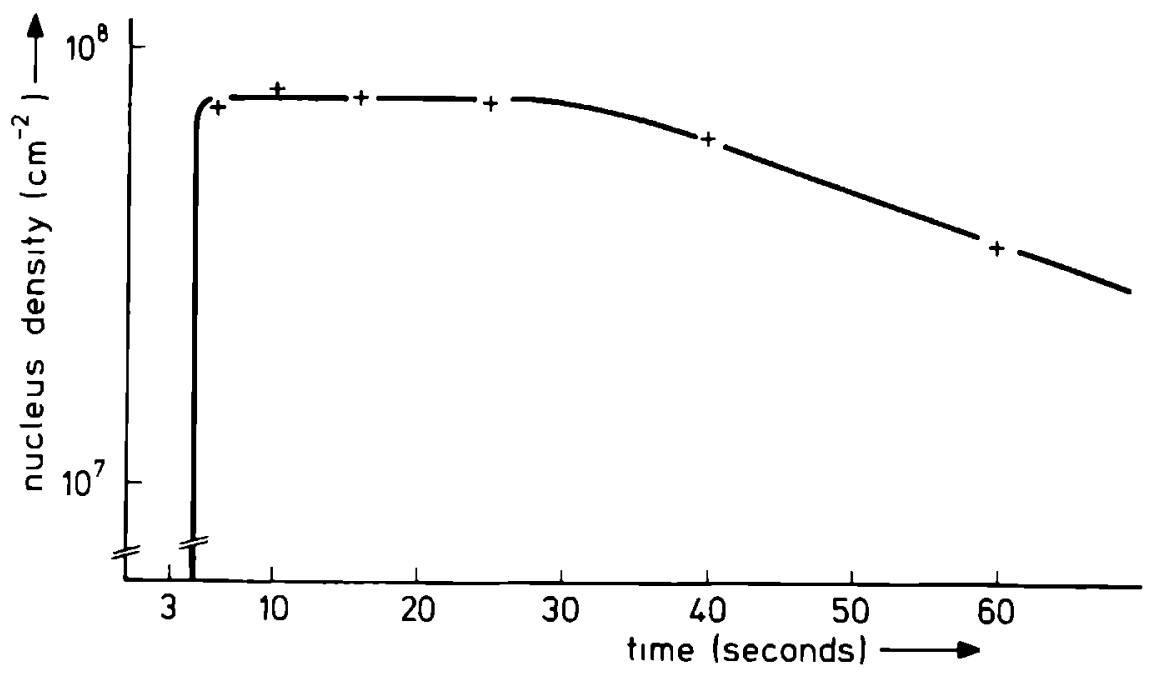

Figure 5

The density of stable nuclet on a $\mathrm{SlO}_{2}$ substrate as a function of the exposure time at $1000^{\circ} \mathrm{C}\left(\mathrm{PStH}_{4}=10^{-3}, \mathrm{PHCl}_{\mathrm{HCl}}=5 \times 10^{-3}\right.$ in hydrogen at atmosphenc pressure $)$ 
the number of nuclei formed on a silicon-oxide surface as a function of the time of deposition. To this end silicon slices were covered with a thin layer of $\mathrm{SiO}_{2}$ or $\mathrm{Si}_{3} \mathrm{~N}_{4}$ via deposition from the gas phase at reduced pressure. In the epitaxial apparatus shown in figure 1 the slices were heated to the desired temperature and a short pulse of silane or silane- $\mathrm{HCl}$ mixtures was introduced into the apparatus. The length of the pulse is the deposition time given in figure 5. After cooling down, the slices were examined in an electron microscope (SEM and TEM). For short pulses no nucleation is observed; after this incubation time the number of stable clusters suddenly increases to a constant value. For longer pulses the number of nuclei remains the same, the nuclei merely growing out to a larger size. Eventually, the clusters overlap and coalescence causes a decrease in the number of nuclei counted per surface area. The nucleation rate after the incubation time is so high that it cannot be determined and therefore the steady state number of nulcei $\left(n_{\mathfrak{s}}\right)$ has been further studied as a function of temperature and gas phase composition. Figures 6 and 7 show some results as regards the concentration of stable nuclei as a function of the $\mathrm{HCl}$ content for a constant silane concentration. As outlined by Claassen [11] the nucleation process can be described by an expression given by Venables $[12,13]$. In the case of incomplete condensation with a high mobility of adatoms and small clusters the maximum density of stable nuclei $n_{\mathbb{S}}$ is given as

$n_{S}=C n_{1} \frac{i+1}{2} \exp \frac{E_{i}+E_{x}-E_{d}}{k T}$

where $C$ is a statistical weighting factor, $n_{1}$ is the concentration of adatoms on the surface, $i$ is the number of atoms in a critical cluster, $E_{i}$ is the heat of formation of a cluster consisting of $i$ atoms, $E_{X}$ is the energy for surface diffusion of mobile clusters, and $E_{d}$ is the energy for surface diffusion of adatoms. In equation (2.1) the concentration of adatoms $\left(n_{1}\right)$ is used, the value of which depends on the supersaturation in the gas phase. An expression for $n_{1}$ can be obtained when the formation of adatoms is conceived of as a sequence of successive steps [11]. A simplified scheme is given here that will be supplemented in subsequent sections.

i adsorption of silane on a free site (*):

$$
\mathrm{SiH}_{4}+* \underset{\mathrm{k}_{.1}}{\stackrel{\mathrm{k}_{1}}{\rightleftharpoons}} \mathrm{SiH}_{4}{ }^{*} \text {, with } \mathrm{K}_{1}=\frac{\left[\mathrm{SiH}_{4}^{*}\right]}{\mathrm{PSiH}_{4} \cdot[*]} \text {. }
$$

ii the reaction of silane, creating adatoms

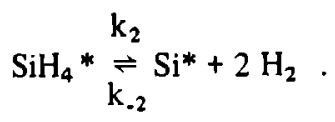



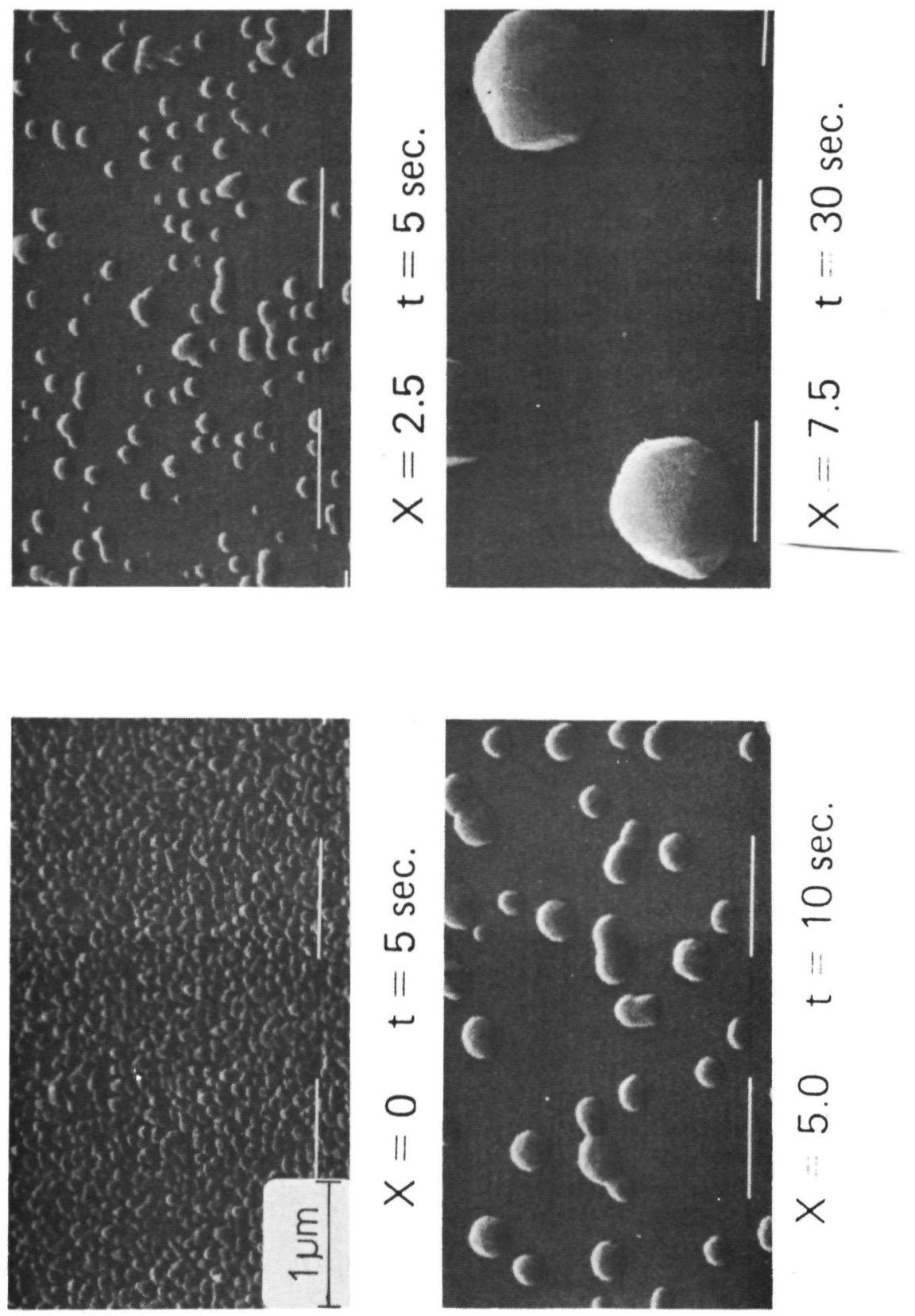

Figure 6.

Nucleus density from mixtures of $\mathrm{SiH}_{4}$ and $\mathrm{HCl}$ for 0.1 volume percent of silane. $X$ denotes the ratio of the input concentration of $\mathrm{HCl}$ and $\mathrm{SiH}_{4},\left(\mathrm{X}=\mathrm{P}_{\mathrm{HCl}} / \mathrm{PSiH}_{4}\right)$. The exposure time is chosen long enough for a constant number of nuclei to be reached. 


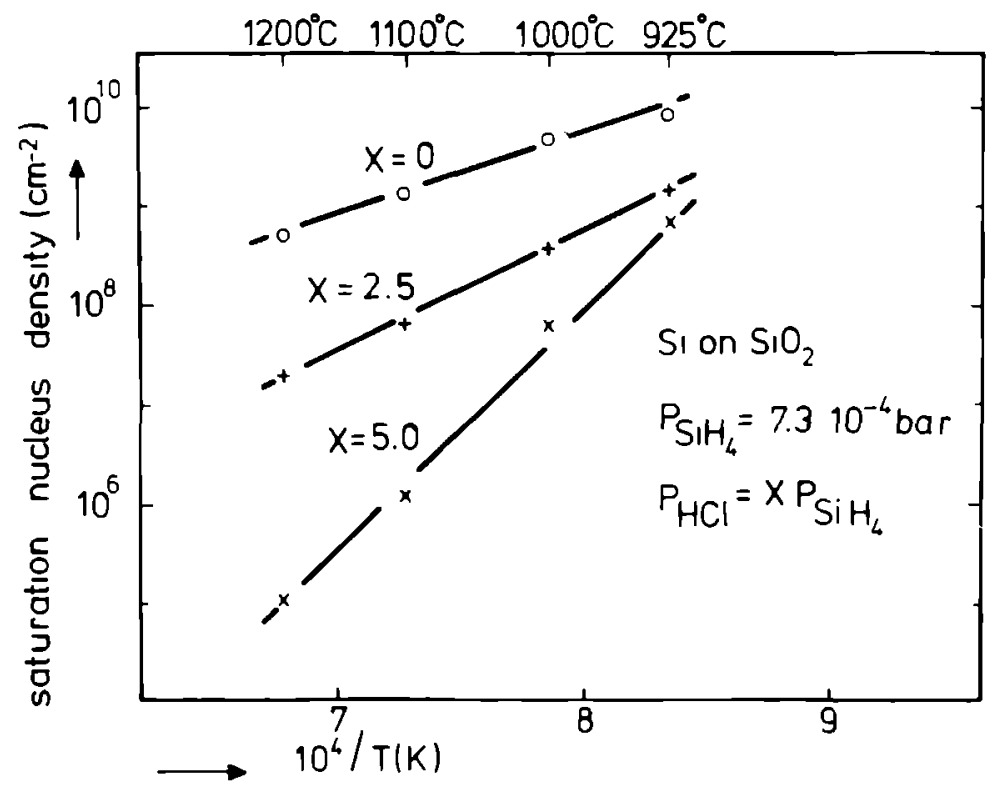

\section{Figure 7.}

The saturation nucleus density of silicon clusters on $\mathrm{SiO}_{2}$ as a function of the reciprocal temperature for different mixtures of $\mathrm{SiH}_{4}$ and $\mathrm{HCl}$.

iii the etching of adatoms

$$
\mathrm{Si}^{*}+2 \mathrm{HCl} \stackrel{\mathrm{k}_{3}}{\stackrel{\mathrm{k}_{-3}}{\rightleftharpoons}} \mathrm{SiCl}_{2}+* .
$$

Reactions with the substrate and the adsorption of species other than silane have been left out of account. In the steady state where $\mathrm{dn}_{1} / \mathrm{dt}=0$, the adatom concentration $\left[\mathrm{Si}^{*}\right]=\mathrm{n}_{1}$ is given by

$$
\mathrm{n}_{1}=\frac{\mathrm{k}_{1} \mathrm{k}_{2} \mathrm{PSiH}_{4}[*]}{\mathrm{k}_{-2} \mathrm{P}_{\mathrm{H}_{2}}^{2}+\mathrm{k}_{3} \mathrm{P}_{\mathrm{HCl}}^{2}} \text {. }
$$

For a fraction of free adsorption sites close to unity and $\mathrm{P}_{\mathrm{H}_{2}}=1$ at atmospheric pressure, eq. (2.5) reduces to

$$
n_{1}=\frac{k^{\prime} P_{S_{i H}}}{1+k^{\prime \prime} P_{\mathrm{HCl}}^{2}} \text {. }
$$


Eq (2.1) now reads

$n_{S}=C\left(\frac{k^{\prime} P_{S 1 H_{4}}}{1+k^{\prime \prime} P_{H C l}^{2}}\right)^{\frac{1+1}{2}} \exp \frac{E_{1}+E_{X}-E_{d}}{k T}$.

In figure 8 expenmental nucleation densities are given for vanous combinations of $\mathrm{PS}_{\mathrm{S}_{4}}$ and $\mathrm{PHCl}$. The results can very well be described by

$n_{\mathrm{S}} \propto \frac{\mathrm{PS}_{\mathrm{S}_{4}}}{1+6 \times 10^{6} \cdot \mathrm{P}_{\mathrm{HCl}}^{2}}$.

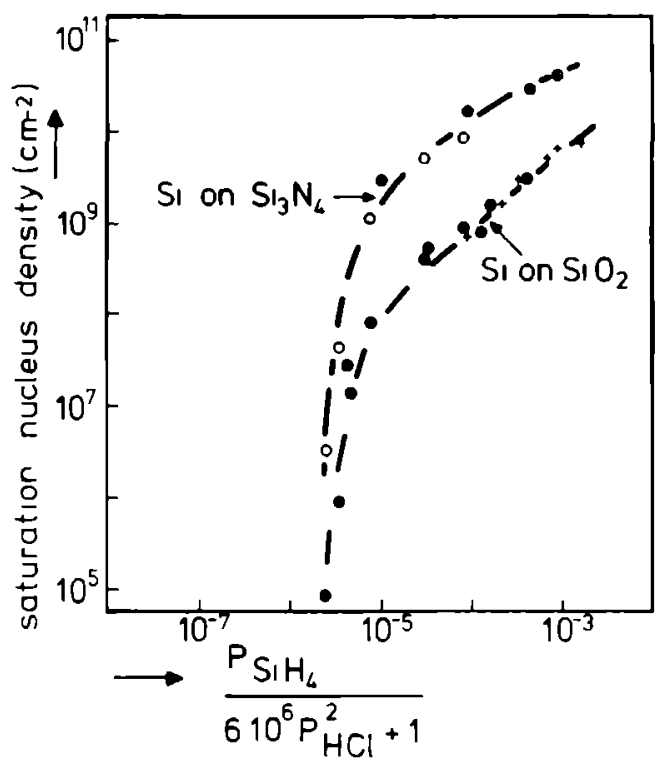

Figure 8.

The saturation nucleus density of silicon clusters at $1000^{\circ} \mathrm{C}$ for different input concentrations of $\mathrm{SiH}_{4}$ with and without $\mathrm{HCl}$.

Inspection of figure 8 shows that, for higher values of $\mathrm{P}_{\mathrm{S}_{1} \mathrm{H}_{4}} / \mathrm{P}_{\mathrm{HCl}}^{2}$, the slope of $\mathbf{n}_{\mathrm{S}}$ versus supersaturation is equal to unity. According to eq. (2.7) the slope is given by $(1+1) / 2$, and hence 1 equals unity, or, the critical cluster consists of one atom. For lower supersaturations the value of $n_{s}$ decreases rapidly, and values of 1 up to 4 are then calculated from the experumental data.

Going to lower temperatures typical differences become visible between the con- 
centrations of stable nucle1 formed on $\mathrm{SiO}_{2}$ and $\mathrm{Sl}_{3} \mathrm{~N}_{4}$ substrates For hydrogen ds a carrier gas the nucleus density on $\mathrm{S}_{1} \mathrm{O}_{2}$ becomes much smaller than on $\mathrm{Si}_{3} \mathrm{~N}_{4}$ (figure 9), in nitrogen the densities are nearly equal on these two substrates This observation suggests that by adsorption of monoatomic hydrogen the adsorption sites for silane are blocked on the $\mathrm{SiO}_{2}$ surface This appears not to be the case on the silicon nitride surface, in which connection it is interesting to note that the $\mathrm{O}-\mathrm{H}$ and $\mathrm{N}-\mathrm{H}$ bond strengths are 102 and $83 \mathrm{kcal} /$ mole respectively This difference is large enough to explain the experimental results providing that the heat of adsorption of the main silicon species is greater than $83 \mathrm{kcal} / \mathrm{mole}$

It has also been shown in the nucleation experiments that the stable nucleus density could be varied between $10^{5}$ and $10^{11}$ per $\mathrm{cm}^{2}$ resulting in polycrystallıne layers with a corresponding number of grains After coalescence of the growing nucles these grains are seen to grow in a columnar fashion On a monocrystalline substrate like sapphire and spinel a comparable number of nucles is formed. In that case the nucles are not randomly oriented, as they are on an amorphous substrate, and reasonably crystalline layers can be formed $[8,9]$.

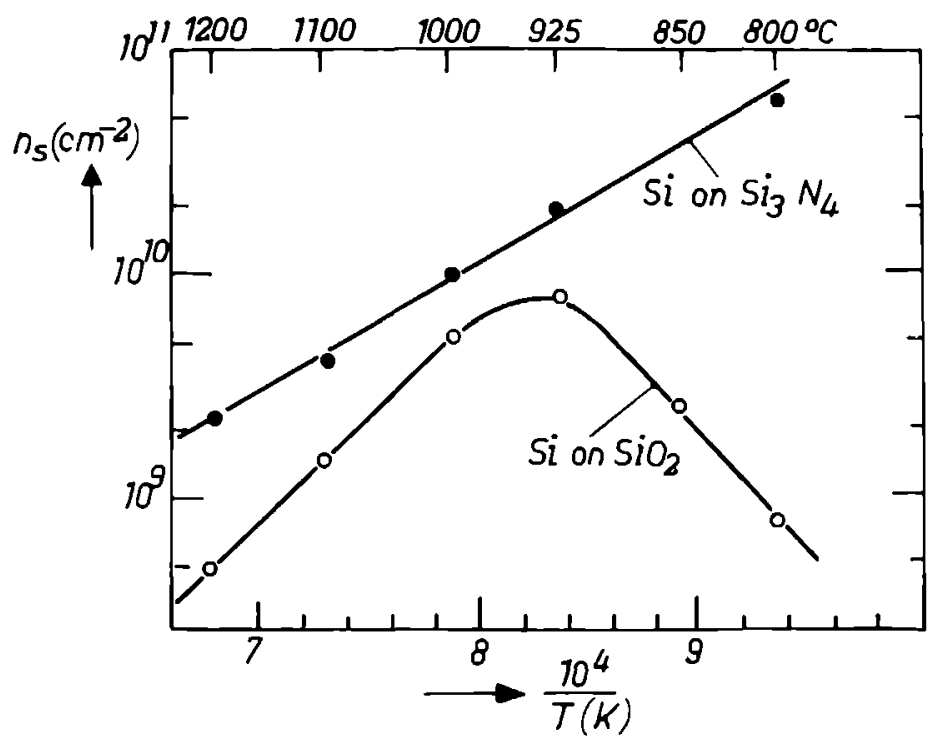

Figure 9

The steady state nucleus densities on $\mathrm{SlO}_{2}$ and $\mathrm{Si}_{3} \mathrm{~N}_{4}$ substrates in hydrogen as a carrier gas. At the lower temperatures hydrogen adsorption on $\mathrm{SiO}_{2}$ hampers the nucleation. 


\section{Growth of silicon on silicon}

A number of recent experiments will now be discussed that give some insight into the kinetics of the growth of silicon from slane and the chloroslanes at tempera tures between 700 and $1000^{\circ} \mathrm{C}$ In order to faclitate the discussion a generalised scheme will be presented first in which the essential steps in the growth from silane and chlorosilanes are formulated in a way that permits a close companson

\section{General scheme for the growth of slicon}

As a result of the experuments it is believed that gas phase reactions close to the slicon surface are important Two main reaction products are of interest, 1 e $\mathrm{SiH}_{2}$ and $\mathrm{SICl}_{2}$, formed accordung to

$\mathrm{S}_{1} \mathrm{H}_{4} \rightleftharpoons \mathrm{SiH}_{2}+\mathrm{H}_{2}$

and

$\mathrm{SlH}_{2}+2 \mathrm{HCl} \rightleftharpoons \mathrm{SlCl}_{2}+2 \mathrm{H}_{2}$

$\mathrm{S}_{1} \mathrm{H}_{2} \mathrm{Cl}_{2} \rightleftharpoons \mathrm{SiCl}_{2}+\mathrm{H}_{2}$

$\mathrm{SlHCl}_{3} \rightleftharpoons \mathrm{SlCl}_{2}+\mathrm{HCl}$

$\mathrm{SiCl}_{4}+\mathrm{H}_{2} \rightleftharpoons \mathrm{SiCl}_{2}+2 \mathrm{HCl}$

The gas phase reactions are followed by adsorption of the $\mathrm{S}_{1} \mathrm{H}_{2}$ and $\mathrm{SiCl}_{2}$ species on the slicon surface $\mathbf{A}$ free surface site is denoted as *, giving

$\mathrm{SiH}_{2}+* \rightleftharpoons \mathrm{SIH}_{2}^{*}$

$\mathrm{SiCl}_{2}+* * \mathrm{SiCl}_{2}^{*}$

The adsorbed species diffuse over the slicon surface until a site is reached where a second slicon-silicon bond can be formed, e g. a free site at an atomic step on the surface. We then have

$$
\begin{aligned}
& \mathrm{SiH}_{2}^{*+*}(\text { step }) \rightleftharpoons \mathrm{S}_{2} \mathrm{H}_{2}^{* *} \\
& \mathrm{SiCl}_{2}^{*}+*(\text { step }) \rightleftharpoons \mathrm{SICl}_{2}{ }^{* *}
\end{aligned}
$$

Next comes the rate-limiting reaction given by the release of the adsorbed $\mathrm{H}$ and $\mathrm{Cl}$ atoms, resultung in 
$\mathrm{SiH}_{2}^{* *} \rightleftharpoons \mathrm{Si}(\mathrm{cr})+\mathrm{H}_{2}$

$\mathrm{SiCl}_{2}^{* *}+\mathrm{H}_{2} \rightleftharpoons \mathrm{Si}(\mathrm{cr})+2 \mathrm{HCl}$.

In the following the considerations leading to this general scheme will be presented.

\subsection{Growth from silane}

The growth of polycrystalline silicon films has been studied at atmospheric pressure in a carrier gas consisting of various mixtures of hydrogen and nitrogen [14]. Care has been taken to use silane concentrations low enough to be sure that no gas phase nucleation occurs [15]. A typical result is shown in figure 10, where it can be seen that the growth rate is high in inert gas and lowest in pure hydrogen. For all experi-

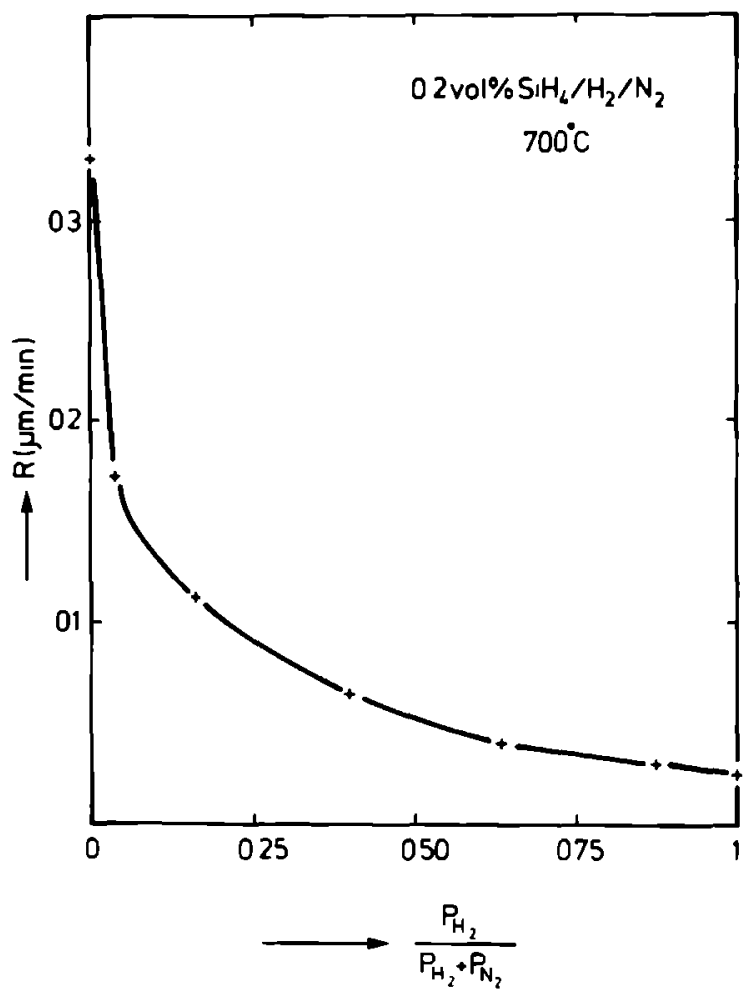

Figure 10.

The growth rate of silicon at $700^{\circ} \mathrm{C}$ as a function of the hydrogen content in the gas phase with silane $\left(\mathrm{SiH}_{4}\right)$ as silicon source material. 


\begin{tabular}{|c|c|c|c|}
\hline \multicolumn{2}{|r|}{ Reaction } & \multicolumn{2}{|c|}{ Growth rate from RLR } \\
\hline adsorption & $\mathrm{SiH}_{4}+* \rightleftharpoons \mathrm{SiH}_{4} *$ & $\mathrm{R}_{1}=\mathrm{k}_{1} \mathrm{PSiH}_{4} \cdot \theta$ & $\mathrm{R}_{1}=\mathrm{k}_{1} \mathrm{PSiH}_{4}$ \\
\hline chemical reaction & $\mathrm{SiH}_{4} * \rightleftharpoons \mathrm{SiH}_{\mathrm{n}}^{*}+\frac{4-\mathrm{n}}{2} \mathrm{H}_{2}$ & $\mathrm{R}_{2}=\mathrm{k}_{2} \cdot \mathrm{PSiH}_{4} \cdot \theta$ & $\mathrm{R}_{2}=\mathrm{k}_{2} \mathrm{PSiH}_{4}$ \\
\hline surface diffusion & $\mathrm{SiH}_{\mathrm{n}}^{*}+* \rightleftharpoons \mathrm{SiH}_{\mathrm{n}} *+*$ & $\mathbf{R}_{3}=\mathrm{k}_{3} \cdot \frac{\mathrm{PSiH}_{4}}{\mathrm{P}_{\mathrm{H}_{2}}^{(4-\mathrm{n}) / 2}} \cdot \theta^{2}$ & $\mathbf{R}_{3}=k_{3} \frac{P_{S_{i H}}}{P_{H_{2}}}$ \\
\hline step attachment & $\mathrm{SiH}_{\mathrm{n}}^{*}+*(\mathrm{st}) \rightleftharpoons \mathrm{SiH}_{\mathrm{n}}^{* *}$ & $\mathrm{R}_{4}=\mathrm{k}_{4} \cdot \frac{\mathrm{PSiH}_{4}}{\mathrm{P}_{\mathrm{H}_{2}}^{(4-\mathrm{n}) / 2}} \cdot \theta \cdot \theta_{\mathrm{st}}$ & $\mathrm{R}_{4}=\mathrm{k}_{4} \frac{\mathrm{PSiH}_{4}}{\mathrm{P}_{\mathrm{H}_{2}}}$ \\
\hline release of $\mathrm{H}_{2}$ & $\mathrm{SiH}_{\mathrm{n}} * * \rightleftharpoons \mathrm{Si}(\mathrm{cr})+\frac{\mathrm{n}}{2} \mathrm{H}_{2}$ & $\mathrm{R}_{\mathrm{s}}=\mathrm{k}_{\mathrm{s}} \cdot \frac{\mathrm{PSiH}_{4}}{\mathrm{P}_{\mathrm{H}_{2}}^{(4-n) / 2}} \cdot \theta \cdot \theta_{\mathrm{st}}$ & $\mathrm{R} 5=\mathrm{k}_{5} \frac{\mathrm{PSiH}_{4}}{\mathrm{P}_{\mathrm{H}_{2}}}$ \\
\hline
\end{tabular}

\section{TABLE I}

Reaction path for the growth of silicon from silane. The last column gives an expression for the growth rate when the corresponding reaction is rate-limiting (RLR). The fraction of free surface and step sites is denoted by $\theta$ and $\theta_{\text {st }}$ respectively. For hydrogen adsorption

$$
\theta=1 /\left(1+\mathrm{k}_{\mathrm{H}} \mathrm{P}_{\mathrm{H}_{2}}^{\prime 2}\right) .
$$


ments the growth rate can farly well be expressed as a function of the input pressures of silane and hydrogen

$\mathrm{R}=\frac{\mathrm{k}_{\mathrm{a}} \mathrm{PS}_{\mathrm{S}_{1}}}{1+\mathrm{k}_{\mathrm{b}} \mathrm{P}_{\mathrm{H}_{2}}} \approx \frac{\mathrm{k}_{\mathrm{a}} \mathrm{P}_{\mathrm{S}_{1} \mathrm{H}_{4}}}{\mathrm{~kb}_{\mathrm{b}} \mathrm{P}_{\mathrm{H}_{2}}}$

The experimental result of eq ( 35 ) is of extreme importance in the interpretation of the silicon growth rate In Table I possible reactions of silane are given, together with an expression for the growth rate when that specific reaction is rate-limiting The adsorption of a fully coordinated compound like $\mathrm{S}_{1} \mathrm{H}_{4}$ is rather improbable because of the low heat of adsorption Formally, however, $\mathrm{S}_{1} \mathrm{H}_{4}$ adsorption can be accepted as a precursor to the adsorption of other $\mathrm{Si}-\mathrm{H}$ molecules It is also possible, by combination of eq 1 and eq 2 in Table I, to describe a dissociative adsorption It has been suggested [16] that adsorption of monoatomic hydrogen hampers the growth at lower temperatures, thereby blocking sites for the adsorption of silane via the reaction

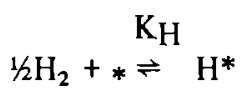

The asterisk denotes a free surface site and $\mathrm{H}^{*}$ stands for an adsorbed hydrogen atom From eq $(36)$ follows the fraction of free surface sites $(\theta)$ in the case of pre dominant hydrogen adsorption, given by

$$
\left[\mathrm{H}^{*}\right]=\mathrm{K}_{\mathrm{H}} \quad \mathrm{P}_{\mathrm{H}_{2}^{2}}^{1 / 2}[*]
$$

and

$$
[*]=\theta=1 /\left(1+\mathrm{K}_{\mathrm{H}} \mathrm{P}_{\mathrm{H}_{2}}^{1 / 2}\right)
$$

From Table I it can be deduced that an expenmental result as given in eq 35 points to a value of $n=2$ with $\theta=1$ or $n=4$ when $\theta=1 / \mathrm{K}_{\mathrm{H}} \mathrm{P}_{\mathrm{H}_{2}}^{1 / 2}$ Most probable is $\mathrm{n}=2$ with $\mathrm{SiH}_{2}$ as surface species, leading to the conclusion that surface adsorption of hydrogen does not result in a complete surface coverage It is also clear from Table I that adsorption of silane cannot explain the expenmental results The actual rate-limiting step has to be found amongst the surface diffusion, step attachment and release of hydrogen Different hydrogen partial pressures will give different amounts of $\mathrm{S}_{1} \mathrm{H}_{2}{ }^{*}$, leading to a higher growth rate in an inert gas, and the same effect is expected for growth under reduced pressures where the value of $\mathrm{P}_{2}$ is equally reduced Indications of a vanation of growth rate with $\mathrm{P}_{\mathrm{H}_{2}}^{-1}$ have also been found by Yasuda [17] At high growth temperatures Manasevit [18] found a growth rate proportional to $\mathrm{P}_{\mathrm{H}_{2}}$ In his expenments, however, the gas phase concentration of slane was so high that gas phase decomposition predominates via 
$\mathrm{S}_{1} \mathrm{H}_{4} \rightleftharpoons \mathrm{S}_{1} \mathrm{H}_{2}+\mathrm{H}_{2}$

$\mathrm{S}_{1} \mathrm{H}_{2}+\mathrm{S}_{1} \mathrm{H}_{4} \rightleftharpoons \mathrm{S}_{2} \mathrm{H}_{6}$ etc.

In a hydrogen ambient the formation of free $\mathrm{S}_{1} \mathrm{H}_{2}$ is hampered giving a smaller rate of deposition of polymers on the reactor wall and thus a higher growth rate on the substrate The present expenments on the growth of silane indicate that $\mathrm{SiH}_{2}$ could be a predominant surface species. A conclusive indication of the nature of the ratelimiting reaction can not be given from these expenments alone Further insight might be gained from additional experiments The first to be discussed is the system in which some $\mathrm{HCl}$ gas is muxed with silane in a hydrogen ambient

\subsection{Growth from $\mathrm{StH}_{4}$ plus $\mathrm{HCl}$}

It has been shown previously by Van der Putte et al [2] that gaseous hydrogen chlonde etches silicon, the main reaction being

$\mathrm{S} 1+2 \mathrm{HCl} \rightleftharpoons \mathrm{SlCl}_{2}+\mathrm{H}_{2}$

Van der Putte et al have studied the etching reaction in some detall, the etch rate is found to be proportional to the amount of $\mathrm{SiCl}_{2}$ formed and can be expressed as

$\mathrm{R}_{\mathrm{etch}}=\mathrm{k}_{\mathrm{c}} \mathrm{P}_{\mathrm{HCl}}^{2} / \mathrm{P}_{\mathrm{H}_{2}}$.

The etch rate therefore is fast in inert ambients and slows down in hydrogen as a carner gas

The addition of a small amount of $\mathrm{HCl}$ to silane has been used in order to prevent the gas phase nucleation of silane [1]. At temperatures above $1000^{\circ} \mathrm{C}$ mixtures of 0.1 volume percent $\mathrm{SiH}_{4}$ and 0.4 volume percent $\mathrm{HCl}$ show a silicon growth rate of $03 \mu \mathrm{m} / \mathrm{min}$, alsmost equal to that shown by slane. The etch rate given by 0.4 volume percent $\mathrm{HCl}$ in hydrogen is small $(0.02 \mu \mathrm{m} / \mathrm{min})$ For growth temperatures exceeding $1000^{\circ} \mathrm{C}$ it has been demonstrated that growth via slane and etching via $\mathrm{HCl}$ occur simultaneously and independent of each other on the slicon surface. Going to lower growth temperatures figure 2 shows that surface reactions begn to hamper the growth rate, but the etch rate remains more or less constant It could be expected that the sum of eqs. (3.9) and (3.5) would represent the outcome of a combined growth and etching behaviour, even at temperatures below $900{ }^{\circ} \mathrm{C}$. Experimentally, however, it is found that below $900^{\circ} \mathrm{C}$ an enormous reduction in growth rate appears [19] This behaviour is interesting as it points to specitic surlace reactions that occur in the kinetically controlled regime Figure 11 gives some results. A strong reduction in growth rate is apparent This reduction depends on the amount of $\mathrm{HCl}$ added. Figure 12 shows that there is a drastic decrease in growth rate on the first addition of $\mathrm{HCl}$ (shown to be proportional to 


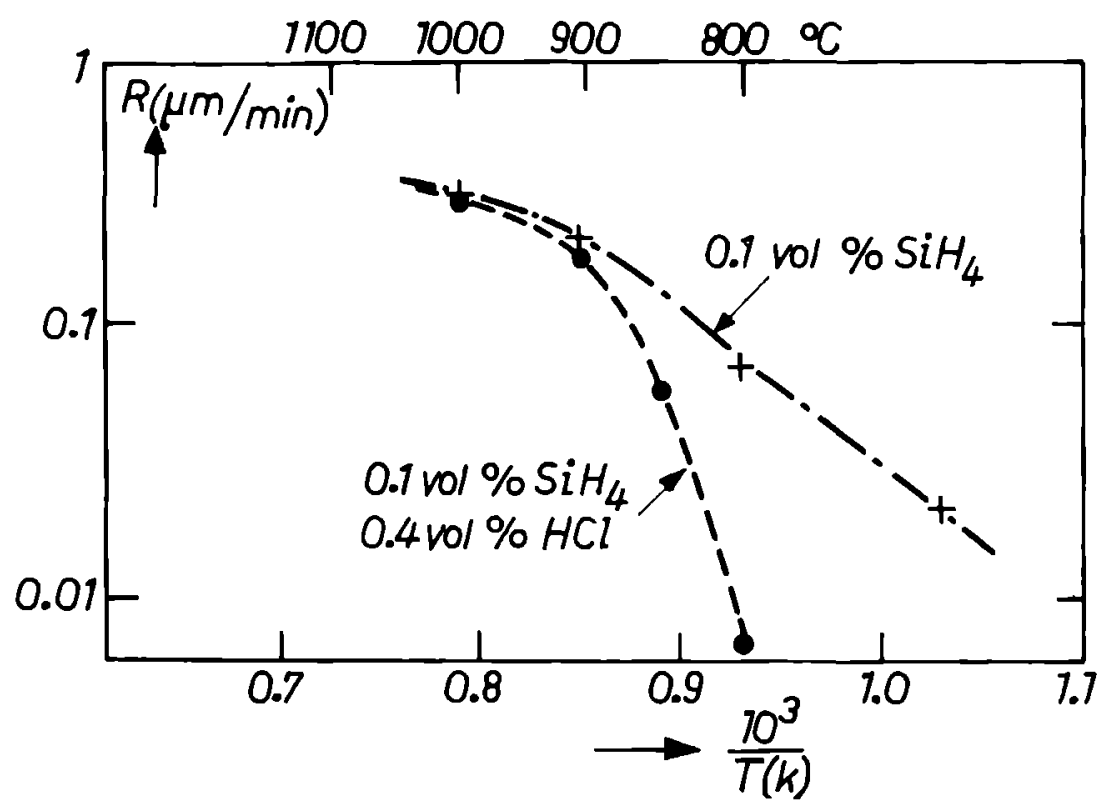

Figure 11 .

Growth rate given by a mixture of 0.1 volume percent silane and 0.4 volume percent $\mathrm{HCl}$ in hydrogen as a function of temperature, compared with the growth rate given by $\mathrm{SiH}_{4}$ without $\mathrm{HCl}$ addition.

$\mathrm{P}_{\mathrm{HCl}}^{2}$ followed by a slower decrease in growth rate. This decrease is also proportional to $\mathrm{P}_{\mathrm{HCl}}^{2}$. The decrease in growth rate when interpreted as an etch rate is such as expected from eq. (3.9). It was concluded that the decrease in growth rate is to be explained by the attack of $\mathrm{Si}^{*}$ and $\mathrm{SiH}_{2}{ }^{*}$ surface species by $\mathrm{HCl}$, leading to the formation of $\mathrm{SiCl}_{2}$ as the main adsorbed surface species in a new steady state situation. The explanation of the reduced growth rate can then be given on the basis of an analysis of the possible rate-limiting reactions. When the rate-limiting step is at the end of the chain of reactions, an increased concentration of $\mathrm{Si}^{*}$ and $\mathrm{SiH}_{2}{ }^{*}$ then builds up. The supersaturation can be a factor of $10^{3}$ for an input concentration of silane of $10^{-3}$ and a calculated equilibrium concentration of $10^{-6}$ bar for silicon in contact with hydrogen at temperatures around $1000^{\circ} \mathrm{C}$ [20]. In this situation $\mathrm{HCl}$ is able to attack these reactive species, giving $\mathrm{SiCl}_{2}{ }^{*}$ on the surface. Desorption of $\mathrm{SiCl}_{2}$ is readily possible under the conditions of increased surface concentration, leading to the observed decrease in growth rate. This new situation is established on the first addition of $\mathrm{HCl}$; any further increase in $\mathrm{HCl}$ content cannot increase the $\mathrm{SiCl}_{2}$ concentration other than via the normal etching of bulk silicon atoms (eq. 3.9). 


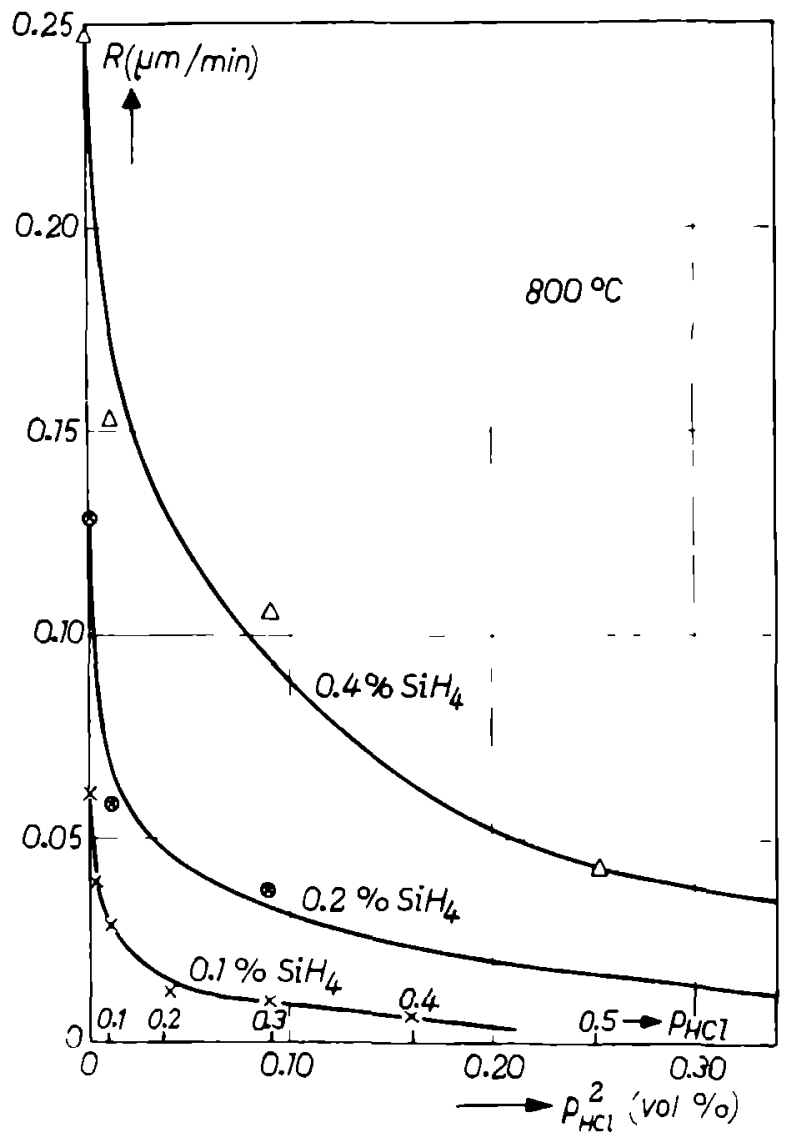

Figure 12.

The growth rate shown by mixtures of 0.1 volume percent silane and various amounts of $\mathrm{HCl}$, plotted as a function of $\mathrm{P}_{\mathrm{HCl}}^{2}$.

A reduction in growth rate by the introduction of $\mathrm{HCl}$ can also be explained by adsorption of chlorine on the silicon surface

$\mathrm{HCl}+* \rightleftharpoons \mathrm{Cl} *+1 / 2 \mathrm{H}_{2}$

The chlorine content would reduce the number of free surface sites and thus make the adsorption of silane more difficult. There are two points that make this explanation less attractive. The first is that the reduction in growth rate is then expected to be proportional to $\mathrm{P}_{\mathrm{HCl}}$, whereas in practice a reduction proportional to $\mathrm{P}_{\mathrm{HCl}}^{2}$ is found. The other point is the new level in growth rate obtained after the first intro- 


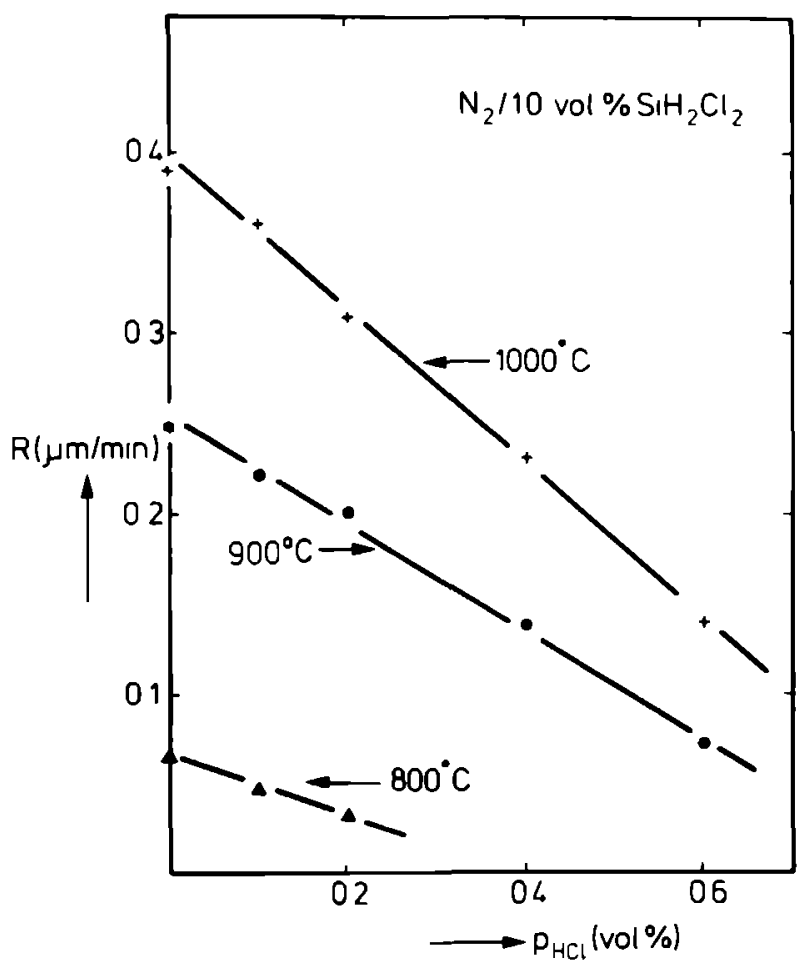

Figure 13

The growth rate of silicon from $\mathrm{SiH}_{2} \mathrm{Cl}_{2}$ as a function of the addition of $\mathrm{HCl}$

duction of $\mathrm{HCl}$, which cannot be explained simply on the basis of chlorine adsorption Therefore, the chemical reaction is favoured in which the original surface species are converted into $\mathrm{SiCl}_{2}{ }^{*}$ In this way the expenments in the $\mathrm{S}_{1} \mathrm{H}_{4} \cdot \mathrm{HCl}$ system shed new light on the kinetics, but still no conclusion can be drawn on the nature of the rate-limiting step Expenments with $\mathrm{S}_{1} \mathrm{H}_{2} \mathrm{Cl}_{2}$ will therefore be interesting, the question being to what extent $\mathrm{SiCl}_{2}$ * will already be present without $\mathrm{HCl}$ addition

\section{Growth vaa $\mathrm{SlH}_{2} \mathrm{Cl}_{2}$}

According to thermochemical data [20] and confirmed by expenment [21] it is to be supposed that the following equlibrium already exists in the gas phase 


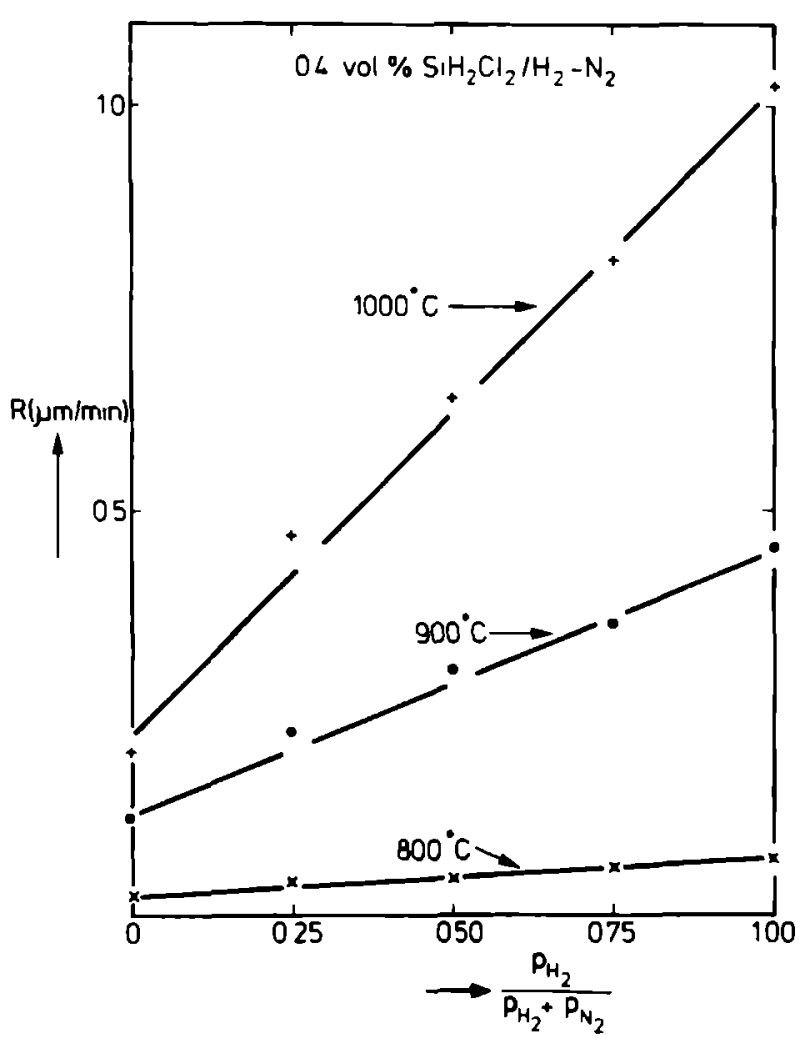

Figure 14.

The growth rate of silicon from $\mathrm{SiH}_{2} \mathrm{Cl}_{2}$ as a function of hydrogen content of the carrier gas with the growth temperature as a parameter.

$\mathrm{SiH}_{2} \mathrm{Cl}_{2} \stackrel{\mathrm{k}_{\mathrm{d}}}{\rightleftharpoons} \mathrm{SiCl}_{2}+\mathrm{H}_{2}$

It can be shown that for the dissociation of eq. (3.11) we have

$\mathrm{PSiCl}_{2}=\frac{\mathrm{k}_{\mathrm{d}}}{\mathrm{k}_{\mathrm{d}}+\mathrm{P}_{\mathrm{H}_{2}}} \cdot \mathrm{P}_{\mathrm{SiH}_{2} \mathrm{Cl}_{2}}^{\mathrm{O}}$

At $1000{ }^{\circ} \mathrm{C}, \mathrm{k}_{\mathrm{d}}$ is equal to 6.1 , and $\mathrm{k}_{\mathrm{d}}=6.6 \times 10^{-2}$ at $700{ }^{\circ} \mathrm{C}$ [20] The dissociation is therefore almost complete in an inert gas ambient, but in hydrogen at lower temperatures only a partial dissociation is expected, giving

$\mathrm{PSiCl}_{2}=\mathrm{P}_{\mathrm{SiH}_{2} \mathrm{Cl}_{2}}^{\mathrm{O}} / \mathrm{P}_{2}$. 


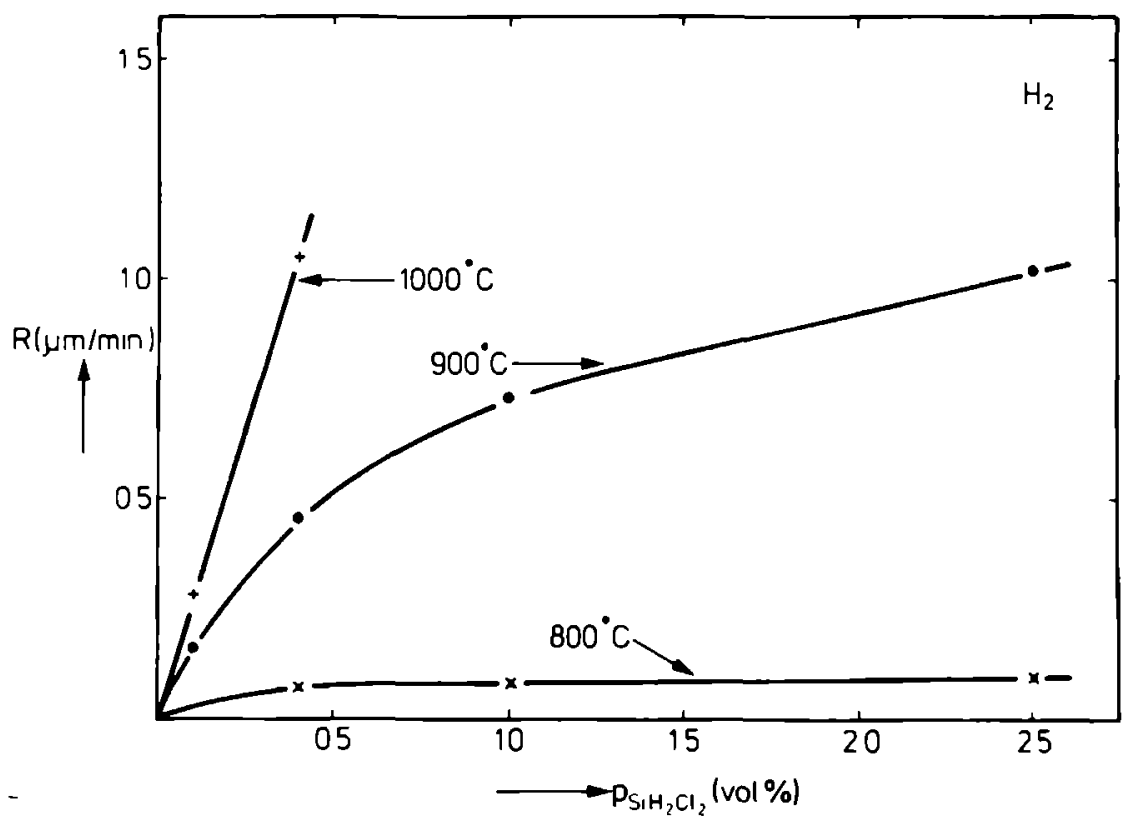

Figure 15

The growth rate of silicon from $\mathrm{StH}_{2} \mathrm{Cl}_{2}$ as a function of the input concentration of $\mathrm{SiH}_{2} \mathrm{Cl}_{2}$ in $\mathrm{H}_{2}$

Our expenments (figure 13) on the growth of sllicon from $\mathrm{SiH}_{2} \mathrm{Cl}_{2}$ showed that addition of $\mathrm{HCl}$ does not give an abrupt decrease in growth rate as found for $\mathrm{SiH}_{4}-\mathrm{HCl}$ In view of the previous section the main conclusion has to be that the dominating silicon-containing surface species will be $\mathrm{SiCl}_{2}$ * The growth via $\mathrm{S}_{1} \mathrm{H}_{2} \mathrm{Cl}_{2}$ has further been studied in mixtures of hydrogen and nitrogen for temperatures between 800 and $1000{ }^{\circ} \mathrm{C}$ Some results are given in figure 14 [22] It is found that the highest growth rates are observed in a hydrogen ambient, especially at higher temperatures Moreover the growth rate as a function of input concentration of $\mathrm{S}_{1} \mathrm{H}_{2} \mathrm{Cl}_{2}$ shows a saturation behaviour as depicted in figure 15 This kind of saturation is also found in the $\mathrm{SiH}_{4} \cdot \mathrm{N}_{2}$ system at growth temperatures below $700{ }^{\circ} \mathrm{C}$ [23] The saturation in growth rate points to a Langmulr type of adsorption, causing a saturation in growth rate at higher input concentrations Adsorption of $\mathrm{SiH}_{2} \mathrm{Cl}_{2}$ as a fully coordinated compound is less probable than adsorption of $\mathrm{SiCl}_{2}$ It is therefore assumed that $\mathrm{S}_{1} \mathrm{Cl}_{2}$ formed in the gas phase (eqs 32,311 ) is adsorbed on the sulıcon surface For a nearly complete dissociation $\mathrm{PSiCl}_{2}$ is nearly

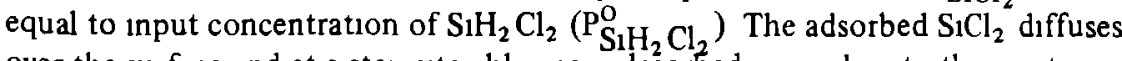
over the surface and at a step site chlonne is desorbed, according to the reaction

$\mathrm{SiCl}_{2}($ step $)+\mathrm{H}_{2} \rightleftharpoons \mathrm{Sl}(\mathrm{cr})+2 \mathrm{HCl}$ 
When reacion $\left(\begin{array}{ll}3 & 12\end{array}\right)$ represents the rate-limiting reaction the growth rde can be calculated analogous to the results given in Table I as being

$$
\begin{aligned}
\mathrm{R}_{\mathrm{gr}} & =\mathrm{ke}_{\mathrm{e}}\left[\mathrm{SlCl}_{2} \text { (step) }\right] \quad \mathrm{PH}_{2} \\
& =\mathrm{kf}_{\mathrm{f}} \mathrm{P}_{\mathrm{SlH}_{2} \mathrm{Cl}_{2}}^{\mathrm{O}} \mathrm{P}_{\mathrm{H}_{2}} \quad \theta \theta_{\mathrm{st}} \frac{\mathrm{k}_{\mathrm{d}}}{\mathrm{k}_{\mathrm{d}}+\mathrm{P}_{\mathrm{H}_{2}}}
\end{aligned}
$$

This result can be compared with the expenmental data shown in figure 14, it can be concluded that a good correlation is obtained for values of $\theta$ and $\theta_{\text {st }}$ close to unity For high input concentrations of $\mathrm{S}_{1} \mathrm{H}_{2} \mathrm{Cl}_{2}$ and at low temperatures a deviation from (313) is observed (figure 15) The fraction of free surface sites is no longer equal to unity, and we have for $\theta$ and $\theta_{\text {st }}$

$$
\begin{aligned}
& \theta=1-\left[\mathrm{H}^{*}\right]-\left[\mathrm{Cl}^{*}\right]-\left[\mathrm{S}_{1} \mathrm{Cl}_{2}{ }^{*}\right]- \\
& \theta_{\mathrm{St}}=1-\left[\mathrm{H}^{*}\right]-\left[\mathrm{Cl}^{*}\right]
\end{aligned}
$$

The difference in the expressions for $\theta$ and $\theta_{\text {st }}$ is explained by the circumstance that, on a one-dimenstional step, no distinction can be made between an adsorbed $\mathrm{SiCl}_{2}$ molecule and a pair of adsorbed chlonne atoms The same applies to $\mathrm{SiH}_{2}$ adsorption versus adsorption of two hydrogen atoms on a step The experimental results shown in figure 15 can be readlly explained by the assumption of $\mathrm{dn}$ important surface adsorption of $\mathrm{SiCl}_{2}$ between the steps, combined with a minor surface coverage by adsorbed hydrogen and chlonne atoms The adsorption of $\mathrm{SiCl}_{2}$ can be accounted for by the use of an expression such as eq (3 7) W1th

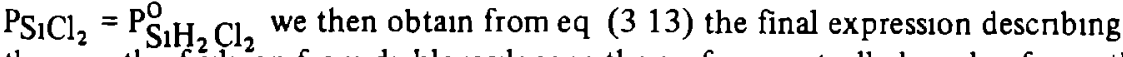
the growth of silicon from dichlorosilane in the surface controlled mode of growth

$\mathrm{R}_{\mathrm{gI}}=\frac{\mathrm{kf}_{\mathrm{S}} \mathrm{P}_{\mathrm{S}_{1} \mathrm{H}_{2} \mathrm{Cl}_{2}}^{\mathrm{P}} \mathrm{P}_{\mathrm{H}_{2}}}{1+\mathrm{k}_{\mathrm{g}} \mathrm{P}_{\mathrm{S}_{1} \mathrm{H}_{2}}^{\mathrm{O}} \mathrm{Cl}_{2}}$

From the present experiments it may be concluded that the rate-limiting reaction in the growth of silicon from dichloroslane has been located at the reduction of $\mathrm{SiCl}_{2}$ at specific sites where silicon is incorporated in the crystal lattice An ad. sorbed $\mathrm{S}_{1} \mathrm{Cl}_{2}$ molecule can be considered to have one $\mathrm{Si}_{1} \mathrm{~S}_{1}$ bond, the formation of a second Si-Sı bond at a step site can then be the decisive reaction in the incorporation of a new silicon atom into the lattice. Additionally, strong supersaturations of $\mathrm{SICl}_{2}$ on the surface are found in accordance with the high value of $\mathrm{PSICl}_{2}$ expected in the gas phase and caused by gas phase dissociation of $\mathrm{SiH}_{2} \mathrm{Cl}_{2}$. 


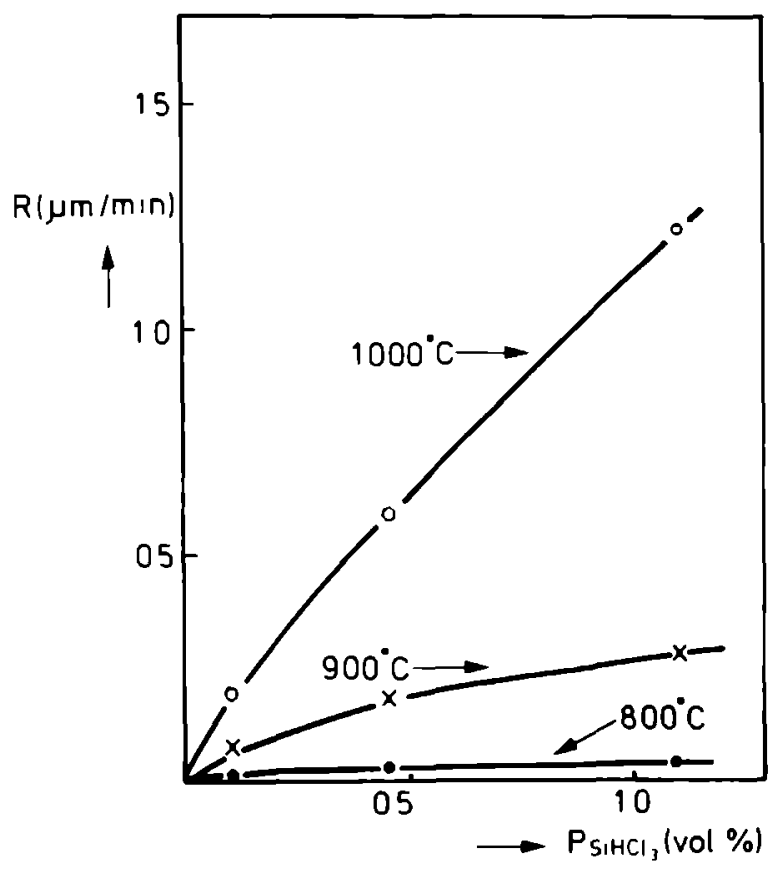

Figure 16

The growth rate of silicon from $\mathrm{SiHCl}_{3}$ as a function of the input concentration of $\mathrm{SiHCl}_{3} / 25 /$

\section{Growth from $\mathrm{StHCl}$}

Experiments with the growth of silicon from $\mathrm{S}_{1} \mathrm{HCl}_{3}$ at lower temperatures show a saturation behaviour [24] as shown in figure 16 In this system it can also be supposed that $\mathrm{SICl}_{2}{ }^{*}$ is the main surface species The rate-limiting reaction will again be the reduction of $\mathrm{SiCl}_{2}$ at step sites Saturation of the growth rate at lower temperatures reflects the increased $\mathrm{SiCl}_{2}{ }^{*}$ concentration waiting for reduction at the step sites In the foregoing sections arguments have been given that led to the general scheme of section 31 The results presented indicate that a complete coverage of the silicon surface with $\mathrm{H}^{*}$ or $\mathrm{Cl}^{*}$ is not in agreement with the expenmental evidence Further discussion of this point will be given in the next section

\section{Adsorption on the silicon surface}

From the expenmental results obtained so far a direct indication of a rate-determining surface adsorption is obtained only for $\mathrm{S}_{1} \mathrm{Cl}_{2}{ }^{*}$ at high gas phase concentrations of $\mathrm{SiCl}_{2}\left(\mathrm{~S}_{1} \mathrm{H}_{2} \mathrm{Cl}_{2}\right.$ system) 
Desorption of $\mathrm{Cl}^{*}$ and $\mathrm{H}^{*}$ is found to involve important, even rdte-limiting steps, indicating that the corresponding concentrations are higher than normal No indications are found, however, to suggest a high equilıbrium surface coverage by $\mathrm{H}^{*}$ and $\mathrm{Cl}^{*}$ species

This finding is in contradiction with the equilibrium calculations of Chernov et al [3], who supposed the heat of adsorption of monoatomic hydrogen and chlorine on the silicon surface to be equal to the heat of dissociation of the gaseous diatomic molecules $\mathrm{S}_{1} \mathrm{H}$ and $\mathrm{SiCl}_{1}$ The heats of adsorption of $\mathrm{S}_{1} \mathrm{Cl}_{2}$ and $\mathrm{S}_{1} \mathrm{H}_{2}$ were taken to be nearly equal to the $S_{1-S i}$ bond strength With a Langmuir type of adsorption a complete surface coverage with $\mathrm{H}^{*}$ is then calculated for slicon in hydrogen even at $1200{ }^{\circ} \mathrm{C}$, in the presence of $\mathrm{HCl}$ large quantities of $\mathrm{Cl}^{*}$ are present too Under equilibnum conditions the partial pressure of $\mathrm{SiCl}_{2}$ is low and so too therefore is the quantity of $\mathrm{SiCl}_{2}$ *

From the nucleation experiments described in section 2 a clear indication of hydrogen adsorption on $\mathrm{SiO}_{2}$ is found for the $\mathrm{SiH}_{4}-\mathrm{H}_{2}$ system below $900{ }^{\circ} \mathrm{C}$ The $\mathrm{OH}$ bond strength is $102 \mathrm{kcal} / \mathrm{mole}$ Adsorption of hydrogen on $\mathrm{Si}_{3} \mathrm{~N}_{4}$ has a minor influence on the nucleation of sulicon, in accordance with the N-H bond strength of $83 \mathrm{kcal} / \mathrm{mole}$ The $\mathrm{SiH}$ bond strength of $70 \mathrm{kcal} / \mathrm{mole}$ is stull lower and the coverage of slicon by hydrogen could thus be less important Another indication is given by the hydrogen content of amorphous silicon when prepared below $300^{\circ} \mathrm{C}$ in a hydrogen plasma. Via infrared absorption measurements $\mathrm{S}_{1} \mathrm{H}_{2}$ and $\mathrm{S}_{1} \mathrm{H}$ bonds appear to be present $\mathrm{On}$ annealing the first adsorption $\left(\mathrm{S}_{1} \mathrm{H}_{2}\right)$ disappears at $375^{\circ} \mathrm{C}$, the $\mathrm{S}_{1} \mathrm{H}$ bonds decompose below $600{ }^{\circ} \mathrm{C}$ [25]

The hydrogen release is confirmed by other quantitative methods [26] as well This evidence, together with the observation that the temperature dependence of the growth rate of silicon below $1000^{\circ} \mathrm{C}(\approx 16 \mathrm{ev})$ is nearly the same in hydrogen as in nitrogen and also under reduced pressure [27], leads to the conclusion that a complete coverage of hydrogen under all these conditions is improbable The number of hydrogen adatoms can be calculated in adsorption equilibrium The number of hydrogen atoms impinging on the silicon surface $\left(R_{H}\right)$ is given by

$R_{H}=\frac{P_{H}}{\left(2 \pi m_{H} k T\right)^{1 / 2}} \mathrm{~cm}^{-2} \sec ^{-1}$

where $\mathrm{P}_{\mathrm{H}}$ is the partial pressure of monoatomic hydrogen, $\mathrm{m}_{H}$ is the atomic mass of hydrogen, $k$ is Boltzmann's constant and $T$ the temperature in $K$ The number of hydrogen atoms desorbing is found from

$\mathrm{n}_{\mathrm{des}}=\mathrm{n}_{\mathrm{H}} \nu \exp \left(-\frac{\mathbf{E}_{\text {des }}}{\mathrm{kT}}\right)$

where $\mathrm{n}_{\mathrm{H}}$ is the surface concentration of adsorbed atoms, $\nu$ is the vibration fre. quency of the $\mathrm{S} 1 \cdot \mathrm{H}$ bond, and $\mathrm{E}_{\text {des }} 1 \mathrm{~s}$ the heat of desorption of the adsorbed atom 
Assumıng d stıcking probability of unity, in the steady state $n_{\text {des }}=R_{H}$, so that the value of $n_{H}$ comes to

$n_{H}=\frac{P_{H}}{\left(2 \pi m_{H} k T\right)^{1 / 2} \nu} \exp \frac{E_{\text {des }}}{k T}$

In the gas phase an equilibrium between $\mathrm{H}_{2}$ molecules and $\mathrm{H}$ atoms is present, leading to

$\mathrm{P}_{\mathrm{H}}=\mathrm{K}_{\mathrm{H}_{2}} \quad \mathrm{P}_{\mathrm{H}_{2}}^{1 / 2}=\mathrm{K}_{\mathrm{H}_{2}}^{\mathrm{O}} \quad \mathrm{P}_{\mathrm{H}_{2}}^{1 / 2} \exp \left(-\frac{\mathrm{E}_{\mathrm{d} 1 s s}}{\mathrm{kT}}\right)$

$\mathrm{K}_{\mathrm{H}_{2}}$ is given in the thermochemical tables and contains the temperature dependent term in which the dissociation energy of $\mathrm{H}_{2}$ is denoted as $E_{\text {diss }}$ For a small coverage the number of adsorbed hydrogen atoms can thus be given as

$$
\begin{aligned}
\mathrm{n}_{\mathrm{H}} & =\frac{\mathrm{K}_{\mathrm{H}_{2}}^{0} \mathrm{P}_{\mathrm{H}_{2}}^{1 / 2}}{\left(2 \pi \mathrm{m}_{\mathrm{H}} \mathrm{kT}\right)^{1 / 2} \nu} \exp \frac{\mathrm{E}_{\text {des }}-\mathrm{E}_{\mathrm{d} \text { iss }}}{\mathrm{kT}} \\
& =\mathrm{K}_{\mathrm{H}} \mathrm{P}_{\mathrm{H}_{2}{ }^{2}}
\end{aligned}
$$

For higher densities of adsorbed hydrogen, the formulation given in eqs (36) and (3 7) leads to the following expression in which $\mathrm{K}_{\mathrm{H}}$ is the same as given in eq (45)

$$
\mathrm{n}_{\mathrm{H}}=\frac{\mathrm{K}_{\mathrm{H}} \mathrm{P}_{\mathrm{H}_{2}}^{1 / 2}}{1+\mathrm{K}_{\mathrm{H}} \mathrm{P}_{\mathrm{H}_{2}}^{1 / 2}}
$$

The value of $E_{\text {diss }}$ is $224 \mathrm{eV}$, the magnitude of $E_{\text {des }}$ is estimated to be equal to the heat of dissociation of the $\mathrm{S} 1 \mathrm{H}$ gaseous dimer, being $31 \mathrm{eV}$ This estimate has been used by Chernov and via eq (4 6) a complete surface coverage is found at temper atures of $1000^{\circ} \mathrm{C}$ to $1200^{\circ} \mathrm{C}$ In order, however, to explain the expenmental evidence in the kınetics of the growth of silicon a lower value for the heat of adsorption of hydrogen on silicon has to be assumed A comparable dilemma exists in the heat of adsorption of silicon on silicon, generally a value of about $2 \mathrm{eV}$ is accepted equal to half the heat of vaponsation of silicon ( $107 \mathrm{kcal} / \mathrm{mole}$ or $46 \mathrm{eV}$ ) whereas the heat of dissociation of the $\mathrm{S}_{1}-\mathrm{S}_{1}$ gaseous dimer amounts to $3 \mathrm{eV}$ (76 $\mathrm{kcal} / \mathrm{mole}$ ) The adsorption of chlonne on the silıcon surface can be treated along simlar lines as for hydrogen The gas phase reaction of $\mathrm{HCl}$ to give chlorine and hydrogen is used to calculate $\mathrm{PCl}$ For chlonne a $\mathrm{SiCl}$ bond strength of $90 \pm 15$ $\mathrm{kcal} / \mathrm{mole}$ is given [28], whereas recent measurements reported by Farber [28] gave a value of $89 \mathrm{kcal} / \mathrm{mole}$ The dissociation energy of $\mathrm{HCl}$ to give chlonne and hydrogen is $46 \mathrm{kcal} / \mathrm{mole}$ The resulting heat of reaction and adsorption comes to 
$43 \mathrm{kcal} / \mathrm{mole}(1.9 \mathrm{eV})$. It is pointed out by Chernov [3] that at a higher surface coverage chlorine adatoms will undergo strong interactive repulsive forces, reducing the adsorption energy to values close to that of the $\mathrm{Si}-\mathrm{H}$ bond. Therefore for chlorine adsorption too, no high coverage need be present.

The adsorption of $\mathrm{SiCl}_{2}$ from the gas phase depends on the value of $\mathrm{PSiCl}_{2}$ and the adsorption energy. In the growth via $\mathrm{SiH}_{2} \mathrm{Cl}_{2}$, the value of $\mathrm{PSiCl}_{2}$ is nearly equal to the input pressure of $\mathrm{SiH}_{2} \mathrm{Cl}_{2}$. A heat of adsorption of $40 \mathrm{kcal} / \mathrm{mole}(1.8 \mathrm{eV})$ is sufficient to explain a complete coverage.

The addition of $\mathrm{HCl}$ to $\mathrm{SiH}_{4}$ is shown to convert the surface species into $\mathrm{SiCl}_{2}{ }^{*}$. A lower growth rate under these circumstances is to be explained by a desorption of $\mathrm{SiCl}_{2}$. This indicates a heat of desorption of $\mathrm{SiCl}_{2}$ lower than that of silicon or $\mathrm{SiH}_{2}$, which is not improbable.

The adsorption of surface species on silicon, therefore, appears to be limited under real growth conditions to the presence of silicon-containing species with $\mathrm{Cl}^{*}$ and $\mathrm{H}^{*}$ being present in amounts that do not hamper the adsorption or surface diffusion of silicon-containing species to any measureable extent. This means that for the fraction of free surface sites, $\theta$ a value near unity can be chosen. Only at lower temperatures can this change, as found in the $\mathrm{SiH}_{2} \mathrm{Cl}_{2}$ system. Furthermore the observation that polycrystalline silicon is formed under reduced pressures at $625^{\circ} \mathrm{C}$ whereas amorphous silicon is produced in a hydrogen ambient, gives an indication that below $700^{\circ} \mathrm{C}$ the surface mobility is hampered seriously in a hydrogen ambient.

\section{Conclusion}

The nucleation and growth of silicon has been studied at atmospheric pressure and temperatures between 800 and $1000^{\circ} \mathrm{C}$, being a temperature region in which growth of polycrystalline silicon is normally performed. Below $700{ }^{\circ} \mathrm{C}$ the growth of amorphous material is observed in hydrogen at atmospheric pressure. The nucletion of silicon on a foreign substrate such as $\mathrm{SiO}_{2}$ and $\mathrm{Si}_{3} \mathrm{~N}_{4}$ is shown to proceed via silicon adatoms fomed on the surface. A critical cluster of a few atoms is found to be sufficient to give a stable nucleus that grows out untill coalescence of the grains leads to a further growth of silicon on silicon.

For the growth of silicon from silane $\left(\mathrm{SiH}_{4}\right)$ it has been deduced that the ratelimiting reaction is not the adsorption of silane or a chemical reaction to give $\mathrm{SiH}_{2}$ but is probably found in the diffusion of $\mathrm{SiH}_{2}$ on the surface or the incorporation of $\mathrm{SiH}_{2}$ units on atomic surface steps, after which desorption of hydrogen follows. In the presence of some $\mathrm{HCl}$ in the gas phase all surface species are converted into $\mathrm{SiCl}_{2}$. The $\mathrm{SiCl}_{2}$ adatoms are stabilised by the formation of a second $\mathrm{Si}-\mathrm{Si}$ bond. The subsequent desorption of chlorine atoms constitutes the rate-limiting reaction for further growth via the addition of new $\mathrm{SiCl}_{2}$ units. The experimental evidence 
cannot be explained by a strong adsorption of monoatomic hydrogen on the silicon surface. The conclusion is drawn that the adsorption energy of $\mathrm{H}^{*}$ on the silicon surface is appreciably lower than the heat of dissociation of the gaseous diatomic $\mathrm{Si}-\mathrm{H}$ molecule. The influence of the addition of $\mathrm{HCl}$ has been explained by the formation of $\mathrm{SiCl}_{2}$ at the cost of $\mathrm{Si}$ and $\mathrm{SiH}_{2}$ as surface species. Saturation in the growth rate as a function of input concentration of $\mathrm{SiH}_{2} \mathrm{Cl}_{2}$ is also explained in terms of $\mathrm{SiCl}_{2}$ adsorption. The evidence could also be explained by chlorine adsorption and a rate-limiting reaction for growth given by the surface diffusion of $\mathrm{SiCl}_{2}$ hampered by adsorbed chlorine atoms (compare eq. 4 in Table I). The constant level in growth rate after introduction of $\mathrm{HCl}$ in the $\mathrm{SiH}_{4}-\mathrm{H}_{2}$ system (figure 12), the absence of a sudden drop in growth rate on the introduction of $\mathrm{HCl}$ in the $\mathrm{SiH}_{2} \mathrm{Cl}_{2}-\mathrm{H}_{2}$ system (figure 13) and the saturation in growth rate for higher values of $\mathrm{PSiH}_{2} \mathrm{Cl}_{2}$ (figure 15), where only small values of $\mathrm{PHCl}_{\mathrm{HC}}$ are present, lead to the additional conclusion that the experimental evidence is most readily explained by a small surface coverage by chlorine in the systems used and at temperatures above $700^{\circ} \mathrm{C}$. 


\section{References}

1 J. Bloem, J. Cryst. Growth 18 (1973) 70.

2 P. van der Putte, L.J. Giling and J. Bloem, J. Cryst. Growth 41 (1977) 133.

3 A.A. Chernov, J. Cryst. Growth 42 (1977) 55. A.A. Chernov and M.P. Rusaikin, J. Cryst. Growth 45 (1978) 73.

4 W.K. Burton, N. Cabrera and F.C. Frank, Phil. Trans. Roy. Soc. 243 (1951) 299.

5 J.A. Venables and G.R. Price in: Epitaxial Growth, J.W. Matthews (ed.). (Academic Press, New York 1975) chapter 4, p. 381.

6 B.A. Joyce, Rep. Progr. Phys. 37 (1974) 363.

7 H.A. Abbink, R.M. Broudy and G.P. McCarthy, J. Appl. Phys. 39 (1968) 4673.

8 J. Blanc and M.S. Abrahams, J. Appl. Phys. 47 (1976) 5151.

9 G.W. Cullen, J.F. Corboy and J.T. McGinn, Semiconductor Silicon 1977, H.R. Huff and E. Sirtl eds (The Electrochemical Society 1977) p. 235.

10 T.I. Kamins and T.R. Cass, Thin Solid Films 16 (1973) 147.

11 W.A.P. Claassen and J. Bloem, J. Electrochem. Soc. 127 (1980) 194.

12 B. Lewis and J.C. Anderson, Nucleation and growth of thin films (Academic Press, New York 1978).

13 J.A. Venables, Phil. Mag. 17 (1973) 697.

14 W.A.P. Claassen and J. Bloem, to be published.

15 F.C. Eversteyn, Philips Res. Rep. 26 (1971) 134.

16 J.P. Duchemin, M. Bonnet and F. Koelsch, J. Electrochem. Soc. 125 (1978) 637.

17 Y. Yasuda, K. Hirabayashi and T. Moriya, Suppl. J. Jap. Soc. Appl. Phys. 43 (1974) 400.

18 H.M. Manasevit, J. Electrochem. Soc. 126 (1979) 1785.

19 J. Bloem and W.A.P. Claassen, J. Cryst. Growth, in press.

20 JANAF Thermochemical Tables 2nd ed. June 1971, NSRDS-NBS-37.

21 T.O. Sedgwick, G.V. Arbach and R. Ghez, CVD VI, 1977, L.F. Donaghey, P. Rai-Choudhurry and R.N. Tauber eds. (The Electrochem. Soc., Princeton, 1977) p. 79.

22 W.A.P. Claassen and J. Bloem, to be published.

23 J. Adamczewska and T. Budzynski, Thin Solid Films 56 (1979) 267.

24 C.H.J. van den Brekel, unpublished results.

25 M.H. Brodsky, M.A. Frisch, J.F. Ziegler and W.A. Lanford, Appl. Phys. Lett. 30 (1977) 561.

26 J.A. McMillan and E.M. Peterson, J. Appl. Phys. 50 (1979) 5238.

27 M.L. Hitchman, CVD VII, T.O. Sedgwick and H. Lydtin eds. (The Electrochem. Society, Princeton 1979) p. 59.

28 M. Farber and R.D. Strivastava, J.C.S. Faraday Trans. 73 (1977) 1672. 


\title{
CHAPTER IX
}

\section{THE GROWTH OF SILICON FROM SILANE IN COLD WALL CVD SYSTEMS}

\begin{abstract}
The authors discuss the growth of sulicon from silane as a function of substrate temperature and hydrogen partial pressure in cold wall CVD systems at dufferent total pressures At high temperatures the growth rate is determined by gas phase diffusion of the slicon compound towards the surface In this regme and at atmosphenc pressure the growth rates of silicon for the $\mathrm{SuH}_{4}-\mathrm{H}_{2}$ and the $\mathrm{SuH}_{4}-1$ nert gas system are almost the same Reducing the total pressure initially increases the growth rate, which is then inversely proportional to the total pressure, while at pressures below 01 bar the growth rate is less than in inverse proportional to the total pressure, owing to the influence of the steep temperature gradients on the diffusional behaviour of the reactants at these low pressures in a cold wall apparatus
\end{abstract}

At low temperatures the growth rate is controlled by surface reactions and is inversely proportional to the hydrogen pressure and proportional to the silane input concentration In this regume the growth rate of sucon uncreases exponentially with uncreasing temperature and the apparent activation energy is in a first approxumation independent of the total pressure and of the partial pressure of hydrogen It is stressed that at high temperatures the physical influence of the total pressure determunes the growth rate, whereas at lower temperatures $\left(<1000^{\circ} \mathrm{C}\right)$ it is the hydrogen partial pressure that exerts a chemical influence on the growth rate

\section{Introduction}

The temperature dependence of the growth rate of slicon from slane in hydrogen at atmosphenc pressure has two temperature regimes [1] , as shown schematically in Figure 1. According to Van den Brekel [2] the local growth rate of slane in hydrogen as a carner gas as a function of temperature in a honzontal cold wall reactor can best be given by the expression

$$
G(X)=\frac{A P_{0}}{T_{S}\left(R_{1}+R_{2}\right)} \exp \left[\frac{-T_{O} X}{V_{O} T_{S} b\left(R_{1}+R_{2}\right)}\right]
$$

where $G(X)$ is the growth rate of slicon along the $X$-axis, $A$ is a reactor constant, $P_{0}$ the input pressure of the reactant, $T_{S}$ the substrate temperature, $T_{0}$ the room temperature, $V_{0}$ the mean gas velocity at room temperature and $b$ the free height above the susceptor. $R_{1}$ and $R_{2}$ are the diffusion and transfer resistances, which can be given by

$$
R_{1}=\frac{\delta T_{0}^{2} \ln \left(T_{s} / T_{b}\right)}{D_{12} T_{S}\left(T_{S}-T_{b}\right)}
$$

and

$$
\mathbf{R}_{2}=\frac{1}{k_{d}}
$$


where $\delta$ is the thickness of the diffusion boundary layer, $D_{12}$ the binary diffusion coefficient of the reactant in the carrier gas at room temperature, $T_{b}$ the bulk gas temperature and $k_{d}$ a mass transfer coefficient. At relatively low temperatures $k_{d}$ is so small that hardly any concentration gradient is present over the boundary layer and along the susceptor. Under these conditions $\left(R_{2} \gg R_{1}\right)$ and with $k_{d}=k_{d} 0$ exp $(-\Delta E / R T)$, equation (1) can be transformed into

$$
\mathrm{G}(\mathrm{X})=\mathrm{G}_{\mathrm{O}} \exp (-\Delta \mathrm{E} / \mathrm{RT})
$$

where $G_{O}=A P_{0} k_{d} / T_{s}$ is a pre-exponential factor and $\Delta E$ an apparent activation energy which is about $37 \mathrm{kcal} / \mathrm{mole}$ for silane in hydrogen at atmospheric pressure [1]. Going to higher temperatures the surface reactions become so fast that the gas phase diffusion of silane towards the surface becomes the real limiting step $\left(R_{1} \gg R_{2}\right)$. This leads to

$$
G(X)=\frac{B D_{12} P_{0}}{\delta} \exp \left(\frac{-C X D_{12}}{\delta}\right)
$$

where $\mathrm{B}$ and $\mathrm{C}$ are constants at a fixed temperature. At high temperatures the growth rate of silicon for $\mathrm{X}=0$ is only a weak function of temperature, because the diffusion coefficient is approximately proportional to $T^{3 / 2}$ and $B / \delta$ is almost independent of temperature. The exponential term of equation (5) describes the decrease of the growth rate of silicon along the susceptor due to the depletion of silane in the gas phase. It should be noted that in the intermediate regime $\left(R_{1} \cong R_{2}\right)$ the temperature dependence of the silicon growth rate gradually changes from about $\mathrm{T}^{3 / 2}\left(\cong 5 \mathrm{kcal} / \mathrm{mole}\right.$ at $\left.1000^{\circ} \mathrm{C}\right)$ to about $37 \mathrm{kcal} / \mathrm{mole}$.

Both at reduced total pressure and in inert ambients at atmospheric pressure the apparent activation energy $\Delta \mathrm{E}$ (equation (4)) is about $37 \mathrm{kcal} / \mathrm{mole}$, as will be discussed below. However, the position of the knee in the curve of growth rate versus $1 / \mathrm{T}$ (Fig. 1) depends on the partial pressure of hydrogen and on the total pressure. According to Van den Brekel the position of this knee is defined by the condition that

$$
R_{1}=R_{2} \text {. }
$$

In the following sections the growth of silicon from silane is reviewed and some new results are presented. Emphasis is placed on the influence of the hydrogen pressure on the growth rate. It is assumed that equation (1) is also valid for inert ambients at atmospheric pressures and under reduced pressures. 


\section{Growth from silane}

2.1 Comparison of the silicon growth rate as a function of hydrogen content of the carrier gas at atmospheric pressure.

As described before, the growth rate of silicon at temperatures below the knee in the curve of the growth rate versus $1 / \mathrm{T}$ (Fig. 1) is limited by the chemical kinetics on the silicon surface. In this regime the growth rate can be given by equation (4) in

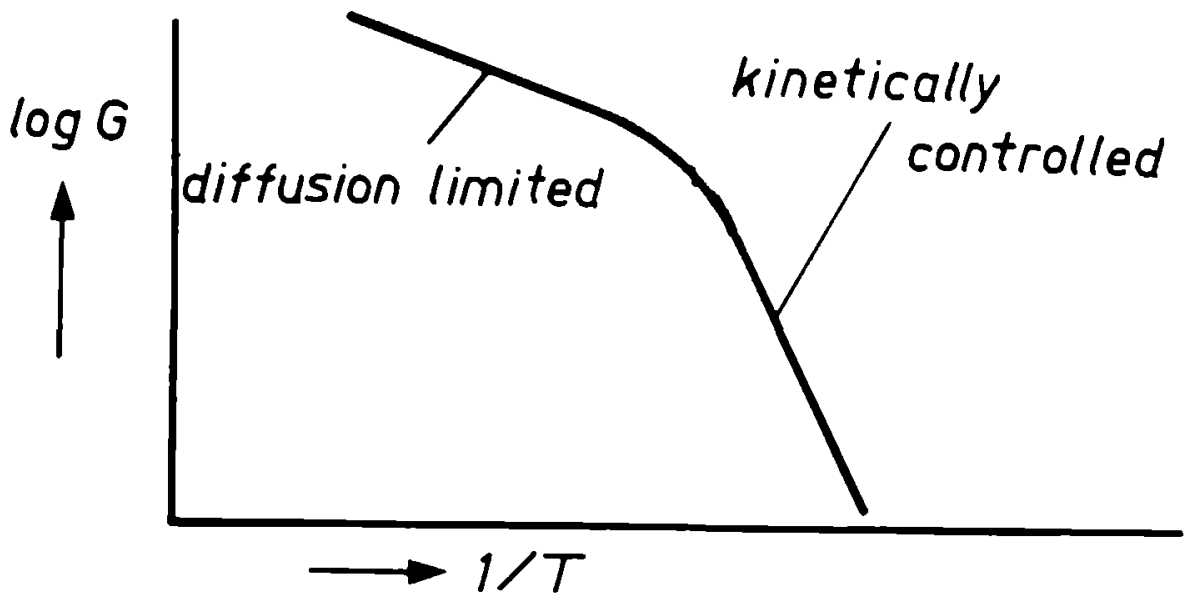

Figure 1 .

The growth rate of silicon as obtained in a chemical vapour-deposition process, schematically given as a function of temperature for a constant input concentration of silane in hydrogen as a carrier gas.

which according to Bryant [3] the apparent activation energy is almost independent of the hydrogen pressure, provided that no gas phase nucleation and growth rate saturation effects are present. It was further observed that the position of the knee in the curve of the silicon growth rate versus $1 / \mathrm{T}$ (Fig. 1) is positioned about $200^{\circ}$ lower for inert carrier gases than for a hydrogen ambient, while at lower temperatures the growth rates are much higher in an inert ambient than in hydrogen. According to Claassen and Bloem [4] the growth rate of silicon at $700{ }^{\circ} \mathrm{C}$ strongly decreases when small amounts of hydrogen are added to a silane-nitrogen mixture. The experimental data could be described by: $G=F P_{o} /\left(1+H_{H_{2}}\right)$, where $\mathbf{P}_{\mathrm{O}}$ is the input pressure of silane, $\mathrm{P}_{\mathrm{H}_{2}}$ the partial pressure of hydrogen and $\mathrm{F}$ and $\mathrm{H}$ are constants at $700^{\circ} \mathrm{C}$. Since the apparent activation energy $(\Delta \mathrm{E})$ is almost independent of the partial pressure of hydrogen in the surface-controlled regime of the silicon growth, the growth rate can be expressed as 
$G=\frac{F^{o} P_{o}}{1+H P_{H_{2}}} \exp (-\Delta E / R T)$.

When the experimental data for the $\mathrm{SiH}_{4} \cdot \mathrm{H}_{2} \cdot \mathrm{N}_{2}$ system at $700^{\circ} \mathrm{C}$ are used [4] the constants $F$ and $H$ can be calculated by plotting $1 / G$ versus $P_{H_{2}}$. In Fig. 2 the growth rate of silicon for $2 \times 10^{-3}$ bar silane and different hydrogen mixtures is plotted as a function of the hydrogen pressure. When the pressure is expressed in bars $\mathrm{F}=1.7 \times 10^{2} \mu \mathrm{m}$ (min.bar) ${ }^{-1}$ and $\mathrm{H}=12 \mathrm{bar}^{-1}$. At relatively high hydrogen pressures the growth is inversely proportional to the hydrogen pressure $\left(\mathrm{G} \propto \mathrm{P}_{\mathrm{H}_{2}}^{-1}\right)$ while at lower hydrogen pressures the tangent gradually changes to zero.

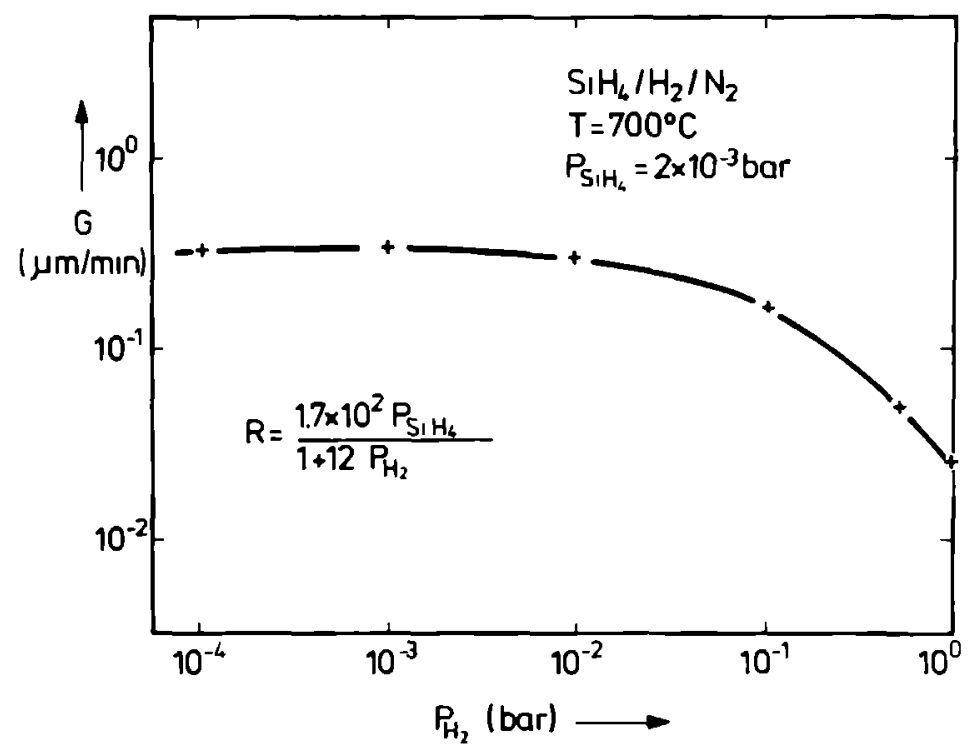

Figure 2.

The influence of the hydrogen pressure on the silicon growth rate at $700^{\circ} \mathrm{C}$ and an input of $2 \times 10^{-3}$ bar silane.

At higher temperatures the gas phase diffusion of the reactant towards the surfaces determines the growth rate; differences in silicon growth rates for the $\mathrm{SiH}_{4}-\mathrm{Hl}_{2}$ system and the $\mathrm{SiH}_{4}$-inert gas system then become smaller, as can be seen in Fig. 3 . In this figure the growth rate of silicon is plotted for an input of 0.1 vol. \% silane at $1000^{\circ} \mathrm{C}$ in hydrogen-helium and hydrogen-nitrogen mixtures. In the case of the $\mathrm{SiH}_{4}-\mathrm{He}$ system the growth rate of silicon is almost independent of the hydrogenhelium ratio (for not too small pressures of hydrogen). At small hydrogen concentrations gas phase nucleation comes into play, leading to a heavily contaminated reactor wall and a decrease in the growth rate on the heated susceptor. This behaviour could be explained by the occurrence of the following gas phase reactions (5): 


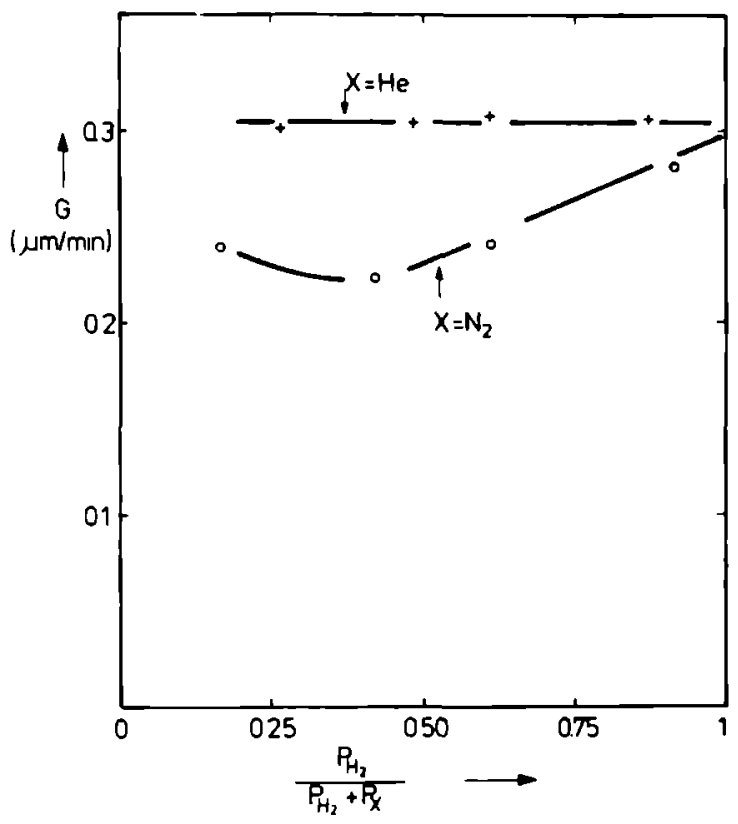

Figure 3.

The growth rate of silicon at $1000^{\circ} \mathrm{C}$ for $\mathrm{PSiH}_{4}=10^{-3}$ bar silane.

$\mathrm{SiH}_{4} \rightleftharpoons \mathrm{SiH}_{2}+\mathrm{H}_{2}$

$\mathrm{SiH}_{2}+\mathrm{SiH}_{4} \rightleftharpoons \mathrm{Si}_{2} \mathrm{H}_{4}+\mathrm{H}_{2}$, etc.

The formation of polymers of silane can therefore be expected at relatively low hydrogen partial pressures. In a cold wall apparatus the clusters formed in the gas phase are transported to the cold walls by the process of thermodiffusion. The apparent growth rate is then reduced because of the lower monomer silane concentration in the gas phase. In the case of the $\mathrm{SiH}_{4}-\mathrm{H}_{2}-\mathrm{N}_{2}$ system it can be observed from Fig. 3 that the growth rate first decreases linearly with decreasing hydrogen content of the carrier gas until the growth rate saturates or even increases. At still lower hydrogen pressures gas phase nucleation is also observed, consequently leading to lower growth rates. As discussed before, the growth rate of silicon depends on the ratio $D_{12} / \delta$ if the growth rate is controlled by gas phase diffusion of the reactant towards the surface.

According to Berkman et al. [6] the diffusion coefficient of reactant (1) in carrier gas (2) can be calculated for this binary system from

$D_{12}=2.628 \times 10^{-19} \frac{\left[T^{3}(1 / 2)\left(1 / M_{1}+1 / M_{2}\right]^{1 / 2}\right.}{P \sigma_{12}^{2} \Omega_{12}}$ 
where $M_{1}$ and $M_{2}$ are the molecular weights of the reactant and the carrier gas, $P$ is the total pressure, $\Omega_{12}$ the collision integral and $\sigma_{12}$ a force constant. The $\Omega_{12}$ and $\sigma_{12}$ values can be calculated from the critical temperatures and pressures [7] . Berkman et al. [6] also give an expression for the thickness of the diffusion boundary layer $(\delta(X))$ in a horizontal reactor, which reads

$$
\delta(X)=1.23\left(\frac{\mathrm{D}_{\mathrm{T}} \mathrm{X}}{\mathrm{V}_{\mathrm{T}}}\right)^{1 / 2}-\frac{0.56}{\mathrm{~b}}\left(\frac{\mathrm{D}_{\mathrm{T}} \mathrm{X}}{\mathrm{V}_{\mathrm{T}}}\right)-\frac{0.077}{\mathrm{~b}^{2}}\left(\frac{\mathrm{D}_{\mathrm{T}} \mathrm{X}}{\mathrm{V}_{\mathrm{T}}}\right)^{3 / 2}
$$

where $\mathrm{D}_{\mathrm{T}}$ is the self-diffusion coefficient of the carrier gas at an average tempera. ture $\mathrm{T}, \mathrm{X}$ is an arbitrary point along the susceptor, $\mathrm{V}_{\mathrm{T}}$ an average gas velocity and $\mathrm{b}$ the free height between the top of the susceptor and the tube wall. The self-diffusion coefficient of the carrier gas at room temperature (DT) can be given by

$D_{\mathrm{T}}=2.628 \times 10^{-19}{\frac{\left[\mathrm{T}^{3} / \mathrm{M}_{2}\right]^{1 / 2}}{\mathrm{P} \sigma_{2}}}^{1 / 2}$

In order to interpret the experimental data, as given in Fig. $3, D_{12}$ and $\delta(X)$ values are calculated using the equations $(9,10,11)$ at a mean temperature $T_{A}$ in a similar way as described by Berkman et al. [6]. In Table 1 these values are given under the operating conditions used [8] $(b=1.5 \mathrm{~cm}, X=10,20$ and $30 \mathrm{~cm}$, a substrate temperature of $1000^{\circ} \mathrm{C}$ and a room temperature gas velocity of $60 \mathrm{~cm} / \mathrm{sec}$ ). The experimental data given in Fig. 3 are for $X=20 \mathrm{~cm}$ (middle of the susceptor).

\section{TABLE 1}

Calculated values for $D_{12}$ of silane and $\delta(X)$ with $X=10,20$ and $30 \mathrm{~cm}$ for the carrier gases hydrogen, helium and nitrogen and a substrate temperature of $1000^{\circ} \mathrm{C}$.

\begin{tabular}{|l|c|c|c|c|}
\hline \multirow{2}{*}{} & \multicolumn{3}{|c|}{$\delta(\mathrm{X}) \mathrm{cm}$} & \multirow{2}{*}{$\mathrm{D}_{12}\left(\mathrm{~cm}^{2} / \mathrm{sec}\right)$} \\
\cline { 2 - 4 } & 10 & 20 & 30 & \\
\hline & & 0.85 & 0.90 & 4,6 \\
$\mathrm{H}_{2}$ & 0.72 & 0.84 & 0.89 & 4,2 \\
$\mathrm{He}$ & 0.69 & 0.48 & 0.55 & 1,2 \\
$\mathrm{~N}_{2}$ & 0.35 & & \\
\hline
\end{tabular}

From Table 1 it can be observed that $\delta$ reaches an almost constant value of approximately $b / 2$ very near the leading edge of the hot susceptor for the carrier gases helium and hydrogen, whereas for nitrogen the diffusion boundary layer is not fully developed along the susceptor. It can further be observed that the ratio $D_{12} / \delta$ for the gases helium and hydrogen are of comparable magnitude, giving approximately 
the same growth rate of silicon, in agreement with the experimental data given in Fig. 3. For nitrogen the $D_{12} / \delta$ value is smaller than for helium and nitrogen and the observed decrease in the growth rate with decreasing hydrogen contents for the $\mathrm{SiH}_{4}-\mathrm{H}_{2}-\mathrm{N}_{2}$ system can be explained in this way. For high nitrogen contents the laminar flow breaks up into a thin stagnant layer covered by a turbulent flow region, as observed by Giling et al. [9]. This may explain an increase in growth rate for low hydrogen contents. Under the experimental conditions as given in Fig. 3 we further observed a small decrease in growth rate along the susceptor. This decrease in the growth rate of silicon is independent of the hydrogen-helium ratio, while for the hydrogen-nitrogen mixture this depletion increases going to lower hydrogen contents. This effect can be explained by an increase of the thickness of the boundary layer along the susceptor, which is strongest for hydrogen-nitrogen mixtures with the lowest concentration of hydrogen (Table 1).

\subsection{Reduced pressures}

As explained in the introduction, it will be assumed that the growth of silicon from silane at reduced pressures can also be described by equation (1). In the surfacecontrolled regime of the growth of silicon $\left(R_{2} \gg R_{1}\right)$ equation (4) can then be used:

$G=G_{0} \exp (-\Delta E / R T)$.

At reduced pressures, with or without hydrogen as a carrier gas, apparent activation energies $(\Delta E)$ of about $37 \mathrm{kcal} / \mathrm{mole}$ are reported by Joyce et al. [10] and Hottier et al. [11]. According to Van den Brekel and Bollen [12] the growth rate of silicon is independent of the carrier gases hydrogen or nitrogen (the silane pressure being equal) at $625^{\circ} \mathrm{C}$ and a total pressure of about $10^{-3} \mathrm{bar}$, in agreement with the curve in Fig. 2, where it is shown that the growth rate of silicon becomes independent of the partial pressure of hydrogen below $P_{H_{2}}=10^{-2}$ bar. Going to higher temperatures the surface reactions become so fast that the temperature dependence of the growth rate deviates from the reported $\Delta \mathrm{E}$ values and at relatively high temperatures the diffusion of silane towards the silicon surface controls the growth rate. In this regime high growth rates can be expected compared with those at atmospheric pressure (the partial pressure of silane being equal) as the diffusion coefficient $D_{12}$ is inversely proportional to the total pressure (equation (9)) and the thickness of the diffusion boundary layer may be assumed to be nearly constant. The thickness of the diffusion boundary layer is independent of the total pressure under the condition that the linear gas velocity is inversely proportional to the total pressure, as will be discussed below, considering that $\mathrm{D}_{\mathrm{T}}$, the self-diffusion coefficient of the carrier gas, is also inversely proportional to the total pressure (equations (10) and (11)). In reality, however, as experienced by Duchemin et al. [13] these high growth rates, notably below a total pressure of $10^{-1}$ bar, are not obtained. 
These authors studied the growth of silicon for the $\mathrm{SiH}_{4}-\mathrm{H}_{2}$ system at temperatures between 700 and $1050^{\circ} \mathrm{C}$ and at total pressures between $1.3 \times 10^{-2}$ and 1 bar. In all their experiments a hydrogen flow of 18 litres/min and a silane molar ratio below $3 \times 10^{-3}$ was used. In order to obtain a constant silane pressure at different total pressures and a constant flow (measured at room temperature and atmospheric pressure) the pumping rate is adjusted, leading to a gas velocity inversely proportional to the total pressure $\left(V \propto P_{\text {tot }}^{-1}\right)$.

From their growth rate measurements Duchemin et al. recalculated the growth rates of silicon as a function of the hydrogen pressure for a fixed partial pressure of silane, using the experimental evidence that for a fixed hydrogen pressure the growth rate is linearly proportional to the silane input pressure. At temperatures between 930 and $1050^{\circ} \mathrm{C}$ and pressures above $10^{-1}$ bar the growth rate is roughly inversely proportional to the hydrogen pressure $\left(\mathrm{G} \propto \mathrm{P}_{\mathrm{H}_{2}}^{-1}\right)$, whereas at pressures below $10^{-1}$ bar a $\left(\mathrm{G} \propto \mathrm{P}_{\mathrm{H}_{2}}^{-1 / 2}\right)$ dependence is found. The $\mathrm{G} \propto \mathrm{P}_{\mathrm{H}_{2}}^{-1}$ behaviour is explained by Duchemin and co-workers as being due to a gas phase diffusion-controlled reaction and could therefore be replaced by $G \propto \mathrm{P}_{\text {tot }}^{-1}$ in agreement with equations (9) and (5). It was also found that in this regime the growth rate is almost independent of temperature, again indicating a gas phase diffusion-limited process. According to Duchemin et al. the $\mathrm{G} \propto \mathrm{P}_{\mathrm{H}_{2}}^{-1 / 2}$ behaviour is caused by the onset of a surface-controlled reaction in which hydrogen adsorption plays an important role. In order to discriminate between a gas phase diffusion-controlled process and a kinetically or surface-limited growth at pressures below $10^{-1}$ bar the following points could be important:

i For the $\mathrm{SiH}_{2} \mathrm{Cl}_{2}-\mathrm{H}_{2}$ system at $990{ }^{\circ} \mathrm{C}$ Duchemin et al. [13] found the same pressure regimes as for the $\mathrm{SiH}_{4}-\mathrm{H}_{2}$ system $\left(\mathrm{G} \propto \mathrm{P}_{\mathrm{H}_{2}}^{-1 / 2}\right)$ below $5 \times 10^{-2}$ bar and $\mathrm{G} \propto \mathrm{P}_{\mathrm{H}_{2}}^{-1}$ above $5 \times 10^{-2}$ bar. However, according to growth rate measurements on the $\mathrm{SiH}_{2} \mathrm{Cl}_{2}-\mathrm{H}_{2}-\mathrm{N}_{2}$ system at atmospheric pressures and tempera. tures below $1000^{\circ} \mathrm{C}[14]$, the growth rate in the $\mathrm{SiH}_{2} \mathrm{Cl}_{2} \cdot \mathrm{H}_{2} \cdot \mathrm{N}_{2}$ system is proportional to the hydrogen pressures $\left(\mathrm{G} \propto \mathrm{P}_{\mathrm{H}_{2}}\right.$ ), which is explained by the surface reaction, $\mathrm{SiCl}_{2}+\mathrm{H}_{2} \rightarrow \mathrm{Si}(\mathrm{cr})+2 \mathrm{HCl}$. The experimental data of Duchemin give $\mathrm{G} \propto \mathrm{P}_{\mathrm{H}_{2}}^{-1}$, as expected for a gas phase diffusion-limited reaction rate.

ii From the growth rate measurements Duchemin et al. deduced an activation energy of $15 \mathrm{kcal} / \mathrm{mole}$ at temperatures between 750 and $1050^{\circ} \mathrm{C}$, which seems somewhat too high for a gas phase diffusion-limited process. However, Hottier [11] measured a temperature dependence between 850 and $1150^{\circ} \mathrm{C}$ of $10 \mathrm{kcal} / \mathrm{mole}$, whereas between 600 and $850^{\circ} \mathrm{C} 40 \mathrm{kcal} / \mathrm{mole}$ was reported. In the high temperature regime above $900{ }^{\circ} \mathrm{C}$ Origirima et al. [15] reported $11 \mathrm{kcal} / \mathrm{mole}$ for the $\mathrm{SiH}_{4} \cdot \mathrm{H}_{2}$ system at atmospheric pressure. These two points suggest that the growth rate for the $\mathrm{SiH}_{4}-\mathrm{H}_{2}$ system at temperatures above $850^{\circ} \mathrm{C}$ is diffusion-limited even at a total pressure below $10^{-1}$ bar and therefore $\mathrm{P}_{\mathrm{H}_{2}}^{-1 / 2}$ can better be given as $\mathrm{P}_{\text {tot }}^{-1 / 2}$. It can now be postulated that the growth rate of silicon at temperatures exceeding $850^{\circ} \mathrm{C}$ is controlled by the supply 
of the reactant through the gas phase $\left(\left(R_{1} \gg R_{2}\right)\right.$ in equation (1)). Under the experimental conditions as used by Duchemin et al. $\left(V \propto \mathrm{P}_{\text {tot }}^{-1}\right)$, the thickness of the diffusion boundary layer can be assumed to be constant, as discussed above, and the growth rate at reduced pressures $\mathrm{G}(\mathrm{X}) \mathrm{P}$ can be given by

$G(X) P=\frac{\beta G(X) P=1 \text { bar }}{P}$

where $\mathrm{G}(\mathrm{X}) \mathrm{P}=1 \mathrm{bar}$ is the growth rate at atmospheric pressure (equation (5)) and $\beta$ is a correction factor due to differences in temperature gradients in the gas phase perpendicular to the surface, as will be discussed below. As Duchemin et al. [13] and Hottier et al. [11] used a horizontal cold wall reactor, it can be assumed that the temperature of the tube wall is higher at atmospheric pressure than at reduced pressure because of the reduced thermal conductivity of the carrier gas. This fact is in agreement with the observation of Duchemin et al. that the temperature difference between susceptor and substrate becomes higher when the total pressure is reduced (at a total pressure of about $10^{-2}$ bar a temperature difference of about $140^{\circ} \mathrm{C}$ was measured), whereas at atmospheric pressure this temperature difference is of the order of $20^{\circ} \mathrm{C}$. If the mean gas temperature decreases the ratio $\mathrm{D}_{12} / \delta$ also decreases as the diffusion coefficients $D_{12}$ and $D_{T}$ are almost quadratic functions of temperature, whereas the gas velocity $\mathrm{V}_{\mathrm{T}}$ is linearly proportional to the temperature. According to Berkman et al. [6] the average temperature $T_{A}$ in the region of laminar flow can be given by:

$T_{A}=1 / 4\left(T_{s}+T_{b}\right)$

where $T_{S}$ is the substrate temperature and $T_{b}$ the bulk gas temperature which is approximately equal to the wall temperature. $A s T_{b}$, and therefore $T_{A}$ as well, will depend on the total pressure, in a first approximation a linear dependence can be assumed.

$\mathrm{T}_{\mathbf{A}}=\mathrm{T}_{\mathbf{A}}^{1}-\mathrm{L} / \mathrm{P}$

where $L$ is a constant, $P$ the total pressure and $T_{A}^{1}=625^{\circ} \mathrm{C}$ at atmospheric pressure in hydrogen [2]. Using the experimental data of Duchemin et al. as given above and the assumption that in their experiments the effective cross-section was $10 \mathrm{~cm}^{2}$ and the free height above the susceptor (b) was $2 \mathrm{~cm}$, the growth rate can be calculated as a function of the total pressure. These growth rates are given in Fig. 4, disregarding thermodiffusion $(\alpha=0)$ for $\mathrm{T}_{S}$ equal to $1000^{\circ} \mathrm{C}$ and assuming that $\mathrm{T}_{b}$ at room temperature and at total pressures below $10^{-3}$ bar leads to $\mathrm{T}_{\mathrm{A}}=270^{\circ} \mathrm{C}$ (equation (13)) and $L=0.36 \mathrm{deg}$. bar $^{-1}$. Because of the steep temperature gradient, which is a function of total pressure, the influence of thermodiffusion cannot be left out of account [1]. Fig. 4 therefore gives the growth rate with the 


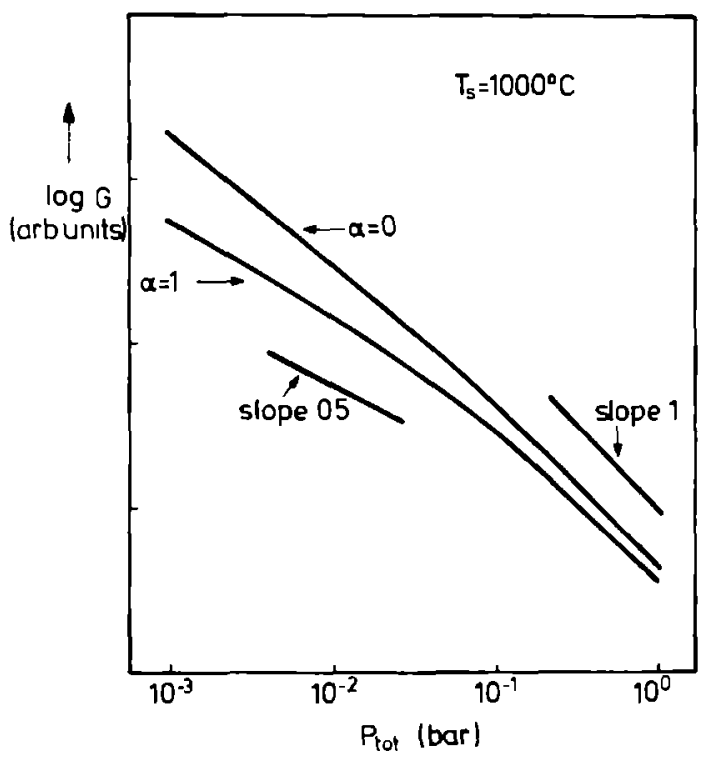

Figure 4.

The calculated growth rate of silicon as a function of the total pressure for a substrate temperature of $1000^{\circ} \mathrm{C}$ and for the thermodifusion factors $\alpha=0$ and $\alpha=1$ in a cold wall apparatus.

thermodiffusion factor $\alpha=1$. As can be observed from Fig. 4, the growth rates deviate from linearity $(\beta<1)$ with decreasing total pressure, notably when thermodiffusion is taken into account. The experimental data of Duchemin can therefore be fitted by introduction of thermal gas conductivity and thermodiffusion in the expression for the gas phase diffusion-limited growth of silicon.

\subsection{Comparison between the growth rate of silicon at atmospheric pressures and at reduced pressures}

In the previous section we have discussed the growth rate of silicon from silane in hydrogen and inert carrier gases, both at atmospheric pressures and at reduced pressures. In this section figures are constructed in which the growth rate of silicon is plotted as a function of temperature using the experimental data as given in the previous sections. Figure 5 gives the growth rate of silicon as a function of temperature for silane $\left(\mathrm{PSiH}_{4}=10^{-3}\right.$ bar) in hydrogen at atmospheric pressure according to experimental data as described by Bloem and Claassen [8] and for equal concentrations of silane in inert ambients at atmospheric pressure. The curve for inert ambients is plotted using the experimental evidence that the growth rate of silicon for temperatures exceeding $1000^{\circ} \mathrm{C}$ is almost independent of the carrier gas (Fig. 3) 


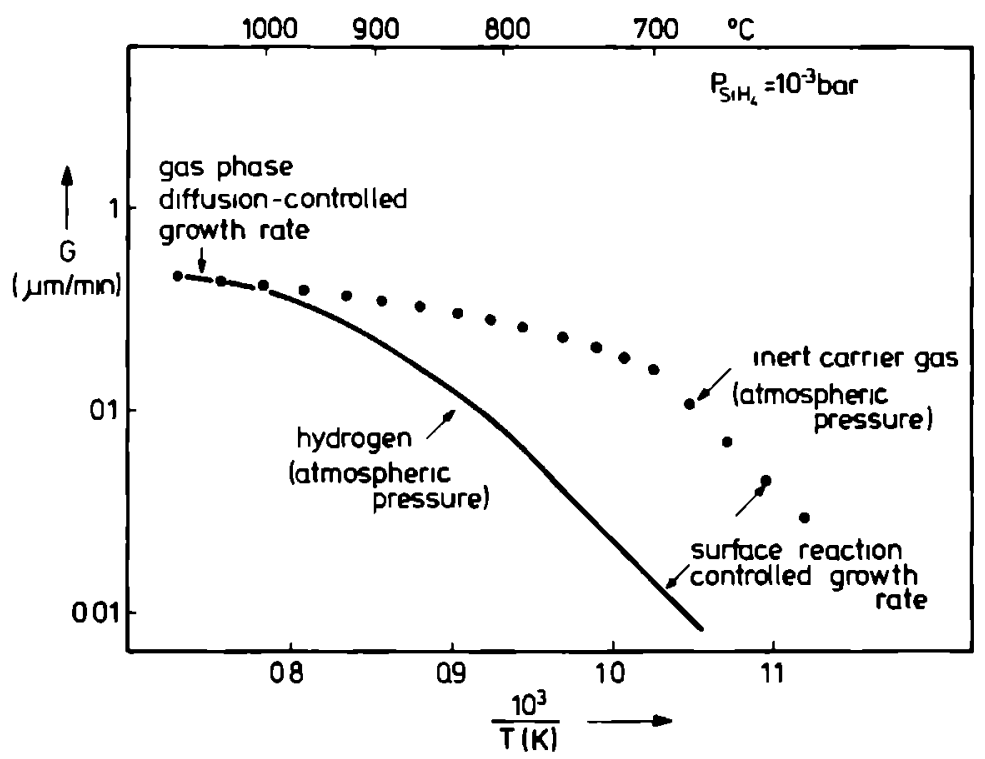

Figure 5.

The growth rate of silicon as a function of temperature from silane $\left(\mathrm{PSiH}_{4}=10^{-3}\right.$ bar) at atmospheric pressure in hydrogen and inert carrier gases.

and that at temperatures below $1000^{\circ} \mathrm{C}$ the growth rate of silicon is much higher in inert ambients than in a hydrogen atmosphere (Fig. 2). The growth rate of silicon for the $\mathrm{SiH}_{4}-\mathrm{H}_{2}$ system below $900{ }^{\circ} \mathrm{C}$ and for the $\mathrm{SiH}_{4}$-inert gas system below about $700^{\circ} \mathrm{C}$ (both at atmopsheric pressure) can be expressed by equation (4) in which the apparent activation energy is about $37 \mathrm{kcal} / \mathrm{mole}$ for both systems. It should be noted that slightly smaller values can be found, notably in an inert carrier gas, because of gas phase nucleation when too high input concentrations of silane are used.

As discussed before, the position of the knee in the growth rate versus $1 / T$ curve is defined by $R_{1}=R_{2}$, where $R_{1} \propto \delta / D_{12}$ and $R_{2}=1 / k_{d}$ (equations (2), (3) and (6)). Van den Brekel [2] defined the CVD number (or Sherwood number) as

$\mathrm{CVD}=\frac{\mathrm{R}_{1}}{\mathrm{R}_{2}} \propto \frac{\mathrm{k}_{\mathrm{d}} \delta}{\mathrm{D}_{12}}$.

At atmospheric pressure the CVD number becomes smaller when hydrogen is used instead of an inert carrier gas because, according to equation (7) we find $\mathbf{k}_{d}=$ $\mathrm{k}_{\mathrm{d}}^{\mathrm{O}} /\left(1+\mathrm{HP}_{\mathrm{H}_{2}}\right)$, and consequently the position of the knee shifts to higher temperatures with increasing values of $\mathrm{P}_{2}$. 
At reduced pressures, with or without hydrogen, an apparent activation energy of about $37 \mathrm{kcal} /$ mole has also been reported for the surface-controlled growth rate, as previously discussed. Further the reported growth rates of silicon in the lowtemperature regime for inert ambients at atmospheric pressure are comparable with those at reduced pressure, provided that $\mathrm{P}_{2} \leqslant 10^{-2}$ bar (Fig. 2). Using the data given above, a figure can be constructed in which the growth rate of silicon is plotted versus $1 / \mathrm{T}$ for $\mathrm{PSiH}_{4}=10^{-3}$ bar and different total pressures (Fig. 6). In this figure the low-temperature growth rate curves are seen to be almost equal for silane in an atmospheric inert ambient $\left(\mathrm{P}_{c}\right)$ and at reduced pressures $\left(\mathrm{P}_{\mathrm{a}}\right.$ and $\mathrm{P}_{\mathrm{b}}$, where $\mathrm{P}_{\mathrm{a}}<\mathrm{P}_{\mathrm{b}}$ ).

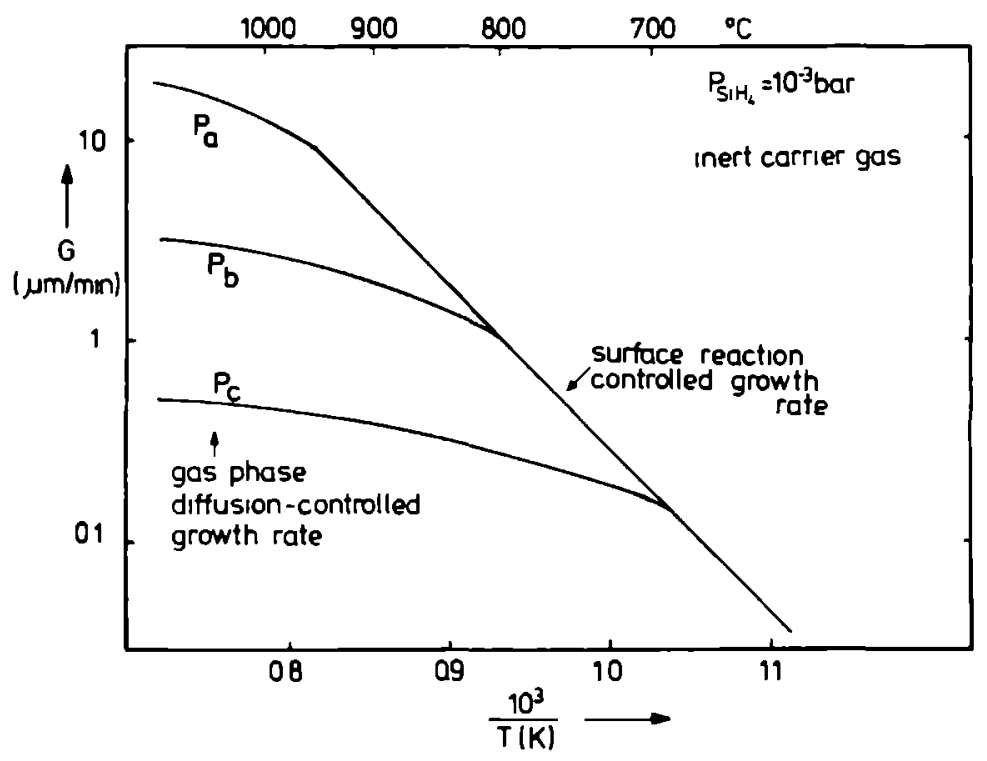

Figure 6.

The growth rate of silicon as a function of temperature at reduced total pressures and in inert ambients at atmospheric pressure. $\left(P_{c}=1\right.$ bar; $\left.P_{a}<P_{b}<P_{c}\right)$.

At higher temperatures the growth rate is higher at reduced pressures as diffusion of the reactant becomes easier at reduced pressures. As discussed earlier, a $G \propto P_{\text {tot }}^{-1}$ behaviour could be expected, but a deviation from this relation occurs in cold wall systems due to the influence of steep temperature gradients on the diffusional behaviour of the reactants. It can further be seen from Fig. 6 that the position of the knee in the growth rate versus $1 / T$ curve shifts to higher temperatures with decreasing total pressures. In an inert gas ambient with a partial pressure of hydrogen below $10^{-2}$ bar (Fig. 2) the position of the knee shifts to higher temperatures when the total pressure is reduced because the CVD number (equation (15)) becomes smaller at these low pressures $\left(R_{1} \propto 1 / D_{12} \propto P_{\text {tot }}\right.$, equations (2) and (9)). This 
conclusion is in agreement with experimental data reported by Joyce et al. [10], who found a knee in the growth versus $1 / \mathrm{T}$ curve at about $1050^{\circ} \mathrm{C}$ when an input of about $10^{-3}$ bar silane was used without a carrier gas.

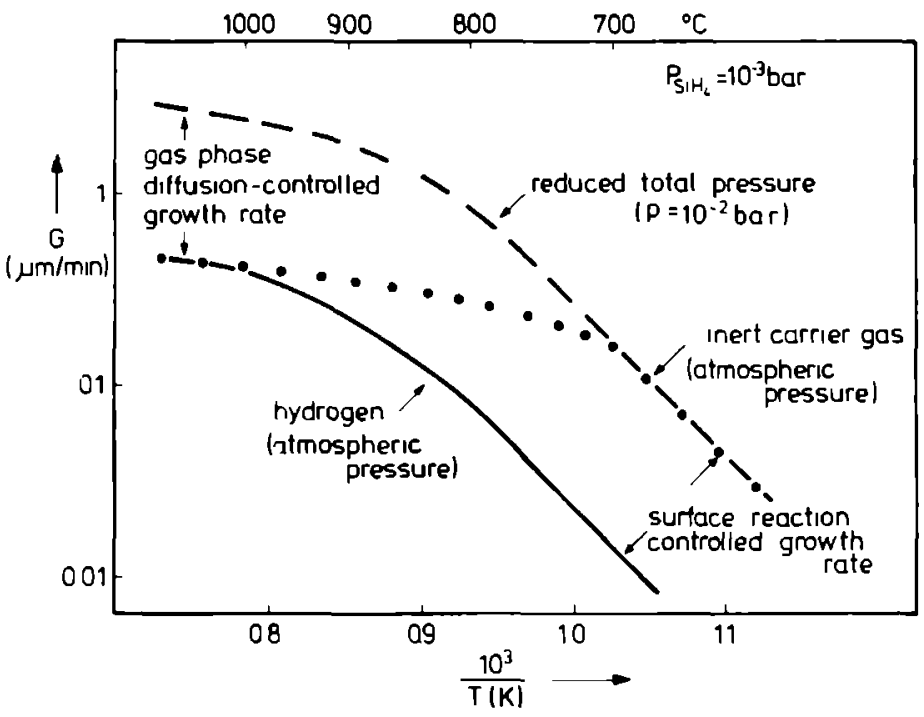

Figure 7.

A combination of Figures 5 and 6, giving the growth of silicon from $10^{-3}$ bar of silane as a function of temperature for different carrier gases ( $\mathrm{H}_{2}$ or inert gas) and total pressures.

Fig. 7 combines Figures 5 and 6 and gives the growth rate of silicon for $\mathrm{PSiH}_{4}=$ $10^{-3}$ bar in hydrogen and inert ambients (both at atmospheric pressure) and for a reduced pressure of $10^{-2}$ bar. It should be noted that Figures 5,6 and 7 are plotted schematically. At high input concentrations of silane, notably in inert ambients, homogeneous gas phase nucleation will probably reduce the expected growth rate.

\section{Temperature dependence of the growth rate}

In the low temperature regime the growth rate is determined by surface reactions and can be given by equation (4), in which the apparent activation energy is, in a first approximation, independent of the total pressure and independent of the partial pressure of hydrogen. According to recent experiments, a generalized scheme may be present for the growth rate of silicon in the surface-controlled regime from silane $[4,8]$. In this scheme gas phase and surface reactions are postulated with $\mathrm{SiH}_{2}$ as the main silicon-containing surface species: 
a. Gaseous reactions

$$
\mathrm{SiH}_{4} \underset{\mathrm{k}_{-1}}{\stackrel{\mathrm{k}_{1}}{\rightleftharpoons}} \mathrm{SiH}_{2}+\mathrm{H}_{2}
$$

b. Adsorption on a free surface site (*)

$$
\mathrm{SiH}_{2}+\underset{\mathrm{k}_{-2}}{\stackrel{\mathrm{k}_{2}}{\rightleftharpoons}} \mathrm{SiH}_{2}^{*}
$$

c. Surface diffusion and incorporation at a free step site (* (step))

$$
\mathrm{SiH}_{2}^{*}+*(\text { step }) \underset{\mathrm{k}_{-3}}{\stackrel{\mathrm{k}_{3}}{\rightleftharpoons}} \mathrm{SiH}_{2}^{*} *
$$

d. The rate-limiting reaction can be found in the release of hydrogen

$$
\mathrm{SiH}_{2}^{* *} \stackrel{\mathrm{k}_{4}}{\rightarrow} \mathrm{Si}(\mathrm{cr})+\mathrm{H}_{2}+2 *
$$

Assuming that $k_{4}$ is rate-limiting [4] the growth rate and its temperature dependence can be given by

$$
\begin{aligned}
\mathrm{G} & =\mathrm{k}_{4}\left[\mathrm{SiH}_{2}^{* *}\right] \\
& =\mathrm{k}_{4}^{\mathrm{O}}\left[\mathrm{SiH}_{2}^{*}\right] \exp \left(-\epsilon_{4} / \mathrm{RT}\right) .
\end{aligned}
$$

In a steady-state situation the concentrations of $\mathrm{SiH}_{2}$ species in the gas phase and on the surface can be calculated $[4,8]$. For a positive growth rate the reactions $k_{-2}$ and $k_{-3}$ can be neglected compared with the reactions $k_{1}$ and $k_{2}$ respectively. This leads to

$$
\left[\mathrm{SiH}_{2}^{* *}\right]=\frac{\mathrm{k}_{1} \mathrm{PSiH}_{4}}{\left(\mathrm{k}_{-1} \mathrm{P}_{\mathrm{H}_{2}}+\mathrm{k}_{2}[*]\right)} \times \frac{\mathrm{k}_{2}[*]}{\left(\mathrm{k}_{-2}+\mathrm{k}_{3}[*(\text { step })]\right)} \times \frac{\left(\mathrm{k}_{3}[* \text { (step) }]\right.}{\left(\mathrm{k}_{-3}+\mathrm{k}_{4}\right)} .
$$

With a fraction of free surface sites and free step sites equal to unity and with $\mathrm{k}_{4}<\mathrm{k}_{-3}$ and $\mathrm{k}_{3}<\mathrm{k}_{-2}[4,8]$ equation (21) can be transformed to

$$
\left[\mathrm{SiH}_{2}^{* *}\right]=\frac{\mathrm{K}_{1} \mathrm{~K}_{2} \mathrm{~K}_{3} \mathrm{PSiH}_{4}}{\left[\mathrm{P}_{\mathrm{H}_{2}}+\left(\mathrm{k}_{2} / \mathrm{k}_{.1}\right)\right]}
$$


Using $K_{i}=K_{i}^{0} \exp \left(-E_{i} / R T\right)$ equation (20) then reads

$\mathbf{G}=\mathrm{K}_{1}^{0} \mathrm{~K}_{2}^{0} \mathrm{~K}_{3}^{0} \mathrm{~K}_{4}^{0} \frac{\mathrm{PSiH}_{4}}{\left[\mathrm{P}_{\mathrm{H}_{2}}+\left(\mathrm{k}_{2} / \mathrm{K}_{-1}\right)\right]} \exp (-\Delta \mathrm{E} / \mathrm{RT})$.

Using hydrogen as a carrier gas $\left(\mathrm{P}_{\mathrm{H}_{2}}>\mathrm{k}_{2} / \mathrm{k}_{-1}\right.$ (Fig. 2)) we find

$\Delta \mathrm{E}=\mathrm{E}_{1}+\mathrm{E}_{2}+\mathrm{E}_{3}+\epsilon_{4}$.

At reduced pressures, or with inert carrier gases the same activation energy is found by experiment (Figures 5 to 7 ). In the present model this points to a small temperature dependence of $k_{2} / k_{-1}$. An evaluation of $\Delta E$ will now be given, based on the reaction scheme given above. For the $\mathrm{SiH}_{4}-\mathrm{H}_{2}$ system the heat of reaction $\left(\mathrm{E}_{1}\right)$ for the gas phase reaction, as given by equation (16), has been determined by Newman et al. [5] , using single-pulse shock tube data $\left(E_{1}=52 \mathrm{kcal} / \mathrm{mole}\right)$. It can furthermore be postulated that the heat of adsorption of $\mathrm{SiH}_{2}$ on the silicon surface is close to that of silicon itself [16], leading to $E_{2} \cong E_{3} \cong-73 \mathrm{kcal} / \mathrm{mole}$, being the energy gain when a Si-Si bond is formed [4]. With $\Delta E=37 \mathrm{kcal} / \mathrm{mole}, \epsilon_{4}$ can be calculated from equation (24). This yields $\epsilon_{4}=130 \mathrm{kcal} / \mathrm{mole}$, which is close to the energy needed to break two $\mathrm{SiH}$ bonds [4]. The model presented for the growth of silicon from silane thus leads to a reasonable explanation of the activation energy in the low temperature growth of silicon.

\section{Conclusion}

The growth rate of silicon in the gas phase diffusion-controlled regime of the high temperature growth is determined by the total pressure and the input concentration of silane but not by the kind of carrier gas used. In this regime the growth rate is found to be linearly proportional to the input concentration of silane and inversely proportional to the total pressure. It is concluded that steep temperature gradients, notably at pressures below $10^{-1}$ bar, give rise to a decrease in growth rate and therefore a deviation from the $\mathrm{G} \propto \mathrm{P}_{\text {tot }}^{-1}$ behaviour can be expected. At lower temperatures, surface reactions control the growth rate, and for the $\mathrm{SiH}_{4}$ system the influence of the hydrogen pressure on the growth rate becomes apparent $\left(\mathrm{G} \propto \mathrm{P}_{\mathrm{H}_{2}}^{-1}\right.$ ). The temperature dependence of the growth rate is found to be about $37 \mathrm{kcal} / \mathrm{mole}$, independent of the total pressure or the hydrogen pressure.

In general it can be said that great differences between growth rate results at reduced pressures and in systems diluted with inert gas only exist at high temperatures, where gas phase diffusion limits the growth rate. At lower temperatures, where the growth rate is determined by surface reactions, growth rates are comparable for equal silane concentrations in inert gas or at reduced pressure, provided the hydrogen pressure is below $10^{-2}$ bar. 


\section{References}

1 J. Bloem and L.J. Giling in 'Current Topics in Materials Science', Ed. E. Kaldis, North-Holland Publishing Comp. Vol. I, Chapter 4, (1978).

2 C.H.J. van den Brekel, Mass Transport and Morphology in Chemical Vapour Deposition Processes, Thesis, University of Nijmegen (1978).

3 W.A. Bryant, the Kinetics of the Deposition of Silicon by Silane Pyrolysis at Low Temperatures and Atmospheric Pressure, Thin Solid Films 60, 19 (1979).

4 W.A.P. Claassen and J. Bloem, Rate-determining Reactions and Surface Species in CVD of Silicon, III. The $\mathrm{SiH}_{4}-\mathrm{H}_{2}-\mathrm{N}_{2}$ system, to be published in J. Crystal Growth.

5 C.G. Newman, H.E. O'Neal, M.A. Ring, F. Fleska and N. Shipley, Kinetics and Mechanism of the Silane Decomposition, Int. J. Chem. Kinetics, XI, 1167 (1979).

6 S. Berkman, V.S. Ban and N. Goldsmidt, An Analysis of the Gas Flow in a Horizontal CVD Reactor, in 'Heterepitaxial Semiconductors for Electronic Devices', Eds. G.W. Cullen and C.C. Wang, Springer-Verlag, Chapter 7 (1978).

7 R.C. Reid and T.K. Sherwood, 'The Properties of Gases and Liquids', McGraw Hill Book Company Inc. (1958).

8 J. Bloem and W.A.P. Claassen, Rate-determining Reactions and Surface Species in CVD of Silicon, I. The $\mathrm{SiH}_{4}-\mathrm{HCl} \cdot \mathrm{H}_{2}$ System, J. Cryst. Growth 49, 435 (1980).

9 L.J. Giling, Gas flow Pattern in Horizontal Epitaxial Reactor Cells observed by Laser Holography, ICCG 6, Moscow, 1980.

10 B.A. Joyce and R.R. Bradley, Epitaxial Growth of Silicon from the Pyrolisis of Monosilane on Silicon Substrates, J. Electrochem. Soc. 110, 1235 (1963).

11 F. Hottier and R. Cadoret, Surface Processes in Low Pressure Chemical Vapour Deposition, ICCG 6, Moscow, 1980.

12 C.H.J. Van den Brekel and L.J.M. Bollen, Low Pressure Deposition of Poly. crystalline Silicon from Silane, to be published.

13 M.J. Duchemin, M.M. Bonnet, M.F. Koelsch, Kinetics of Silicon Growth under Low Hydrogen Pressure, J. Electrochem. Soc. 125, 637 (1978).

14 W.A.P. Claassen and J. Bloem, Rate-determining Reactions and Surface Species in CVD of Silicon, II. The $\mathrm{SiH}_{2} \mathrm{Cl}_{2} \cdot \mathrm{H}_{2}-\mathrm{N}_{2} \cdot \mathrm{HCl}$ System, J. Cryst. Growth 50, 807 (1980).

15 M. Ogirima, H. Saida, M. Suzuki and M. Maki, Low Pressure Silicon Epitaxy, J. Electrochem. Soc. 124, 903 (1977).

16 A.A. Chernov, Growth Kinetics and Capture of Impurities during Gas Phase Crystallization, J. Cryst. Growth 42, 55 (1977). 


\section{SUMMARY}

Polycrystalline silicon layers are widely used in the electronics industry. The electrical properties of these layers closely depend on the size of the polysilicon grains in the layers. The experimental study on the nucleation of silicon on $\mathrm{SiO}_{2}$ and $\mathrm{Si}_{3} \mathrm{~N}_{4}$ substrates shows that the grain size of the polysilicon layers is subject to various extemal conditions, among which the initial nucleation of silicon on the substrate plays a decisive role. The nucleation of silicon was studied at atmospheric pressure and at temperatures between 600 and $1200^{\circ} \mathrm{C}$ for the $\mathrm{SiH}_{4} \cdot \mathrm{H}_{2} \cdot \mathrm{HCl}$ system (chapters II and III) and between 800 and $1100^{\circ} \mathrm{C}$ for the $\mathrm{SiH}_{2} \mathrm{Cl}_{2} \cdot \mathrm{H}_{2} \cdot \mathrm{N}_{2}$ system (chapter IV). The saturation cluster densities were determined as a function of gas phase composition and temperature and can be varied between $10^{4}-10^{11} \mathrm{~cm}^{-2}$. It is shown that the nucleation of silicon proceeds via the formation of $\mathrm{SiH}_{2}$ monomers on the surface. Addition of hydrogen chloride to the system produces a strong decrease in $\mathrm{SiH}_{2}$ concentration due to the conversion of $\mathrm{SiH}_{2}$ into $\mathrm{SiCl}_{2}$, and consequently the saturation nucleus density $\left(\mathrm{N}_{\mathrm{S}}\right)$ decreases $\left(\mathrm{N}_{\mathrm{S}} \propto \mathrm{PSiH}_{4} / \mathrm{P}_{\mathrm{HCl}}^{2}\right.$, where $\mathrm{P}$ denotes the input pressure). It is further shown that a strong hydrogen adsorption exists notably on $\mathrm{SiO}_{2}$ substrates, which may explain the substantial differences in nucleation on $\mathrm{SiO}_{2}$ and $\mathrm{Si}_{3} \mathrm{~N}_{4}$ substrates at temperatures below $1000^{\circ} \mathrm{C}$. The nucleation experiments can be described satisfactorily by comparing the experimental data with predictions of existing nucleation theories using analysis of the silicon adatom (or $\mathrm{SiH}_{2}$ monomer) concentration. In this way approximate values are derived for the size of the critical cluster and values between 1 and 4 atomic units are obtained.

Chapters $\mathrm{V}$ to VII deal with the growth of polycrystalline silicon for the $\mathrm{SiH}_{4} \cdot \mathrm{H}_{2} \cdot \mathrm{HCl}$ system, the $\mathrm{SiH}_{2} \mathrm{Cl}_{2} \cdot \mathrm{H}_{2} \cdot \mathrm{N}_{2} \cdot \mathrm{HCl}$ system and the $\mathrm{SiH}_{4} \cdot \mathrm{H}_{2} \cdot \mathrm{N}_{2}$ system. In the kinetically controlled regime of silicon growth in the $\mathrm{SiH}_{4} \cdot \mathrm{H}_{2} \cdot \mathrm{N}_{2}$ system it is found that the growth rate is linearly proportional to the input concentration of silane and inversely proportional to the partial pressure of hydrogen. Analysis of the experimental data shows that hydrogen adsorption does not influence the growth rate, $\mathrm{SiH}_{2}$ being the most abundant surface species. Addition of hydrogen chloride to this system results in a strong decrease in growth rate, due to the conversion of $\mathrm{SiH}_{2}$ into $\mathrm{SiCl}_{2}$. The reduction of $\mathrm{SiCl}_{2}$ at step sites is proposed to be the rate-limiting step, leading to a surface concentration of $\mathrm{SiCl}_{2}$ far above the equilibrium concentration and favouring desorption of $\mathrm{SiCl}_{2}$. Going to higher temperatures the surface reactions become so fast that gas phase diffusion of the reactant towards the surface becomes the rate-limiting step. It is shown that in this regime the growth rate is almost independent of the carrier gas used at atmospheric pressure. At reduced pressures the growth rate of silicon first increases in inverse proportion to the total pressure while at total pressures below 0.1 bar the growth rate deviates from the $\mathrm{R} \propto \mathrm{P}_{\text {tot }}^{-1}$ behaviour, due to increasing temperature gradients in the gas phase which tend to slow down the gas phase diffusion of reactants towards the growing interface. In the growth of silicon from $\mathrm{SiH}_{2} \mathrm{Cl}_{2}$ the dissocia- 
tion of this compound into $\mathrm{SiCl}_{2}$ and $\mathrm{H}_{2}$ plays an important role. Addition of $\mathrm{HCl}$ to the $\mathrm{SiH}_{2} \mathrm{Cl}_{2}-\mathrm{H}_{2}$ system reduces the growth rate because the gas phase dissociation of $\mathrm{SiH}_{2} \mathrm{Cl}_{2}$ is followed by formation of $\mathrm{SiHCl}_{3}$. It is concluded that a strong adsorption of atomic hydrogen and chlorine is not needed to explain the experimental evidence, whereas adsorption of $\mathrm{SiH}_{2}$ and $\mathrm{SiCl}_{2}$ has been found to reduce the growth rate at lower temperatures.

In chapter VIII a review is given of the experimental data presented in chapters II to VII.

In chapter IX it is pointed out that it is only at high temperatures, where gas phase diffusion limits the growth rate, that great differences exist between growth rate results at reduced pressures and in systems diluted with inert gas. In the low temperature region, where surface reactions are predominant, it is found that the growth rates are comparable for the two systems. 


\section{SAMENVATTING}

Polycrystalline sllicium lagen worden uitgebreid toegepast in de elektronische industrie. De elektrische eigenschappen van deze lagen hangen onder andere af van de grootte van de polysilicium korrels in de lagen. Een expenmentele studıe waarbij de k1emvorming van silicium op $\mathrm{SiO}_{2}$ en $\mathrm{Sl}_{3} \mathrm{~N}_{4}$ wordt onderzocht toont aan dat de grootte van polysilicıum korrels sterk afhangt van de allereerste aanleg van sliciumatomen op de verschillende substraten. De kiemvorming van silicium is bestudeerd bij atmosfensche druk en voor temperaturen tussen 600 en $1200^{\circ} \mathrm{C}$ voor het $\mathrm{S}_{1} \mathrm{H}_{4}-\mathrm{HCl}-\mathrm{H}_{2}$ systeem (hoofdstukken II en III) en tussen 800 en $1100^{\circ} \mathrm{C}$ voor het $\mathrm{SiH}_{\mathbf{2}} \mathrm{Cl}_{\mathbf{2}}-\mathrm{H}_{\mathbf{2}}-\mathrm{N}_{\mathbf{2}}$ systeem (hoofdstuk IV). De verzadigingsdichtheid aan silicium kemen is bepaald als functie van de gasfase samenstelling en de temperatuur en kan worden gevaneerd tussen $10^{4}-10^{11} \mathrm{~cm}^{-2}$. Het is aangetoond dat de kiemvorming van silicium plaatsvindt door vorming van $\mathrm{SiH}_{2}$ monomeren op het oppervlak. Toevoeging van zoutzuurgas aan het systeem verlaagt de $\mathrm{SiH}_{2}$ oppervlakte concentratie doordat $\mathrm{SiH}_{2}$ wordt omgezet in $\mathrm{SiCl}_{2}$ en als gevolg huervan daalt de verzadigingsdichtheid aan silicium kiemen $\left(\mathrm{N}_{\mathrm{s}}\right)\left(\mathrm{N}_{\mathrm{s}} \propto \mathrm{PSiH}_{4} / \mathrm{P}_{\mathrm{HCl}}^{2}\right.$, waarbyj $\mathrm{P}$ de partiaal druk voorstelt). Het is verder aangetoond dat atomaire waterstof sterk adsorbeert met name op $\mathrm{SiO}_{2}$ substraten, en dat de verschillen in kuemvormungsgedrag op $\mathrm{SiO}_{2}$ en $\mathrm{Si}_{3} \mathrm{~N}_{4}$ voor temperaturen beneden $1000^{\circ} \mathrm{C}$ hierop kunnen worden teruggevoerd. De kiemvormingsexpenmenten kunnen goed worden beschreven met bestaande atomistische kıemvormungstheorieen en een vergelık tussen theore en expenment leidt tot een kritıeke kiemgrootte tussen de 1 en 4 atomare eenheden

In de hoofdstukken $\mathrm{V}$ tot en met VII wordt het groeiproces van silicium beschreven uitgaande van het $\mathrm{S}_{1} \mathrm{H}_{4} \cdot \mathrm{H}_{2} \cdot \mathrm{HCl}$ systeem, het $\mathrm{SiH}_{2} \mathrm{Cl}_{2} \cdot \mathrm{H}_{2} \cdot \mathrm{N}_{2} \cdot \mathrm{HCl}$ systeem en het $\mathrm{S}_{1} \mathrm{H}_{4} \cdot \mathrm{H}_{2} \cdot \mathrm{N}_{2}$ systeem. Het is aangetoond dat voor het $\mathrm{S}_{1} \mathrm{H}_{4}-\mathrm{H}_{2}-\mathrm{N}_{2}$ systeem de groelsnelheid lineair evenredig is met de silaan concentratie en omgekeerd evenredig met de partiaal druk van het waterstofgas in het temperatuurgebied waar de groessnelheid van silicium kinetisch is bepaald. Een analyse van de expenmentele resultaten toont aan dat adsorptie van atomair waterstof op het sulicium oppervlak de groelsnelherd niet beinvloedt en dat $\mathrm{S}_{1} \mathrm{H}_{2}$ de meest belangnjke siliciumhoudende verbinding op het oppervlak is. De toevoeging van zoutzuurgas aan dit systeem resulteert in een sterke daling van de groeisnelheid hetgeen wordt veroorzaakt door de omzetting van $\mathrm{SiH}_{2}$, met behulp van het zoutzuurgas $(\mathrm{HCl})$, in $\mathrm{SiCl}_{2}$. De reductie van $\mathrm{SiCl}_{2}$ aan een atomaire stap is mogelijk de snelheidsbepalende stap, hetgeen leidt tot een $\mathrm{SiCl}_{2}$ oppervlakteconcentratie welke veel groter is dan de evenwichtsconcentratie en desorptie van $\mathrm{SiCl}_{2}$ is dan ook te verwachten $\mathrm{By}$ hogere temperaturen worden de oppervlakte reacties zo snel dat de werkelyke snelheidsbepalende stap kan worden gevonden in de gasfase diffusie van de reactanten naar het slicium oppervlak. Ook wordt aangetoond dat in dit gebied de groeisnelhe1d in eerste benadenng onafhankelijk is van het gebrukte dragergas bij atmosfensche druk. Bij een verlaagde totaal druk neemt de groeisnelheld van silıcium eerst toe (omgekeerd evenredig met de totaal druk) terwill voor totaal drukken beneden 01 bar de groei- 
snelheid afwijkt van het $\mathrm{R} \propto \mathrm{P}_{\text {tot }}^{-1}$ gedrag doordat steilere temperatuursgradienten de gasfase diffusie van de reactanten naar het oppervlak bemoeilijken. Bij de groei van silicium uitgaande van $\mathrm{SiH}_{2} \mathrm{Cl}_{2}$ speelt de gasfase ontleding van deze verbinding in $\mathrm{SiCl}_{2}$ en $\mathrm{H}_{2}$ een belangrijke rol. De toevoeging van $\mathrm{HCl}$ aan het $\mathrm{SiH}_{2} \mathrm{Cl}_{\mathbf{2}} \cdot \mathrm{H}_{\mathbf{2}}$ systeem heeft een verlaging van de groeisnelheid van silicium tot gevolg doordat $\mathrm{HCl}$ tezamen met $\mathrm{SiCl}_{2} \mathrm{SiHCl}_{3}$ vormt. De conclusie wordt getrokken dat een sterke adsorptie van atomair waterstof en chloor niet nodig is om de experimenten te verklaren maar dat adsorptie van $\mathrm{SiH}_{2}$ en $\mathrm{SiCl}_{2}$ wel kan leiden tot een verlaging van de groeisnelheid, met name bij relatief lage temperaturen.

In hoofdstuk VIII wordt een overzicht gegeven van de experimentele resultaten zoals beschreven in de hoofdstukken II tot en met VII.

In hoofdstuk IX wordt benadrukt dat bij hogere temperaturen waarbij gasfase diffusie de groeisnelheid bepaalt, er een groot verschil bestaat tussen groeisnelheden zoals verkregen bij verlaagde totaal druk en het systeem bij atmosferische druk waarbij een inert gas als dragergas werd gebruikt. In het lage temperatuur gebied, waar oppervlakte reacties de groeisnelheid bepalen, is gevonden dat de groeisnelheid voor beide systemen van gelijke grootte is. 
170

CURRICULUM VITAE

11 april 1948 : Geboren te Uden.

1960-1964 : Lagere Landbouwschool, respectievelijk te Uden en Veghel.

1964-1966 : Middelbare Landbouwschool te Oss.

1966-1967 : Avondopleiding voor het Middenstandsdiploma te Uden.

1966-1971 : Werkzaam in de landbouw.

1967-1972 : Avondcollege (Atheneum B) te 's Hertogenbosch.

1971-1976 : Studie Scheikundige Technologie aan de Technische Hogeschool te Eindhoven. Afstudeeronderwerp "Orientatie-Orde in Nematische Vloeibare Kristallen".

1974-heden : In dienst bij de N.V. Philips' Gloeilampenfabrieken te Eindhoven. Eerst in de groep "Physics of Condensed Matter" en sinds 1 januari 1977 in de groep "Semiconductor Materials". 


\section{STELLINGEN}

bij het proefschrift

"KINETIC STUDIES ON THE NUCLEATION AND GROWTH OF SILICON VIA CHEMICAL VAPOUR DEPOSITION" 
1 De experimentele gegevens betreffende de chemisorptie van waterstof op silicium zoals gerapporteerd door Sdkurai en Hagstrum, worden door Hottier en Cadoret verkee rd geinterpreteerd

T Sakurat en H D Hagstrum, J Vac Scı Techn 13,807 (1976)

F Hottier en R Cadoret, ICCG 6, Moscow, 1980

2 Dat de decompositiegraad van $\mathrm{S}_{1} \mathrm{H}_{4}$ in de gasfase mogelıjk wordt verlaagd door toevoegung van $\mathrm{N}_{2} \mathrm{O}$, zoals wordt heweerd door Knolle et al, is hoogst onwaarschunnlık

W R Knolle, H R Maxwell, Jr en R E Benenson, J Appl Phys 51,4385 (1980)

3 De zuiver geometrische modellen voor de fluctuerende mıkroscopische groelsnelhe1d bij knstalgroei uit de smelt, zoals die zijn voorgesteld door Monzane et al en door Barthel en Junsch, voeren door het verwaarlozen van het transport van stollingswarmte tot onjuiste uitdrukkingen voor de fluctuatieamplitude van deze groessnelheld

K Morizane, A F Witt, en H C Gatos, J Electrochem Soc 114, 738 (1967)

J Barthel en M Jurisch, Kristall und Technik, 8, 199 (1973)

4 De berekening van Chernov en Rusakın dat een sllıcıum oppervlak, in evenwıcht mit een waturstof waterstofchlonie gasmengsel, buj temperaturen boven 1000 ${ }^{\circ} \mathrm{C}$, nagenoeg geheel bed $2 \mathrm{kt}$ is met atomaire waterstof en chloor is in tegenspraak met expenmentele gegevens

A A Chernot en M P Rusalkın, J Crystal Growth 45, 73 (1978)

Dit pruefschrift, hoofdstuk VII

5 Het model, voor de overgang van smektısch naar nematısch vloeıbaar knstallın gedrag, gebaseerd op metıngen van de elastische constanten van de homologe reeks 4,4'-d (n-alkoxy) azoxybenzenen, zoals voorgesteld door Gruler, is an bedenkingen onderhevig

H Gruler, Z Naturforsch 28a, 474 (1973)

W II de Jeu en W.A P Claassen, J Chem Phys 67, 3705 (1977)

6 Het bepalen van absolute hoeveelheden adsorbaat door vergelıjking van piekhougten in Auger spectra, gemeten met verschullende soorten analysatoren, kan aanleıding geven tot aan $\angle$ enlıjke fouten

1 Solymori en J Kiss, Proc ICSS IV and ECOSS III Cannes 1980

7 In tegenstelling tot wat gebruıkel ${ }_{1} \mathrm{k}$ is in de elektronische industrie wordt in de landbouw de opbrengst aan consumeerbare chups per plak verhoogd door het toevoegen van alkalımetalen adn $\mathrm{S}_{1} \mathrm{O}_{2}$ 
8. Het woord "milieuvriendelijk", dat vaak in advertenties gebruikt wordt in de uitdrukking "milieuvriendelijk produkt", is misleidend.

9. Het is bij innovatie van produkten uiterst gevaarlijk om de opmerking "als dat zo eenvoudig was, zou het al lang uitgevonden zijn" te plaatsen. 


